\title{
IntechOpen
}

\section{Parenting in South American and African Contexts}

Edited by Maria Lucia Seidl-de-Moura 



\section{PARENTING IN SOUTH AMERICAN AND AFRICAN CONTEXTS}

Edited by Maria Lucia SeidI-de-Moura 


\section{Parenting in South American and African Contexts}

http://dx.doi.org/10.5772/57520

Edited by Maria Lucia Seidl-de-Moura

\section{Contributors}

Lília lêda Chaves Cavalcante, Celina Magalhães, Simone Silva, Tatiana Afonso, Thamyris Maués dos Santos, Fernando Augusto Ramos Pontes, Esther Foluke Akinsola, Maria Lucia Seidl-De-Moura, Mauro Vieira, Maria Aparecida Crepaldi, Carina Nunes Bossardi, Lauren Beltrão Gomes, Simone Dill Azeredo Bolze, Cesar Piccinini, Patricia Mawusi Amos, Sílvia Koller, Eva Diniz Bensaja Dei Schiro, Jenny Ortiz, Olga Alicia Carbonell Blanco, Luciana Fontes Pessôa, Deise Maria Leal Fernandes Mendes

\section{(c) The Editor(s) and the Author(s) 2013}

The moral rights of the and the author(s) have been asserted.

All rights to the book as a whole are reserved by INTECH. The book as a whole (compilation) cannot be reproduced, distributed or used for commercial or non-commercial purposes without INTECH's written permission.

Enquiries concerning the use of the book should be directed to INTECH rights and permissions department (permissions@intechopen.com).

Violations are liable to prosecution under the governing Copyright Law.

\section{(cc) BY}

Individual chapters of this publication are distributed under the terms of the Creative Commons Attribution 3.0 Unported License which permits commercial use, distribution and reproduction of the individual chapters, provided the original author(s) and source publication are appropriately acknowledged. If so indicated, certain images may not be included under the Creative Commons license. In such cases users will need to obtain permission from the license holder to reproduce the material. More details and guidelines concerning content reuse and adaptation can be foundat http://www.intechopen.com/copyright-policy.html.

\section{Notice}

Statements and opinions expressed in the chapters are these of the individual contributors and not necessarily those of the editors or publisher. No responsibility is accepted for the accuracy of information contained in the published chapters. The publisher assumes no responsibility for any damage or injury to persons or property arising out of the use of any materials, instructions, methods or ideas contained in the book.

First published in Croatia, 2013 by INTECH d.o.o.

eBook (PDF) Published by IN TECH d.o.o.

Place and year of publication of eBook (PDF): Rijeka, 2019.

IntechOpen is the global imprint of IN TECH d.o.o.

Printed in Croatia

Legal deposit, Croatia: National and University Library in Zagreb

Additional hard and PDF copies can be obtained from orders@intechopen.com

Parenting in South American and African Contexts

Edited by Maria Lucia Seidl-de-Moura

p. cm.

ISBN 978-953-51-1212-9

eBook (PDF) ISBN 978-953-51-5142-5 


\section{We are IntechOpen, \\ the world's leading publisher of Open Access books}

\section{Built by scientists, for scientists}

\section{$4,300+$}

Open access books available

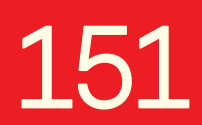

Countries delivered to

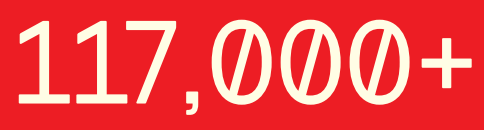

International authors and editors
$130 \mathrm{M}+$

Downloads

Our authors are among the

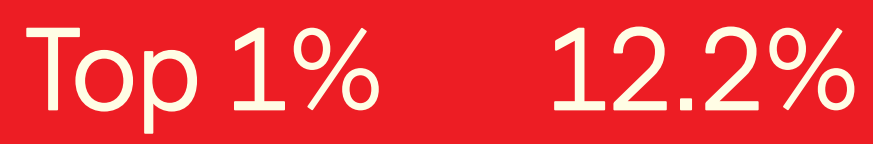

most cited scientists

Contributors from top 500 universities

\section{Interested in publishing with us? \\ Contact book.department@intechopen.com}

Numbers displayed above are based on latest data collected.

For more information visit www.intechopen.com 



\section{Meet the editor}

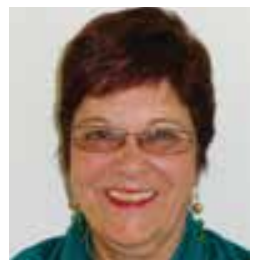

Maria Lucia Seidl-de-Moura is a full professor at the State University of Rio de Janeiro. She has a Ph.D. in Cognitive Psychology and is a Fellow from the Brazilian National Research Council - Level 1A. She coordinates the research group Social Interaction and Development, developing studies on parental beliefs and practices, early mother-infant interactions and development of self, under an evolutionary developmental psychology perspective.

Formerly, among other positions, she has been the President of the National Association for the Graduate Studies and Research, head of the psychology committee at Brazilian National Research Council and member of the National Committee for Evaluation of Graduate Programs in Psychology. She was one of the founders of The Brazilian Association of Developmental Psychology. 



\section{Contents}

Preface XI

Chapter 1 Brazilian Mothers' Cultural Models: Socialization for Autonomy and Relatedness 1

Maria Lucia Seidl-de-Moura, Rafael Vera Cruz de Carvalho and Mauro Luís Vieira

Chapter 2 Child-Rearing Practices of Brazilian Mothers and Fathers: Predictors and Impact on Child Development 17

Cesar Augusto Piccinini, Patricia Alvarenga and Angela Helena Marin

Chapter 3 Paternity in the Brazilian Context 35

Mauro Luís Vieira, Maria Aparecida Crepaldi, Carina Nunes Bossardi, Lauren Beltrão Gomes, Simone Dill Azeredo Bolze and César-

Augusto Piccinini

Chapter 4 Parenting and Culture - Evidence from Some African Communities 65

Patricia Mawusi Amos

Chapter 5 Cultural Variations in Parenting Styles in the Majority World Evidences from Nigeria and Cameroon 79

Esther F. Akinsola

Chapter 6 Parenting in Amazonian Riverside Context 97 Simone Souza da Silva Costa, Tatiana Afonso, Thamyris Maués dos Santos and Fernando Augusto Ramos

Chapter 7 Socialization Goals of Mothers and Grandmothers of Children in Institutional Shelter Situation in the North of Brazil 115 Lília lêda Chaves Cavalcante and Celina Maria Colino Magalhães 
Chapter 8 Emotion, Affection and Maternal Speech in Parental Care 129

Deise Maria Leal Fernandes Mendes and Luciana Fontes Pessôa

Chapter 9 Interventions for Enhancing Parenting Quality in Early Infancy 147

Jenny A. Ortiz M., Eva Diniz Bensaja dei Schiró, Olga Alicia Carbonell Blanco and Silvia H. Koller 


\section{Preface}

Values, beliefs, goals, ethno-theories, and childrearing practices are part of children's developmental niche [1]. They vary between cultures and across diverse contexts in specific cultures. Parental styles also vary in different families in the same cultural context depending on socio-demographic characteristics such as educational level of its members. We need to understand aspects of those niches in order to explain development and developmental trajectories. Generally, this is part of studies in parenting and there is an extensive literature in this subject. However, most of the studies are from a minority of countries populations [2] from North America and Europe. This book has nine chapters and it aims at contributing to the literature, presenting data from African and South American contexts, such as Brazil, Colombia, Cameroon, Ghana, Liberia and Nigeria. Brazilian studies are from a variety of contexts across the country.

Seidl de Moura, Carvalho and Vieira's chapter - Brazilian mothers' cultural models: Socialization for autonomy and relatedness - focuses on evidence from Brazilian studies about mothers' parental models. Brazil is the largest South American country, with very distinct regions. The country hosts diverse historical and cultural backgrounds. Brazilian HDI has been growing equally in the three dimensions: health, education and income, but the country still has a high index of concentration of income, despite federal government programs aiming at income distribution. The authors report evidence on mothers' beliefs and practices of care from several Brazilian cities located on diverse regions and of varied population size. The chapter introduction discusses the theoretical assumptions about human development and characteristics of the Brazilian context. The authors argue for the importance of studies of intra-cultural variations using varied methods to understand development in context and present and discuss mothers' socialization goals, maternal beliefs about practices of care of young children; mothers' "narrative envelope"; and mothers' ideas about their children.

Piccinini, Alvarenga, Marin and Sobreira present in their chapter - Child-rearing practices of Brazilian mothers and fathers: Predictors and impact on child development - various issues related to childrearing practices investigated by the Center for Children and Families (NUDIF / UFRGS) to which the authors belong. They discuss the predictors of childrearing practices related to cultural differences, parental values, socialization goals and social class; the predictors related to individual characteristics of parents and of children; and the impact of childrearing practices on children's social competence and behavior problems. The studies they review indicate that childrearing practices are linked to the cultural and social context in which families live, including variations inside one country, especially a large one such as Brazil. They discuss the difficulty in identifying childrearing practices most commonly used by mothers and fathers when data from different regions and cultural backgrounds is compared and report differences related to the mother's cultural background, type of situation, 
child's age and sex, besides the family's SES are reported. Regarding predictors of practices involving parents' and children's characteristics, Piccinini et al present evidence of intergenerational transmission, and similarities and differences in mother's and father's childrearing practices according to child's age, illness and birth order. The presence of chronic disease in childhood was also observed as a possible predictor factor of the quality of mother-child interaction.

According to the authors, results of their studies support evidences from the literature that guidance practice, assertive control and positive parental involvement to social competence, while coercive and permissive practices were found to be related to externalizing problems. The authors highlight the complexity of factors related to parents' childrearing practices and the need for a theoretical model that portrays the dynamic interaction of these factors.

Vieira, Crepaldi, Bossardi, Gomes, Bolze and Piccinini's chapter - Paternity in the Brazilian context - also present a review of a group of Brazilian studies, but they orient their efforts toward paternity. The authors begin by discussing the changing roles of fathers and mothers in different countries and the concepts concerning to the relation of father with his child, proceeding to review studies on paternity in Brazil. They present data on contemporary family configurations, the participation of the father in the context of pregnancy, birth, and postpartum; the function of fathers; the effect of fathers in children's development; variables related the exercise of paternity, gender identity; perception and conception of paternal behavior; and specific cases such as paternity and adolescence and fathers of disabled or hospitalized children. The review is quite thorough and shows that the interest on paternity in Brazilian studies is increasing in the last 13 years. The authors conclude that participation of fathers in the raising of children has been augmenting and that this is altering family dynamics and it is having an effect on children's development. They also point out the need of further studies to characterize the experiences of paternity in some specific situations such as caring for children with special needs; to understand the effect of sex and birth order in Brazilian family organization; and to understand how men perceive their roles as fathers. Other gaps in the literature are pointed out, contributing to future development of this field of studies.

The forth chapter brings some data from African studies - Parenting and culture: evidence from some African communities. Amos explores some of childrearing practices observed in some sub-Saharan countries (Ghana, Nigeria and Liberia) which she argues foster good parenting and she discusses them in terms of their relevance as perceived by Africans. She reports the prevalence of extended families and considers this is as a context that fosters the development of a strong sense of security and of social responsibility in the child from his early years. Folktales are another tool of good parenting in the selected countries. Amos gives lovely examples of folktales, transmitted across generations, told to children in pleasant contexts, helping to share beliefs, values and behavior considered important by the cultural group. Puberty rites are also considered a good parenting practice. Although variations are observed between countries, those ceremonies are seem as preventing teenage pregnancy, prostitution and the spread of sexually transmitted diseases, besides transmitting cultural values of responsibility and family care by women. In line of this, the author stresses the role of mothers in African families and the contribution of African cultural childrearing models to healthy child development. She concludes "African culture is rich. We should not neglect it out rightly because it is that which makes us Africans. Let us embrace our good parenting practices so we can nurture responsible youth for the African conti- 
nent". I believe that this contribution goes beyond that and that it may help us promote child development in general.

Akinsola's chapter - Cultural variations in parenting styles in the majority world: Evidences from Nigeria and Cameroon - contributes with further data from African countries, this time about parental styles in Nigeria and Cameroon. She points out that in Nigeria all the three single parenting styles discussed in the literature (authoritarian, authoritative and permissive) are observed. However, the emphasis is on obedience to authority and compliance with parental instructions. The author explains this tendency as a result of the collectivist, hierarchical and patriarchal model of Nigerian society, with values of respect for elders and authority figures. Parental authority is central and the father is the head of the family. However such demands for obedience and compliance with orders are balanced by responsiveness, love, care, sensitivity, reciprocal dialogue, and explanations for parental disciplinary actions. This combination leads Nigerian children to perceive their parents as both authoritative and authoritarian.

In this chapter we also learn that Cameroon is a collectivistic society with different ethnic groups and parents present somewhat different cultural models from the Nigerian ones. Although diversity is observed between ethnic groups, certain values are common, including the importance attributed to learning by example / observation and through play. The predominant family pattern in Cameroon is the patrilineal and extended or joint family which is argued to foster interdependence. The author focuses on Nsos who live in the Anglophone sector of Cameroon. She describes childrearing practices emphasizing relationship. To this group of Cameroonians, good parenting involves parents monitoring, instructing, training, directing and controlling infants' activities. Both the permissive and authoritarian parenting styles are reported. It is discussed that although Nigeria and Cameroon are both collectivistic societies, they present different parenting styles which are effective for each group. Amos points out the importance of the consistency of parenting behaviors in relation to cultural values, and how the positive or negative child development outcome related to a particular parenting style depends on the culture.

Costa, Afonso, Santos and Ramos present data about a Brazilian context in their chapter Parenting in Amazonian riverside context. They studied two families from different communities. One of them is located at Araraiana's riverside and it is more isolated than the other, which is located near the city of Belém. In the first community, the population has little or no access to written media, television or radio, in the other, city life is available within 15 minutes by boat. Both Amazonian riverside communities live from the river and smallscale agricultural production. The Survey of Family Routines - SFR, adapted to use of the communities studied, was administered to all members of the participant families with the request that they describe the activities performed in the day previous to the interview, and the routine of the last Sunday. Family activities were described, identifying family tasks and who performs them, as well as the moments of meeting, of close coexistence or isolation. Similarities and differences were found between the two families indicating a more traditional way of family life and one that shows a transition to an urban model.

Cavalcante and Magalhães discuss values and beliefs from two generations in their chapter: Socialization goals of mothers and grandmothers of children in institutional shelter situation in the north of Brazil. Their data is also from an Amazonian context, the city of Belém. The authors discuss how in Brazil, nowadays, there are thousands of children in shelter institu- 
tions, and many parents do not live in desirable social conditions. They studied socialization goals of a group of mothers and grandmothers of children who are institutionalized. Two open ended questions focusing on the qualities the participants want their children to have in the future and how should they be achieved were used. The results indicate that both mothers and grandmothers mentioned predominantly traces of a socio-centric cultural model, valuing characteristics of interdependence and promotion of well being for the collectivity. To the second question "What do you think it is necessary for him/her to develop these qualities?" different strategies were mentioned by mothers and grandmothers. The answers were grouped accordingly to the categories: centered in the self, centered in the child, or centered in the context. It was observed a convergence between the strategies mentioned by the two groups. The most cited were the ones in the category centered in the self. Although their children were living in a shelter institution and their ability to protect and educate them was being temporarily questioned from the social and judicial standpoint, according to the child social protection legislation, they still think of themselves as the main responsible for their development. The second category valued is of factors associated to the context. They stress the importance of available resources in the family and social environments, seen as fundamental to achieve their valued socialization goals. Those resources can either attenuate what might be prejudicial for the child, or support networks formed by people and institutions (such as shelters and preschool). The study is important for the development of social policies that promote child development in underprivileged conditions including the empowerment of members of their family.

The eighth chapter is Emotion, affection and maternal speech in parental care by Mendes and Pessôa. It discusses the role of emotions and affective communication in childrearing of care and the relevance of these components in children development. The authors stress the importance of considering different development trajectories as related to culture. According to the authors, the literature indicates the role of affective parent-child exchanges in promoting healthy development. Mothers' affective speech is also discussed and how it affects language development. The literature is reviewed by the authors, including some studies developed with Brazilian dyads. The chapter brings a contribution in widening the focus on parenting to include emotional aspects besides cognitive ones.

The last chapter - Interventions for enhancing parenting quality in early infancy - by $\mathrm{Mu}$ ñoz, Schiró, Blanco and Koller is directed to an important issue: how effective interventions promoting child development can be constructed and implemented. Considering the importance of early childhood for building biological and psychological resources aiming at healthy human development, they stress the need for social, economic and political commitment. The development of social policies has to be based on good theoretical explanations the role of early experiences on subsequent human development and expertise on the creation of interventions. The authors argue that those two efforts need to be integrated. They use Bronfenbrenner's proposals about the ecology of development and the proximal processes as central in human development, namely by the establishment of emotional attachment bonds, as a theoretical model. Based on that, they discuss the role of the caregiver as central in interventions to promote healthy child development. Muñoz and colleagues consider risk contexts in Latin-America and present very interesting and effective intervention programs in Colombia and Brazil: Primeira Infancia Melhor and Formación en Ambiente. Those programs can be the base for further initiatives to promote development in risk and underprivileged contexts. 
This set of chapters brings a contribution to the literature on parenting, presenting theoretical models that consider the biological and cultural nature of this process and evidence from a sample of countries from the "majority world". We hope that our readers find them useful for the development of more research projects dealing with the populations from countries from this part of the world and inspiring for the construction and implementation of good intervention programs that promote healthy development of children.

Rio de Janeiro, Brazil, December, 9, 2013.

Maria Lucia Seidl de Moura University of the State of Rio de Janeiro, Brazil

\section{References}

[1] Harkness, S. \& Super, C. M. Parents' cultural beliefs systems: their origins, expressions, and consequences. Introduction (pp.1-23). New York: The Guilford Press, 1996

[2] Henrich, J., Heine, S. J., \& Norenzayan, A. The weirdest people in the world? Behavioral and Brain Sciences, 33, 61-135, 2010. 

Chapter 1

\title{
Brazilian Mothers' Cultural Models: Socialization for Autonomy and Relatedness
}

\author{
Maria Lucia Seidl-de-Moura, \\ Rafael Vera Cruz de Carvalho and Mauro Luís Vieira
}

Additional information is available at the end of the chapter

http://dx.doi.org/10.5772/57083

\section{Introduction}

Brazil is the largest South American country, with a population of 190,732,694 inhabitants living in $8,514,877 \mathrm{~km}^{2}$, with very distinct regions. There had been a population growth of $12.3 \%$ in a decade. Most of the population lives in urban centers (84\%) (Brazil, 2012); in the decade of 1960 Brazil had an urbanization index of $44.7 \%$ of its population. Two decades later, $67.6 \%$ of the population was living in cities (see table 1 ).

\begin{tabular}{cccc}
\hline Census Year & Urbanization index & Population growth & Urban growth \\
\hline 1900 & - & - & - \\
\hline 1920 & $16.55 \%$ & $43.08 \%$ & $37.19 \%$ \\
\hline 1940 & $26.35 \%$ & $33.46 \%$ & $72.46 \%$ \\
\hline 1950 & $36.16 \%$ & $25.70 \%$ & $70.13 \%$ \\
\hline 1960 & $45.52 \%$ & $35.13 \%$ & $65.55 \%$ \\
\hline 1970 & $56.80 \%$ & $32.69 \%$ & $55.02 \%$ \\
\hline 1980 & $68.86 \%$ & $27.87 \%$ & $35.33 \%$ \\
\hline 1991 & $73.80 \%$ & $26.28 \%$ & $31.36 \%$ \\
\hline 2000 & $81.00 \%$ & $12.90 \%$ & $13.74 \%$ \\
\hline
\end{tabular}

Table 1. Data about urbanization in the country 
The country has high human development (longevity, knowledge and life quality), ranking 84 th among all countries in the world. Brazilian HDI (.718) has been growing equally in the three dimensions: health, education and income (PNUD, 2013). Life expectancy at birth is 73.5 years, and average number of years at school is 7.2. Life satisfaction is generally good, with an index of 6.8 (in a scale from 0 to 10), considering the highest score observed is 7.4 (in Norway). However, although Federal social programs from the last 10 years have been responsible for recent diminishing inequality, the country still has to deal with this problem. When HDI is adjusted to inequality, the score lowers to .519 (PNUD, 2013).

The country hosts diverse historical and cultural backgrounds. Despite having been colonized by Portugal, Brazil shares with the Latin American countries colonized by Spain (such as Costa Rica, Mexico and Argentina) the religious influence, mostly Catholicism, but not the language (Brazilian people speak Portuguese, not Spanish). Three main influences constituted Brazilian people: Portuguese colonizers, native people, from different ethnic groups, and Africans from different origins brought as slaves until the end of the 19th century (Ribeiro, 1997, Torres \& Dessen, 2006). Later, Brazil received several groups of immigrants from all continents, who ended up interacting with each other forming a much diversified society. The influences from these groups are differentially expressed across the country. Brazil has five geographic regions (North, Northeast, Central-West, Southeast and South), which have diverse ecological characteristics and a variety of social, economic and cultural profiles. The North region, located mainly in the Amazon basin, is home of many native Brazilian tribes. Although diverse in many ways, they represent traditional life styles and collectivistic contexts. Urban centers in the North region, such as Belém, are influenced by these life styles. In contrast, in the South region the higher influence is from European immigrants, mainly Italians and Germans. The Southeast region, which includes the two largest cities of the country, the state capitals of Rio de Janeiro and São Paulo, has received many waves of diverse Brazilian and foreign immigrants because of its historical and economic influence. Finally, in one of the states in the Northeast region, Bahia, where we studied two contexts, we still have strong African influence.

Social differences can be identified between regional realities (urban and rural populations), as well as among different social classes. Since the end of last century, due mainly to urbanization and other influences, some authors believe there is some homogeneity in life styles, with the predominance of an urban and 'modern' symbolic system, which tends to minimize the differences in living conditions.

Since most of the population lives in urban centers, the predominant form of family organization is that of the nuclear family (Biasoli-Alves, 1997). Mothers are usually the main caretaker, gaining progressively more autonomy because of the increasing participation of women in the job market ( $51.4 \%$ in 2004). As a consequence, families have tended to search for alternatives to mothers' exclusive care for children, resorting to the support of grandmothers, nannies (in middle and high classes), and day-care centers.

For Georgas (2006), the family is a critical and specific group in what concerns its role played in psychological differentiation. Moreover, the family is the mediator between the individual and society, and a privileged setting in the social construction of reality. Reviewing the literature, Vieira, Lacerda, Vieira and Seidl-de-Moura (2011) have indicated changes in 
Brazilian families' organization and values over the last decades of the 20th century. In the 1930 's there was a predominance of a traditional family model, with emphasis on moral values and behavior control. In the following two decades there was greater influence of formal education and an educational model that attributed importance to stimulation and the meeting of children's needs. In the1970's and 1980's, mothers' discourse revealed worries about giving affection and understanding their children. Socialization goals of recent years - not much different for boys and girls - are guided towards the development of an independent, autonomous and competitive adult, who is able to succeed professionally. The preoccupation with children's subjective well-being is observed. Mothers allow their children to have initiative and maintain a flexible structure in family daily life. Child rearing rules become less rigid, although children have now less free time to play. Planned activities are valued and considered a sign of good child care. Families gradually changed and patriarchal models have been substituted for more equalitarian ones. Dessen and Torres (2002) argue that some macrosocial and historical factors, such as globalization and modernization, new patterns of consumption and flexibility at work, have probably modified Brazilian families' dynamics and ideas about child development. Aizpurúa, Jablonski and Féres-Carneiro (2007) studied Brazilian and Argentinean family transformations and identified new family organizations influenced by divorce acceptance and women's increasing insertion in the job market.

We believe that it is important to study parenting in Brazil and that the country may be a good setting to investigate socialization trajectories. One of the important aspects to consider is how those trajectories value separation or autonomy and the relation to others. Psychology has dealt with those characteristics in diverse ways along the decades. Until the first half of last century, separation and individualization were considered by developmental theories as the natural and desired trajectory in human social-emotional development. It was proposed that (1) children are born without a sense of self and not able to distinguish themselves from their mothers' bodies and that (2) they develop from this initial state of no differentiation towards becoming separated and autonomous. The first idea has some of its origins in authors from the 19th century, such as William James (1890), who thought babies were born experiencing a state of confusion, unable to differentiate stimulation towards their own body from other kind of stimulation. The literature on infant development (i.e. Rochat, 2001; Seidl-de-Moura \& Ribas, 2004) has brought evidence against this assumption. We now know that human babies are born with a capacity to perceive their own body and others', and, thus, have a basic sense of self. They present capacities for perception and actions that enable them to have a sense of their own bodies as separate from others' and from the environment, as well as to be responsive to social events since birth.

The idea that healthy development should proceed towards separation and autonomy, reflects an ethnocentric tendency in Developmental Psychology. Studies have privileged a specific trajectory, namely the urban Western one. It is the trajectory of a minority of human beings. Why is this? According to Tomlinson and Swartz (2004) approximately 135 million babies were born each year worldwide, $90 \%$ of them not in European, North-American, Australian or New Zealand contexts. They are part of what Kağitçibaşi $(1996,2007)$ calls "the Majority World". However, in the period from 1996 to $2004,95 \%$ of research on infancy is by authors from those 
countries and about people from their respective contexts. The same tendency is discussed by Henrich, Heine and Norenzayan (2010). They affirm that studies in behavioral science concentrate in a very specific group they name WEIRD (Western, educated, industrialized, rich and democratic groups), mostly psychology students. In a review of studies from 2003-2007, 96\% of the samples of psychological studies were from countries with only $12 \%$ of the world's population. They have reviewed mostly studies with adults, but, one of the commentators of the central article (Lancy, 2010) criticizes specifically developmental studies, which discuss play, parent-child interactions, parental styles and attachment evidences, as well as generalizations made by the authors of these studies.

Considering that human development is based on evolved characteristics of our species, occurring in social-cultural contexts, through epigenetic processes, we can assume that it can follow diverse pathways. Thus, we can ask whether the movement towards separation and autonomy is a universal natural developmental trajectory. We are members of a species with a complex social organization, and the relation to our co-specifics is essential to our survival, both physical and psychological (Kline, 2008). Thus, autonomy and relatedness are fundamental aspects of human development, hardwired in our adapted mind (Kağitçibaşi, 2007, 2012, Kline, 2008).

This is the proposal made by Kağitçibaşi $(1996,2007,2012)$ in her Theory of Family Change. This theory argues that autonomy and interdependency are not extreme poles in a continuum. She hypothesizes two basic dimensions: agency (varying from autonomy to heteronomy poles) and personal distance (varying from separation to connection). The dynamics of the two dimensions lead to the possible development of four kinds of selves: autonomous separated; autonomous related; heteronomous separated, and heteronomous related. Using samples of mothers from prototypical contexts, such as those from Berlin, Germany, from a rural community from Cameroon, and from San Jose, Costa Rica, among others, cross-cultural studies have been conducted aiming to compare development of self trajectories (e.g. Keller et al., 2006, Keller, 2007).

In this chapter, we review some studies conducted in Brazil by a national network of researchers. We aim to contribute to the literature on the dynamics of autonomy and relatedness in developmental contexts. We believe that the investigation of intra-cultural variety in valuing the dimensions of autonomy and relatedness in a large country such as Brazil is relevant. Not only it can be a contribution to understanding characteristics of developmental contexts in the country, but also to the enrichment of the international literature, testing hypotheses derived from Kağitçibaşi's (2007) model.

Considering the importance of studying contexts from the Majority World under-represented in the literature, this chapter aims to offer a contribution to this book on culture and parenting, presenting data on Brazilian mothers' cultural models. Our assumption is that the country may function as a good laboratory for testing the Theory of Family Change. On one side, Brazil has a Latin Catholic influence that may favor a culture of relatedness. On the other side it has a high urbanization trajectory, which may promote changes towards sharing values of other Western urban societies, such as the importance of autonomy. We are aware that mothers are 
just one of the actors in parenting, which involves mothers and fathers. Another chapter in this book will deal with fathering in Brazil (Vieira et al.) and complements this one.

We will present evidence from studies conducted in several Brazilian contexts, using different methodologies. Their results indicate the dynamic trajectories of development of related autonomy, and will be discussed in terms of Kağitçibaşi's theory.

The studies conducted have focused on 16 different Brazilian contexts. Table 2 presents socialdemographic data about them. As can be seen, they are distributed in the country's five geographic regions, and include state capitals, as well as smaller cities of different population sizes.

\begin{tabular}{|c|c|c|c|c|}
\hline \multirow[t]{2}{*}{ State } & \multirow[t]{2}{*}{ City } & \multicolumn{3}{|c|}{ Population } \\
\hline & & Total & Urban (\%) & Rural (\%) \\
\hline ES & Boa Esperança & 14,199 & 74.60 & 25.40 \\
\hline ES & Vitória & 327,801 & 100 & Zero \\
\hline BA & W. Guimarães & 22,189 & 33.85 & 64.15 \\
\hline BA & Salvador & $2,675,656$ & 99.94 & .06 \\
\hline MS & Campo Grande & 786,797 & 98.65 & 1.35 \\
\hline PA & Santa Bárbara do Pará & 17,141 & 33.05 & 66.95 \\
\hline PA & Belém & $1,393,399$ & 98.82 & 1.18 \\
\hline PB & João Pessoa & 723,515 & 99.53 & .47 \\
\hline RJ & Distrito de Amparo & 1,283 & 70.10 & 29.90 \\
\hline RJ & Rio de Janeiro & $6,320,446$ & 100 & Zero \\
\hline RS & Porto Alegre & $1,409,351$ & 100 & Zero \\
\hline SC & Corupá & 13,852 & 72,00 & 28,00 \\
\hline SC & Itajaí & 183,373 & 94.34 & 5.66 \\
\hline SC & Florianópolis & 421,240 & 96.26 & 3.74 \\
\hline SP & Taiúva & 5,447 & 82.83 & 17.17 \\
\hline SP & São Paulo & $11,253,503$ & 99.10 & .90 \\
\hline
\end{tabular}

Table 2. Contexts studied, total population and urban and rural distribution (cities underlined are state capitals)

The studies have focused on several developmental aspects, mainly related to mothers' beliefs and values. One study focused on toddlers' development, with the assumption that it reflects the prevalent socialization trajectory in that specific context.

We will describe data on what mothers desire for their children in the future; how they want their children to turn out in the future (socialization goals); what they think is important in caring for them (beliefs about practices); what they highlight in their description of them (ideas 
about their children); and the way they talk to them (narrative envelope). Finally, some results on children's social-emotional development will be presented. Our assumption is that data on mothers reflect somewhat the trajectory they favor in the orientation of their children's development. Results on young children's self recognition and self-regulation tasks show congruency with the trajectory of related autonomy evidenced in mothers' answers to belief scales.

\section{Socialization goals: What do Brazilian mothers value in the education of their children?}

The characteristics parents want to foster on their children or their socialization goals reflect their cultural models and are important parts of the social-cultural context of children's development. Three studies have focused on mothers' socialization goals (Seidl-de-Moura et al., 2008, 2009; Vieira, Seidl-de-Moura, Macarini et al., 2010). They studied, respectively, mothers from seven cities and five geographic regions $(\mathrm{N}=349)$; from Rio de Janeiro $(\mathrm{N}=200)$, and from 12 localities, state capitals and small cities $(\mathrm{N}=600)$.

Mothers' Socialization goals were studied using two different kinds of instruments. One was the Socialization Goals Interview (SGI), developed by Harwood (1992), which consists of open questions asked to mothers about the qualities they expect their children to have in the future. It was used in Seidl-de-Moura et al. $(2008,2009)$ study. The open ended question made to all participants was: "What qualities would you like your child to possess as an adult?". Mothers' answers were coded in terms of individual word and phrase descriptors according to different categories described in the published papers: Self-maximization; Self-control; Lovingness; (4) Proper demeanour; and Decency. The categorizations were submitted to independent judges and presented adequate consistency scores. The first two categories (Self-maximization and Self-control) have been considered as characteristic of goals of autonomy and individual development, whereas Proper Demeanour and Decency reflect sociocentric goals of interdependency (Harwood, 1992). The score in each category was determined by dividing the number of descriptors for each category by the total number of descriptors (Leyendecker et al., 2002). The scores' distributions in the Self-control's category presented several wild outliers. For this reason, this variable was not included in the next analyses.

The Scale of Socialization Goals (Keller et al., 2006), adapted for Brazilian use, was the instrument employed in Vieira, Seidl-de-Moura, Macarini et al. (2010). It includes a list of ten items indicating opinions about parents' goals to their children's future during their first three years of life. For each item the mothers marks in a 5-point Likert scale, ranging from "Not important" to "Very important". In the original instrument (Keller et al., 2006), a Principal Components Factor Analysis produced two dimensions: autonomy (with five items) and relational goals (with five items). One example of the first dimension is "to develop competitiveness", whereas one example of the relational dimension is "to learn to obey elderly persons". The authors report good Cronbach's Alphas $(\alpha)$ for both dimensions (autonomy =. 93, and relational $=.88$ ). 
Two studies have indicated that mothers studied have goals for their children oriented to both the development of autonomy and towards relatedness. Seidl-de-Moura et al. (2008) observed that mothers from state capitals presented an autonomous-related profile. Considering their socialization goals, they want their children to be happy, healthy, self-confident, successful, self-sufficient, and adaptable, to make good decisions, to be assertive, have a good education, and to stand up for themselves (Self-maximization). They value equally qualities of appropriate behavior in the context of being part of or getting along with a larger group, both in terms of being respectful and well brought up and of fulfilling role obligations within the family (Proper demeanor). Mothers from this study showed different perspectives, either more oriented towards goals of interdependency or autonomy, depending if they live in medium, large or very large cities. Mothers' educational level was a significant factor in their socialization goals. Mothers with higher levels of education tended to give more importance to goals of autonomy than mothers with lower levels of education.

The study of mothers from Rio de Janeiro (Seidl-de-Moura et al., 2009) confirmed some tendencies of the study mentioned above. Answers to the SGI were coded in five categories and their subcategories: Self-maximization (SM), Self-control (SC), Lovingness (L), Proper demeanor (PD) and Decency (D), and scores in each of them were calculated. Mothers in this study indicated the valuing of autonomy as an end-product of their socialization efforts. Scores on Self-maximization were indeed the highest. Autonomy, however, is not valued in this group without references to sociocentric preoccupations. The second highest mean score was Decency, which refers to personal standards of behavior, concerns that the child behaves respectfully, gets along well with others, and fulfills reciprocal obligations. The analyses did not indicate a significant difference between Self-maximization and Decency mean scores. However, the variation in scores may indicate that mothers from this city present diverse profiles regarding what they expect their children to become.

After further investigation of the subcategories used, specific patterns of beliefs were identified. The highest mean in the Self maximization category is in the subcategory related to the development of the child's talents and potential (including economic). In this sample, the three aspects of autonomy (emotional and physical well-being, psychological independence, and economic success) did not correlate, indicating the complexity of a parenting cultural model oriented towards autonomy. This complexity is complemented by the results in the subcategories of Decency. The highest mean observed was in Personal integrity and religious values, which relate to basic societal standards, such as being hardworking and honest. Mothers want their children to achieve success and fulfill their potential, but through hard work and with honesty. The study's results related to the importance of the "development of the child's personal and economic potential" show an interesting pattern that could be related to this increase of educational opportunities in the country's recent history. Mothers with the highest educational level gave fewer responses in this subcategory than mothers with less than high school education. Maybe mothers who have a higher level of education take for granted the fulfillment of their children's potential more than mothers who had fewer opportunities to study. This result is complemented by the observation that mothers who had higher level of 
education give more answers related to self well-being as a socialization goal for their children than mothers with less years of formal education.

\section{Beliefs about practices: How do Brazilian mothers think they should care for their children?}

Goals for the future are somewhat translated into practices. Hence, we have focused also on mothers' beliefs about appropriate care practices. They were investigated in two studies: Vieira, Seidl-de-Moura, Macarini et al., 2010; Vieira, Seidl-de-Moura, Lordelo et al. 2010). Data were collected using two instruments: The Inventory of Beliefs about Practices (adapted from Suizzo, 2002) and the Scale of Practices of Care (Keller, 2007). Both were adapted for use in Brazil.

Suizzo's (2002) inventory of "Beliefs and Ideas about Infants and Young Children" was employed in the study by Vieira, Seidl-de-Moura, Lordelo et al. (2010). The original version of the instrument has 50 items, 25 of them related to babies less than one year-old, and 25 related to infants between one and three years-old. For each item, the mother is asked to rate the level of importance attributed to the practice using a 6-point Likert scale $(0=$ disagree, $1=$ without importance, 2 = of little importance, $3=$ of average importance, $4=$ very important, and $5=$ extremely important). The mother is asked to answer according to what she thinks, and not according to what she does with her child. In the Brazilian version, three factors were identified and a total of 27 items were used. The first factor named "Exposing the child to diverse stimulation" ("Stimulation") is composed by 12 items ( $\alpha=.70)$.One example of item is: "Giving toys to one's baby to waken his/her senses". The second factor, named "Ensuring the proper presentation of the child" ("Proper presentation"), is composed by 10 items $(\alpha=.70)$, one of which is "Teaching one's child to be quiet (tranquil) in public". The last factor was named "Responsiveness and bonding", which is constituted by 5 items $(\alpha=.60)$. The first factor is associated with a trajectory valuing the development of autonomy, and the second valuing interdependence. We have not used the score in the third factor.

Keller's (2007) scale of Beliefs about Practices has ten items that indicate mothers' opinions about the proper way to care for children during the first three years of age. The scale comprises two dimensions, relational practices and autonomous practices, each with five items. The dimension of relational practices $(\alpha=.78)$ includes items that emphasize body contact and the immediate satisfaction of babies' needs; and the second, autonomous practices, includes items dealing with the promotion of early child self-regulation, object stimulation, and face-to-face interaction relational practices $(\alpha=.86)$. They are presented as affirmatives to be evaluated in a 5-point Likert scale, ranging from "Not important" to "Very important".

Vieira, Seidl-de-Moura, Lordelo et al. (2010) used a national sample. Mothers from seven cities answered an inventory on their beliefs about care practices of young children. The dimensions of practices most valued were "Proper Presentation" (oriented by socially accepted daily rules), followed by "Stimulation" (aimed to stimulate their children's development). However, these characteristics were modulated by the parents' educational level and cultural conditions. 
For example, "Proper Presentation" was influenced by city of origin. Mothers living in Belém attributed greater value to this dimension than mothers living in Porto Alegre. The former city is located in North of Brazil, with strong influence of the indigenous culture. The latter city is located in South of Brazil, with greater influence of the European colonization. In addition, the importance of stimulation is related to mothers' educational level. Mothers with a higher educational level show more stress on the stimulation of their children.

In Vieira, Seidl-de-Moura, Macarini et al. (2010), using Keller's scales and a sample of 606 mothers from state capitals and small cities, it was observed that mothers from capitals report more practices of stimulation and value more these practices than the ones from small cities. In small cities, mothers with a higher educational level reported having more stimulation practices with their children. It was observed the inclusion of autonomy values and practices in a context traditionally more interdependent, which can be interpreted to be the result of social-economic changes in small cities. However, in small cities there was a greater appreciation of relatedness. In capitals, both relatedness and autonomy are valued. The conclusion is that there is a dynamic relationship between autonomy and relatedness depending on the place of the mothers' residence (capital or small city). Although differences were observed, characteristics of autonomy and relatedness were present in mothers' beliefs in both contexts.

\section{Mothers' ideas about their children: What are the characteristics of Brazilian children according to their mothers?}

Complementing data presented on mothers' goals for their children's development and their related practices of care, mothers' ideas about their children were the focus in Seidl-de-Moura et al. (in press) study. Considering mothers' answers to the request to describe their children, we could infer the most valued characteristics, and thus the predominant cultural model indicated in these descriptions.

A group of 94 mothers from two Brazilian cities (Rio de Janeiro and Itajaí) participated. An open question was used, based on studies by Harkness and Super (2005). As part of a larger study, mothers were interviewed individually and asked to talk about their target child, describing him/her. The instruction was: "Tell me about your son/daughter. How would you describe him/her?" Mothers could talk freely about their children and were not limited in the number of descriptors they could use. All the adjectives and expressions reported in the description were listed and constituted the corpus for analyses. For data reduction, we followed two kinds of procedures: a) the same from the studies that use the SGI (Seidl-de-Moura et al., 2008, 2009); b) the ones from Harkness and Super (2005). Similar to the procedures adopted by the latter researchers, we analyzed the adjectives and expressions used, the ones most frequently used, and the patterns that could be inferred. The analyses in the first case were conducted in a similar way as the ones related to socialization goals, although the categories were not previously defined, as in the SGI studies. Rather, the categories emerged from data. The steps in data reduction in this case were the following: first, through repeated readings of mothers' descriptions of their children, common patterns or categories were identified; 
descriptors were then classified based on these categories; the frequency of use of each category for each participant was computed; finally, a score for each category was obtained for all participants, dividing the frequency of descriptors used in each category by all the descriptors.

It was observed that the adjectives most frequently used were "intelligent" and "active", as well as "loving" and "caring". Children were described with more positive than negative temperament characteristics, and with more externalization than introversion characteristics. The adjectives were further categorized as relating to autonomy and relatedness. Analyses have indicated no significant difference between the proportions of descriptors in the two categories, indicating a tendency for valuing both aspects equally.

\section{The narrative envelope: How do Brazilian mothers talk to their children indicate their values?}

Another aspect of mothers' language, namely their "narrative envelope" or the symbolic context they surround their children, was followed longitudinally by observation and video recording at dyads' homes during early development in six mother-infant dyads (Two from birth to six months - Mendes \& Seidl-de-Moura, in press; four from 13 to 24 months - Pessôa \& Seidl-de-Moura, 2011).

Mothers' "narrative envelope" or language used with their child is a concept developed by Keller (2007), and one of the parental systems in the component model proposed by the author. It consists of the social discourse that involves the child through mother's conversations, presenting different styles and contents according to cultural models.

Mendes \& Seidl-de-Moura (in press) and Pessôa and Seidl-de-Moura (2011) verified that along the periods studied (birth to six months; and 13 to 24 months) mothers' speech was marked by expressions of agency and mental states (intentions, desires, cognitions, preferences, emotions and decisions) attributed to the baby, and statement of needs, categories which are associated to an autonomous self. It was also observed the significant presence of categories of social rules and co-agency, associated to a trajectory aimed at relatedness. This indicates the presence of tendencies to foster both autonomy and relatedness.

In synthesis, we believe that this set of results indicate, in different ways, that mothers' beliefs about outcomes for their children's development, the kind of practices they value, how they talk about them and to them reflect or indicate what Kağitçibaşi (2012) considers a trajectory towards the development of autonomous-related selves.

\section{Final considerations}

Based on Kağitçibaşi's theory, we have focused on demonstrating that autonomy and relatedness are not opposite dimensions, being present in specific dynamics in different contexts, aiming to contribute to the discussion on basic dimensions of human development. Brazil is a 
large and diverse country of the "majority world", and it has undergone important socialdemographic and economic changes in the last 10 years. Thus, we consider it especially appropriate to study this dynamics.

The studies reviewed in this chapter have the advantage of being developed by a cooperative network of researchers from different parts of the country and from different institutions. They have focused on a variety of aspects both from mothers' ideas, beliefs, values, language and practices, using a variety of instruments, such as inventories, interviews and behavioral observation. In addition, they had participants from urban centers of different population sizes in all the country's regions, in a total of 16 contexts, which we believe to be unusual in the literature.

Based on the evidence of the studies reviewed, we can argue that developmental trajectory of autonomous-related selves is somewhat privileged in Brazil. Our results indicate that, in general, both autonomy and relatedness are valued by Brazilian mothers in their conception of their children, their narrative styles, their socialization goals, and their practices. However, this model shows variations depending on social-demographic and cultural variables and cannot be considered as presenting a fixed or unique form.

Parental educational level is one important example of these variables. As observed in the studies, women with higher educational levels tend to value their children's autonomy. They have self-maximization goals for their children, and they want them to succeed and be happy. At the same time, it seems that this increase in educational level does not decrease some of the relatedness tendencies that may have cultural origins and be associated to our African and Indigenous heritage.

Education is associated to another important variable: urbanization. Although the country has a vast territory, most of its population lives in urban centers. We have verified that population size of mothers' cities is another factor that can modulate the importance attributed to autonomy and relatedness. Larger cities present typical conditions of post-industrial complex societies that lead to goals of autonomy: increase in the number of potential in-groups and of competition, decrease of loyalty among individuals of any of these in-groups, less social support from extended family, more isolation, etc. (Velho, 1987, Simmel, 1973, Triandis, 1989). In these contexts individuals have the opportunity to focus on their own personal goals rather than on the goals of any group they might belong (Triandis, 1989).

Finally, we have the cultural mixture that constitutes Brazilian people. Our three basic origins - Portuguese, Indigenous and African people - have been mixed with people from different immigration waves across the centuries. First, second and third generation immigrants married Brazilians and are well integrated to society. Thus, the influence from these different cultures, many of them oriented towards autonomy and independence (i.e., Germans), have been tempered by the relatedness tendency of our ancestors, in varying degrees and forms.

Differences in the products of the relationship between autonomy and relatedness can be observed in the results of our studies, according to varied levels of urbanization (size of population), diverse predominant cultural influences, and educational levels. 
We believe that the findings reviewed in this chapter not only present evidence supporting Kağitçibaşi's theoretical model, and contribute to the understanding of aspects of Brazilian developmental contexts. They can also contribute to developmental science and the relation between universal characteristics and the cultural forms they present. We also think that Brazilian childrearing beliefs and practices including autonomy and relatedness, can aid putting into practice Kağitçibaşi's (2012) integrative synthesis proposal. This author has discussed how the development of related-autonomy and social-cognitive development can be universal and desired healthy developmental goals. Although understanding cultural orientation towards interdependency in rural or traditional groups, and aware of tendencies for autonomy goals in urban educated contexts, we can aim at developing persons who have the best of both tendencies. They would have the benefits of formal education, the opportunities for self-maximization, and, at the same time, would be able to relate and to be close to others, to cooperate. Thus, as shown, we support the hypothesis that autonomy and relatedness are not mutually exclusive and they seem to be two faces of the parenting models from all over this large country.

\title{
Acknowledgements
}

The authors are grateful to the Brazilian National Research Council (CNPq), FAPERJ (Fundação Carlos Chagas Filho), from the State of Rio de Janeiro, the International Society for the Study of Behavioural Development (ISSBD) and Jacobs Foundation (JF) for support received. We also thank Ç. Kağitçibaşi for her ideas and inspiration.

\section{Author details}

\author{
Maria Lucia Seidl-de-Moura ${ }^{1}$, Rafael Vera Cruz de Carvalho ${ }^{1}$ and Mauro Luís Vieira ${ }^{2}$ \\ 1 University of the State of Rio de Janeiro, Brazil \\ 2 Federal University of Santa Catarina, Florianópolis, Brazil
}

\section{References}

[1] Aizpurúa, R. I., Jablonski, B., \& Féres-Carneiro, T. (2007). Familias brasileras y argentinas: entre la tradición y la modernidad. Revista Interamericana de Psicología, 41(2), 189-196.

[2] Biasoli-Alves, Z. M. M. (1997). Famílias Brasileiras do século XX: Os valores e as práticas de educação [Brazilian families in the 20th century: educational values and practices]. Temas de Psicologia, Ribeirão Preto, 2(4), 33-49. 
[3] Brazil, IBGE (2012). População nos censos demográficos segundo as grandes regiões, as unidades da federação e a situação do domicílio (1960/2010) [Population in the demographic census, according to regions, federation units and the situation of the domicile]. Retrieved from http://www.censo2010.ibge.gov.br/sinopse/index.php?dados $=8 \& u f=00$

[4] Campos, M. M., \& Gomes, J. V. (1996). Brazilian children: images, conceptions, projects. In C. P. Hwang, M. E. Lamb, \& I. E. Sigel (Eds.), Images of childhood (pp. 143-166). Mahwah, New Jersey: Lawrence Erlbaum.

[5] Dessen, M. A., \& Torres, C. V. (2002). Family and socialization factors in Brazil: an overview. In W. J. Lonner, D. L. Dinnel, S. A. Hayes, \& D. N. Sattler (Eds.), Online Readings in Psychology and Culture (Unit 13, Chapter 2). Center for Cross-Cultural Research, Western Washington University, Bellingham, Washington USA. Retrieved from http://www.wwu.edu/ culture.

[6] Georgas, J. (2006). Families and family change. In J. Georgas, J. W. Berry, F. J. R. van de Vijver, Ç. Kağitçibaşi, \& Y. H. Poortinga (Eds.), Families across cultures (pp. 3-50). Cambridge, UK: Cambridge University Press.

[7] Harkness, S., \& Super, C. M. (2005). Themes and variations: Parental ethnotheories in Western cultures. In K. Rubin, \& O. B. Chung (Eds.), Parental beliefs, parenting, and child development in cross-cultural perspective (pp. 61-79). New York: Psychology Press.

[8] Harwood, R. L. (1992). The influence of culturally derived values on Anglo and Puerto Rican mothers' perceptions of attachment behavior. Child Development, 63, 822-839.

[9] Henrich, J., Heine, S. J., \& Norenzayan, A. (2010). The weirdest people in the world? Behavioral and Brain Sciences, 33, 61-135.

[10] James, W. (1890). The principles of psychology (Vol. II). New York: Henry Holt \& Colt.

[11] Kağitçibaşi, Ç. (1996). The autonomous-relational self: a new synthesis. European Psychologist, 1(3), 180-186. doi: 10.1027/1016-9040.1.3.180

[12] Kağitçibaşi, Ç. (2007). Family, self and human development across cultures. London: Lawrence Erlbaum Associates.

[13] Kağitçibaşi, Ç. (2012). Socio-cultural change and integrative syntheses in human development: autonomous-related self and social-cognitive competence. Child Development Perspectives, 6(1), 5-11.

[14] Keller, H. (2007). Cultures of infancy. Mahwah, NJ: Lawrence Erlbaum Associates.

[15] Keller, H., Lamm, B., Abels, M., Relindis, Y., Borke, J., Henning, J., Papaligoura, Z., Holub, C., Lo, W., Tomiyana, A. J., Su, Y., Wang, Y., \& Chaudhary, N. (2006). Cultural models, socialization goals and parenting ethnotheories: a multicultural analysis. Journal of Cross-Cultural Psychology, 37(2), 155-172.

[16] Kline, K. K. (2008). Authoritative communities: The scientific case for nurturing the whole child. New York: Springer. 
[17] Lancy, D. (2010). When nurture becomes nature: ethnocentrism in studies of human development. Behavioral and Brain Sciences, 33, 99-100.

[18] Leyendecker, B. Lamb, M. E. Harwood, R. L. \& Schölmerich, A. (2002). Mothers' socialization goals and evaluation of desirable and undesirable everyday situations in two diverse cultural groups. International Journal of Behavioral Development, 26, 248-258.

[19] Mendes, D. M. L. F., \& Seidl-de-Moura, M. L. (in press). O envelope narrativo e o desenvolvimento do self. [Narrative envelope and the development of self] Interação em Psicologia.

[20] Pessôa, L. F.; Seidl-de-Moura, M. L. (2011). Fala materna dirigida à criança em cenários comunicativos específicos: Um estudo longitudinal. [Maternal speech directed to children in specific communication frames: A longitudinal study]. Psicologia: Teoria e Pesquisa, 27, 439-447.

[21] PNUD, Programa das Nações Unidas para o Desenvolvimento. (2011). Relatório do Desenvolvimento Humano de 2011. Disponível em: <http://hdr.undp.org/en/media/ HDR_2011_PT_Complete.pdf>. Accessed at: Abril, 17, 2013.

[22] Ribeiro, D. (1997). O povo brasileiro: A formação e sentido do Brasil [Brazilian people: The formation and meaning of Brazil]. São Paulo: Companhia das Letras.

[23] Rochat, P. (2001). The infant's world. Cambridge: Harvard University Press.

[24] Seidl-de-Moura, M. L., Lordelo, E., Vieira, M. L., Piccinnini, C. A., Siqueira, J. e O., Magalhães, C. M. C., Pontes, F. A. R., Salomão, N. M., \& Rimoli, A. (2008). Brazilian mothers' socialization goals: intracultural differences in seven cities. International Journal of Behavioral Development, 32(6), 465-472.

[25] Seidl-de-Moura, M. L., \& Ribas, A. (2004). Evidências sobre características de bebês recém-nascidos: um convite a reflexões teóricas [Evidence on newborn babies' characteristics]. In M. L. Seidl-de-Moura (Ed.), O bebê do Século XXI e a psicologia em desenvolvimento [The XXIth Century baby and psychology in development] (pp.21-60). São Paulo: Casa do Psicólogo.

[26] Seidl-de-Moura, M. L., Targino, T., Nahum, K., Cruz, E. M., Amaral, G., \& De Marca, R. (2009). Parenting cultural models of a group of mothers from Rio de Janeiro, Brazil. Spanish Journal of Psychology, 12(2), 506-517.

[27] Seidl-de-Moura, M. L., Vieira, M. L., Kobarg, A. P. R. ; Pessôa, L.F., Mendes, D.M.L.F., Bandeira, T.T.A (in press). Brazilian mothers description of their children and implicit cultural models. Psicologia: Teoria e Pesquisa.

[28] Simmel, G. (1973). A metrópole e a vida mental [The Metropolis and the mental life]. In O. G. Velho (Ed.), O fenômeno urbano [The urban phenomenon], Rio de Janeiro: Zahar. 
[29] Suizzo, M. A. (2002). French parents' cultural models and childrearing beliefs. International Journal of Behavioral Development, 26, 297-307.

[30] Tomlinson, M., \& Swartz, L. (2003). Representing infancy across the world: does Osama bin Laden love his children. J. DeLoache, \& A. Gottlieb (Eds.). A world of babies: imagined childcare guides for seven societies. Culture $\mathcal{E}$ Psychology, 9, 487-497.

[31] Torres, C. V., \& Dessen, M. A. (2006). The Brazilian jeitinho: Brazil's sub-cultures, its diversity of social contexts, and its family structures. In J. Georgas, J. W. Berry, F. J. R. van de Vijver, Ç. Kağitçibaşi, \& Y. H. Poortinga (Eds.), Families across cultures: a 30nation psychological study (pp. 259-266). Cambridge, UK: Cambridge University Press.

[32] Triandis, H. C. (1989). The self and social behavior on different cultural contexts. Psychological Review, 96, 506-520.

[33] Velho, G. (1987). Individualismo e cultura. Notas para uma antropologia da sociedade contemporânea [Individualism and culture. Notes for anthropology of the contemporary society]. Rio de Janeiro: Jorge Zahar Editor.

[34] Vieira, M. L.; Seidl-de-Moura, M. L.; Macarini, S. M.; Martins, G. D.; Lordelo, E. da R.; Tokumaru, R. S. (2010). Autonomy and interdependence: beliefs of Brazilian mothers from State capitals and small towns. Spanish Journal of Psychology, 13, 816-824.

[35] Vieira, M. L.; Seidl-de-Moura, M. L.; Lordelo, E.; Piccinnini, C. A.; Martins, G. D. F.; Macarini, S. M., et al. (2010). Brazilian mothers' beliefs about child-rearing practices. Journal of Cross-Cultural Psychology, 41(2): 195-211.

[36] Vieira, M. L; Lacerda, A. L. R.; Vieira, M. C.; Seidl-de-Moura, M. L. (2011). Características sociodemográficas e aspectos psicossociais de famílias brasileiras residentes em capitais e cidades pequenas do interior. Barbarói, 34(1), 60-79. 

Chapter 2

\title{
Child-Rearing Practices of Brazilian Mothers and Fathers: Predictors and Impact on Child Development
}

\author{
Cesar Augusto Piccinini, Patricia Alvarenga and \\ Angela Helena Marin
}

Additional information is available at the end of the chapter

http://dx.doi.org/10.5772/57242

\section{Introduction}

The chapter is divided into three parts, which highlight various issues related to child-rearing practices that were investigated by the Brazilian Center for Children and Families/NUDIF (www.ufrgs.br/nudif), to which the authors belong. The first issue we discuss is the predictors of child-rearing practices related to cultural differences, parental values, socialization goals, and social class. The second issue refers to the predictors related to the individual characteristics of the parents (their experiences with their own caregivers and the parents' gender) and the children (age, temperament, illness and birth order). Finally, the third issue concerns the impact of parental child-rearing practices on children's social competence and behavior problems of the children.

\section{Child-rearing practices related to cultural and social contexts}

In the first part of the chapter we present and discuss some of the studies carried out in our group that show that child-rearing practices are closely linked to the cultural and social context in which families are included.

Variations in cultural contexts can coexist even within the same country, such as in Brazil, with a recent history, a large territory, much social inequality, and a strong presence of immigrants. In developed countries, which have much more consolidated histories, it is sometimes easier to establish the prevailing cultural patterns and their relation to specific child-rearing practices. In contrast, in a developing country such as Brazil, this is more difficult to grasp, in part due 
to its complexity and cultural diversity. Brazil is the fifth largest country and occupied the seventh position among the world's economies in 2012 (IMF, 2012). Its population of approximately 194 million inhabitants (IBGE, 2012) has been formed by groups of people and cultures, including indigenous people who inhabited the American continent when it was discovered, by people who immigrated from Europe (Portuguese, Italians, Germans, Polish), and Asia (Japanese, Chinese), or slaves who were bought from Africa, among others groups. Over the years the blending of these people has occurred to a greater or lesser degree depending on the ethnic groups involved, and there have been important cultural exchanges. Conversely, some immigrant groups still preserve important cultural traits, especially in the south, with a strong presence of descendants of European immigrants. Added to this is a great religious diversity, from traditional religions, such as Catholic, Protestant and Jewish, those of African origin and a set of new sects and religions called Evangelical. Several of these religions have in their indoctrination clear messages about the socialization of children and how to make them obedient and respectful to God and their own parents.

Considering the extent and diversity of Brazil, it is difficult to characterize the child-rearing practices most commonly used by mothers and fathers. For example, in the southern region of the country, where our research has been developed, cities can be found with large Italian, German, or Japanese colonization. Furthermore, in addition to cultural variation within the same city, we find huge socioeconomic differences, with neighborhoods of wealthy families situated next to slums. It should be noted that in the ranking of the 2012 Global Human Development Index (HDI) Brazil occupied the $85^{\text {th }}$ position $(\mathrm{HDI}=0.73$ ) among the 187 countries assessed (UNDP, 2013), with huge variations between Brazilian cities, ranging from an HDI of 0.92 (the city of São Caetano do Sul, SP, similar to the HDI of 0.94 in Norway, which ranks first in the global ranking) to an HDI of 0.47 (the city of Manari, EP) identical to the HDI of 0.47 in Tanzania, Africa, which ranks $152^{\text {nd }}$ in the overall ranking (UNDP, 2013). This might be reflected in the socialization goals of mothers and fathers of these different cities, which also impact on child-rearing practices. For instance, in one of the studies in which we took part (Seidl-de-Moura et al., 2008) we investigated the socialization goals of 349 primiparous Brazilian mothers., from seven different cities representing each of the five geographical regions of the country. The results revealed that overall the mothers tended to present a pattern that fosters the development of children's autonomous-relational selves, based on Kağitçibaşi's (2007) self development model. According to this author, autonomy and relatedness both tend to be encouraged by families that value emotional closeness, proximity and, at the same time, children's autonomy to make decisions and act by themselves. This model is prevalent in families that live in traditionally interdependent contexts that have been undergoing modernization processes, including urbanization, economic development and educational opportunities. However, intracultural variation was also revealed in mothers' socialization goals, which was related to the different cities studied and mothers' educational levels.

In a previous study (Piccinini, Maggi, \& Carro, 1993) we investigated mothers' child-rearing practices, from two cities of the south of the country, with different cultural backgrounds (40 mothers were of German descent and 38 mothers were of Italian descent). The mothers had either a child of two to three years of age or a child of five to six years of age. In an interview the mother was presented with six hypothetical situations related to the child's behavior and, 
among other questions, was asked how she would behave with her child in a similar situation. Half of the situations involved conventional issues (e.g. mealtime refusal, school refusal, refusal to go to sleep) while the others involved moral issues (e.g. hitting another child, stealing a toy from another child, damaging something at home), based on Kolberg's (1984) conceptualization. Differences in the use of child-rearing practices were found which were related to the mother's cultural background and type of situation. In relation to conventional situations, the mothers of Italian descent mentioned more permissive strategies for younger children than did the mothers of German descent. As far as the moral situations were concerned, few differences were found between the groups.

Even within a single city, variations in child-rearing practices tend to be expressed and have been associated with differences in the social class of the families. For instance, in one of our studies (Tudge, Lopes et al., 2013) we examined the social class differences in child-rearing values and the extent to which parents are influenced by their children. Twenty-five middleclass and working-class families living in a city of the south of the country participated in interviews, observations, and completed Kohn's Q-sort measure when their children were 3, 36 , and 72 months of age. We found that the parental child-rearing values significantly differed by social class: middle-class parents were more likely to value self-direction and autonomy in their children, whereas working-class parents were more likely to value conformity. In addition, the strength and direction of the parental values significantly changed as their children developed.

The studies carried out in the NUDIF support the literature and show the importance of different cultural and social factors, which often coexist within the same country or even within the same city and are associated with parental child-rearing practices. Obviously this is not a deterministic and unilateral relationship, with the child-reading practices also being influenced by many other factors, related, for example, to the characteristics of the parents and the child and to the specific contexts of childhood development, which will be presented in the next section.

It is important to emphasize that human values are mutually influenced by the social world and by individual characteristics (Tudge, Piccinini et al., 2013), and although it is possible to distinguish, analytically, between these factor, they are closely related within a whole that cannot be reduced to the sum of its elements (Tudge, 2008). A cultural-ecological approach to values can help to view developmental phenomena in more complex ways that stem from the intersection of multiple facets (Tudge et al., 2013). For instance, as pointed out by these authors, parents' child-rearing values are more than just the product of culture or class, they involve a dynamic interplay between aspects of the context (e.g. social class) and aspects of the individuals, just as any contextualist theory specifies.

\section{Parents' and children's characteristics as predictors of child-rearing practices}

Seeking to investigate the attitudes and behaviors of parents regarding the socialization of their children, studies have highlighted some factors associated with parental child-rearing 
practices, which can be classified into three broad categories (Belsky, 1984): social context, personal characteristics of the parents, and characteristics of the child. In this sense, studies conducted in the NUDIF have concentrated on investigating some of these factors, such as, differences in mothers' and fathers' child-rearing practices according to age, health conditions of the child, birth order, and evidence of intergenerational transmission of parental childrearing practices.

A series of four studies (Alvarenga, Piccinini, Frizzo, Lopes, \& Tudge, 2009; Marin, Piccinini, \& Tudge, 2011a, 2011b; Piccinini, Frizzo, Alvarenga, Lopes, \& Tudge, 2007) investigated mothers' and fathers' child-rearing practices in the child's early years, examining the stability and change in child-rearing practices during the child's preschool years. In the study by Piccinini et al. (2007) we investigated differences in child-rearing practices of mothers and fathers of children aged 18 months. Thirty-four families took part in the study, with both parents interviewed in relation to six day-to-day situations that commonly involve inappropriate behavior or disobedience by the child, namely: a) mealtimes; b) being cared for by someone else; c) dressing; d) bedtime; e) bath time; and f) when the parents said 'no'. Content analysis and statistical analysis revealed the predominance of inductive practices reported by both the mothers and fathers. The absence of differences in child-rearing practices between the parents indicates a low relevance of parental gender in determining the practices in the developmental phase that was investigated. Therefore, it is plausible that other characteristics of parents, the child and the context may be more influential in the child-rearing practices than parental gender itself. Actually, some of these factors have already been highlighted in the literature such as parent's beliefs and values, level of education, experience with their own caregivers, quality of the marital relationship and child characteristics. These may be more influential in the child-rearing practices than gender itself (Bentley, \& Fox, 1991; Weber, Prado, Viezzer, \& Brandenburg, 2004). Such aspects may be particularly relevant in the first two years of life because eventual disagreements between the mother and father in the way they conceive of the socialization of the baby may not yet be expressed in different attitudes and behaviors.

In a follow-up study (Alvarenga et al., 2009) we investigated the stability and changes in childrearing practices of mothers and fathers in the period between 18 and 24 months after the birth of their child, using a sample of 18 families, where the mothers and fathers responded separately to the same interview described in the study above. The initial hypothesis was that at 24 months fathers and mothers would report more inductive practices than at 18 months, due to the increasing dominance of language by the child (Mussen, Conger, Kagan, \& Huston, 1990), the development of assertiveness (Crockenberg \& Litman, 1990) and greater allocation of competence and responsibility to the child (Dix, Ruble, \& Zambarano, 1989). This hypothesis was partially supported by the results, as only the mothers reported significantly more inductive practices at 24 months. This difference between fathers and mothers can be explained by the fact that, as the mothers deal with daily tasks that generate conflict, such as those that have been investigated, more often than the fathers (Booth, Spieker, Barnard, \& Morisset, 1992) they eventually develop a broader repertoire of inductive strategies, such as the use of explanations, to deal with such situations (Schaffer, 1996). 
A second hypothesis was that there would be no differences in the maternal and paternal childrearing practices at 24 months, considering the findings of the study by Piccinini et al. (2007), which included a sample of families from the same study. However, the mothers mentioned a significantly higher frequency of practices involving explanation and organization of the environment than the fathers. In addition, they also reported more coercive practices than the fathers. These findings strengthen the case that mothers are more involved in child care, even when verbalizations and actions aimed at restricting certain behaviors are necessary.

The study by Marin et al. (2011a) followed the same families when the child was 24, 36 and 72 months. When the children reached 24 and 72 months, the mothers and fathers responded to the same interview used in the study above; however, when they were aged 36 months, the families were also observed during their lunch and parental practices were investigated. Statistical analysis revealed differences between the maternal inductive practices at 24 and 36 months, and between the practices of non-interference at 24 and 36 months, and at 36 and 72 months. In relation to the fathers, differences were found between the inductive practices at 24 and 72 months and between the practices of non-interference at 24 and 36 months, and at 36 and 72 months. These results suggest that the use of inductive practices may be related to the allocation of greater competence and responsibility to the children, associated with the age or maturity attributed to them. The practices of non-interference, in turn, also became more frequent as the child grew and are possibly related to the emergence of assertiveness (Crockenberg, \& Littman, 1990). In contrast to the inductive and non-interference practices, coercive practices tended to maintain some stability throughout the development of the child. Peisner (1989) emphasized that, in the childhood socialization process, some practices tend to remain stable while others do not. Perhaps this is the case for the coercive practices, which appeared to be used more in situations of greater conflict with the child or as a last resort to achieve the desired disciplinary goal, especially after using inductive practices and even non-interference practices. The results suggest that both stability and change are present in the parental practices throughout the development of the child. It is noteworthy that some practices tend to change due to the development of the child, although the way parents deal with their children often tends to remain more stable (McNally, Eisenberg, \& Harris, 1991). What appears to occur, according to McNally et al. (1991), is that the parental values remain relatively stable, while some specific practices that favor these tend to change with the age of the child, due to the acquisition of new skills and greater autonomy.

Similarly, Marin et al. (2011b) used the same sample, considering only the data from the interview about parental child-rearing practices applied at 24 and 72 months; and revealed that the mothers were significantly more inductive than the fathers at 24 months, however, at 72 months there were no significant differences. The mothers also presented higher mean scores in the reported practices, which can be explained by the predominant role they still play in the socialization of the children (Wagner, 2003), although the fathers started participating more in the education of their children. Compared with the fathers, the mothers tended to talk more with their children, to express feelings, opinions, set limits, and praise appropriate behaviors (Braz, Dessen, \& Silva, 2005; Silveira, Pacheco, Cross, \& Schneider, 2005).

Still related to specific contexts which may have an impact child-rearing, we carried out other two studies, with the first investigating the role of the health condition of the child in the child- 
rearing practices of the mother, while in the other study we compared the child-rearing practices of parents with one only child with those of parents with a second child. In relation to the first study (Piccinini, Castro, Alvarenga, Vargas, \& Oliveira, 2003) it was reported that the presence of a chronic disease in childhood may constitute an important predictor for the quality of mother-child interaction, especially regarding the child-rearing practices. We interviewed 40 mothers of five-year-old children, half having a child with a chronic illness and the other half having children without health problems. Statistical analysis revealed that the first group of mothers tended to use less physical punishment and punishment/chastisement, which indicates that the infrequent use of these practices may be related to physical fragility and the health condition of their children, who are constantly undergoing painful procedures and rigorous medical treatment. In this sense, the less frequent use of coercive practices could be linked to the need to protect the child from further suffering. It is also possible that, due to the disease characteristics of the child, the mothers are afraid that practices involving the use of force can cause harmful effects on the health of the child. Furthermore, the pain of seeing the sick child (Espíndula, \& Valle, 2002) and the extreme concern and even overprotection associated with more serious health situations (Bradford, 1997), can impact on the maternal behavior of protecting the child from physical and psychological stress, which represents the use of coercive practices.

With regard to birth order, Freitas and Piccinini (2010) interviewed 12 families with one child and 10 with two children, matched for socioeconomic level, age and gender of the children. Statistical analysis revealed differences in maternal and paternal practices only within the onechild group, revealing a tendency toward the predominant use of inductive practices by the mothers and coercive practices by the fathers, which could be associated with the idea that care is still more linked to the maternal figure, while authority is more related to the paternal figure (Tudge et al., 2000). It is also plausible to think that the fathers seek to compensate for the inductive practices of the mothers in order to impose stricter limits on the single child. In addition, the mothers and fathers with one child tended to primarily use inductive practices, going over to coercive practices when the disciplinary goal was not achieved. This finding corroborates the notion that the child is not a mere receiver of the child-rearing practices, these being substantially determined by the nature of the situation and by the child's needs (Grusec \& Kuczynski, 1980). Therefore, the fact of having a sibling does not necessarily imply the predominant use of coercive practices, representing just one more of the factors that can determine different responses of the parents in relation to each child.

Finally, one of our studies (Marin et al., 2013) focused on the intergenerational transmission of parental practices in 30 mothers and 22 fathers, who had only one child of three years of age. We performed three sets of analysis. The first considered the group of mothers and fathers as a whole, comparing the proportions of practices received and used among the participating mothers and fathers and found that there was a tendency to maintain coercive practices between the generations. The second set, considered the intergenerational transmission case by case, aiming to examine whether the mothers and fathers who predominantly received a certain type of child-rearing practice in their childhood tended to repeat the same model with their own children. It was found that the results were not homogeneous, i.e., the transmission of the practices was only detected in some cases, but not in the majority of them. Finally, a qualita- 
tive analysis was performed for the descriptions of the child-rearing practices and for other parental reports that referred to their relationship with their own parents and to the intergenerational transmission of the practices, seeking to broaden the comprehension of other aspects that could be related to the transmission. Many parents reported the reproduction of coercive patterns, even though they mentioned attempts to avoid this as they were related to the idea of the experience of suffering. Taken together, the results indicate both the maintenance of the practices received, whether inductive, coercive or non-interference, as well as changes in the type of practice used due to the characteristics of the couple and of the child.

The results of this study support the literature that suggests that a continuity of aggressive behaviors and inconsistent child-rearing practices is associated with memories of inadequate parenting styles as children (Bailey, Hill, Oesterle, \& Hawkins, 2009; Hennig, 2008). However, although the coercive practices were maintained as a socialization strategy, the fathers also used a combination of inductive and coercive practices with greater frequency, which may suggest a historical change between generations in the concepts of how to properly raise children (Biasoli-Alves, 1997; Weber, Selig, Bernardi, \& Salvador, 2006).

These findings support the idea that child-rearing practices, as well as parent-child interaction, constitute a dynamic and reciprocal processes involving characteristics of the child and the parents (Belsky, 1984; Biasoli-Alves, 1997). In this sense, their intergenerational transmission does not only involve the reproduction for the children of the patterns received in childhood, but also leads to the construction of models of what should be followed or avoided in the subsequent relationships (Ângelo, 1995). Furthermore, how the mothers and fathers evaluate the way in which they were raised possibly has an influence on the continuity or discontinuity of the child-rearing practices (Shaffer, Burt, Obradovic, Herbers, \& Masten, 2009), with their experience during the their own upbringing not being inevitably repeated (Belsky, Conger, \& Capaldi, 2009), giving space to the pursuit of the replication or the correction of previous experiences in the relationship with their children (Byng-Hall, 1990).

In short, although the studies presented highlight the complexity and multiplicity of factors that have been shown to be relevant in the use and adequacy of parental child-rearing practices, they also indicate important features particularly in relation to the context in which they occur. The lack of more consistent and empirically validated knowledge regarding the practices of mothers and fathers with children of different ages means that sometimes parents may relate to their children with some uncertainty, taking into account the numerous options, all valid in certain contexts and, simultaneously, potentially questionable, regarding the use of one or another child-rearing practice in the day-to-day engagement with their child.

\section{The role of parental child-rearing practices in the socio-emotional development of the child}

In this part of the chapter we present and discuss some of the studies carried out by our group that revealed the role of the parents' child-rearing practices as a predictor for the child's socioemotional development. 
The hypotheses found in the literature regarding the impact of the interaction between parents and children and the parental child-rearing practices on the socio-emotional development of children, especially in early childhood, have received support from numerous recently published studies. Research in this area primarily focuses on issues such as social competence (Fraley, Roisman, \& Haltigan, 2013), emotional self-regulation (Braungart-Rieker, HillSoderlund, \& Karrass, 2010), behavior problems, especially in relation to antisocial behavior and externalizing (Alvarenga \& Palma, 2012), and internalizing problems (Bayer, Sanson, \& Hemphill, 2009).

Although there are still controversies and gaps in this field, certain types of child-rearing behavior and practices that tend to contribute to the full emotional development of the child have been consistently identified, and the deleterious effects of some disciplinary strategies and family interaction patterns have been highlighted (Grusec \& Davidov, 2010). Furthermore, the role of moderator variables, among them that of the culture, has become clearer (Grusec, 2011).

Some studies conducted by the NUDIF investigated the relationship between child-rearing practices and social-emotional development, in particular, externalizing problems and the social competence of children between the third and sixth years of age. Among these, four studies investigated, through interviews and observations, maternal child-rearing practices and externalizing problems.

The study by Alvarenga and Piccinini (2001) compared a group of mother-child dyads with children with clinical profiles of externalizing problems, with another group of dyads composed of children without behavior problems. All the children were between five and six years of age. The maternal child-rearing practices were evaluated through a structured interview consisting of six hypothetical situations, as described above (Piccinini et al., 2007), involving conflicts in the everyday life of the mothers and children, as well as situations spontaneously reported by the mothers as being difficult to manage. The children's behavior problems were evaluated using the Child Behavior Checklist - CBCL (Achenbach, 1991). The results revealed that the mothers of children who presented externalizing problems reported using coercive child-rearing practices more often than the mothers of the group of children without problems. Concerning the child-rearing practices reported by the mothers in the situations spontaneously highlighted by them as difficult to manage, there was a significant difference between the two groups in the physical punishment category, with reports of more frequent use among the mothers in the group of children with externalizing profiles. In another study Marin, Piccinini, Gonçalves and Tudge (2012) investigated the maternal and paternal child-rearing practices in 48 families with six-year-old children, and their relationships with childhood internalizing and externalizing problems. The parental child-rearing practices were evaluated using the same interview and category structure for the content analysis that was used by Alvarenga and Piccinini (2001), and the externalizing problems were examined using the Social Skills Rating System (Gresham \& Elliott, 1990). A positive correlation was found between the maternal coercive practices and the total score for externalizing problems, although the same trend was not revealed for paternal child-rearing practices. Conversely, the paternal coercive practices were positively correlated with the internalizing problems of the children. 
In an attempt to examine these relationships in an observational context, Alvarenga and Piccinini (2009) analyzed the child-rearing practices and their relationships with externalizing problems during a family meal, which usually involves sporadic or even frequent conflicts between the parents and children. This study involved 23 mother-child dyads, when the child was three years old. Both the child-rearing practices and indicators of externalizing problems of the children were analyzed in the observed interactive episode. In this study, two broad categories of child-rearing practices were used, practices that facilitate childhood social development (guidance, sensitivity, positive involvement and assertive control), and practices that do not facilitate childhood social development (ambiguous control, coercive control, intrusiveness, and permissiveness). The indicators for externalizing problems were analyzed in three distinct categories: inadequacy, passive disobedience, and negativism. In addition to the numerous correlations between the specific categories of practices and externalizing problems that were analyzed, the results revealed positive correlations between the total of non-facilitating practices and the indicators of externalizing problems. Finally, the multiple regression model including the non-facilitating practices explained $56 \%$ of the total variance of the children's externalizing problems. Alvarenga and Piccinini (2007) study should also be highlighted, which was performed with the same sample of dyads, and confirmed the predictive power of the maternal non-facilitating child-rearing practices in relation to the externalizing problems of children. This study was based on a model that assumed an interaction between the childhood temperament variables, maternal responsiveness, and maternal child-rearing practices for the explanation of the externalizing problems. Regression analysis showed that, although the temperament of the child and the maternal responsiveness did not show predictive value, each further occurrence of non-facilitating practices, increased the total frequency of indicators of externalizing problems of the child by 0.73 , explaining $44 \%$ of total variance.

Three of the five studies described above also investigated the relationships between parental child-rearing practices and the child's social competence. Alvarenga and Piccinini (2009) found significant positive correlations between the total of facilitating practices and the total of indicators of social competence of the children, as well as several other positive correlations between specific indicators of social competence and maternal facilitating practices. Finally, the multiple regression model including the facilitating practices explained $36 \%$ of the total variance of the children's social competence. The study by Alvarenga and Piccinini (2007) confirmed the relevance of the maternal child-rearing practices as predictors of childhood social competence, as when childhood temperament and maternal responsiveness factors, evaluated in child's third month, were also considered in the explanatory model, only the maternal child-rearing practices that facilitate social development explained the variance in the social competence of the children (36\%).

The study by Marin et al. (2012) also revealed the impact of the paternal child-rearing practices on the child's social competence. In this study, the inductive practices used by the fathers were positively correlated with the children's total cooperation score, and the non-interference of the fathers in day-to-day conflict situations with the child was negatively correlated with the total assertiveness scores of the children.

The findings of the five studies by the NUDIF, with samples from southern Brazil, largely corroborate the results of the literature published in other countries. The relationships found 
between the use of coercion and the development of externalizing problems in children is initially highlighted. Several recent studies confirm this relationship (Alvarenga \& Palma, 2012; Bayer et al., 2012; Grusec, 2011), and different theoretical hypotheses have been developed to explain it. One of these assumes that a harsh and coercive disciplinary style generates deficits in the child's emotional self-regulation and behavioral capacity, which would explain, at least in part, externalizing symptoms, such as impulsivity and aggression (Burnette, Oshri, Lax, Richards, \& Ragbeer, 2012). Paternal coercive practices were also positively correlated with internalizing problems in one of the studies examined (Marin et al., 2012). It is assumed that such practices contribute to the configuration of an unpredictable and threatening domestic environment, which constitutes a "fertile ground" for the development of symptoms of anxiety and depression (Laskey \& Cartwright-Hatton, 2009).

Some authors argue that the relationship between coercive practices and externalizing problems are a characteristic of individualistic societies, because in collectivist societies, such as in some Eastern countries, coercive practices are not associated with anger and rejection from the parents, but with the care and common well-being of the social group (Grusec, 2011; Rothbaum \& Trommsdorff, 2008), possibly producing a positive impact regarding childhood development. However, there are studies that have found relationships between coercive practices and aggressivity, even in Eastern cultures (Xu, Farver, \& Zhang, 2009). The studies reviewed here suggest that the cultural values prevailing in southern Brazil, in relation to the childhood socialization process in the family context, align with those of more individualistic societies. Thus, coercive child-rearing practices should be considered as risk factors for childhood socio-emotional development, and constitute an important target for prevention and intervention programs.

Also corroborating the literature, social competence was correlated with different types of practices considered to be facilitators of social development. Unlike coercive practices, inductive practices (e.g. reasoning with the child) and lower levels of coercion are generally associated with the internalization of social and moral norms, as well as better results in the childhood socialization process (Grusec \& Davidov, 2010). In Marin et al.'s (2012) study, attention is drawn to the positive correlations found between the paternal inductive practices and the total cooperation score of the children, which indicates the relevance of the investigation of paternal styles of socialization.

In summary, the findings of the studies conducted by the NUDIF reported here converge with the same trends identified in the general literature. This indicates that the theoretical models, mainly constructed based on studies carried out with European and North American samples, are useful for helping to understand the mechanisms implicated in the childhood socialization process, in the context in which these families live in southern Brazil.

\section{Final considerations}

In this chapter we highlighted several factors related to parental child-rearing practices, among which are the cultural and social context and the personal characteristics of the parents and 
children, some of which have been studied in the NUDIF. Results of this group's studies, which demonstrate the impact of parental child-rearing practices on the socio-emotional development of the children, were also presented.

It was emphasized that the mother still plays a predominant role in the socialization of the child, although the father has participated more in this process. Compared to fathers, the mother more often deals with daily tasks that generate conflict, such as those investigated in our studies, and they develop a wider repertoire of both inductive and coercive strategies to cope with such situations.

The results of our studies have corroborated the Brazilian and international literature, pointing out to the relevance of the child's age and development in understanding child-rearing practices employed by the parents. These two factors are associated with the allocation of greater competence and responsibility to the children. Furthermore, in the childhood socialization process both stability and change are present in the parental practices throughout the development of the child. It is noteworthy that some practices tend to change due to the development of the child, whereas parents' style of dealing with their children tends to remain more stable. The results regarding the impact of the age of the child on the practices reinforce the reciprocal nature of the child's socialization process and the parent-child relationship, showing that the child-rearing practices are largely affected by the specific child's developmental needs and characteristics.

Likewise, studies that investigated the child-rearing practices and their relationship with the child's health condition and birth order, also highlighted its bidirectional characteristic, the child affecting the disciplinary conduct of parents, and interfering with the choice and use of child-rearing practices. These findings are also supported by our study about the intergenerational transmission of child-rearing practices, noting that it is not possible to understand this process as a mere reproduction of a model learned in childhood. It is necessary to consider that models undergo changes over time according to the relations established between parents and children.

The studies carried out in our group also show the role of parental child-rearing practices as a predictor for the child's socio-emotional development. Relationships found between the use of coercion and the development of externalizing problems are particularly prominent. Thus, a high frequency of coercive child-rearing practices should be considered a risk factor for the socio-emotional development of the child, and deserves special attention from those involved with the child's development, in order to implement prevention and intervention programs.

Also corroborating the literature, social competence was correlated with different types of practices that are considered facilitators of social development. In this sense, the studies of the NUDIF support the notion that the use of inductive practices and lower levels of coercion are usually related to the internalization of social and moral norms, and better results in the socialization process of the child.

Thus, regarding the relations between child-rearing practices and children's socio-emotional development, the studies carried out by NUDIF confirm the trends pointed out in studies conducted internationally. Those studies provided empirical basis for the theoretical hypoth- 
eses that relate the frequent use of coercion to externalizing and internalizing behavior problems, as well as the use of non-coercive strategies to the development of social competence. The results of the studies presented on this chapter provide additional support to these hypotheses, showing that socio-emotional development of children from a distinct culture such as the one found at Southern Brazil, can also be explained by typical characteristics from child-rearing practices that have already been described in the international literature.

Due to the number and complexity of factors related to child-rearing practices we think there is still a need for a theoretical model that portrays their dynamic interaction, where each factor can enhance the role of the other. Furthermore, such a model should take into account both the child-rearing practice predictors, and their role in childhood development, particularly with regard to their socio-emotional components. This is certainly a complex task, where not only objective factors may be significant, but also the parents' subjective experiences with their own parents and how they re-signified their early experiences when using child-rearing practices with their own children. In contrast to most studies on child-rearing practices that focus on unidirectional influences, there is a need to consider the dynamic interplay of several factors. The parental child-rearing values are a function of the intersection of the context and the individual, played out in everyday interactions between parents and their developing children (Tudge et al., 2013). These values cannot simply be attributed either to the social group of which they are a part or to the children's characteristics, but require the intersection of social and individual to be considered. For all these reasons, child-rearing practices remain a major field of study, specially in modern societies that are in constant transformation, in which parents are anxious to have a better understanding about how to socialize their children and in which child-rearing practices can better contribute to raising a happy, autonomous and social compentent child.

\section{Author details}

Cesar Augusto Piccinini ${ }^{1}$, Patricia Alvarenga ${ }^{2}$ and Angela Helena Marin ${ }^{3}$

1 Universidade Federal do Rio Grande do Sul - UFRGS, Brazil

2 Universidade Federal da Bahia - UFBA, Brazil

3 Universidade do Vale do Rio dos Sinos - UNISINOS, Brazil

\section{References}

[1] Achenbach, T. M. (1991). Manual for the Child Behavior Checklist/4-18 and 1991 profile. Department of Psychiatry. University of Vermont. 
[2] Alvarenga, P., \& Piccinini, C. (2001). Práticas Educativas Maternas e Problemas de Comportamento em Pré-Escolares. Psicologia: Reflexão e Crítica,14, 449-460.

[3] Alvarenga, P., \& Piccinini, C.A. (2009). Práticas educativas maternas e indicadores do desenvolvimento social no terceiro ano de vida. Psicologia: Reflexão e Crítica, 22, 191-199.

[4] Alvarenga, P., \& Palma, E. (2012). Parentalidade e comportamento antissocial infantil. Em C. A. Piccinini \& P. Alvarenga (Eds.). Maternidade e Paternidade. A parentalidade em dieferentes contextos (pp. 227-251). São Paulo: Casa do Psicólogo.

[5] Alvarenga, P., \& Piccinini, C. A. (2007). O impacto do temperamento, da responsividade e das práticas educativas maternas no desenvolvimento dos problemas de externalização e da competência social. Psicologia: Reflexão e Crítica, 20, 314-323.

[6] Alvarenga, P., Piccinini, C. A., Frizzo, G., Lopes, R S., \& Tudge, J. R. H. (2009). Estabilidade e mudanças nas práticas educativas de mães e pais dos 18 para os 24 meses. Interação, 13, 253-262.

[7] Ângelo, C. (1995). A escolha do parceiro. Em M. Andolfi, C. Ângelo \& C. Saccu (Orgs.), A crise do casal (pp. 47-57). São Paulo Summus

[8] Bailey, J. A., Hill, K. G., Oesterle, S., \& Hawkins, J. D. (2009). Parenting practices and problem behaviors across three generations: monitoring, harsh discipline, and drug use in the intergenerational transmission of externalizing behavior. Developmental Psychology, 45, 1214-1226.

[9] Bayer, J. K., Sanson, A. V., \& Hemphill, S. A. (2009). Early childhood etiology of internalising difficulties: a longitudinal community study. International Journal of Mental Health Promotion, 11(1), 22-32. doi: 10.1080/14623730.2009.9721777.

[10] Bayer, J. K., Ukoumunne, O. C., Mathers, M., Wake, M., Abdi, N., \& Hiscock, H. (2012). Development of children's internalising and externalising problems from infancy to five years of age. Australian and New Zealand Journal of Psychiatry, 46(7), 659-668. doi: http://dx.doi.org/10.1177/0004867412450076.

[11] Belsky, J. (1984). The determinants of parenting: a process model. Child Development, $55,83-54$.

[12] Belsky, J., Conger, R., \& Capaldi, D. M. (2009). The intergenerational transmission of parenting: introduction to special section. Developmental Psychology, 45, 1201-1204.

[13] Bentley, K. S., \& Fox, R. A. (1991). Mothers and fathers of young children: Comparison of parenting styles. Psychological Reports, 69, 320-322.

[14] Biasoli-Alves, Z. M. (1997). Famílias brasileiras do século XX: Os valores e as práticas de educação da criança. Temas em Psicologia, 3, 33-49.

[15] Booth, C. L., Spieker, S. J., Barnard, K. E., \& Morisset, C. E. (1992). Infants at risk: The role of preventive intervention in deflecting a maladaptative developmental trajecto- 
ry. Em J. McCord, \& R. E. Tremblay (Orgs.), Preventing antisocial behavior: Interventions from birth through adolescence (pp. 21-42). New York/London: Guilford Press.

[16] Bradford, R. (1997). Children, families and chronic disease. Londres: Routdlege.

[17] Braungart-Rieker, J., Hill-Soderlund, A., \& Karrass, J. (2010). Fear and anger reactivity trajectories from 4 to 16 months: The roles of temperament, regulation, and maternal sensitivity. Developmental Psychology, 46(4), 791-804. doi: 10.1037/a0019673.

[18] Braz, M. P., Dessen, M. A., \& Silva, N. L. P. (2005). Relações conjugais e parentais: Uma comparação entre famílias de classes sociais baixa e média. Psicologia: Reflexão e Crítica, 18(2), 151-161.

[19] Burnette, M. L., Oshri, A., Lax, R., Richards, D., \& Ragbeer, S. N. (2012). Pathways from harsh parenting to adolescent antisocial behavior: A multidomain test of gender moderation. Development and Psychopathology, 24(3), 857-870. doi: 10.1017/ S0954579412000417.

[20] Byng-Hall, J. (1990). Attachment theory and family therapy: a clinical view. Infant Mental Health Journal, 11, 228-236.

[21] Crockenberg, S. B., \& Litman, C. (1990). Autonomy as competence in 2-year-olds: Maternal correlates of child defiance, compliance and self-assertion. Developmental Psychology, 26(6), 961-971.

[22] Dix, T., Ruble, D. N., \& Zambarano, R. J. (1989). Mother's implicit theories of discipline: Child effects, parent effects, and the attribution process. Child Development, 60 , 1373-1391.

[23] Espíndula, J. A., \& Valle, E. R. M. (2002). Experiência materna diante da iminência de morte do filho com recidiva de câncer. Pediatria Moderna, 38(5), 188-194.

[24] Fraley, R. C. Roisman, G. I., \& Haltigan, J. D. (2012). The legacy of early experiences in development: formalizing alternative models of how early experiences are carried forward over time. Developmental Psychology, 49(1):109-126. doi: 10.1037/a0027852

[25] Freitas, A.P., \& Piccinini, C. A. (2010). Práticas educativas parentais em relação ao filho único e ao primogênito, submetido novembro. Estudos de Psicologia, 27(4) 515-528.

[26] Gresham, F. M., \& Elliott, S. N. (1990). Social skills rating system: Manual. Circle Pines, $\mathrm{MN}$ : American Guidance Service.

[27] Grusec, J. E. (2011). Socialization processes in the family: social and emotional development. Annual review of psychology, 62, 243-69. doi: 10.1146/annurev.psych. 121208.131650

[28] Grusec, J. E., \& Kuczynski, L. (1980). Direction of effect in socialization: a comparison of the parent's versus the child's behavior as determinants of disciplinary techniques. Developmental Psychology, 16(1), 1-9. 
[29] Grusec, J., \& Davidov, M. (2010). Integrating different perspectives on socialization theory and research: a domain-specific approach. Child Development, 81(3), 687-709. doi: 10.1111/j.1467-8624.2010.01426.x

[30] Hennig, F. (2008). Relação entre práticas educativas parentais e memórias de cuidado na infância. (Dissertação de mestrado não publicada). Universidade Federal de Santa Catarina, Florianópolis.

[31] International Monetary Fund (2013). Report for Selected Countries and subjets". World Economic Outlook Database. Retrieved Octobr 8, 2013

[32] Instituto Brasileiro de Geografia e Estatística - IBGE (2012). Retrieved in 04/06/2013

[33] from http://www.ibge.gov.br/home/.

[34] Kagitcibasi, C. (2007). Family, self, and human development across cultures: Theory and applications. Mahwah, NJ: Lawrence Erlbaum.

[35] Kolberg, L. (1984). Essays on moral development: Vol. 2. The psychology of moral development. San Francisco: Harper \& Row.

[36] Laskey, B. J., \& Cartwright-Hatton, S. (2009). Parental discipline behaviours and beliefs about their child: Associations with child internalizing and mediation relationships. Child: Care, Health and Development, 35, 717-727. doi: 10.1111/j. 1365-2214.2009.00977.x

[37] Marin, A. H., Martins, G. D. F; Freitas, A. P. C. O.; Silva, I. M.; Lopes, R. C. S.; Piccinini, C. A. (2013). Transmissão intergeracional de práticas educativas parentais: evidências empíricas. Psicologia: Teoria e Pesquisa, 29(2), 123-132

[38] Marin, A. H., Piccinini, C. A., \& Tudge, J. (2011a). Estabilidade e mudança nas práticas educativas maternas e paternas ao longo dos anos pré-escolares da criança. Psicologia: Reflexão e Crítica, 24, 71-79.

[39] Marin, A. H., Piccinini, C. A., \& Tudge, J. (2011b). Práticas educativas maternas e paternas aos 24 e aos 72 meses de vida da criança. Psicologia: Teoria e Pesquisa, 27, 419-427.

[40] Marin, A. H., Piccinini, C. A., Goncalves, T. R., \& Tudge, J. R. H. (2012). Práticas educativas parentais, problemas de comportamento e competência social de crianças em idade pré-escolar. Estudos de Psicologia, 17(1), 05-13.

[41] McNally, S., Eisenberg, N., \& Harris, J. D. (1991). Consistency and change in maternal child-rearing practices and values: A longitudinal study. Child Development, 62, 190-198.

[42] Mussen, P. H., Conger, J. J., Kagan, J., \& Huston, A. C. (1990). Child development \& personality. New York: Harper \& Row. 
[43] Peisner, E. S. (1989). To spare or not spare the rod: A culturalhistorical view of child discipline. In J. Valsiner (Ed.), Child development in cultural context (pp. 111-141). Toronto, Canada: Hogrefe and Huber.

[44] Piccinini, C. A., Castro, E. K., Alvarenga, P., Vargas, S., \& Oliveira, V. Z. (2003). A doença crônica orgânica na infância e as práticas educativas maternas. Estudos de Psicologia, 8, 75-83.

[45] Piccinini, C. A., Frizzo, G. B., Alvarenga, P., Lopes, R. S., \& Tudge, J. (2007). Práticas educativas de pais e mães de crianças aos 18 meses de idade. Psicologia: Teoria e Pesquisa, 23, 369-378.

[46] Piccinini, C.A., Maggi, A., Carro, J.W. (1993). Strategies used by mother of german and italian descent for regulating their children's behaviour. In: XXII Biennial Meetings of the International Society for the Study of Behavioral Development (pp. 157). Recife, Brasil.

[47] United Nations Developmental Programme (UNDP, 2013). Atlas do Desenvolvimento Humano no Brasil. Retrieved in 22/09/2013 from http://www.pnud.org.br/IDH/ Atlas2013.aspx?indiceAccordion=1\&li=li_Atlas2013

[48] Rothbaum, F., \& Trommsdorff, G. (2007). Do roots and wings complement or oppose one another? The socialization of relatedness and authonomy in cultural context. In: J. E. Grusec \& P. D. Hastings (Eds). Handbook of socialization. Theory and research.(pp. 461-489). New York: The Guilford Press.

[49] Schaffer, H. R. (1996). Social development. Oxford: Blackwell.

[50] Seidl-de-Moura, M. L., Lordelo, E., Vieira, M.L., Piccinini, C.A., Oliveira, S.J., Colino, M.C.M., Ramos, P.F.A., Salomao, N.M., Rimoli, A. (2008). Brazilian mothers' socialization goals: Intracultural differences in seven Brazilian cities. International Journal of Behavioural Development, 32, 465-472.

[51] Shaffer, A., Burt, K. B., Obradovic, J., Herbers, J. E., \& Masten, A. S. (2009). Intergenerational continuity in parenting quality: the mediating role of social competence. Developmental Psychology, 45, 1227-1240.

[52] Silveira, L. M. O. B., Pacheco, J., Cruz, T., \& Schneider, A. A. (2005). Estratégias educativas desejáveis e indesejáveis: Uma comparação entre a percepção de pais e mães de adolescentes. Aletheia, 21, 31-42.

[53] Tudge, J., Hayes, S., Doucet, F., Odero, D., Kulakova, N., \& Tammeveski, P. (2000). Parents' participation in cultural practices with their preschoolers. Psicologia: Teoria e Pesquisa, 16(1), 1-11.

[54] Tudge, J. R. H., Lopes, R. S. C., Piccinini, C.A., Sperb, T. M., Chipenda-Dansokho, S., Marin, A. H., Vivian, A. G., De Oliveira, D. S., Frizzo, G. B., Freitas, L. B. L. ChildRearing Values in Southern Brazil: Mutual Influences of Social Class and Parents' 
Perceptions of Their Children's Development. Journal of Family Issues, v. 34, p. 1379-1400, 2013.

[55] Tudge, J. R. H., Piccinini, C.A., Sperb, T. M., Odero-Wanga, D., Lopes, R. C. S., Freitas, L. (2013). Vulnerable children? The heterogeneity of young children s experiences in Kenya and Brazil. In: D.J. Johnson et al.. (Eds.). Vulnerable Children: Global Challenges in Education, Health, Well-Being, and Child Rights. (pp.121-137). 1ed.New York: New York: Springer.

[56] Wagner, A. (2003). A família e a tarefa de educar: algumas reflexões a respeito das famílias tradicionais frente a demandas modernas. Em T. Féres-Carneiro (Org.), Família e Casal: Arranjos e demandas contemporâneas (pp. 27-33). Rio de Janeiro: Editora Loyola.

[57] Weber, L. N. D., Prado, P. M., Viezzer, A. P., \& Brandenburg, A. J. (2004). Identificação de estilos parentais: $\mathrm{O}$ ponto de vista dos pais e dos filhos. Psicologia: Reflexão e Crítica, 17(3), 323-331.

[58] Weber, L. N. D., Selig, G. A., Bernardi, M. G., \& Salvador, A. P. V. (2006). Continuidade dos estilos parentais através das gerações: transmissão intergeracional dos estilos parentais. Paidéia, 16(35), 407-414.

[59] Xu, Y., Farver, J. A. M., \& Zhang, Z. (2009). Temperament, harsh and indulgent parenting, and chinese children's proactive and reactive aggression Child Development, 80, 244-258. doi: 10.1111/j.1467-8624.2008.01257.x.

[60] Tudge, J. R. H. (2008). The everyday lives of young children: Culture, class, and child rearing in diverse societies. New York: Cambridge University Press. 

Chapter 3

\title{
Paternity in the Brazilian Context
}

\author{
Mauro Luís Vieira, Maria Aparecida Crepaldi, \\ Carina Nunes Bossardi, Lauren Beltrão Gomes, \\ Simone Dill Azeredo Bolze and \\ César-Augusto Piccinini
}

Additional information is available at the end of the chapter

http://dx.doi.org/10.5772/57027

\section{Introduction}

This chapter aims to report and discuss studies investigating paternity in the Brazilian context. Primarily, it presents a contextual and theoretical discussion about the changing roles of fathers and mothers in different countries and the concepts concerning to the relation of father with his child and, subsequently, it presents a review of studies on paternity in Brazil.

The economic and social transformations have changed the structure, roles and functions of family members in the context of various countries. In both national and international scenarios, the changes caused by the increase of female participation in the labor market have changed the traditional model of fathers as providers, who go out to work while women are dedicated to home and children care. Greater paternal involvement in child care has been evidenced and opened space for future research, especially regarding the determinants of father's involvement. Mothers' roles and attitudes towards their children and families have also changed over the years, given the economic transformations in family settings in many countries such as India, Canada, Argentina, France, United States of American (Bornstein et al., 1996; Mendonça, Cossette, Strayer, \& Gravel, 2011), and Brazil (Jablonski, 2010; Wagner, Predebon, Mosmann, \& Verza, 2005).

Considered as a social system, responsible for the transmission of values, beliefs, ideas and meanings, family, therefore has a strong influence in children's behavior (Kreppner, 2000). New and diverse family settings are outlined, for example, divorced families, remarried, adoptive parents, families headed exclusively by men or women, homosexual couples, among others. These changes in family arrangements will influence parental behavior and attitudes 
(Jablonski, 2010; Kamers, 2006). For instance, it is reasonable to think that the relationships in two-parent families with biological children differ from the relationships in remarried families, cohabiting stepfathers or stepmothers.

Changes in family structure and in the traditional family model (in which the father is identified as the provider, while the mother is responsible for the care of home and children) to a family functioning where household chores and child care are divided between father and mother, even if not in an egalitarian way, are identified as an outcome of female emancipation. Several researchers (Gauthier, Smeeding, \& Furstenberg, 2004; Jablonski, 2010; Mendonça, et al., 2011; Perucchi \& Beirão, 2007; Saraff \& Srivastava, 2010; Wagner, et al., 2005) emphasize that the increased participation of women in the labor market generates changes in gender relations, late marriages, decrease in the number of children and greater autonomy and independence for women, which in turn cause changes in parental roles (Jablonski, 2007).

Maternal and paternal roles are multidimensional, complex and varied, and thus need to be considered in their cultural, historical and intergenerational dimensions, comprising a diversity of roles, modes of participation, and multiple determinants (Dessen \& Silva Neto, 2000; Kreppner, 2000; Lamb, 1997). Father's role can be classified as: traditional (provider), modern (part of the academic and moral development of children) or emerging (sharing the activities with the mother wife) (Dessen \& Lewis, 1998).

More studies about changes in paternal involvement may contribute to the understanding of how paternity is being configured (Fleck \& Wagner, 2003). For that, fathers can be used as informants in an attempt to understand the activities they actually engage in with their children. Obtaining data from multiple informants with a multi-methodological approach, longitudinal, comparative and cross-cultural planning can promote advances in the field of family psychology. Rather than studying the types of family, it is important to establish a planning of interfamily studies to check the conditions within families and differences among family members (Dessen \& Lewis, 1998; Dessen \& Silva Neto, 2000; Kreppner, 2000).

Authors who write about modern families agree that among family settings - such as those composed by two-parents, single-parents, divorced or remarried parents, both men and women, for the most part, perform activities outside the home, or have a professional occupation. In these terms, it seems that the mother continues to assume the greatest responsibility at home and in caring for children, while the father participates in providing support in some tasks. Children suffer an important decrease in meeting their basic needs - emotional and entertaining - due to the reduction of hours spent in the company of parents (Fleck \& Wagner, 2003; Jablonski, 2010; Mendonça, et al., 2011; Perucchi \& Beirão, 2007).

Some studies published today focus on family issues related to parenting, but most of them still focus primary on motherhood, maybe because mothers continue to be the primary caregiver in various societies (Keller \& Chasiotis, 2007). However, some literature review such as the one carried out by Souza and Benetti (Souza \& Benetti, 2009) and Borsa and Nunes (Borsa \& Nunes, 2011) show that studies concerned specifically on paternity has increased in recent decades. Further studies are needed to check if there are changes in parental relationships and, if they exist, their impact in family and society (Borsa \& Nunes, 2011). 
Nowadays, when referring to family configurations, some authors prefer, instead of focusing on the influence exerted by each parent, to emphasize the combined influence of both parents, through the definition of coparenting (Dubeau, Devault, \& Paquette, 2009; Gomes \& Resende, 2004; Silva \& Piccinini, 2007). Coparenting is defined by the reciprocal and joint involvement of both parents in education, training and decisions regarding children's lives, meaning that father and mother share the leadership and support each other in their roles as householders and parents. In the current context of Western societies, in which father involvement has been increasingly valued, understanding how coparenting affects human development has become of great importance, either for theoretical or interventional purposes. Coparenting is influenced by individual characteristics of each parent (education, mental health, and well-being), the dynamics of marital relationships, family factors, and extra-family environment. It is composed by the agreement regarding parenting practices, the division of labor, and mutual support between the dyads (Frizzo, Kreutz, Schmidt, Piccinini, \& Bosa, 2005).

Surveys show changes in parental roles as the result of women entering the labor market, and of greater paternal involvement in child care and household chores (Saraff \& Srivastava, 2010; Silva \& Piccinini, 2007; Wagner, et al., 2005). The increased participation of women in the labor market is seen as a factor that had led men to take more responsibility at home. Working outside the home reduces the contact established between the mother and her children. Thus, the father, who used to spend most of his time outside the home to ensure family support, is called to establish a more direct contact with his children. Although occurring at a much smaller scale than expected or desired, the participation and involvement of fathers in child care and household functions are being shown, even if the mother is still identified as the main responsible for home and child care (Jablonski, 2010).

Several studies aim at characterizing paternal functions within the family and in child development, demonstrating an increase in paternal involvement and pointing to a movement for greater involvement of fathers in child care (Frizzo, et al., 2005; Goetz \& Vieira, 2009; Pleck, 1997; Silva \& Piccinini, 2007). Investigations on mothers', and especially on fathers' parenting, which have been recently gaining prominence, have been adopting different conceptualizations, which will be discussed below.

\subsection{Investment, involvement and engagement}

The term investment comes from an evolutionary comprehension, considering the direct and indirect activities undertaken by fathers and mothers that contribute or not to the immediate survival of species (Hewlett, 1992; Trivers, 1972). The term involvement is understood as a type of investment that refers to activities in which parents interact directly or indirectly with children, seeking care (Lamb, 1997; Lamb, Pleck, Chanov, \& Levine, 1985). The term engagement is the most recent in psychological literature, being introduced in studies of paternity, and used as a synonym for involvement (Dubeau, et al., 2009).

The parental investment theory was proposed by Trivers (Trivers, 1972), who defines the term as the investment of energy, once the guarantee for species' survival and the chances of 
reproductive success depend on a high investment, as well as on the amount of energy involved in that process. Thus, parental investment is understood as the degree in which each sex invests in their offspring, meaning any investment parents (father and mother) make in favor of the offspring to increase survival and reproduction, thus reinforcing the link between parental investment and sexual selection. The sex who invests more in the offspring (female) is the most demanding in terms of partners' choice, while the sex who invests less (male) competes more actively with members of the opposite sex to ensure reproductive success (Borrione \& Lordelo, 2005; Trivers, 1972).

More specifically, the parental investment involves both evolutionary and cultural aspects (Geary, 2000). Among the factors associated with the evolution of parental investment are: the survival of offspring, mating opportunities, and certainty of paternity (or maternity). Cultural factors relate to the desire for social equality among maternal and paternal functions, meaning the understanding that both men and women should contribute to the welfare of children. The integrative perspective between the two dimensions (evolution and culture) can be a factor important to better understand the complexity of parental investment. However, is necessary also to understand how the individuals experiencing the maternity and paternity currently. In this case are used different terms such as involvement and engagement.

Regarding the term involvement, the definition mostly adopted in the literature refers to the concept of Lamb, Pleck, Charnov, and Levine (Lamb, et al., 1985), which define its' three dimensions: accessibility (presence and availability of the parent to the child, though without direct interaction between them), interaction (engagement or direct contact with the child in care and shared activities, such as play or leisure), and responsibility (parental role in providing care and resources, such as taking the child to the doctor or attending meeting at school).

The term paternal engagement is adopted by some authors (Dubeau, et al., 2009) (and is similar, in some extend to the concept of paternal involvement). It is defined as participation and ongoing concern of the biological father or stepfather, regarding the physical and psychological development and well-being of his children. Engagement is expressed in different forms: 1) Interaction: the presence of the father with the child, directly or indirectly, 2) Basic care: share of everyday tasks, 3) Affectionate: provides gestures and words that reassure and encourage the child; 4) Responsibility: performs tasks for the development of the child; 5) Provider: promotes financial support for the child's needs and 6) Evocative / significant: father who thinks about the child.

Futhermore, Turcotte and Gaudet (Turcotte \& Gaudet, 2009) performed an analysis of the forms and terms most used in the paternal studies which are interconnected: 1) parental participation, and especially fathers' participation, has been defined by the intensity of the relationship established with the child (how long the parent spends with the child); 2) the nature of the relationship with the child (what the parent does with the child) and 3) the quality of the relationship established with the child (how the parent does with the child).

Since the term engagement is recent in the psychological literature, it is not frequently adopted, especially by the Brazilian literature (Gomes, Bossardi, Crepaldi, \& Vieira, 2010). It was originally introduced in studies of paternity, since social changes paved the way for the 
conceptualization of each parent's engagement, and the involvement of mothers had been already studied for years.

In summary, parenting over time and in different societies has changed. This situation is potentiated in relation to paternity. On the other hand, different terms and concepts are used to describe the dimension or factors related to this phenomenon (the father in the familiar context), which are linked with different theories and epistemological perspectives. In the next section is showed the specificities of paternity in the Brazilian context. Through an integrative review of the literature will show the extent and nature of parental involvement in the family context in Brazil.

\subsection{Scientific literature on paternity in Brazil: An overview}

Between 1960 and 1976, only 3\% of the Brazilian studies on child development included the father (Dessen \& Lewis, 1998). The results of these studies were similar, in some extension, to that detached by other authors (for example, Lamb, 1997), in other contexts, emphasizing that the main father's role was to play with the children and that the greater impact of father involvement on children's development consisted in the promotion of girls' social development and children's sexual identity formation. Only in the $80^{\prime}$ s the themes related to the social construction of masculinity and their influence in the performance of parenting emerged more consistently in the literature, indicating a more effective participation of Brazilian fathers in the family routine (Hennigen \& Guareschi, 2002). However, until the late 90's few studies had effectively investigated paternal behavior and father-child relationship, since most research on child development and well-being remained focused on the mother-child dyad (Lewis \& Dessen, 1999). It is since the beginning of the $21^{\text {st }}$ century that scientific research has been demonstrating the new characterization father's role more emotionally involved and committed to their children, and as capable as mothers to educate their children (Souza \& Benetti, 2009), even if it remains in the social imaginary the traditional structure of the provider parent.

Review studies of scientific literature on paternity are crucial to identify which aspects of the subject are investigated by researches in a specific society. In this sense, this chapter aims at presenting an overview of the Brazilian scientific production, through the publication of empirical articles related to paternal behavior and experience. Considering that the choice for a research topic aims at contributing to the advancement of knowledge in a specific field, reviews of literature are helpful in indicating how the configuration of fatherhood in a society is. Furthermore, it may allow us to take a more objective perspective on data regarding the current reality of paternity in the family and their relationship with children.

In order to characterize the research on paternity in Brazil, it was conducted an integrative review of the literature, which it is a research method that allows the search, critical evaluation and synthesis of the available evidence on a topic investigated. The revision was based on publications found in the following databases: The Scientific Electronic Library Online (SciELO), Electronic Journals in Psychology (PePSIC) and INDEXPsi Technical and Scientific Journals, all indexed in the portal Virtual Library of Psychology (BVS-Psi). The descriptors selected for screening publications were father, paternity, and paternal. Previously to the definition of descriptors it was conducted a consultation in the Terminology Psychology BVS- 
Psi and the site of the Health Sciences Descriptors (DeCS), BVS. The terms father and paternity were indexed in at least one of the sites mentioned above. We chose to add the search function on the paternal descriptor that makes specific reference to the variable of interest in this study.

Regarding the limits of the search, the studies selected for analysis comprised only scientific articles published between the years from 2000 until 2012, with full text available and that provide results and discussions about the father figure, even when paternity was not the central theme. We excluded books, book chapters, reviews, theses, dissertations, and articles without full text available. From a total of 1447 documents found, 90 complete articles were chosen to be analyzed in function of their contributions to the production of knowledge of fatherhood in Brazil. The analysis of the articles was carried out in according to the structure of nine categories which represent the major topics of interest on fathers and fatherhood research in the Brazilian context. The following we describe each category and present the main finds.

\section{Family configurations}

This category includes issues investigated by several studies that present the new characteristics of family's configurations which are different from the traditional one. It refers to families with stepfather, due to divorce, adoption or remarried families. Examples of the major issues referred in this category are described below.

One study (Grzybowski \& Wagner, 2010) investigated parenting practices of mothers and fathers who are divorced or separated, emphasizing that even in this situation mothers were more involved with their children than fathers, and mothers usually cohabited with children. The results reveal a traditional configuration of parental involvement after separation/divorce, meaning that the maternal involvement is greater than the paternal after the end of marriage, and that cohabitation may lead to greater direct involvement with children.

The process of adopting a child has a specific configuration within the family dynamic and organization, once men who wish to have a child see in adoption an opportunity to become fathers. Fathers interviewed referred desire to form a family composed by the couple and their children, although they also reported difficulties with the legal adoption and the threat of biological parents. Parents claim to be happy and satisfied with the adoption, and describe the role of father as good, requiring a present and accountable parent in daily activities. The articles (Andrade, Costa, \& Rossetti-Ferreira, 2006; Tomé \& Schermann, 2004) dealing with nonbiological parents, as in the case of adoption or stepfathers, refer to the construction of paternity in a context that aims at overcoming the lack of consanguineous ties by affective ones. In adoptive parenthood, even when inserted in the labor market, mothers are the primary caregivers, as well as those who primarily perform the home chores, while fathers assume the role of helpers and of dealing with the economic support.

Couples who get together to form a family were, for a long time, the focus of research. However, given current social and economic changes, many women begin to participate 
actively in the labor market, starting to head up their families, and being responsible for livelihood as well. These findings show the coexistence with traditional family arrangements of single parent homes, consisting of one parent (usually the mother), as well as divorced or remarried families, who do not require the coexistence of a parent with the child. In such cases, in most studies the father is focused as the parental figure who leaves home and starts living with another family - with biological children or not, which is reconstituted through remarriage (Jablonski, 2010; Kamers, 2006; Wagner, et al., 2005). Research indicates that even in cases of non-biological children, such as adoption and the existence of stepfathers, parental involvement and participation become possible through the construction of emotional bonds that overcome the limitation of consanguinity. Even in divorced, remarried families, or with adoptive parents, mothers' role in caring for children seems to be more expressive, while fathers assume traditional roles in supporting mothers and children. Therefore, the mother appears as the primary responsible and the father as a helper in this process (Perucchi \& Beirão, 2007; Wagner, et al., 2005).

\section{The father in the context of pregnancy, birth, and postpartum}

This category includes Brazilian studies on paternal involvement during periods of pregnancy, birth, and postpartum, encompassing topics such as breastfeeding and non-normative events, such as postpartum depression, prematurity, and admission to neonatal intensive care units. It is subdivided into the subcategories described below:

\subsection{Pregnancy}

The pregnancy of wife or partner was the subject of seven studies. One of the studies (Piccinini, Silva, Gonçalves, Lopes, \& Tudge, 2004) included as participants men who were expecting their first child and the results indicate that fathers were involved in different ways during the pregnancy of their partners, being emotionally connected to both the mother and the baby. However, some of these fathers still found difficulties of involvement with their children, seemingly not perceiving them as real and showing low emotional connection to pregnancy. In contrast, one of the studies (Piccinini, Levandowski, Gomes, Lindenmeyer, \& Lopes, 2009) investigated the expectations and feelings of future fathers about their babies and the authors concluded that few fathers reported difficulty imagining the baby: they had built a mental image of the baby, including their physical and psychological characteristics. Moreover, they had participated in the choice of name and raised concerns about the child's health. Another paper (Krob, Piccinini, \& Silva, 2009 ) was characterized as a longitudinal study that investigated the expectation of men during the last trimester of the partner's pregnancy, as well as feelings about fatherhood during the second month of the baby's life. Results indicate that pregnancy was experienced as emotionally intense, characterized by joy, anxiety, and conflict. Men also reported concerns about the baby and the partner's health, as well as feelings of exclusion. After the child's birth, the sense of exclusion persisted. However, fathers reported positive feelings 
and satisfaction, confirming the expectations built up during pregnancy. The involvement in caring for the baby was not as effective as planned, although there was great affection and closeness between father and infant (Krob, et al., 2009). These data point to signs of changes concerning paternity during pregnancy, which is increasingly less restricted to the female universe.

One of the researches (Martini, Piccinini, \& Gonçalves, 2010) investigated indicators of couvade syndrome in primiparous parents during wives' pregnancy. This syndrome is characterized by a set of physical and psychological symptoms experienced mainly by biological fathers starting in the first and third trimesters of their partners' pregnancy, and ending shortly after the baby's birth. Participants in this study were 30 couples in different periods of pregnancy. Results revealed that more than half of the fathers had physical (increased appetite, food preference, and episodes of nausea) and/or emotional indicators (nervousness and moodiness) associated with couvade syndrome. Thus, the presence of indicators of couvade syndrome among fathers showed the complexity in the transition to parenthood, and the importance of understanding fathers' experiences and feelings during wives or partners' pregnancy.

Another study (Witter \& Guimarães, 2008) aimed at verifying the perception of pregnant teens (females) regarding the participation of their partners in monitoring pregnancy. The study showed that about $66 \%$ of the participants had their partners participating in the process of pregnancy in several ways, which indicate the evidence of fathers' positive attitudes and behaviors towards pregnancy. Another study involving pregnant adolescents stresses the importance of rethinking the question of including fathers in prenatal public programs (Siqueira, Mendes, Finkler, Guedes, \& Gonçalves, 2002).

Thus, it is clear that men can experience their wives or partners' pregnancy in terms of physical and emotional dimensions. The father participation in children's lives from pregnancy corroborates the perception of pregnancy as a period of transition to the exercise of parenthood, allowing the emergence of feelings of inclusion, and helping men to develop their new role as fathers. At this stage, values and priorities are reconfigured in the conjugal relationship. Some men refer concerns about fetal malformation, adversities in contemporary world, and the period of adolescence their children will face (Bornholdt, Wagner, \& Staud, 2007). Other concerns related by adolescent fathers in the exercise of parenthood are financial difficulties, and the desire to be involved in children's development.

\subsection{Childbirth}

The investigation of father's involvement in childbirth was the subject of four studies. The experience of childbirth is considered a unique experience in the men and women's lives. One of the studies (Perdomini \& Bonilha, 2011) revealed that fathers understand that their role involves to be present, to give comfort, and to use words of support. Fathers believe the opportunity of experiencing the birth of their child, regardless of the number of births accompanied by them, to be a unique experience, and a moment hard to explain. Another study (Motta \& Crepaldi, 2005) showed that mothers think be important the presence of their partners in the delivery, because they represent important emotional support references. The 
father often has a desire to attend the childbirth, though not always receiving the support of team of health care, especially in the case of the father being a teenager (Luz \& Berni, 2010).

The study of Carvalho (2003) aimed to investigate in a public hospital the impact children's birth had on men. The authors conclude that paternal involvement was influenced by various factors, such as institutional difficulties, mothers and fathers' motivation, social representations on childbirth and paternity, and the exclusion of father from reproductive health and pediatric services. The presence of fathers was not valued by staff neither as support for mothers, or as a transitional phase to fatherhood (Carvalho, 2003). In this way, is necessary to encourage the participation of fathers in prenatal care, childbirth, postpartum and pediatrics appointments, the training of staff working with families, the expansion of social discussion about fatherhood, and the formulation of labor policies that ensure the presence of fathers in health services. For this reason, it should be noted that it is necessary that hospitals comply with the Brazilian Law No. 11,108, enacted on April 7, 2005, which ensures the presence of the partner of choice during women's labor.

\subsection{Prematurity and monitoring of the child in the Intensive Care Unit - ICU}

Paternal participation at the ICU in the case of premature births was investigated in four studies. One of the studies (Tronchin \& Tsunechiro, 2005) stressed the importance of fathers' presence in child care during hospitalization and in supporting mothers. Another research indicates that fathers of preterm babies engage in psychic reorganization because they need to carry out unexpected activities (Coutinho \& Morsch, 2006). The same study presents the concept of 'engrossment', which refers to fathers' predisposition to show paternal concern and interest by their babies. It also claims that fathers' experience in ICU allows them to fall in love with their preterm babies, and to admire their strength and ability to fight for life. The same authors (Coutinho \& Morsch, 2006) also showed that the moments of hospitalization considered by mothers and fathers as the most painful were the delivery, the first visit to the baby at the ICU, the mother's first visit to the baby in neonatal intensive care unit, and the moment of leaving the hospital, when the couple 'leaves empty-handed', having to leave the child under hospital care. Research results also indicate that having a hospitalized child in the intensive care unit is an experience that triggers unexpected reactions of shock, disbelief, grief, and deep sorrow (Tronchin \& Tsunechiro, 2006), fear, anguish, anxiety, loneliness, but also joy and hope (Carvalho, Araújo, Costa, Brito, \& Souza, 2009). However, information received from healthcare professionals is important and represents a relief to parents frightened and frail in the face of this situation. Therefore, studies underscore the need to create models of care that include the father in this process, so that he can learn to work with this reality, defining and implementing measures to ensure his role in child care (Tronchin \& Tsunechiro, 2005; Tronchin \& Tsunechiro, 2006). After leaving the ICU, fathers reported to be joyful and to experience a sense of relief. However, this period was also permeated by difficulties, especially for those whose children needed special care. Religiosity and faith were described in two studies, regardless of religion, as an important resource for dealing with the situation (Carvalho, et al., 2009; Tronchin \& Tsunechiro, 2006). 


\subsection{Puerperium}

One of the studies (Oliveira \& Brito, 2009) investigated fathers' attitudes in the household during the postpartum period, and concluded that men take care of their partners and offer them advice concerning physical recovery and injury prevention. Fathers also recognize that the partner and the newborn require more dedication and time after birth, and develop attitudes of dedication and concern about the child's health. Their accounts also confirm they prepare financially for children's arrival, playing the role of main provider to the family (Jager \& Bottoli, 2011; Oliveira \& Brito, 2009).

Another article (Maranhão, Gomes, \& Oliveira, 2012) showed that during pregnancy men had performed tasks that require more physical effort (such as cooking, doing the laundry, and performing other heavy activities). When the baby was born, however, this concern disappeared and fathers failed to assist mothers with household chores, while spending more time caring for their children, especially when they are older. In this way, one other study (Falceto, Fernandes, Baratojo, \& Giugliani, 2008) involving 153 families with babies of four months, the authors concluded that there is a high prevalence of families in which the father is not actively involved in children's care, especially when the marital relationship is problematic and mothers do not have a paid job. The feeling of emotional detachment between the couple appears as a significant factor in the postpartum period (Maranhão, et al., 2012).

Regarding breastfeeding, studies have indicated that men do not participate in encouraging this practice, because they did not have this experience in their own families, schools and/or health institutions. Hence, they do not recognize the importance of this act (Pontes, Alexandrino, \& Osório, 2008; Pontes, Alexandrino, \& Osório, 2009). The authors propose the construction of a model to encourage fathers' involvement in this practice, and to design a health program with the goal of changing the culture of breastfeeding, increasing the duration of breastfeeding.

Regarding the non-normative events in the puerperium, the differences in dyadic (motherinfant, father-infant and mother-father) and triadic relationships (father-mother-child) were investigated in families with and without maternal depression, during a session of free interaction (Frizzo \& Piccinini, 2007 ). Only one category involving cognitive stimulation was significantly different between the mother-infant and father-child dyads in families with maternal depression, indicating that, despite the depression mothers stimulated their babies more than fathers. Families without the experience of depression also showed higher disengagement (less emotional involvement and responsiveness) in father-infant than in motherinfant dyads. For the authors, it is possible that fathers exercise a moderating role in the possible effects of maternal depression in the family, perhaps mitigating such effects in triadic contexts, once there seems to be a change in the family pattern in families with maternal depression.

\section{The father and the performance of his functions}

This category is related to the performance of the paternal role and the achievement of tasks and practices related to child care. The way each parent exercises his/her parental role depends 
on several factors, including welfare, availability and satisfaction of both mothers and fathers with their activities. Fathers and mothers tend to evaluate positively their performance of parental roles, and to feel satisfied, although not so competent, in relation to their functions. Stress and emotional well-being may interfere with their satisfaction and perception of their parental role (Ribas, Ribas Junior, \& Valente, 2006).

In another study (Bruschini \& Ricoldi, 2012), fathers reported to children's care and domestic tasks with their wives, even corroborating the role of others as providers and moral supervisors. Furthermore, men showed concern for being involved in tasks related to feeding, hygiene, and doing the homework. The traditional role often includes the affective dimension and fathers' concerns with children (Freitas et al., 2009; Pereira Junior, Siqueira, \& Rezende, 2011). Although there is evidence of the increases paternal involvement in child care, the same is not true with respect to household chores, indicating the predominance of fathers' care to the child, but not of fathers as the main responsible for the home (Sutter \& Bucher-Maluschke, 2008). Some fathers, even performing activities such as feeding, bathing and caring directly to their children, still refer to these activities as female responsibilities in children's lives, while considering themselves responsible for disciplining, guiding, and monitoring of children's conducts (Bustamante, 2005a; Romanelli, 2003). Satisfaction in the relationship with their wives seems to favor the involvement of fathers with the child and increases their participation in basic care and responsibilities in raising children (Bustamante, 2005b). Participants reported that being a father includes functions that go beyond the responsibility as providers, thus involving being present and establishing limits and responsibilities to children.

In relation to educational practices, participants reported frequently adopting inductive practices - indicating to children the consequences of their behaviors to other people, while calling attention to logical aspects of the situation -, in contrast to coercive practices, characterized by the direct application of imposition to control children's behaviors (Piccinini, Frizzo, Alvarenga, Lopes, \& Tudge, 2007). It was also found that participants displayed a profile closer to self-relational models in relation to their socialization goals. Parents wanted their children to be self-reliant, independent, and professionally successful, while valuing them being honest and executors of his duties with the family and society.

In synthesis, studies show changes in both paternal functions and parental roles, resulting from the increased participation of women in the labor market. It has been noted a greater paternal involvement in childcare and household chores, even if mothers continue to be identified as the main responsible for such activities. Although fathers and mothers have different roles, they seem to be complementary, and to express changes if their participation in children's care, moving from a traditional model of division of labor to the sharing of functions. The social, economic and family changes, the concepts of co-parenting and the notion of complementarity of parental functions are important factors to be considered in the study of parental involvement and in the characterization of maternity and paternity in contemporary family. 


\section{Impact of paternity on children}

This category deals with the impact of fathers in children's development and behavior. According to Benczik (Benczik, 2011), the literature indicates that the effective participation of fathers in family life promotes to children safety, self-esteem, emotional stability, and independence. Along these lines, some research in Brazil has shown the implications of fathers in the school context. Cia and Barham (2009), for instance, found a positive relationship between paternal involvement in children's school, cultural and leisure activities, and the academic performance of children in $6^{\text {th }}$ and $7^{\text {th }}$ grades. In one study conducted with parents of children enrolled at the ${ }^{1 s t}$ and $2^{\text {nd }}$ grades, the authors found that paternal involvement was associated with low rates of hyperactivity and behavioral problems, and these children displayed more appropriate social skills.

However, inadequate paternal practices (such as hostile and antisocial behaviors) may have negative consequences for children (Jaffee, Moffitt, Caspi, \& Taylor, 2003). One case study conducted with a family exposed to multiple adversities indicates that some aspects may function as protective factors; one of these factors is fathers' sensitivity to their children's needs (Silva, Lacharité, Silva, Lunardi, \& Lunardi Filho, 2009). The authors also mention that fathers' accepting support in their roles as children's caregivers and providers emerged from the data as something significant, with a positive impact on both fathers (who felt supported) and children, who meet a safer father in performing his functions.

In synthesis, the father is a figure that has an important role to children. However, it is not only the father's presence that will ensure this importance, but the quality of the relationship established between fathers and children. The focus on quality also applies to the relationship mothers establish with children. For example, it has been found that parenting styles perceived by teens as neglectful, indulgent or authoritarian had significant association with drug use (Benchaya, Bisch, Moreira, Ferigolo, \& Barros, 2011). When these educational styles are displayed by mothers, the chances for teenagers to use drugs increases in three times. The role performed by fathers, however, does not seem to have the same relevance. For instance, fathers' authoritative style is not associated with children's drug use.

If paternal involvement has a positive effect on children, one question that arises is what happens when the father is not present. In a literature review with data from Brazil and other countries, authors have indicate that due to current family structure fathers' absence is an increasing reality in families (Eizirik \& Bergmann, 2004). This context may have behavioral and emotional implications for children. Thus, the authors conducted a case study and found that fathers' absence can lead to conflicts in children's psychological development. In that specific case, there was evidence of behavioral problems even considering the mother had played an important role in minimizing these problems. In another study, Lopes and Paula (2011) studied two groups of adolescents (one group lived with their fathers, while the other did not). The authors found that half of the sample of the group 1 chose a substitute figure for the father; the other half, in which this has not occurred, there was a strong influence of the maternal figure in their career choice. That is, in the absence of either the father or of a father 
figure, the mother occupies this role. However, it is not known what the implications are for youth of this change in the reference figure.

\section{Variables that affect the exercise of paternity}

This category includes research dealing with variables that influence the exercise of paternity. The literature suggests that the characteristics of fathers and children, the family and social environment are factors that can increase or decrease fathers' participation in their children's lives. Three surveys constitute this category. Fathers' occupation is the focus in two of them (Fabiana Cia \& Barham, 2008; Souza \& Benetti, 2008). These studies investigate the influence of unemployment, as well as working conditions and work shifts (night or day), in the activities performed by fathers. Another survey (Silva \& Guzzo, 2007) deals with the situation of incarcerated fathers and their children. Variables such as paternal depression, social-economic conditions (fathers' educational level and income), and family relationships are also investigated.

Results of these three studies agree that the labor factor, as well as paternal educational level, conditions and social environment for family coexistence seem to be associated to paternal involvement. The higher father's educational level and the better his working conditions and income are the greater father's involvement. The existence of a high degree of affection between the father and his wife is also related to great involvement with his children. Living with their children can also affect the quality of paternal relationship. Incarcerated fathers, who maintain contact with their children through visits or letters, refer concerns about the lack of contact with the children, as well as with their children's future.

Although the mentioned studies focus on the determinants or variables that affect fathers' engagement, it is possible to recognize many gaps in the literature regarding paternal engagement and its determinants. In terms of the variables influencing paternal behavior, it is necessary to emphasizes that the level of paternal commitment results from the dynamic interaction of factors such as fathers' characteristics (experiences from their own childhood, attitudes and beliefs about gender roles, feelings of competence and socio-demographic characteristics), family characteristics (relationship with their wives and mothers' attitudes and behavior towards paternity, including whether mothers encourage or inhibit paternal participation), children's characteristics (gender, age, and temperament) and characteristics of the social environment (life and working conditions, culture, and social policies). The relationship with their wives, mothers' perception about the paternal role, maternal encouragement and facilitation of paternal participation can lead to variations in paternal involvement. Children's characteristics, such as gender, age and temperament can impact the level of paternal involvement. The social environment, such as financial instability and work characteristics can be associated with paternal behavior as well. It seems that employment instability and low income affect fathers' attitudes with children. Although these evidences were found in several studies, results are inconclusive and often contradictory, which means that new variables should be better investigated. 


\section{Gender identity}

Gender identity and the roles played by males are discussed in relation to parenting. The four articles that address this theme refer to a new father who arises as the result of a redefinition of male identity in response to social changes. With women's emancipation, new male roles are outlined, and current fathers are faced with the new challenge of responding social demands required from them. Fathers are investigated concerning their feelings towards identity and paternity in this context of social changes. Gradual changes in the male role, especially with regards to paternity, are noted over the years. From the 1960s men are held more accountable for their actions in the domestic sphere and with children and, in subsequent years, there have been valued gender equality and a model of participant fathers (Santos, Caldana, \& Alves, 2001). Marriage reconfigures masculinity through paternity. Single men have an identity and responsibilities different from married men. Paternity is not only about having children, but is related as the ability to support and educate them (Almeida \& Hardy, 2007; Freitas, Coelho, \& Silva, 2007 ). The traditional model of paternity according to which fathers are defined exclusively as providers coexists with a new model where fathers' affective bonding is valued from pregnancy. It seems that fathers are asked to take on additional functions beyond those typically performed, thus modifying the meaning of paternity. Pregnancy constitutes a change in male role as well, since fathers can establish an emotional bond with children from conception (Almeida \& Hardy, 2007; Freitas, et al., 2007).

Changes in parental involvement are also found in studies that focus on gender identity. Once more male and female roles are highlighted as products of social changes that produce the redefinition of male roles and identity. Fathers try to adapt to the expected new model, which is characterized by greater participation in their children's lives, thus distancing from the traditional model on fatherhood.

\section{Perception and conception on paternal behavior}

The category refers to beliefs, values and cognitions related to paternity according to reports of mothers, children, fathers, and the media. Conceptions on paternity constructed by women who are heads of households refer to the valuation of present and participative fathers. These conceptions surpass the father/provider model and highlight their role as educators and authority figures, emphasizing the tasks of establishing limits and imposing rules of conduct. One study pointed to paternal involvement, especially in children's education, and as an essential factor in building children's personality (Perucchi \& Beirão, 2007). While women interviewed perceived fathers' dedication in interacting with children, especially in joint activities, such as playing, singing, talking and going out, not all of them recognized these as care activities (Crepaldi, Andreani, Hammes, Ristof, \& Abreu, 2006).

Three studies dealt with the concepts of real and ideal father (Goetz \& Vieira, 2008; Goetz \& Vieira, 2009; Prado, Piovanotti, \& Vieira, 2007). Parents believe the ideal of paternal behavior to be far from the real behavior in relation to social interactions and educational dimensions. 
However, with respect to discipline (identified as an area of great paternal involvement), fathers consider a match between the ideal and the actual paternal behavior. In relation to the actual behavior, it has been noted a trend fathers assessing their participation as more effective than mothers' assessment. Regarding the participation in household chores, fathers consider their concrete participation to be optimal, whereas mothers expect more commitment from her partners. Men indicate they should be more involved with their children (Goyea, Omene, \& Ogbebor, 1979).

According to reports from children between 10 and 11 years-old, the real father does not match the ideal one in aspects related to care and interaction, especially in families in which parents are separated (Goetz \& Vieira, 2008). This study have showed a match between the ideal and the real mother while there is the expectation that the ideal father be more involved in care and devote more time to play and fun. Children whose parents live together understand that caring and interacting through play should be performed by both parents, privileging an equal sharing of parental tasks.

Two studies investigated the conception of university students on parental roles. In one study, mothers are seen as the central figure in families and are identified as responsible for household chores (Rabinovich, Moreira, \& Franco, 2012). Fathers are no longer identified as primarily responsible for providing economic support to the family, because this responsibility in now shared with mothers. While preserving some aspects of the traditional view on parental roles, indicating mothers as primary caregivers (Perosa \& Pedro, 2009; Rabinovich, et al., 2012) and responsible for household chores the respondents refer that fathers play with young children and provide emotional support for the whole family (Perosa \& Pedro, 2009). It has been noted that fathers are affectionate with their children, and seem to be in a transition time, playing both old and new roles (Gabriel \& Dias, 2011).

Paternity was also investigated in relation to how it is seen and influenced by the media. The media is an important vehicle for the transmission of values. It appears that the model portrayed is of a father who is available and participates in children's lives. There is a desire to show the new man who comes to parenting, who must adjusts to the demands of both the traditional and the new father (Chechi \& Hillesheim, 2008). According to several participants, such as children, mothers, fathers and the media, paternity is perceived as a phenomenon in transition, where traditional roles are mixed with more modern roles, being expected from fathers to be loving, caring, and more participative in parenting.

\section{Father in the context of adolescence}

This category covers paternity in the context of adolescence. The articles analyzed here refer to teenage parents or parents who have children in their teens. In one of these articles (Trindade \& Menandro, 2002), there are discussions about the planning and the desirability of pregnancy with the partner, and about the use of contraceptive methods and prevention, suggesting the need for public policy on sexual and reproductive rights that can guide teenagers to play their parental roles effectively. 
On the other hand, the partner was identified as being responsible for the pregnancy or its prevention, which refers to an ancient pattern of reproductive allocation of responsibility to women. It was also pointed out the positive aspects of parenthood. Teenage parents were satisfied with their condition as fathers, and reported attachment to their children, even considering the increase of responsibility (Meincke \& Carraro, 2009; Trindade \& Menandro, 2002). For the subjects of these two studies, the father is the one who works and supports his children, as well as the one who accompanies, educates and prepares them for life.

Furthermore, family support and encouragement were central to the exercise of adolescent fatherhood. It is emphasized the importance of supporting men at this stage, so that they can experience responsible parenthood with all the changes it encompasses. Family contributes to both providing support and transmitting parental role models (Meincke \& Carraro, 2009).

On the other hand, two other articles (Levandowski \& Piccinini, 2002, 2006) compared adult and adolescents' fatherhood, and the results showed similar outcome in the two groups, suggesting that age did not appear to be a determining factor in the experience of parenthood. Parents appeared to be responsive to their children, living with them and their mothers (Levandowski \& Piccinini, 2002, 2006).

Among the studies analyzed, one refers to the father who had child in his adolescent (Faria, 2007). The major difficulties reported by fathers were the affective approach, the establishment of limits, the aggressiveness, and the construction of adolescent autonomy. Being a parent of a teenager can make the man review his life. Even when this moment is experienced as distressing and conflicting, it can result in a positive solution for the father because of the broader approach to life, and to his child, because of the gain of autonomy.

In two studies, teenagers answered about the father. In one of them (Wagner, Falcke, Silveira, \& Mosmann, 2002), about the family relationship, teenagers show little or no talk to the father, compared to the conversation with the mother, which shows a wide discrepancy between the parental figures. While being evaluated positively, father seems to occupy a peripheral place in adolescents livels' in regards to matters of personal and intimate contact. The other study (Sena \& Farias, 2010) presents the importance of paternal role in disciplining and transmitting social norms to adolescents. When this function is not assumed, adolescents demonstrate intolerance and lack of boundaries that culminate in violence displayed in the school context.

Based on the assumption that parental involvement is understood as a complex and multidetermined phenomenon, the context of adolescence appears to be the focus of studies in the Brazilian scenario because it represents one important aspect of parental participation nowadays, which it involves specific risk and protective factors.

\section{Father of disabled or hospitalized children}

This category is dedicated to scientific researches that have focused on studying the characteristics of fatherhood in the context of parents with hospitalized children or parents with children with disabilities. Some studies have investigated various dimensions of parenting in 
parents of children with any health problems, such as congenital heart disease, leukemia and intellectual disabilities. It is highlighted the prevalence of Down Syndrome as one of the main focus of investigations (Henn \& Piccinini, 2010; Pereira-Silva \& Dessen, 2006). Overall, the researchers showed the importance of the father figure to children's development, and some of them emphasize the deep involvement of fathers in children's treatment (Chacon, 2011; Henn \& Piccinini, 2010; Kruel \& Lopes, 2012). Despite the deep involvement, the father usually performs the role of a collaborator in the task of caring for children and the home, providing occasional assistance to the mother (Canho, Neme, \& Yamada, 2006; Chacon, 2011). It is possible to perceive the continuity of the traditional division of parental roles, as several studies that show fathers as the main providers of financial support to the family, thus having less time to stay with their children when compared to mothers (Canho, et al., 2006; Chacon, 2011; Henn \& Piccinini, 2010).

It appears that there are differences in parents' time for assimilating children's disability (Pereira-Silva \& Dessen, 2006). The information is usually given by the doctor. However, when the disability does not have a high degree of visibility and prejudice, it will only be seen over time. The shock of the discovery, as well as behaviors and feelings of rejection are reported by both fathers (Chacon, 2011; Kruel \& Lopes, 2012) and mothers (Kruel \& Lopes, 2012). However, even if fathers have similar feelings than related to the diagnosis of children, cultural beliefs about male behavior seem to affect the exercise of paternity (Chacon, 2011). In this sense, the research of Canho et al. (2006) revealed that fathers have used denial, repression of feelings and rationalization as the main defense mechanisms when facing the diagnosis of children with hearing problems. The paternal figure also seems to adopt an attitude of companion and protection towards the baby and the mother, in addition to being the main responsible for maintaining the optimism of the entire family with regards to the sick child (Kruel \& Lopes, 2012).

Most parents refer to the feeling of fear to generate other children with disabilities, as well as low expectations in terms of their total independence. Among parents who have more than one child, most of them acknowledge the existence of differential treatment of the sick child on the basis of his disability (Chacon, 2011). It is stressed the importance of investing the relationship established between parents and health professionals, promoting their participation in children's treatment and informing them on how to properly stimulate their children. There is a lack of national surveys on variables related to fathers in families with children with special needs, indicating a promising field for future studies.

In synthesis, it has been noted concern by researchers in investigating paternal participation in various contexts, such as in the cases of different family configurations and adolescence, as discussed previously. Other unusual context is related in having children with disabilities or hospitalized. These situations configure a peculiarity that may cause changes in both the family development and the parenting. Such situations require specific interaction and care from the father with the child, and that even in this kind of situations the traditional roles held by father and mother are displayed. 
One summary quantitative of articles analyzed are showed in the Table 1 . The category 'The father in the context of pregnancy, birth, and postpartum' had the largest number of articles $(n=22,24,5 \%)$. The majority of the articles was characterized by qualitative approach $(n=64$, $71 \%)$ and transversal research $(n=84,93 \%)$. The survey was the method more used $(n=68,75 \%)$ and the father was the main participant in 54 researches (60\% of studies).

\begin{tabular}{|c|c|c|c|c|}
\hline Categories & Approach & Method & Participants & $\begin{array}{l}\text { Transversal X } \\
\text { Longitudinal }\end{array}$ \\
\hline $\begin{array}{l}\text { Family configurations } \\
(\mathrm{N}=4)\end{array}$ & $\begin{array}{l}\text { Quanti: } 1 \\
\text { Quali: } 3\end{array}$ & $\begin{array}{c}\text { Survey: } 1 \\
\text { Study of case: } 3\end{array}$ & $\begin{array}{c}\text { Father and mother: } 3 \\
\text { Stepfather: } 1\end{array}$ & Transversal: 4 \\
\hline $\begin{array}{l}\text { The father in the } \\
\text { context of pregnancy, } \\
\text { birth, and postpartum } \\
(\mathrm{N}=22)\end{array}$ & $\begin{array}{l}\text { Quanti: } 2 \\
\text { Quali: } 17 \\
\text { Mixed: } 3\end{array}$ & $\begin{array}{c}\text { Survey: } 20 \\
\text { Study of case: } 1 \\
\text { Observation: } 1\end{array}$ & $\begin{array}{c}\text { Father: } 13 \\
\text { Father and mother: } 4 \\
\text { Pregnant adolescents: } 1 \\
\text { Parturient: } 1 \\
\text { Adolescent mothers: } 1 \\
\text { Families: } 2\end{array}$ & $\begin{array}{l}\text { Transversal: } 21 \\
\text { Longitudinal: } 1\end{array}$ \\
\hline $\begin{array}{l}\text { The father and the } \\
\text { performance of his } \\
\text { functions } \\
(\mathrm{N}=16)\end{array}$ & $\begin{array}{l}\text { Quanti: } 5 \\
\text { Quali: } 10 \\
\text { Mixed: } 1\end{array}$ & $\begin{array}{c}\text { Survey: } 15 \\
\text { Study of case: } 1\end{array}$ & $\begin{array}{l}\text { Father and mother: } 8 \\
\text { Father: } 5 \\
\text { Child: } 1 \\
\text { Father and mother and } \\
\text { grandmother: } 1 \\
\text { Father, mother and child: } 1\end{array}$ & Transversal: 16 \\
\hline $\begin{array}{l}\text { Impact of paternity on } \\
\text { children } \\
(\mathrm{N}=4)\end{array}$ & $\begin{array}{l}\text { Quanti: } 2 \\
\text { Quali: } 2\end{array}$ & $\begin{array}{c}\text { Survey: } 3 \\
\text { Study of case: } 1\end{array}$ & $\begin{array}{c}\text { Father and children: } 1 \\
\text { Adolescent: } 2 \\
\text { College students: } 1\end{array}$ & Transversal: 4 \\
\hline $\begin{array}{l}\text { Variables that affect } \\
\text { the exercise of } \\
\text { paternity } \\
(\mathrm{N}=3)\end{array}$ & $\begin{array}{l}\text { Quanti: } 2 \\
\text { Quali: } 1\end{array}$ & Survey: 3 & Father: 3 & Transversal: 3 \\
\hline $\begin{array}{l}\text { Gender identity } \\
(\mathrm{N}=4)\end{array}$ & Quali: 4 & $\begin{array}{c}\text { Survey: } 3 \\
\text { Study of case: } 1\end{array}$ & $\begin{array}{l}\text { Articles: } 1 \\
\text { Men: } 1 \\
\text { Father: } 2\end{array}$ & Transversal: 4 \\
\hline $\begin{array}{l}\text { Perception and } \\
\text { conception on } \\
\text { paternal behavior } \\
(\mathrm{N}=15)\end{array}$ & $\begin{array}{l}\text { Quali: } 10 \\
\text { Quanti: } 4 \\
\text { Mixed: } 1\end{array}$ & $\begin{array}{c}\text { Survey: } 10 \\
\text { Study of case: } 5\end{array}$ & $\begin{array}{c}\text { Father: } 2 \\
\text { Mother: } 2 \\
\text { Father and mother: } 2 \\
\text { Children: } 5 \\
\text { Mother and children: } 1 \\
\text { Others: } 3\end{array}$ & $\begin{array}{l}\text { Transversal: } 14 \\
\text { Longitudinal: } 1\end{array}$ \\
\hline $\begin{array}{l}\text { Father in the context } \\
\text { of adolescence }\end{array}$ & $\begin{array}{l}\text { Quanti: } 1 \\
\text { Quali: } 12\end{array}$ & $\begin{array}{c}\text { Survey: } 9 \\
\text { Study of case: } 3\end{array}$ & $\begin{array}{l}\text { Father: } 8 \\
\text { Mother: } 1\end{array}$ & $\begin{array}{l}\text { Transversal: } 12 \\
\text { Longitudinal: } 1\end{array}$ \\
\hline
\end{tabular}




\begin{tabular}{|c|c|c|c|c|}
\hline Categories & Approach & Method & Participants & $\begin{array}{l}\text { Transversal X } \\
\text { Longitudinal }\end{array}$ \\
\hline$(\mathrm{N}=13)$ & & Observation: 1 & $\begin{array}{c}\text { Women and men: } 1 \\
\text { Men: } 2 \\
\text { Movie: } 1\end{array}$ & \\
\hline $\begin{array}{l}\text { Father of disabled or } \\
\text { hospitalized children } \\
(\mathrm{N}=9)\end{array}$ & $\begin{array}{l}\text { Quali: } 5 \\
\text { Quanti: } 2 \\
\text { Mixed: } 2\end{array}$ & $\begin{array}{c}\text { Survey: } 4 \\
\text { Study of case: } 3 \\
\text { Observation: } 1 \\
\text { Experiment: } 1\end{array}$ & $\begin{array}{l}\text { Father: } 5 \\
\text { Father and mother: } 2 \\
\text { Father, mother and children: } \\
2\end{array}$ & $\begin{array}{c}\text { Transversal: } 6 \\
\text { Longitudinal: } 3\end{array}$ \\
\hline
\end{tabular}

Table 1. A quantitative summary of the articles analyzed in function of different criteria.

\section{Discussion and conclusion}

The present study aimed to elucidate aspects of paternity in the Brazilian context through the scientific production published in Brazilian journals. The data analyzed showed that most of the existing research on paternity has been produced from 2000, and the interest of researchers seems to increase every year. The articles analyzed indicated that although mothers still appear as the main responsible for child care, fathers have been increasingly engaged in various aspects of their children's lives.

In Western societies, it is assumed that men and women's social roles have been changing, creating new expectations, beliefs and attitudes about how parents should act within the family (Jablonski, 2010; Wagner, et al., 2005). Specifically in Brazil, contemporary social changes, which include the entry of women in the labor market and new family configurations, modified the structure and patterns of family functioning, demanding from men a more active role as fathers. Such changes have implications to the family dynamics and to marital relationships, as well as to childcare, and have produced transformations in the roles and functions performed by each parent (Fleck \& Wagner, 2003). The traditional view of fathers as main providers is changing, since women have been also exerting the role of family provider, while fathers have been gradually associated to greater participation in relation to child care (Gauthier, et al., 2004; Jablonski, 2010; Mendonça, et al., 2011; Perucchi \& Beirão, 2007; Saraff \& Srivastava, 2010; Wagner, et al., 2005).

However, the present review has shown that researches investigating different family configurations, such as divorced or adoptive parents indicate that men's attitudes seem to follow a pattern, regardless of the family configuration in which they are inserted as fathers or stepfathers. Generally, fathers, even when not biological, seem to be satisfied with their children. These results confirm the literature that show mothers to be the main responsible for children, while fathers are not usually responsible for children's daily care, appearing as adjuvants (Jablonski, 2010; Kamers, 2006).

Regarding pregnancy, the literature review demonstrates that, in general, men are involved in this stage of their partners' lives and report mixed feelings of joy and anxiety. 
They even refer to physical and emotional reactions during pregnancy and these feelings seem to be important to prepare themselves for fatherhood. However, some fathers demonstrate difficulties in performing the new paternal role of greater participation and involvement in the partners' pregnancy. This probably happens because the future father feels lost and confused with his new role, once he is caught in redefinition process: on one side there are the demands to perform fathers' traditional roles (as family providers), and on the other there are the new demands for greater engagement with the mother and the baby (Bustamante, 2005b). Studies show that male participation in children's lives starting from pregnancy contributes to the perception of pregnancy as a period of transition to the exercise of fatherhood, allows for a feeling of inclusion, and helps fathers to develop their new role in the life cycle (Bornholdt, et al., 2007).

Concerning the participation in childbirth, there are fathers who wish to experience this moment and who see it as an opportunity unique. On the other hand, there are those who are afraid of being unprepared for the experience. Data also show that although mothers consider the presence of their partners in the parturition room as an important emotional reference (Motta \& Crepaldi, 2005), fathers are not usually encouraged to do it, especially from the health team in charge. Even after the baby is born, men are not included in the routines of child care, and are very little motivated to do so. The articles call attention to the importance of providing encouragement to fathers' participation in the childbirth, which benefit both mother and baby. Along the same lines, Carvalho (2003) argues that fathers should be included in the process as a whole, and be encouraged to participate in prenatal care, childbirth, postpartum and pediatric appointments. The author still points to the need to formulate work policies that allow for the inclusion of fathers in health services. According to Crepaldi et al., (2006), the awareness of health and educational sectors is fundamental for the inclusion of fathers in child care.

The fact that mothers are considered the main interlocutors in these environments legitimates representations that fathers are unable to care for their children's issues, which position them as mere helpers for mothers and as family providers. In addition, it is noteworthy fathers' difficulties to engage with their children when they are born premature and need to stay in the Intensive Care Units (ICU). However, researches indicate that the experience of caring for a premature child can benefit father-child's bond (Tronchin \& Tsunechiro, 2006). Hence, the support of the healthcare team should be reinforced.

In the puerperium phase, men seem unable to help much their partners, either with household chores or in breastfeeding. However, women in general report to be satisfied with men's behavior. Furthermore, although fathers do not carry out many functions soon after the baby's birth, they seem to have a role in mitigating the effects of postpartum depression when this event takes place (Frizzo \& Piccinini, 2007 ). These results can be further investigated to understand the processes surrounding these aspects of paternal involvement.

Regarding gender roles, the articles analyzed demonstrate that men are required to get deeper engaged in their children's lives, as well as to share household chores due to social demands, mainly because, in general their wives also work outside the home. Thus, in relation to issues 
concerning gender identity, Jablonski (2010) highlights that transformations in the performance of parenting had implications on masculine identity, including aspects related to values and beliefs. Family transformations have been generating expectations and demands from men in terms of their roles as fathers and husbands, characterizing the phenomenon called "new paternity". Although it seems evident men's growing interest in participating, this interest does not materialize with the same force, once the division of child care still seems unbalanced between men and women (Brasileiro, Jablonski, \& Féres-Carneiro, 2002; Jablonski, 2010; Kamers, 2006).

In relation to the housework, the study carried out by Prado et al. (2007) points out to a contradiction in parents' perceptions: while mothers believe fathers should do more than what they assess to be their role in household chores, men believe their participation to be very close to the ideal one. Publications show that in addition to their low participation in household tasks, fathers hardly get involved in children's care, devoting their time only to games and physical play (Prado, et al., 2007). Other researches refer to greater male participation in child care than in domestic chores (Gomes \& Resende, 2004). Although there had been significant changes in order to reduce the gap between men and women in regards to domestic activities, it remains a considerable gap between rhetoric and practice. Even men whose attitudes are positive towards the division of home tasks continue to adopt behaviors not consistent to such conviction (Brasileiro, et al., 2002; Jablonski, 2010; Kamers, 2006). Regarding paternal functions, there seems to be two models: one in which fathers share tasks with mothers, and another one in which mothers are the primary caregiver. Overall, studies argue that men do not see themselves only as providers, but also as responsible for raising children.

On the performance of paternal functions, researchers have concluded that although we are in a process of changes in what is expected from fathers and mothers, the figure of fathers as financial providers to the family and of mothers as emotional and affective caregivers still remain (Dessen \& Braz, 2000; Trindade \& Menandro, 2002). Freitas et al. (2009) argue that fathers perceive paternity as a new social role still strongly linked to the function of moral and material provision for the family, even though they have been experiencing a transition process in which coexist the traditional model of paternity and the current model that includes also the dimensions of care and affection.

The reviewed studies also suggest that paternal involvement can benefit children in emotional, behavioral and social terms. There is evidence that, especially with regards to the school performance, involved fathers contribute to children's satisfactory academic performance. These studies support international research indicating that fathers who are affectionate and able to impose rules and limits help children developing confidence that allows them to become responsible and cooperative with adults and peers in preschool, as well as developing social skills in academic school age (Paquette, Eugène, Dubeau, \& Gagnon, 2009).

Although analyzed researches in this present revision show no consensus regarding the variables influencing paternity, studies indicate that fathers' personality characteristics, children's temperament, and the context may be important variables. Moreover, families' social-economic situation, fathers' educational background and can result in greater or lesser degree of paternal involvement. Reviewed studies suggest that fathers play different roles 
depending on the cultural context in which they are inserted, and these roles are multidimensional and complex. Furthermore, issues related to personality traits, relationship with wives and family, as well as the social environment must be considered in understanding parental involvement (Turcotte \& Gaudet, 2009).

When dealing with the perception and conception of paternal behavior, the reviewed publications indicate that fathers report being involved with their children, especially in leisure activities, and in imposing discipline. However, Goetz and Vieira (2008) found that children perceive the real father to be far from the ideal one regarding his functions of care and interaction, especially in cases where parents are separated. The authors point out that children's expectations towards their parents are a reflection of the culture in which they live. Hence, if the pattern in contemporary culture is related to a more involved and active father, then children will require these behaviors from fathers. Concerning the imposition of discipline, parents (mothers and fathers) seem to agree that fathers are important in the imposition of rules, limits and transmitting concepts on "what is right and what is wrong." Thus, fathers play an important role in relation to children's appropriate behavior in the social sphere (Goetz \& Vieira, 2008).

In relation to adolescence, in this present review, researches have demonstrated that many teenage fathers report being satisfied and demonstrate responsibility for their children and partners. In terms of future studies, it is necessary to investigate more thoroughly teenagers' expectations and feelings, as well as their marital relationships and their relation with the baby (Levandowski \& Piccinini, 2002, 2006).

On the other hand, fathers of disabled or hospitalized children, despite the difficulties of having a sick child, are described as deeply involved with their children. However, they describe themselves as helping mothers in child care, while women are perceived to be primary caregivers. In addition, they refer to be responsible for the family economical support. These findings show that fathers, regardless of having healthy or sick children, still position themselves in the traditional role of providers (Dessen \& Lewis, 1998).

Therefore, it seems that paternity has been increasingly attracting researchers' attention, possibly because the theme is of both scientific and social relevance. Paternal participation in the family context has been increasing and this greater involvement has repercussions in family dynamics and children's development. However, due to the complexity of the theme, much still has to be done in order to build a broader and more accurate perspective on the reality of fathers in Brazil.

For instance, more studies are necessary to characterize the experiences of paternity in the context of children with disabilities, as well as possible implications of children with special needs, sex and birth order in the family organization. In addition, it is necessary to increase the amount of researches on fathers' perceptions regarding their roles. Another demand is related to the participation of fathers whose children belongs to different age groups, considering that demands of children change over time, and the specificities of paternal involvement during childhood development. In relation to participants, future research should incorporate data from other generations of participants in order to investigate the intergenerational 
transmission of parenting. Other family configurations, besides father-mother families, need to be more emphasized in research, especially with regards to the role of fathers in divorced and remarried families. Moreover, the issue of co-parenting is a topic that has been gaining researchers' attention, but is still very recent in the literature. It is necessary to invest in research to identify which aspects of paternal involvement effectively indicate a co-parental relationship and the effects of this relationship to children.

\section{Acknowledgements}

One special thanks goes to CNPq and CAPES for financial support via scholarship to the authors of the paper.

\section{Author details}

Mauro Luís Vieira ${ }^{1}$, Maria Aparecida Crepaldi ${ }^{1}$, Carina Nunes Bossardi ${ }^{1}$, Lauren Beltrão Gomes ${ }^{1}$, Simone Dill Azeredo Bolze ${ }^{1}$ and César-Augusto Piccinini ${ }^{2}$

1 Psychology Department, Federal University of Santa Catarina, Florianópolis, Brazil 2 Institute of Psychogy, Federal University of Rio Grande do Sul, Porto Alegre, Brazil

\section{References}

[1] Almeida, A. F. F., \& Hardy, E. (2007). Vulnerabilidade de gênero para a paternidade em homens adolescentes. Revista de Saúde Pública, 41(4), 565-572.

[2] Andrade, R. P., Costa, N. R. A., \& Rossetti-Ferreira, M. C. (2006). Significações de paternidade adotiva: um estudo de caso. Paidéia (Ribeirão Preto), 16(34), 241-252.

[3] Benchaya, M. C., Bisch, N. K., Moreira, T. C., Ferigolo, M., \& Barros, H. M. T. (2011). Pais não autoritativos e o impacto no uso de drogas: a percepção dos filhos adolescentes. Jornal de Pediatria (RJ), 87(3), 238-244.

[4] Benczik, E. B. P. (2011). A importância da figura paterna para o desenvolvimento infantil. Revista Psicopedagogia, 28(85), 67-75.

[5] Bornholdt, E. A., Wagner, A., \& Staud, A. C. P. (2007). A vivência da gravidez do primeiro filho à luz da perspectiva paterna. Psicologia Clínica, 19(1), 75-92.

[6] Bornstein, M. H., Tamis-LeMonda, C. S., Parcual, L., Haynes, O. M., Painter, K. M., Galperín, C. Z., \& Pêcheux, M. G. (1996). Ideas about parenting in Argentina, France and the United States. International Journal of Behavior Development, 19(2), 347-367. 
[7] Borrione, R. T. M., \& Lordelo, E. R. (2005). Escolha de parceiros sexuais e investimento parental: Uma perspectiva desenvolvimental. Interação em Psicologia, 9(1), 35-43.

[8] Borsa, J. C., \& Nunes, M. L. T. (2011). Aspectos psicossociais da parentalidade: O papel de homens e mulheres na família nuclear. Psicologia Argumento, 29(64), 31-39.

[9] Brasileiro, R. F., Jablonski, B., \& Féres-Carneiro, T. (2002). Papéis de gênero e a transição para a parentalidade. Psico (Porto Alegre), 3(2), 289-310.

[10] Bruschini, M. C. A., \& Ricoldi, A. M. (2012). Revendo estereótipos: O papel dos homens no trabalho doméstico. Estudos Feministas, 20(1), 259-287.

[11] Bustamante, V. (2005a). Participação paterna no cuidado de crianças pequenas: Um estudo etnográfico com famílias de camadas populares. Cadernos de Saúde Pública, 21(6), 1865-1874.

[12] Bustamante, V. (2005b). Ser pai no subúrbio ferroviário de Salvador: Um estudo de caso com homens de camadas populares. Psicologia em Estudo, 10(3), 393-402.

[13] Canho, P. G. M., Neme, C. M. B., \& Yamada, M. O. (2006). A vivência do pai no processo de reabilitação da criança com deficiência auditiva. Estudos em Psicologia (Campinas), 23(3), 261-269.

[14] Carvalho, J. B. L., Araújo, A. C. P. F., Costa, Í. C. C., Brito, R. S., \& Souza, N. L. (2009). Representação social de pais sobre o filho prematuro na unidade de terapia intensiva neonatal Revista Brasileira de Enfermagem, 62(5), 734-738.

[15] Carvalho, M. L. M. (2003). Participação dos pais no nascimento em maternidade pública: dificuldades institucionais e motivações dos casais. Cadernos de Saúde Pública, 19(2), 389-S398.

[16] Chacon, M. C. M. (2011). Aspectos relacionais, familiares e sociais da relação pai-filho com deficiência física. Revista Brasileira de Educação Especial, 17(3), 441-458.

[17] Chechi, P., \& Hillesheim, B. (2008). Paternidade e mídia: representações sobre o pai na contemporaneidade. Barbarói, 28, 89-108.

[18] Cia, F., \& Barham, E. J. (2008). Trabalho noturno e o novo papel paterno: Uma interface difícil. Estudos de Psicologia (Campinas), 25(2), 211-221.

[19] Cia, F., \& Bahram, E. J. (2009). O envolvimento paterno e o desenvolvimento social de crianças iniciando as atividades escolares Psicologia em Estudo, 14(1), 67-74.

[20] Coutinho, H. R. B., \& Morsch, D. S. (2006). A paternidade em cuidados intensivos neonatais. Revista da SBPH, 9(1), 55-69.

[21] Crepaldi, M. A., Andreani, G., Hammes, P. S., Ristof, C. D., \& Abreu, S. R. (2006). A participação do pai nos cuidados da criança, segundo a concepção de mães. Psicologia em Estudo, 11(3), 579-587. 
[22] Dessen, M. A., \& Braz, M. P. (2000). Rede social de apoio durante transições familiares decorrentes do nascimento de filhos. Psicologia: Teoria e Pesquisa, 16(3), 221-231.

[23] Dessen, M. A., \& Lewis, C. (1998). Como estudar a "família" e o "pai"? Paidéia (Ribeirão Preto), 8(14/15), 105-121.

[24] Dessen, M. A., \& Silva Neto, N. A. (2000). Questões de família e desenvolvimento e a prática de pesquisa. Psicol Teor Pesqui, 16(3), iii-v.

[25] Dubeau, D., Devault, A., \& Paquette, D. (2009). L'engagement paternel, un concept aux multiples facettes. In D. Dubeau, A. Devault \& G. Forget (Eds.), La paternité au XXI sièle (pp. 71-98). Québec, Canada: Les Presses de l'Université Laval.

[26] Eizirik, M., \& Bergmann, D. S. (2004). Ausência paterna e sua repercussão no desenvolvimento da criança e do adolescente: Um relato de caso. Revista de Psiquiatria do Rio Grande do Sul, 26(3), 330-336.

[27] Falceto, O. G., Fernandes, C. L., Baratojo, C., \& Giugliani, E. R. J. (2008). Fatores associados ao envolvimento do pai nos cuidados do lactente. Revista de Saúde Pública, 42(6), 1034-1040.

[28] Faria, D. L. (2007). A paternidade de filhos adolescentes: A crise do meio da vida e o processo de individuação masculino. Boletim de Psicologia, 57(1), 107-118.

[29] Fleck, A. C., \& Wagner, A. (2003). A mulher como principal provedora do sustento econômico familiar. Psicologia em Estudo, 8(num. esp.), 31-38.

[30] Freitas, W. M. F., Coelho, E. A. C., \& Silva, A. T. M. C. (2007). Sentir-se pai: A vivência masculina sob o olhar de gênero. Cadernos de Saúde Pública, 23(1), 137-145.

[31] Freitas, W. M. F., Silva, A. T. M. C., Coelho, E. A. C., Guedes, R. N., Lucena, K. D. T., \& Costa, A. P. T. (2009). Paternidade: Responsabilidade social do homem no papel de provedor. Revista de Saúde Pública, 43(1), 85-90.

[32] Frizzo, G. B., Kreutz, C. M., Schmidt, C., Piccinini, C. A., \& Bosa, C. (2005). O conceito de coparentalidade e suas implicações para a pesquisa e para a clínica. Revista Brasileira de Crescimento Desenvolvimento Humano, 15(3), 84-93.

[33] Frizzo, G. B., \& Piccinini, C. A. (2007). Depressão materna e a interação triádica paimãe-bebê. Psicologia: Reflexão e Crítica, 20(3), 351-360.

[34] Gabriel, M. R., \& Dias, A. C. G. (2011). Percepções sobre a paternidade: Descrevendo a si mesmo e o próprio pai como pai. Estudos em Psicologia (Natal), 16(3), 253-261.

[35] Gauthier, A. H., Smeeding, T. M., \& Furstenberg, F. F. (2004). Are parents investing less time in children? Trends in selected industrialized countries. Population and Development Review,30(4), 647-672. doi: 10.1111/j.1728-4457.2004.00036.x

[36] Geary, D. C. (2000). Evolution and proximate expression of human paternal investment. Psychological Bulletin, 126(1), 55-77. doi: 10.1037/0033-2909.126.1.55 
[37] Goetz, E. R., \& Vieira, M. L. (2008). Diferenças nas percepções de crianças sobre cuidado parental real e ideal quando pais vivem juntos ou separados. Psicologia: Reflexão e Crítica, 21(1), 83-90.

[38] Goetz, E. R., \& Vieira, M. L. (2009). Percepções dos filhos sobre aspectos reais e ideais do cuidado parental. Estudos em Psicologia (Campinas), 26(2), 195-203.

[39] Gomes, A. J. S., \& Resende, V.R. (2004). O pai presente: O desvelar da paternidade em uma família contemporânea. Psicologia: Teoria e Pesquisa, 20(2), 119-125.

[40] Gomes, L. B., Bossardi, C. N., Crepaldi, M. A., \& Vieira, M. L. (2010). Engajamento Paterno: Uma revisão da produção acadêmica referente ao período compreendido entre 2000 e 2010. Unpublished work.

[41] Goyea, H. S., Omene, J. A., \& Ogbebor, M. I. (1981). Retrospective genetic counselling in sickle cell disease: A second look. Patient Counselling and Health Education, 3(2), 84-85. doi: 10.1016/s0738-3991(81)80070-5

[42] Grzybowski, L. S., \& Wagner, A. (2010). O envolvimento parental após a separação/ divórcio. Psicologia: Reflexão e Crítica, 23(2), 289-298.

[43] Henn, C. G., \& Piccinini, C. A. (2010). A experiência da paternidade e o envolvimento paterno no contexto da Síndrome de Down. Psicologia: Teoria e Pesquisa, 26(4), 623-631.

[44] Hennigen, I., \& Guareschi, N. M. F. (2002). A paternidade na contemporaneidade: um estudo de mídia sob a perspectiva dos estudos culturais. Psicologia \& Sociedade, 14(1), 44-68.

[45] Hewlett, B. S. (1992). Father-child relations: Cultural and bisocial contexts. New York: Aldine de Gruyter.

[46] Jablonski, B. (2007). O cotidiano do casamento contemporâneo: a difícil e conflitiva divisão de tarefas e responsabilidades entre homens e mulheres. In Feres-Carneiro T (Ed.), Família e casal: saúde, trabalho e modos de vinculação. (pp. 203-228). São Paulo: Casa do Psicólogo.

[47] Jablonski, B. (2010). A divisão de tarefas domésticas entre homens e mulheres no cotidiano do casamento. Psicololgia: Ciência e Profissão, 30(2), 262-275.

[48] Jaffee, S. R., Moffitt, T. E., Caspi, A., \& Taylor, A. (2003). Life with (or without) father: the benefits of living with two biological parents depend on the father's antisocial behavior. Child Development 74(1), 109-126.

[49] Jager, M. E., \& Bottoli, C. (2011). Paternidade: Vivência do primeiro filho e mudanças familiares. Psicologia: Teoria e Prática, 13(1), 141-153.

[50] Kamers, M. (2006). As novas configurações da família e o estatuto simbólico das funções parentais. Estilos da Clínica, 11(21), 108-125. 
[51] Keller, H., \& Chasiotis, A. (2007). Maternal investment. In C. Salmon \& T. K. Shackelford (Eds.), Family Relationships. Oxford: Oxford University Press.

[52] Kreppner, K. (2000). The child and the family: interdependence in developmental pathways. Psicologia: Teoria e Pesquisa, 16(1), 11-22.

[53] Krob, A. D., Piccinini, C. A., \& Silva, M. R. (2009). A transição para a paternidade: da gestação ao segundo mês de vida do bebê. Psicologia USP, 20(2), 269-291.

[54] Kruel, C. S., \& Lopes, R. C. S. (2012). Transição para a parentalidade no contexto de cardiopatia congênita do bebê. Psicologia: Teoria e Pesquisa, 28(1), 35-43.

[55] Lamb, M. (1997). The role of the father in child development. New York: John Wiley \& Sons.

[56] Lamb, M., Pleck, J. H., Chanov, E. L., \& Levine, J. A. (1985). Paternal behavior in humans. American Zoologist(25), 883-894.

[57] Levandowski, D. C., \& Piccinini, C. A. (2002). A interação pai-bebê entre pais adolescentes e adultos. Psicologia: Reflexão e Crítica, 15(2), 413-424.

[58] Levandowski, D. C., \& Piccinini, C. A. (2006). Expectativas e sentimentos em relação à paternidade entre adolescentes e adultos. Psicologia: Teoria e Pesquisa, 22(1), 17-28.

[59] Lewis, C., \& Dessen, M. A. (1999). O pai no contexto familiar. Psicologia: Teoria e Pesquisa, 15(1), 9-16.

[60] Lopes, S. R. A., \& Paula, S. F. (2011). A importância da figura paterna no processo de escolha profissional: Um estudo comparativo entre jovens universitários. Psicologia: Teoria e Prática, 13(1), 165-181.

[61] Luz, A. M. H., \& Berni, N. I. O. (2010). Processo da paternidade na adolescência. Revista Brasileira de Enfermagem, 63(1), 43-50.

[62] Maranhão, T. A., Gomes, K. R. O., \& Oliveira, D. C. (2012). Relações conjugais e familiares de adolescentes após o término da gestação. Acta Paulista de Enfermagem, 25(3), 371-377.

[63] Martini, T. A. D., Piccinini, C. A., \& Gonçalves, T. R. (2010). Indicadores de síndrome de couvade em pais primíparos durante a gestação. Aletheia, 31(1), 121-136.

[64] Meincke, S. M. K., \& Carraro, T. E. (2009). Vivência da paternidade na adolescência: Sentimentos expressos pela família do pai adolescente. Texto Contexto Enfermagem, 18(1), 83-91.

[65] Mendonça, J., Cossette, L., Strayer, F. F., \& Gravel, F. (2011). Mother-child and fatherchild interactional synchrony in dyadic and triadic interactions. Sex Roles, 64(1), 132-142. doi: 10.1007/s11199-010-9875-2

[66] Motta, C. C. L., \& Crepaldi, M. A. (2005). O pai no parto e apoio emocional: A perspectiva da parturiente. Paidéia, 15(30), 105-118. 
[67] Oliveira, E. M. F., \& Brito, R. S. (2009). Ações de cuidado desempenhadas pelo pai no puerpério. Escola Anna Nery Revista de Enfermagem, 13(3), 595-601.

[68] Paquette, D., Eugène, M. M., Dubeau, D., \& Gagnon, M.-N. (2009). Les pères ont-ils une influence spécifique sur le développement des enfants? In D. Dubeau, A. Devault \& G. Forget (Eds.), La paternité au XXI sièle (pp. 99-122). Québec, Canada: Les Presses de l'Université Laval.

[69] Perdomini, F. R. I., \& Bonilha, A. L. L. (2011). A participação do pai como acompanhante da mulher no parto. Texto Contexto Enfermagem, 20(3), 445-452.

[70] Pereira-Silva, N. L., \& Dessen, M. A. (2006). Padrões de interação genitores-crianças com e sem síndrome de Down. Psicologia: Reflexão e Crítica, 19(2), 283-291.

[71] Pereira Junior, G., Siqueira, V. H. F., \& Rezende, L. A. (2011). Paternidade e saúde reprodutiva: Discursos de jovens em documentários autobiográficos. Pro-Posições, 22(1), 131-149.

[72] Perosa, C. T., \& Pedro, E. N. R. (2009). Perspectivas de jovens universitários da Região Norte do Rio Grande do Sul em relação à paternidade. Revista da Escola de Enfermagem da USP, 43(2), 300-306.

[73] Perucchi, J., \& Beirão, A. M. (2007). Novos arranjos familiares: Paternidade, parentalidade e relações de gênero sob o olhar de mulheres chefes de família. Psicologia Clínica, 19(2), 57-69.

[74] Piccinini, C. A., Frizzo, G. B., Alvarenga, P., Lopes, R. S., \& Tudge, J. (2007). Práticas educativas de pais e mães de crianças aos 18 meses de idade Psicologia: Teoria e Pesquisa, 23(4), 369-377.

[75] Piccinini, C. A., Levandowski, D. C., Gomes, A. G., Lindenmeyer, D., \& Lopes, R. S. (2009). Expectativas e sentimentos de pais em relação ao bebê durante a gestação. Estudos em Psicologia (Campinas), 26(3), 373-382.

[76] Piccinini, C. A., Silva, M. R., Gonçalves, T. R., Lopes, R. S., \& Tudge, J. (2004). O envolvimento paterno durante a gestação. Psicologia: Reflexão e Crítica, 17(3), 303-314.

[77] Pleck, J. H. (1997). Paternal involvement: Levels, sources and consequences. In M. Lamb (Ed.), The role of the father in child development. New York: John Wiley \& Sons.

[78] Pontes, C. M., Alexandrino, A. C., \& Osório, M. M. (2008). Participação do pai no processo da amamentação: Vivências, conhecimentos, comportamentos e sentimentos. Jornal de Pediatria (RJ), 84(4), 357-364.

[79] Pontes, C. M., Alexandrino, A. C., \& Osório, M. M. (2009). O envolvimento paterno no processo da amamentação: Propostas de incentivo. Revista Brasileira de Saúde Materno Infantil, 9(4), 399-408.

[80] Prado, A. B., Piovanotti, M. R. A., \& Vieira, M. L. (2007). Concepções de pais e mães sobre comportamento paterno real e ideal. Psicologia em Estudo, 12(1), 41-50. 
[81] Rabinovich, E. P., Moreira, L. V. C., \& Franco, A. (2012). Papéis, comportamentos, atividades e relações entre membros da família baiana. Psicologia E Sociedade, 24(1), 139-149.

[82] Ribas, A. F. P., Ribas Junior, R. C., \& Valente, A. A. (2006). Bem-estar emocional de mães e pais e o exercício do papel parental: Uma investigação empírica. Revista Brasileira de Crescimento e Desenvolvimento Humano, 16(3), 28-38.

[83] Romanelli, G. (2003). Paternidade em famílias de camadas médias. Estudos e Pesquisas em Psicologia, 3(2), 79-96.

[84] Santos, M. C., Caldana, R. H. L., \& Alves, Z. M. M. B. (2001). O papel masculino dos anos quarenta aos noventa: Transformações no ideário. Paidéia (Ribeirão Preto), 11(21), 57-68.

[85] Saraff, A., \& Srivastava, H. C. (2010). Pattern and determinants of paternal involvement in childcare: An empirical investigation in a metropolis of India. Population Research and Policy Review, 29(2), 249-273. doi: 10.1007/s11113-009-9139-4

[86] Sena, I. J., \& Farias, M. L. S. O. (2010). Função paterna e adolescência em suas relações com a violência escolar. Revista Mal-Estar e Subjetividade, 39(1), 111-136.

[87] Silva, M. F., \& Guzzo, R. S. L. (2007). Presidiários: Percepções e sentimentos acerca de sua condição paterna. Revista Brasileira de Crescimento e Desenvolvimento Humano, 17(3), 48-59.

[88] Silva, M. R., \& Piccinini, C. A. (2007). Sentimentos sobre a paternidade e o envolvimento paterno: Um estudo qualitativo. Estudos em Psicologia, 24(4), 561-573.

[89] Silva, M. R. S., Lacharité, C., Silva, P. A., Lunardi, V. L., \& Lunardi Filho, W. D. (2009). Processos que sustentam a resiliência familiar: um estudo de caso. Texto Contexto Enfermagem, 18(1), 92-99.

[90] Siqueira, M. J. T., Mendes, D., Finkler, I., Guedes, T., \& Gonçalves, M. D. S. (2002). Profissionais e usuárias(os) adolescentes de quatro programas públicos de atendimento pré-natal da região da grande Florianópolis: onde está o pai? Estudos de Psicologia (Natal), 7(1), 65-72.

[91] Souza, C. L. C., \& Benetti, S. P. C. (2008). Paternidade e desemprego: Características do envolvimento paterno e aspectos do relacionamento familiar. Contextos Clínicos, 1(2), 61-71.

[92] Souza, C. L. C., \& Benetti, S. P. C. (2009). Paternidade contemporânea: levantamento da produção acadêmica no período de 2000 a 2007. Paidéia (Ribeirão Preto), 19(42), 97-106.

[93] Sutter, C., \& Bucher-Maluschke, J. S. N. F. (2008). Pais que cuidam dos filhos: A vivência masculina na paternidade participativa. Psico, 39(1), 74-82. 
[94] Tomé, G. L., \& Schermann, L. (2004). Padrasto, o novo pai: nova postura paternal. Aletheia, 19(1), 21-30.

[95] Trindade, Z. A., \& Menandro, M. C. S. (2002). Pais adolescentes: Vivência e significação. Estudos de Psicologia (Natal), 7(1), 15-23.

[96] Trivers, R. L. (1972). Parental investment and sexual selection. In B. Campbell (Ed.), Sexual selection and the descent of man (pp. 136-179). Chicago: Aldine.

[97] Tronchin, D. M. R., \& Tsunechiro, M. A. (2005). A experiência de tornarem-se pais de prematuro: um enfoque etnográfico. Revista Brasileira de Enfermagem, 58(1), 49-54.

[98] Tronchin, D. M. R., \& Tsunechiro, M. A. (2006). Cuidar e o conviver com o filho prematuro: A experiência do pai. Revista Latino-Americana de Enfermagem, 14(1), 93-101.

[99] Turcotte, G., \& Gaudet, J. (2009). Conditions favorables et obstacles à l'engagement paternel: Un bilan des connaissances. In D. Dubeau, A. Devault \& G. Forget (Eds.), La paternité au XXI sièle (pp. 39-70). Québec, Canada: Les presses de l'Université Laval

[100] Wagner, A., Falcke, D., Silveira, L., \& Mosmann, C. (2002). A comunicação em famílias com filhos adolescentes. Psic. estud., 7(1), 75-80.

[101] Wagner, A., Predebon, J., Mosmann, C., \& Verza, F. (2005). Compartilhar tarefas? Papéis e funções de pai e mãe na família contemporânea. Psicologia: Teoria e Pesquisa, 21(2), 181-186.

[102] Witter, G. P., \& Guimarães, E. A. (2008). Percepções de adolescentes grávidas em relação a seus familiares e parceiros. Psicologia: Ciência e Profissão, 28(3), 548-557. 
Chapter 4

\title{
Parenting and Culture - Evidence from Some African Communities
}

\author{
Patricia Mawusi Amos \\ Additional information is available at the end of the chapter
}

http://dx.doi.org/10.5772/56967

\section{Introduction}

Parenting requires interpersonal skills and makes emotional demands (Santrock, 2006). According to Santrock, most parents learn parenting practices from their own parents - some they accept and some they discard. The author argues that when parenting methods are passed on from one generation to the next, both desirable and undesirable practices are perpetuated. These practices may be cultural values which have been passed on from one parent to another.

Culture on the other hand is a way of life of a group of people- the behaviours, symbols, values, beliefs that people accept, not really thinking about them and are passed by mostly communication and imitation from one generation to another. With regards to African culture, people perceive most of its practices as something which is devilish in the sense that a lot of its practices are attributed to gods. Some people especially Africans, who have not fully experienced the indigenous culture believe that to be too culturally aware makes one backward and or ancient. This is as a result of lack of knowledge of our cultural values and principles.

In the African system, parenting is again perceived to take a lot of forms which is able to lead the child to be a responsible adult. Though there are various parenting styles, there are ways in which the African parent brings up a child in order for the child to imbibe the cultural values of the land and also be a responsible adult. Some of these forms of parenting are through story telling (folktales), the extended family, traditional rites and the mother's care, attention and love. One may ask; are these cultural practices still in vogue? This chapter is an attempt to take readers through some of the parental cultural practices in some African communities. 


\subsection{Purpose}

The purpose of this chapter will therefore be to expatiate on some of the various cultural practices in some sub-Saharan Africa which foster good parenting and also state their relevance or importance to the African. The author will also state their various implications to parenting and suggest some recommendations.

\subsection{Significance}

Research shows that majority of books concerning infancy are from the western world (Tomlinson \& Swartz, 2003). In view of that African cultural values as far as parenting is concerned are being forgotten and the western practice is rather adopted. This chapter will therefore enable readers especially, Africans to be aware of some of the rich cultural practices of parenting. It will also add up to literature as far as parenting and culture in Africa is concerned as well as in the majority world.

In view of this some important aspects that will be discussed in this chapter with respect to parenting and culture are:

- Parenting

- Culture

- Some common values and practices in Ghana, Nigeria and Liberia which foster good Parenting.

- Some relevance of the cultural values and practices

- Implication

- recommendations

\section{Parenting}

Parenting is the process of raising and educating a child from birth or before until adulthood (Self Growth, 2012). Synonymously, parenting refers to carrying out the responsibilities of raising and relating to children in such a manner that the child is well prepared to realize his or her full potential as a human being. This implies that parenting is the process of taking care or supporting a child from birth to adulthood involving the physical, emotional, social and intellectual capabilities. It can simply mean the process or state of being a parent. In fact one can be a parent both to the biological or non-biological children.

Parenting usually takes place when one meets the defined criteria mentioned in the definition. According to Santrock (2006), parenting requires interpersonal skills and again makes emotional demands. Also, other researchers, for example Baumrind (1967) have suggested that there are four major styles of parenting. The researchers argue that majority of the parents display one of four different parenting styles. These styles are authoritarian parenting, authoritative parenting, permissive parenting and uninvolved parenting. 
According to Cherry (2012), authoritarian parenting style expect the child to adhere or follow the strict rules established by the parents. Failure to follow the rules will result in punishment. Usually, because the parents have ordered, it must be done without explanations and questions. On the other hand, authoritative parents establish rules and guidelines that their children are expected to follow. Nevertheless, this parenting style is much more democratic (Cherry, 2012 \& Santrock, 2006). Parents with this style are responsive and ready to listen and cooperate. Baumrind (1991) argues that these parents are assertive but not intrusive and restrictive.

Santrock (2006) also stated that permissive parents have few demands to make of their children. These parents allow their children a lot of freedom. They hardly punish or discipline them (Baumrind, 1991) whiles uninvolved parenting is attributed with few demands and little communication. Though the parents fulfil the needs of the child, they rarely get attached to the child (Cherry, 2012). Similarly, uninvolved parents make few to no demands of their children and they are often indifferent, dismissive or even completely neglectful.

Numerous works on parenting have brought about a number of conclusions as far as the impact of parenting styles on children are concerned. Cherry (2012) reported that authoritarian parenting styles normally result in children who are obedient and proficient but rank lower in happiness, social competence and self-esteem. On the contrast, Maccoby (1992) informed that authoritative parenting styles lead to children who are happy, capable and successful. Also, permissive parenting styles breed children who are low in happiness and uninvolved parenting styles lead to children who have low self-control, low self-esteem and highly incompetent.

\section{Differences in parenting styles}

According to Cherry (2012), parenting styles differ due to certain factors. These factors include culture, personality, parental background, educational level, socio-economic status, family size and religion. Of these factors, culture will be used to explain some similarities that exist in parenting in Ghana, Nigeria and Liberia.

\subsection{Culture}

Culture is the way a group of people live and it is a learned human behaviour patterns. Tylor (1958, p. 1) defined culture this way: "that complex whole which includes knowledge, belief, art, law, morals, custom and any other capabilities and habits acquired by man as a member of society".

According to $\mathrm{O}^{\prime} \mathrm{Neil}$ (2006), no matter where people live in the world, they share some human cultural traits which are universal. Examples of such "human cultural" traits include: communicating with a verbal language consisting of a limited set of sounds and grammatical rules for constructing sentences, using age and gender to classify people (e.g., teenager, senior citizen, woman, man), classifying people based on marriage and descent relationships and having kinship terms to refer to them (e.g., wife, mother, uncle, cousin). The others are raising children in some sort of family setting, having a concept of privacy, distinguishing between 
good and bad behaviour, having a sexual division of labour (e.g., men's work versus women's work) making jokes and playing games.

While all cultures have these and possibly many other universal traits, different cultures have developed their own specific ways of carrying out or expressing them. So also is parenting. A culture is normally passed from one generation to another, from knowledgeable adult to learning child. Since the adult has imbibed the norms and practices of the culture from older acculturated adults, this transmission is often simply through exposure and through example. For instance the Orangutan mother, who uses a specially prepared stick to fish out food from a crevice, learnt this skill and is now teaching it to her child who is hanging on her shoulder and intently watching (parenting and culture).

\section{Some common values and practices in Ghana, Nigeria and Liberia that foster good parenting}

\subsection{The extended family system}

According to Degbey (2012), the family is usually the major source of the basic necessities of life and health; the love and tenderness, food, water, clothing, shelter and sanitation which are made possible by the socio-economic, cultural and environmental conditions. Thus in discussing major issues with regards to parenting, it would be impossible to overlook the functions of the family (Degbey, 2012).

It is basically known that there are two types of the family. These are the nuclear and the extended family. The nuclear family is made up of only both parents and the children. The extended family is also made up of the nuclear family; in addition are the uncles, aunties, grandparents and cousins. It would be emphasized that in the African community, the extended family is traditionally practiced (Degbey, 2012). In the same vein, it is a common knowledge that when one speaks of the family in an African context, one is referring not to the nuclear family but the extended family (Gyekye, 1996).

According to Degbey (2012), the extended family system includes several generations plus cousins, uncles, and aunts living in a compound or close to one another. Similarly, Adinlofu (2009) stated that the extended family is composed of a number of joint, compound, elementary and nuclear families occupying separate but nearby homesteads. Degbey (2012) and Adinlofu (2009) further noted that the extended family provides emotional needs to all involved. It is a cohesive unit which ideally provides economic, social and psychological security to all its members. Adinlofu (2009) made mentioned that the extended family ensures procreation of children and provides for the early care and training of children. Degbey (2012) also added that this same family system defines "social and moral norms and safeguards both material and spiritual customs and traditions as well as providing a variety of role models preparing the way for adulthood". Degbey (2012) emphasized that the dominance of the elders/aged has a relatively high degree of social control on the individual especially, the youth. 
The uniqueness of this system with regards to parenting in our traditional African communities is that the responsibility in taking care of the child is not only to the biological parents. This is shared by all in the extended family. This is buttressed by the African proverb on parenting which says that, "a single hand cannot nurse a child". This implies that although the mother has the responsibility of taking care of the child, the responsibility is being shared by all. Most of us went to school on the strength of this system; otherwise we would have been stark illiterate and walking about aimlessly (Adinlofu, 2009). According to the author, some of us must have read and heard comments like: "my parents were so poor that it was my mum's brother or father's sister, that helped towards my education" or, that "it was my father's brother that trained me to read medicine, law or pharmacy and it was my in-law that gave me money to go into business". It is intriguing to know that this system is where a brother trained a younger brother or sister and they in turn help to train younger ones or older siblings' children. This is why it is even said that even when parents are dead, a child would always have 'parents'. This is because the extended family is there to cushion or parent the child.

Another uniqueness of this extended family system is that children or the youth stay at home i.e. live with the family until they are ready for marriage. Even if the young adult is staying with the nuclear family, the practice is that you marry before you leave the house. According to Gyekye (1996), growing adults are generally expected to live at home-in the family house and they may leave only after they marry. Even after marriage the parents would still want to offer advice and guidance since they believe they the adults have richer experiences than their children at any age.

At other instances, the extended family may not be together, but then the nuclear family may live with other nuclear families who may not be relatives. This system of living is what we call the "compound house" system. Also, this system allows any elderly person to discipline or correct a child.

\subsection{Relevance}

The extended family is a strong tool in parenting. It helps to develop a strong sense of social responsibility in the child from his early years and learns to be respectful, responsible and supportive member of the extended family and society.

\section{Folktales}

"A folktale may be described as a story handed down by oral tradition from mouth to ear among people generally; in fact illiterate, though not necessarily so ..." (Dawkins, 1951, p. 417). Dawkins reiterated that many genuine folk stories have been at first literary and passed later into oral tradition. In a similar manner Emery (2012) says a folktale is a traditional narrative, usually anonymous, handed down orally e.g. fables, fairy tales, legends etc. In African culture Story telling (folk tales) which used to be part and parcel of us is no more seen in our daily lives. During storytelling, we will have the older ones telling the younger ones stories which depicted attributes such as giving, caring for one another, greed, selfishness and so on. These 
elderly people serve as parents in that their word of advice during the story time helps to shape the younger ones. For instance in Ghana, the Spider (traditionally called Kwaku Ananse) is mostly used in our folktales as the main character. He is used to depict acts of greed, love, forgiveness, wisdom, pride etc.

One will be reminded that the story time is always in the evening; when the sun is set and all activities have come to a halt. According to Martin (2000) often such stories were told by the light of the moon around a village fire after the completion of a long day of work. It is believed that such times children and the youth will have a good listening ear for advice and what is ahead of them as they climb the adulthood ladder. Let us bear in mind that these stories are not told by parents alone, but by any adult who is depicted as responsive and caring and can impact good morals to the children. This even is evidence that parents are not the only caretakers of the child as he/she grows, but any adult in the community who is responsible. Martin (2000) pointed out that the stories rarely ended with the words ... "and they all lived happily ever after". Most stories didn't end happily ever after. The author noted, usually, the stories taught a lesson and frequently, the selfish person learned that lesson the hard way.

\section{Here is an excerpt:}

One day Ananse collected all the wisdom in the world and decided to keep it all in a large pot for himself. Now he said "I have all the wisdom of the world for myself. At least that was what he thought; being such a greedy person.

Kweku Ananse then tied the pot of wisdom around his neck with a strong vine rope and let the pot hang in front of him. But then he was afraid that someone would find the pot of wisdom and steal it." What shall I do with my pot of wisdom" He thought and thought and at last he said," I shall hide the pot on top of the tallest tree in the forest." So he searched the forest until he found the tallest tree which happened to be the thorny silk cotton tree and brought the pot of wisdom to the tree. While Ananse was trying to climb the thorny silk cotton tree his son was watching him." Father," he said," "What are you doing" "Well" said Ananse, I have in this clay pot all the wisdom of the world and I am going to hang it on the top of the tallest tree away from everybody, then I will be the wisest in the whole wide world." "I have an idea." said his son" Why not hang the pot behind you instead of in front of you. Then you will be able to climb the tree". Well the sly one Ananse hanged the pot behind him and to his surprise; he was able to climb to the top of the tree with his pot.

Finally Ananse sat on a branch of the tree holding the pot of wisdom. "I thought I had all the wisdom in the world" He thought to himself.

"I thought I had it all in my pot but my own son has wisdom not in my pot." Then he made a statement that we still use today." No one-person can have all the wisdom in the world. "On his way down he dropped the pot and it smashed into many pieces and scattered all the wisdom all over the world.

(This story is contributed by Rev Peter E Adotey Addo from his book, How the Spider became Bald...Folktales and Legends from West Africa adopted from http://www.allfolktales.com/ wafrica/ananse_pot_of_wisdom.php). 
The following are some examples of stories that were told and the lessons being learnt.

\begin{tabular}{ll}
\hline Story & Virtue/morals learnt \\
\hline Don't pay bad for bad & Friendship \\
Grasshopper and toad & Greed \\
Anansi and turtle & \\
Why wisdom is everywhere (Anansi and the Wisdom pot) & Lying \\
The jealous brother & Kindness \\
The twin brothers & \\
No condition is permanent & Obedience \\
The riot & \\
The Leopard man & Wisdom \\
Rere, the disobedient son & \\
Why wisdom is everywhere & \\
\hline
\end{tabular}

These are but a few of some folktales told in the Ghanaian, Nigeria and Liberia communities in Africa.

Table 1. Folktales and the virtues/morals learnt

\subsection{Relevance}

A folktale in traditional setting is an effective means of inculcating the virtues in children (Gyekye, 1996). It is obvious from the explanations given and their examples that these folktales carry with it values and morals which are being handed from one generation to the other. It teaches good morals which helps in parenting the child so he/she will learn to be a responsible adult.

\section{Puberty rites}

Another significant traditional practice which instils discipline and fosters good parenting in our youth especially, the young girls is puberty rites. It is one of the main traditional practices which have strongly been influenced by modernization and education.

Puberty rite is a traditional practice which is performed mainly on adolescent girls to initiate them to womanhood. This rite is therefore believed to make women or girls good wives if they are able to go through the process successfully. Though this process is being celebrated or performed by Nigeria, Liberia, Ghana and some African communities, there may be certain practices which may differ among the countries. However, they follow a general pattern. These general patterns include:

- notification of the adolescent, 
- period of seclusion,

- initiation rite then

- Reintegration into the family as an adult.

In view of this, the author would like to describe briefly how adolescent girls in Ghana and Nigeria go through this process of puberty.

In Ghana the puberty rite is being celebrated by most of the ethnic groups in Ghana. For instance some ethnic groups from the eastern part of Ghana call it "Dipo" and another from the central and again eastern part of Ghana call it "Bragro". As the time approaches for the initiation, announcement is given on behalf of the gods to prepare young girls who have reached the adolescent stage to partake in the rituals.

Qualified adolescent girls are then taken to the queen mother who will then prepare them physically for the ritual. In the case of the Dipo, the girls are given to the traditional priest. The queen mother will then examine the girls including their menstrual cycle to ensure that the girls are indeed virgins. If they pass the test, their parents will then prepare them to the initiation house. This initiation house is under the supervision of responsible, elderly women and also some girls. The identified pubertal girls are then taught issues concerning women. These are marriage, housewifery, how to dress, pregnancy, child birth and parenting. Similarly, in Igbo land in Nigeria, the young girls (the celebrants) would gather to learn private lessons of life from older women. In this gathering, young ladies learn personal grooming, among other values. Their hair would be plaited and their body polished with ufie (red cam wood) and adorned with uli designs. Songs, storytelling, and dancing would permeate the night. Mothers would lay out the facts of life and what it meant to be beautiful. Traditionally in Ghana, before the final initiation, the girls are regarded unclean. In view of that, they are shaved, cleaned (bathed) and smeared with some sheabutter. The women will then take the celebrants to the river side to wash three times every day. This will last for the period of the ceremony. When it gets to the evening this same girls and women will assist the celebrants to sing and dance with traditional love songs. This is done to invite suitors for the being initiated girls.

The last day is more remarkable. On this day, the girls are again led to the river. They are given a boiled egg to swallow. The egg must be swallowed whole. If the egg is chewed there is the fear that they may not have children if they do chew it. After all these, the girls are finally dressed in special clothes and ornaments. These clothes are called 'Kente'. They are then seated in an open place. This is to show to the public that these girls have now entered womanhood and also showcase themselves to the men who would want suitors or wives. During this process, people including the girls' parents present their gifts for all to see. This is done amidst singing and dancing. For the Igbo's of Nigeria, on the last day of the festivities, mothers would cook and send the young girls off for a day of fun at the designated Village Square. Here, the girls would dance, trade tips, share meals, and simply have a great time. Meanwhile, eligible bachelors would watch from the periphery. At the end of it all, the girls can now be taken home to their parents. At this juncture, they are given the right to marry any man who comes to seek their hand in marriage from the parents. 
One aspect of this initiation is that, during the past years, whenever a girl ceases to go through the rite due to pregnancy or pre-marital sex, they are known to bring disgrace, shame and a curse to their families and the society. In view of that they are ostracized. This forever will bring a stigma to the girl's family. In some communities, a ritual is performed for both the girl and the man responsible for the pregnancy. The rite is a form of punishment for not waiting to get married before having sex and becoming pregnant. The rite is performed in public in order to deter other young girls and boys who are soon to become adolescents to be patient until they are initiated and get married.

Most often, when puberty rite is mentioned, adolescent girls often come to the fore; but then boys who have also reached the adolescent stage also go through this passage. In Ghana puberty rite for boys is often common in the northern part of the country which is scarcely talked about as compared to the girls'. In Liberia, some communities do initiate boys as well as in Nigeria. In Liberia for instance, Young Mano men of Liberia go through a ceremonial "death" at puberty. These young men are stabbed with a spear and thrown over a cliff to symbolize death and rebirth into adulthood. Actually, a protective padding is kept in the spear from penetrating them, and a sack of chicken blood was tied over the spot to appear as though the young men had been stuck. They are then tossed over the cliff, but a heavy object is thrown over instead to sound like they have been thrown.

Presently, this puberty rite has been modernized due to education and also foreign religion. At present, the duration for the initiation has been reduced. Sometimes it even last for a day. Again, the breasts of the ladies have now been covered and also the adolescent stage is no more strictly enforced. Currently, parents even initiate their young girls as early as $4-10$ years. Some do this with the reason being that they don't want the girls to have pre-marital sex or get pregnant when they have not gone through the initiation.

\subsection{Relevance}

Though puberty rite activities may differ from one African community to another, their reason for this initiation is similar. For instance this puberty rite was initiated to prevent young girls and adolescents from teenage pregnancy, prostitution and the spread of sexually transmitted diseases. It was also introduced to teach the young woman how to be responsible and take care of her own family.

\section{The mother}

Presently mothers are not often seen in the house as they used to be. It must be emphasized that the involvement of more mothers in the modern labour force, deprives the children as well as the whole family of the daily love and care so necessary for proper child rearing and development.

During infancy, the child is breastfed for a longer time as compared to this modern time. This, it is believed, develop a bond between the baby and the mother. As the child grows, he/she sees the virtues being exhibited by the mother and all of these enhance good parenting. 
African culture and values see the mother as the keeper of the house. She is a housewife and makes sure that as the father is the bread winner, she must cater for all the domestic aspect of the children. Currently, there has been a paradigm shift. Since our day to day lives many of us are overstretched, we sometimes approach parenting tired and overwhelmed and as a result leave the children to the neglect of house helps and caretakers. This reduces the amount of time parents should spend with their wards. It should be stressed that even when the extended family is no longer in function, parents especially mothers, should be around to help bring up the child in a responsible manner.

\subsection{Relevance}

The mother serves as a support to the child especially, when the extended family is not around.

\section{Implications to parenting}

The traditional African systems as described have gone through the influence of external systems and forces which has transformed the rich parental values we have as Africans. The extended family system which is under pressure is rapidly eroding and failing to fulfil its primary role of socialization. In the urban areas for instance, the nuclear family is prominently cropping up. Presently, there is no cohesion; it is just the individual family, his work and his property. This has resulted in less socialization. Currently, families bring up their children in Estate houses whereby one group of a family does not know who his/her neighbour is. In view of that when problems arise in such communities, nobody cares and families are destroyed as a result of this.

Again, the media has taken precedence in our families that children no longer listen to folk stories anymore; they are rather with the television, internet, foreign books and computers. These modernization gadgets have limited information with regards to African cultural values and proper traditional parenting which can easily be assessed by all. In view of that a lot of young people have lost touch of the rich cultural values we have as Africans. A lot of young people presently no longer give a helping hand to the adult and do not offer their seat to the elderly whether in public or private.

Presently, teenage pregnancy is on the increase. Young girls do not regard their cultural values as far as virginity and marriage is concerned. Young couples give birth before they think about marriage. Some are as a result of the decision of the man to be sure that the woman is fertile before he marries her. This is for him to prevent childlessness in his home and the extended family. Others due to poor parental care and control, lack the love and commitment to stay with one woman. This has ended in the spread of sexually transmitted diseases and bearing children who have been abandoned by their parents; roaming in the bigger cities as hawkers, prostitutes, pick pockets and armed robbers.

Let us take for instance, the wife or mother who works in the bank and wakes up early dawn each day. If she has no extended family staying with her, then, she has to make sure the children 
have been bathed, eaten and goes to work around 5:30 or 6 O'clock am. She spends the whole day at work and comes home when sometimes the children are asleep. These often times result in the children not being well fed, and also developing bad habits.

\section{Recommendations}

From the factors given with regards to parenting, it would be noted that African culture contributes immensely in the upbringing of young people. This exposition is calling on our African nuclear families to rise up if they have completely neglected the extended family. The extended family is tearing apart especially in our bigger, busy cities. Nuclear families should make it a point to visit their hometowns and patch up with their extended families. Parents should frequently introduce their children to their extended families on both sides.

It is recommended that parents should endeavour to visit the old stories, make time and narrate them to their children. During my childhood school days I remember when it is story time; we take turns in the classroom to narrate these folktales to ourselves. Presently, the stories are rather the foreign ones we read. I believe our teachers should be reminded of this practice so the children can have rich cultural training. Again, curriculum developers should be reminded to revisit the times some of the stories were included in the reading books.

There is a statement in the Ghanaian language which says that whenever you neglect or abandoned something and later you go back for it; it is never forbidden. Meaning, you can still revisit whatever you neglected. It then behoves on our law makers and cultural authorities, to make sure that puberty rite is again established. Our parents and community leaders should make sure that every growing child, entering into the adolescent stage has undergone this event.

Working mothers and housewives; in as much as there is so much to be done at home and also at the workplace, please do endeavour to make time for the children. Some parents have so much to do that during vacations and weekends when the children are supposed to spend time with them, they allow these children to go for extra tuition which sometimes is unnecessary. These busy schedules of parents have influenced private schools to organise so many activities for the children that they are not able to socialise properly and also stay home and learn at the feet of their parents.

\section{Conclusion}

African culture is rich. We should not neglect it out rightly because it is that which makes us Africans. Let us embrace our good parenting practices so we can nurture responsible youth for the African continent. 


\section{Author details}

Patricia Mawusi Amos*

Address all correspondence to: pathogrey@gmail.com

University of Education, Winneba, National Centre for Research into Basic Education (NCRIBE), Winneba, Ghana

\section{References}

[1] Addo, P. E. A. (2009). Ananse and the pot of wisdom. Retrieved from http:// www.allfolktales.com/wafrica/ananse_pot_of_wisdom.php

[2] Adinlofu, E. (2009). Modernity and the "Extended family system". Retrieved on $4^{\text {th }}$ April, 2009 from www.nigeriansinamerica

[3] Baumrind, D. (1967). Child-care practices anteceding three patterns of preschool behaviour. Genetic Psychology Monographs, 75, 43-88.

[4] Baumrind, D. (1991). The influence of parenting style on adolescent competence and substance use. Journal of Early Adolescence, 11(1), 56-95.

[5] Cherry, K. (2012). Parenting styles: The four styles of parenting. Retrieved from http://psychology.about.com/od/developmentalpsychology/a/parenting-style.htm

[6] Dawkins, R. M. (1951). Folklore: Transactions of the folk-lore society. Folklore, 62(4), 417-429.

[7] Degbey, J. L. (2012). Africa family structure. Retrieved from http://www.jicef.or.jp/ wahec/ful217.htm

[8] Emery, D. (2012). Folktale. Retrieved from http://urbanlegends.about.com/od/glossary/g/folktale.htm

[9] Gyekye, K. (1996). African cultural values: An introduction, Legon: Sankofa Publishing Company

[10] Maccoby, E.E. (1992). The role of parents in the socialization of children: An historical overview. Developmental Psychology, 28, 1006-1017.

[11] Martin, P. (2000). African folktales. Retrieved from http://www.phillipmartin.info/ liberis/text_folktales_intro.html

[12] O'Neil, D. (2006). What is culture? Retrieved $2^{\text {nd }}$ June, 2012 from www.anthro.palomar.edu/culture/culture_1.htm 
[13] Santrock, J.W. (2006). Life-Span Development (10 ${ }^{\text {th }}$ Ed.).New York: McGraw Hill Companies, Inc.

[14] Selfgrowth.com (2012). Retrieved from http://www.selfgrowth.com/articles/Definition_Parenting.html

[15] Tomlinson, M. \& Swartz, L. (2003). Imbalances in the knowledge about infancy: the divide between rich and poor countries. Infant mental health journal, 24(6), 547-556.

[16] Tylor, E.B. (1958). Religion in primitive culture. New York: Harpers \& Brothers. 

Chapter 5

\title{
Cultural Variations in Parenting Styles in the Majority World Evidences from Nigeria and Cameroon
}

\author{
Esther F. Akinsola \\ Additional information is available at the end of the chapter \\ http://dx.doi.org/10.5772/57003
}

\section{Introduction}

\subsection{Culture and parenting strategies}

From anthropological perspective culture may be defined as a whole complex of traditional behaviour which includes knowledge, belief, art, law, morals, religion and customs, and any other capabilities, and habits, that have been acquired and developed by the human race, as members of societies, and which is successively learned by each generation. In addition culture also consists of learned ways of acting, feeling and thinking, [1, 2]. The implication from this definition is that culture could be learned, acquired, experienced, and transmitted from one generation to another generation, or can be transferred from one place to another through acculturation.

From psychological perspective culture was conceptualised as a dynamic and socially interactive process and as comprising of two components [3]. One component deals with the creation of shared activity which is reflected in the cultural practices of members of the society. The second component deals with the creation of shared meaning which leads to cultural interpretations collectively given to behavioural patterns in the society. The cultural practices are regarded as the material side of culture while the shared meaning represents the symbolic side of culture and the interpretation and evaluation of the world. This perspective signifies the fact that culture is both inside and outside the individual [3].

From cross cultural perspective, two types of cultures have been identified and differentiated into individualistic and collectivistic cultures [4]. From this perspective it is believed that culture shapes people's values and beliefs, and that specific attitudes and values differ between the individualistic and collectivistic societies [4]. 
Individualistic cultures tend to give priority to independence and the pursuit of individual achievement, whereas collectivistic cultures tend to place more emphasis on the individual's contribution to the well-being of the family and the community [5]. The implication here is that there are cultural differences between individualistic and collectivistic societies, and these differences are variations in values that are of particular importance to each society and differential emphases placed upon particular practices in the society $[3,6]$. The cultural values of a society thus shape people's values in that society and consequently their interactions with their children and their parenting styles. This inference is what informed the deduction that in collectivistic countries parents tend to promote values such as helpfulness, conformity, and interdependence within the family [5].

The promotion of different values in different cultures would affect child outcomes in such cultures because each culture would have different goals and expectations of their citizens and children in such cultures would be socialized under different conditions. As such an effective parenting style in one culture may not be as effective as in other cultures. In a study carried out on cultural differences in parenting styles the researchers found cultural differences in effective parenting styles practiced by White American and Asian American families [7]. They found that White American families practiced authoritative parenting which involves support in form of (hugging and praising their children), and control in form of (setting clear expectations and moderate limits). These parental behaviours are also taken as parental warmth and acceptance. In the case of the Asian American families, who are made up of Chinese and Fillipino Americans, it was found that they are stricter in their parenting strategy and exhibit high control over their children and they lack warmth [7]. The researchers found that these Asian American families practice this parenting approach because they believe that control is necessary to parenting and strictness is an attempt to protect their children and not to inhibit them. They found that the Chinese Americans in particular value respect for authority, devotion to parents, emotional restraint (which is developed as a strategy for saving face later in life), and education. They also found that Chinese parents who train their children are very involved with their children's lives and they must have been using these parenting strategies, (e.g. authoritarian parenting strategy + involvement which indicates love), including (physical discipline -which they found difficult to practice in the U.S.), to achieve their goals of parenting which include developing these values in the children. They also found that the Fillipino Americans are interdependent and they depend on each other for support because they value reciprocal relationships. They also value affection and closeness and protection for their children especially their daughters. These values must have also guided their parenting strategies. In addition, it was also reported that first- generation Chinese youth from authoritarian homes do just as well in school as those from authoritative homes indicating that although authoritative parenting may benefit some ethnic groups it is not necessarily more beneficial than authoritarian parenting [7].

Families as social groups are influenced by the context around them and family relationships and parent-child interactions are each influenced by cultural context [4]. Depending on the culture therefore there are differences in child rearing practices. It has also been suggested that if parenting behaviour is consistent with cultural values then children in that culture will accept 
it [8], and if certain goals or expectations or attributes are preferred more in one culture compared to another then parents will likely place more emphasis on those particular attributes that are preferred in their culture for their children to acquire [9]. The implication here is that the culture in which one lives will likely impact on the particular type of parenting style that one uses or practices.

\section{Parenting strategies in Nigeria \& Cameroon}

Baumrind (1971) categorized parenting strategies into three types of parenting style namely authoritarian, authoritative, and permissive parenting styles. She described authoritarian parenting as restrictive and punitive, placing firm limit and control on children with little or no verbal exchange, and is said to be associated with social incompetence and poor communication skills [11]. Authoritative parents put some limits and controls on their children's actions, but they allow verbal dialogue which promotes parental responsiveness, encourages independence, social and cognitive competence, self reliance and social responsibility in the children. In permissive parenting few or no rules and little or no controls are exerted over the children. The children under this parenting style are given complete freedom to make their life decisions and behave autonomously and independently [11]. This type of parenting style is also presumed to be associated with social incompetence and lack of self control $[12,10]$.

In Nigeria, parenting strategies embrace all the three single parenting styles that has been described [10], with emphasis on obedience to authority and compliance with parental instructions [13]. This emphasis arises from the fact that, Nigeria being predominantly a hierarchical and patriarchal nation, the traditional society values respect for elders and authority figures and in particular parental authority in a family where the man is the head of the family. As a result many Nigerian parents demand for obedience to parental authority, and compliance with parental instructions from their children. However many of the parents accompany such demands for obedience and compliance with instructions, with responsiveness, love, care, sensitivity, reciprocal dialogue, and explanations for parental disciplinary actions. The combination of demand for obedience and responsiveness by parents allows Nigerian children to perceive their parents as authoritative some of the time and authoritarian at other times. This inference has been supported by research findings that indicated that authoritative and authoritarian parenting styles as well as their hybrids are significantly practiced by Nigerian parents [14, 13]

In Cameroon, child bearing is highly valued and beliefs and practices concerning child rearing vary by ethnic group. However certain values are commonly held by the ethnic groups. These values include the importance that the Cameroonians attach to learning by example and learning through play. They also attribute importance to observational learning by teaching their children to observe and imitate tasks performed by adults $[15,16]$. It has been reported that the dominant family pattern in Cameroon is the patrilineal and extended or joint family [17]. This family pattern promotes interdependence, and the culture of the society is collectiv- 
istic and communal in orientation [4, 3]. The Cameroon parents (represented by Nso people in this write up, and who live in the Anglophone sector of Cameroon) engage in relationshipsupporting parenting practices. These practices involve parental monitoring of children's health, teaching life skills to the children and stimulating their growth and development [3, pp. 138]. Good parenting to this group of Cameroonians consists of parents taking the lead with monitoring, instructing, training, directing and controlling infants' activities [3]. These parenting practices reflect a collectivistic society with an authoritarian parenting strategy.

On the other hand in a study carried out on cultural differences in parenting and infant's socialization, in which two traditional farming community families ((Cameroon Nso families), \& (India Gujarati Rajputs families)) and one western middle-class families (German families), were compared, it was found that parenting strategies in the two community families promoted communion [18]. Further, it was found that the Cameroonian and Indian infants were exposed to multiple caregivers and social cohesiveness within extended family networks. This finding further affirms the collectivistic and communal nature of the Cameroonian society. However, the results of the study also indicated that the socialisation strategy, used by Cameroon parents with their infants, was more indulgent (permissive) than that of the Indian parents. This second finding tends to portray the Cameroon parents as permissive and not authoritarian. It is however possible that these two parenting styles are actually being practiced by Cameroonian parents.

Deductions made from a study on family structure and juvenile delinquency [17], provided some insight into this possibility. According to these deductions, the traditional Cameroonian culture acknowledges and sanctions the authority of the father over his family but fails to specify a routine childcare role for him. The father therefore represents only an authority figure in the family but distant from his children, with a rigid attitude and emotional-non involvement posture. This father role omission created a gap between the high and lofty status and high esteem accorded the fathers in the culture and their appropriate and qualitative inputs needed for their children's adequate development. In turn this gap was maintained by the societal attitude towards fathers who tend to be tender and nurturing towards their infants and young children, in that such fathers are either seen as effeminate or behaving inappropriately [19]. This societal position created confusion for the contemporary Cameroonian parents who struggle with the conflict between traditional and modern directives regarding parenting [17]. It was also asserted that the values of Cameroonian parents create the conditions that permit children to spend more time within the peer culture and less in the parent-child dyads [17]. As such most toddlers in Cameroon learn more from each other than from their parents or other adults, and the responsibility for the development of toddlers therefore falls less on parents and more on the children themselves or other children within the peer culture, $[17,20$, 21-22].

From this indirect parental influence on the socialization of Cameroon children, it was inferred that Cameroonian parents especially fathers seemed to have evolved from being authoritarian and emotionally distant from their children to being permissive but still emotionally distant, (a situation in which control is now given over to children, with very few rules if any exist at all and these rules are inconsistently enforced, and where pa- 
rents feel helpless or indifferent) [17]. He further stated that while the Cameroonian parents were struggling to preserve the traditional authoritarian parenting stereotype, they have been forced to become "unconsciously permissive" in their parenting style, which is tagged "indirect parental impact on children", [17, 22]. This form of indirect parental influence on Cameroon children has been claimed to be effective, and effective because of a mechanism of self-regulation which exists within the peer culture and which is maintained by the power inherent in the expectations and directives of absent (authoritarian) parents whose direct intervention is no longer needed [22]. In essence the situation in the Cameroonian society seems to be that, in each family, there is the generation of an ambivalent father image which is "domineering" and "inaccessible" and which has "delegated the socialization process" to the peer culture. The deductions made and inferences arrived at, [17] have provided explanation for the dichotomy or ambivalence between the traditional authoritarian parenting stereotype seemingly adhered to by Cameroonian parents [3, pp138] and the prevailing permissive parenting strategy practiced by them especially mothers whose responsibility it is to nurture their infants and young children, [18]. The implication is that Cameroonian parents practice a form of permissive parenting strategy that is peer culture centred and driven by invisible and underlying authoritarian power of parents and promoted early in the children's life by their mothers' permissiveness. It is therefore expected that Cameroonian adolescents and young people would report authoritarian parenting style, permissive parenting style, and authoritarian/permissive parenting style hybrid as the parenting strategies adopted by their parents in bringing them up.

\section{Studies on parenting styles using Nigerian and Cameroon samples}

\subsection{General method}

The design used for the studies reported here was cross sectional. The participants were assessed only once but at different times and different periods and from different locations and different schools. The sampling method used was convenience sampling based on availability of the participants.

\subsection{Parenting style scale used}

The parenting style scale used for the studies being reported here is a 20 - item parenting style scale adapted from the parenting care scale, originally developed by Baumrind, (1971)[10]. The Baumrind's parenting care scale that was available to the researcher and which was adapted consists of 20- items. Seven of the items (7) measures authoritarian parenting style, another seven (7) measures permissive parenting style, and the remaining six (6) measures authoritative parenting style. Response to Baumrind's parenting care scale items is a "Yes" or a "No". An internal consistency alpha coefficient of.86 was reported for this scale.

The adapted parenting style scale used for the studies reported here also consists of 20-items, but which contains items from Baumrind's version and items from Rohner's (1990) acceptance - rejection questionnaire [23]. In this scale, 5 of the items measures permissive parenting style, 
6 items measures authoritarian parenting style while 9 items measures authoritative parenting style. In addition participants' responses to the scale items in the adapted version varied according to the five point Likert Scale from strongly agree to strongly disagree on a scale of 1 to 5. This differs from the responses to the scale items in Baumrind's version which is a "yes" or "no" response.

Examples of the items in the adapted scale include "My parents respects my privacy", "My parents really expects me to follow family rules", "My parents give me a lot of freedom". For the permissive parenting style, the number of items is five. If a respondent is uncertain for all the items his score would be 15. Therefore any score that is higher than 15 is taken as a permissive score. Consequently for authoritarian parenting style (6 items), any score that is higher than 18 is taken as an authoritarian score, and for authoritative parenting style ( 9 items) any score that is higher than 27 is taken as an authoritative score. For this adapted scale, the following correlation coefficients for a 5-week interval test retest reliability analysis were obtained: Permissive $r=0.67$, authoritarian $r=0.35$, Authoritative $r=0.80[24]$.

It is important to note here that the low test retest reliability coefficient for authoritarian parenting items may be explained on the following premise. Since Nigerian children's perception of their parents' parenting styles progresses and shifts towards authoritative parenting as they grow up, a shift in this direction might have occurred between the first test and the retest of the participants to the effect that it lowered the reliability of the authoritarian parenting items and increase the reliability of the authoritative parenting items at the retest point. This shift in perception is more likely because the reliability data was collected on Yoruba participants who tend to perceive their parents as more authoritative than authoritarian as they grow older. The implication then is that the reliability coefficient for authoritarian items may still be lower if samples that are older than the present sample is tested.

\section{Studies on Nigerian samples: Study 1 [14]}

\subsection{Participants}

The participants were made up of 852 secondary school students from Ibadan a city in the South West of Nigeria and Ikom another city in the South East of Nigeria respectively. Of this sample, 585 students were from Ibadan, and 267 students were from Ikom. The students from Ibadan are from the Yoruba tribal group, and those from Ikom are from the Efik tribal group. There were 436 males and 416 females in the sample with their ages ranging between 11yrs and $24 \mathrm{yrs}$, and a mean age of $15.7 \mathrm{yrs}$.

The convenience sampling method which was based on availability was employed in this study. Three research assistants who doubled as secondary school graduate teachers on national youth service assignments were recruited and requested to administer the questionnaires to the students in their respective schools in Ibadan, (South West, Nigeria) and Ikom, (South East Nigeria). 


\subsection{Yoruba tribal group}

Behaviourally, the Yoruba tribal group demands respect for and obedience to authority figures and elders and they tend to believe that children are to be seen and not heard and to do as they are told. At the same time they demonstrate parental responsiveness and warmth by using behavioural and monitoring controls over their children by monitoring where they are, what they are doing and with whom they are because they are more family oriented and they value family integrity and dignity. Although they do not allow parent-child dialogue, they explain and give reasons for their disciplinary measures and actions. In this respect their children may perceive their parenting style as either authoritarian, or authoritative, or a mixture of both.

\subsection{Efik tribal group}

Behaviourally, the Efik tribal group are not as demanding of respect and obedience to authority figures as the Yoruba tribal group. This is because they tend to be more community oriented by organising themselves into community associations and ensuring regular and frequent meetings for cohesion and bonding, and they punish defaulters. The enforcement of community or tribal bonding and involvement may be perceived as authoritarian approach by members of the tribal group. It is therefore expected that young people of Efik decent would perceive the parenting style under which they were brought up as more authoritarian.

\subsection{Procedure}

All the participants were secondary school students in their respective schools. As requested by their teachers, they completed a written questionnaire. The questionnaire contains three sections. The first section is a biographical information form. One of the remaining two sections contains measures of parenting style. Below are results of the parenting style section of the research.

Results:

\begin{tabular}{|c|c|c|c|}
\hline \multirow{2}{*}{ Parenting Styles } & \multicolumn{2}{|c|}{ Sample/Parenting style } & \multirow{2}{*}{$\mathrm{X}^{2}$} \\
\hline & No & $\%$ & \\
\hline Permissive & 15 & 1.6 & \\
\hline Authoritarian & 72 & 8.1 & $2.42^{*}$ \\
\hline Authoritative & 381 & 45.3 & $8.35^{\star}$ \\
\hline Permissive \& Authoritarian & 11 & 1.4 & \\
\hline Permissive \& Authoritative & 13 & 1.4 & \\
\hline Authoritarian \& Authoritative & 248 & 29.8 & $5.41 *$ \\
\hline Permissive/ Authoritarian/ Authoritative & 31 & 3.5 & \\
\hline Undifferentiated & 81 & 9.0 & $2.51 *$ \\
\hline Total & 852 & 100 & \\
\hline
\end{tabular}

* Note: Critical X2 = 1.645, P<.05 Extracted from [14]

Table 1. Distribution of Parenting styles and their hybrids 
In table 1, the highest number of participants perceived their parenting style as authoritative (381 or $45.3 \%$ ). This is followed by the hybrid combination of authoritarian/ authoritative style ( 248 or $29.8 \%$ ). Undifferentiated parenting style hybrid followed with (81 or $9.0 \%$ ), and then authoritarian parenting style with (72 or $8.1 \%$ ). The chi-square values for these proportions are significant at $\mathrm{P}<.05$. These are the parenting styles that had over $5 \%$ representation in the sample studied. These results indicate that adolescents and young people brought up under authoritative parenting style and the hybrid combination of authoritarian and authoritative parenting styles are significantly represented in the sample studied in this research.

\begin{tabular}{lcccc}
\hline \multicolumn{1}{c}{ Parenting Styles } & (Yoruba) & No $\mathbf{5 8 5}$ & \multicolumn{2}{c}{ (Efik) $\mathbf{~ N o = 2 6 7}$} \\
\hline Permissive & No & \% & No & \% \\
\hline Authoritarian & 7 & 0.90 & 8 & 0.70 \\
\hline Authoritative & 44 & 4.90 & 28 & 3.10 \\
\hline Permissive \& Authoritarian & 289 & 34.3 & 92 & 11.00 \\
\hline Permissive \& Authoritative & 5 & 0.70 & 6 & 0.70 \\
\hline Authoritarian \& Authoritative & 4 & 0.40 & 9 & 0.90 \\
\hline Permissive/ Authoritarian/ & 157 & 18.50 & 91 & 11.30 \\
Authoritative & 19 & 2.10 & 12 & 1.40 \\
\hline Undifferentiated & 60 & 6.60 & 21 & 2.40 \\
\hline Total & 585 & 68.66 & 267 & 31.34 \\
\hline
\end{tabular}

Table 2. Number \& Percentages of Participants under each Parenting Style by Ethnic Groups (Extracted from [14])

\begin{tabular}{|c|c|c|c|c|c|}
\hline \multirow[t]{2}{*}{ Parenting Styles } & \multicolumn{2}{|c|}{ Cross River (Efik) No = 267} & \multicolumn{2}{|c|}{ Oyo State (Yoruba) No = 585} & \multirow[b]{2}{*}{$" \mathrm{t} "$} \\
\hline & Mean & Std. Deviation & Mean & Std. Deviation & \\
\hline Authoritarian & 18.73 & 4.52 & 17.57 & 4.89 & $3.29^{* \star}$ \\
\hline Authoritative & 31.52 & 7.28 & 33.07 & 7.05 & $-2.94^{\star *}$ \\
\hline Permissive & 11.04 & 3.87 & 9.97 & 3.41 & $4.09 * *$ \\
\hline
\end{tabular}

Table 3. Means \& Standard Deviations for Participants' scores on Parenting Styles by Ethnic groups df $=849{ }^{* *} \mathrm{P}<.01$ (Extracted from [14])

Results in table 2 under the ethnic groups indicate that more participants of Yoruba decent perceived their parenting style as authoritarian, authoritative, and the hybrid combination of authoritarian/authoritative than participants of Efik decent. The results are: authoritarian: Yoruba -44 or $4.9 \%$, Efik- 28 or $3.10 \%$; authoritative: Yoruba- 289 or 34.3\%, Efik- 92 or 11\%; authoritarian/authoritative combination: Yoruba- 157 or $18.5 \%$, Efik- 91 or $11.3 \%$. 
The analysis presented in table 3 indicated that participants of Yoruba decent significantly perceived their parenting style as more authoritative, less authoritarian and less permissive, while participants of Efik decent significantly perceived their parenting style as more authoritarian, more permissive and less authoritative.

\section{Study 2 [13]}

\subsection{Participants and procedure}

Participants in this study were made up of 352 students from a Private University in Ogun State, and a Federal University in Lagos State, both from the South Western part of Nigeria. The students from both universities were sampled on the basis of availability. They were undergraduate students studying psychology, and they were selected from 100 to 400 level. The ages of the participants ranged from 18 to 32 years. 144 of the participants were males and 208 were females. All the participants were full time students in their respective universities. The participants completed a written questionnaire that contained biographical information section and measures of parenting style, and some selected personality variables. Below are the results for the parenting style measure.

Results:

\begin{tabular}{lccc}
\hline \multicolumn{1}{c}{ Parenting Styles } & No/Parenting style & $\%$ & $\mathbf{X}^{2}$ \\
\hline Authoritarian & 32 & 9.1 & $2.51^{*}$ \\
\hline Authoritative & 215 & 61.1 & $10.37^{*}$ \\
\hline Authoritarian \& Authoritative & 105 & 29.8 & $5.41^{*}$ \\
\hline Total & 352 & 100.0 & \\
\hline
\end{tabular}

* Note: Critcal X2 = 1.645, P<.05 Extracted from [13]

Table 4. Distribution of parenting styles and their hybrid

In table 4 above, the highest number of participants (215, or $61.10 \%)$ fell under authoritative parenting style. This is followed by the hybrid combination of authoritarian and authoritative parenting style (105, or $29.80 \%)$. The next in number is authoritarian parenting style (32, or $9.10 \%$ ). The chi-square values for these proportions were significant at $\mathrm{P}<.05$. From this result, participants brought up under the three parenting styles were significantly represented in the sample studied. This result therefore validates an earlier documentation of the practice of the authoritarian and authoritative parenting style hybrid by Nigerian parents. 


\section{Study 3 [25]}

\subsection{Participants and procedure}

567 primary school children aged between 7 and 16 years selected from four primary schools in Yaba and Surulere areas of Lagos mainland in Lagos State participated in the study. Lagos State is located in the South Western part of Nigeria. The participants were made up of 275 male and 292 females. Three instruments namely, parenting style scale, children social anxiety scale and performance anxiety scale were administered to the children after ensuring that they understood the instructions and what they were expected to do. Below are the results for the parenting style measure.

Results:

\begin{tabular}{|c|c|c|c|}
\hline Parenting Styles & $\begin{array}{c}\text { No/ } \\
\text { Parenting style }\end{array}$ & $\%$ & $X^{2}$ \\
\hline Permissive & 11 & 1.9 & \\
\hline Authoritarian & 13 & 2.3 & \\
\hline Authoritative & 79 & 14 & $3.92 *$ \\
\hline Permissive \& Authoritarian & 19 & 3.4 & \\
\hline Permissive $\&$ authoritative & 37 & 6.5 & \\
\hline Authoritarian \& Authoritative & 273 & 48.3 & 8.54 * \\
\hline Permissive/Authoritarian/Authoritative & 113 & 20.0 & $4.75^{*}$ \\
\hline Undifferentiated & 20 & 3.5 & \\
\hline Total & 565 & 100 & \\
\hline
\end{tabular}

* (Note: Chi-square table values are: (x2 =1.96 P<.05); Extracted from [25]

Table 5. Distribution of parenting styles and their hybrids in the Sample

From table 5 above, out of 565 participants 273 or $48.3 \%$ of the children reported being brought up under the authoritative/authoritarian parenting style hybrid. The chi-square $(x 2)$ value for this proportion is 8.54 and it is significant at $\mathrm{P}<.05$. Similarly out of 565 children studied 79 of them or $14 \%$ reported being brought up under authoritative parenting style. The chi-square (x2) value for this proportion is 3.92 and it is also significant at $\mathrm{P}<.05$. In addition out of the 565 children who participated in this study, 113 or $20 \%$ of them reported being brought up under the permissive/authoritative/authoritarian parenting style hybrid. The chi-square $(x 2)$ value for this proportion is 4.75 and it is also significant at $\mathrm{P}<.05$. These results further confirm that a significant number of Nigerian parents as perceived by their children, practice the authoritarian/authoritative parenting style hybrid. In addition the children in this study perceived a 
significant number of their parents to also be practicing another hybrid, the permissive/ authoritarian/authoritative parenting style.

\section{Study 4 [26]}

\subsection{Participants and procedure}

668 primary and junior secondary school children aged between 7 and 13 years selected from three primary and three junior secondary schools on Lagos mainland in Lagos State participated in the study. Lagos State is one of the States situated in the South Western part of Nigeria. The participants were made up of 281 males and 387 females. The children were administered five measuring instruments namely, parenting style scale, Nigerian Children's self concept scale, self esteem scale, locus of control scale, and sense of competence scale. The measures were administered to the children after ensuring that they understood the instructions and what they were expected to do. In addition the children were guided while responding to the measures by four research assistants employed to assist in carrying out the study. Below are the results for the parenting style measure.

\begin{tabular}{|c|c|c|c|}
\hline Parenting style & No/Parenting style & $\%$ & $\mathrm{X}^{2}$ \\
\hline Permissive & 1 & 0.15 & \\
\hline Authoritarian & 14 & 2.10 & \\
\hline Authoritative & 122 & 18.26 & $4.45^{*}$ \\
\hline Permissive/Authoritarian & 6 & 0.90 & \\
\hline Permissive/Authoritative & 23 & 3.44 & \\
\hline Authoritarian/Authoritative & 410 & 61.38 & $10.48 *$ \\
\hline $\begin{array}{l}\text { Permissive/Authoritarian/ } \\
\text { Authoritative }\end{array}$ & 84 & 12.57 & $3.25^{*}$ \\
\hline Undifferentiated & 8 & 1.20 & \\
\hline Total & 668 & 100 & \\
\hline
\end{tabular}

* Note: Critical X2 =1.96, P<.05; table extracted from[26]

Table 6. Distribution of Parenting styles and their hybrids in the sample

From the results in table 6 above 410 or $61.38 \%$ of the children reported being brought up under the authoritarian/authoritative parenting style hybrid, 122 or $18.26 \%$ reported being brought up under authoritative parenting, and 84 or $12.57 \%$ reported being brought up under the hybrid combination of the three parenting styles. The chi-square values for these three proportions were significant at $P<.05$. The results in table 6 again confirm that Nigerian parents do regularly practice the parenting styles significantly represented in the sample. 
It is necessary to note at this point that some consistencies have been recorded in the outcome of the studies. For example in the first two studies (study 1 and study 2) where the participants were adolescents and young people, the highest proportion of them ( e.g. $45.3 \%, 61.1 \%$ ), reported being brought up under authoritative parenting. This was followed by the authoritarian/authoritative parenting style proportion of $(29.8 \%, 29.8 \%)$ respectively. In study 3 and study 4 where the children that participated in the research were younger, the highest proportion of them reported being brought up under the authoritarian/authoritative parenting style hybrid (e.g. $48.3 \%, 61.38 \%$ ) respectively. The next higher proportion in study 3 is the hybrid that combines the three single parenting styles which is $(20 \%)$, and this is followed by the proportion for the authoritative parenting style (14\%). For study 4 the next higher proportion is for the authoritative parenting which is (18.26\%), and which is followed by the proportion of the combination of the three single parenting styles hybrid. One deduction that can be made from these results is that for Nigerian children when they are young dominantly perceive their parents' parenting styles as a combination of authoritarian and authoritative parenting style. As they grow older they begin to see their parents as more authoritative and less authoritarian. The next study reported below compares the parenting styles of Nigerian parents with that of Cameroonian parents.

\section{Study 5 - Comparison of parenting styles of Nigerian and Cameroonian samples [27]}

\subsection{Participants and Procedure}

The participants were made up of 355 secondary school students from Lagos and Ibadan cities in Nigeria, and 156 college students from Bamenda in Cameroon. There were 221 males and 290 females in the sample and their ages ranged between 13 and 27years.The participants responded to questionnaires on parenting style and sexual attitude. Results for the distribution of the parenting styles are presented below:

From the results in table 7, 151, (42.5\%) Nigerian respondents reported being brought up under authoritative parenting strategy, and 147, (41.4\%), reported being brought up under the authoritarian/authoritative parenting style hybrid. 85 (54.5\%) Cameroonian respondents reported being brought up under permissive parenting, and $49(31.4 \%)$ reported being brought up under the permissive/authoritarian parenting style hybrid. The chi-square values for these proportions are significant at $\mathrm{P}<.05$. These results indicate therefore that the dominant parenting styles adopted by Nigerian parents are the authoritative parenting style and the authoritarian/authoritative parenting style hybrid. Furthermore the results indicate that the dominant parenting styles adopted by Cameroonian parents are the permissive parenting style and the permissive/authoritarian parenting style hybrid.

The results for Nigerian samples in table 7 are consistent with earlier findings in studies (1-4) reviewed above and further confirm the authoritative/authoritarian parenting style hybrid and the authoritative parenting style as the parenting styles being actively practiced by Nigerian 


\begin{tabular}{|c|c|c|c|c|c|c|c|c|c|}
\hline \multirow[t]{2}{*}{ Parenting styles } & \multicolumn{3}{|c|}{$\begin{array}{c}\text { Nigeria } \\
\text { No of Participants }=355\end{array}$} & \multicolumn{3}{|c|}{$\begin{array}{c}\text { Cameroon } \\
\text { No of Participants }=156\end{array}$} & \multicolumn{3}{|c|}{$\begin{array}{c}\text { Total Sample } \\
\text { No of Participants }=511\end{array}$} \\
\hline & No & $\%$ & $\mathbf{X}^{2}$ & No & $\%$ & $\mathrm{X}^{2}$ & No & $\%$ & $X^{2}$ \\
\hline Permissive & - & - & - & 85 & 54.5 & $9.47^{*}$ & 85 & 16.63 & $4.20^{*}$ \\
\hline Authoritarian & 15 & 4.23 & - & 2 & 1.28 & - & 17 & 3.33 & - \\
\hline Authoritative & 151 & 42.5 & $8.11^{*}$ & 1 & 0.64 & - & 152 & 29.75 & $5.40^{*}$ \\
\hline $\begin{array}{l}\text { Permissive/ } \\
\text { Authoritarian }\end{array}$ & 4 & 1.13 & - & 49 & 31.4 & $5.72^{*}$ & 53 & 10.37 & $3.82^{*}$ \\
\hline $\begin{array}{l}\text { Permissive/ } \\
\text { Authoritative }\end{array}$ & 4 & 1.13 & - & 8 & 5.13 & - & 12 & 2.35 & - \\
\hline $\begin{array}{l}\text { Authoritarian/ } \\
\text { Authoritative }\end{array}$ & 147 & 41.4 & $8.01 *$ & - & - & - & 147 & 28.77 & $5.11 *$ \\
\hline Permissive/ & & & & & & & & & \\
\hline $\begin{array}{l}\text { Authoritarian/ } \\
\text { authoritative }\end{array}$ & 13 & 3.66 & - & 3 & 1.92 & - & 16 & 3.13 & - \\
\hline Undifferentiated & 21 & 5.92 & - & 8 & 5.13 & - & 29 & 5.68 & - \\
\hline Total & 355 & 100 & - & 156 & 100 & - & 511 & 100 & - \\
\hline
\end{tabular}

* Note: (Critical value of X2 $=1.96 \mathrm{P}<.05)$ table extracted from [27]

Table 7. Distribution of Parenting styles and their hybrids for Nigeria and Cameroon Samples

parents. From the results in studies 3 and 4 above (tables 5 and 6) it can be deduced that Nigerian parents are evolving by progressing from being authoritarian and authoritative simultaneously to being authoritative and this may be the reason why the authoritarian/ authoritative parenting style hybrid had highest proportions when the children were younger ( e.g. tables 5 and 6), and authoritative parenting style had highest proportions when the respondents were older.

For Cameroonian sample the results in table 7 that indicated that Cameroonian parents are predominantly permissive (e.g. $54.5 \%$ of sample), agrees with Ngale's deduction that the Cameroonian parenting style that puts the responsibility of parenting on the peer culture is permissive and that the stereotypic traditional authoritarian parenting style they so claim to be practicing has become dysfunctional or at best superficial. On the other hand the second dominant parenting style of permissive/authoritarian parenting style hybrid $(31.4 \%$ of the sample) documented in this study, supports the notion of the power inherent in the expectations and directives of absent (authoritarian) parents, the power which enforces and maintain self-regulation within the peer culture, [22]. The implication here is that Cameroonian parents actively practice permissive parenting style as well as the permissive/authoritarian parenting style hybrid. The scores of the participants on the three single parenting styles were analysed and compared. The results are presented in table 8 below: 


\begin{tabular}{|c|c|c|c|c|c|c|}
\hline \multirow[t]{2}{*}{ Parenting Style } & \multicolumn{2}{|c|}{$\begin{array}{c}\text { Nigeria } \\
\text { No of Participants }=355\end{array}$} & \multicolumn{2}{|c|}{$\begin{array}{c}\text { Cameroon } \\
\text { No of Participants }=156\end{array}$} & \multirow[t]{2}{*}{$\begin{array}{l}\text { T calculated } \\
\text { "t" }\end{array}$} & \multirow[t]{2}{*}{$\mathbf{P}$} \\
\hline & Mean & Std. Dev. & Mean & Std. Dev. & & \\
\hline Permissive & 9.76 & 3.43 & 20.30 & 5.61 & 26.05 & $P<.05$ \\
\hline Authoritarian & 17.81 & 5.12 & 20.64 & 3.87 & 6.17 & $\mathrm{P}<.05$ \\
\hline Authoritative & 33.19 & 7.21 & 16.86 & 4.01 & -26.55 & $P<.05$ \\
\hline
\end{tabular}

Table 8. Parenting style mean scores for Nigerian and Cameroon participants (Extracted from [27])

From table 8 above it can be seen that Nigerian participants scored significantly higher than Cameroonian participants on authoritative scale indicating that Nigerian parents are more authoritative in their parenting strategy than Cameroonian parents. On the other hand Cameroonian participants scored significantly higher than Nigerian participants on permissive and authoritarian parenting scale. This indicates that Cameroonian parents are more permissive and authoritarian in their parenting approach than Nigerian parents. However the authoritarian parenting style being practiced by Cameroonian parents are indirect and invisible. The findings also agree with the findings of [18], that reported permissive parenting practices among Cameroonian parents on the one hand and report of Cameroonian parents' belief in and adoption of authoritarian parenting strategy on the other hand [3].

\section{Conclusion}

The importance of studying parenting practices is (i) to determine the nature, and variety of practices that parents adopt while bringing up their children, and (ii) to examine the effectiveness and benefits of such practices. From the reviewed literature, " see [18, 7], and the studies reported here, it can be deduced that parental practices vary from one culture to another culture and such practices reflect the cultural values of the society. Nigeria is a collectivistic and patriarchal society with values such as obedience to authority figures, compliance with parental instructions, cooperation and helpfulness within and outside the extended family systems, communal living and good interpersonal relationship. According to the studies reported here, the Nigerian parents practice dominantly authoritative parenting style and the hybrid authoritarian/authoritative parenting style. Cameroon is also a collectivistic and patrilineal society that values communal living, extended family system and observational learning, learning through play and interaction with peers, and from the findings reported here, the Cameroonian parents dominantly practice permissive parenting style and the permissive/authoritarian parenting style hybrid. Although Nigeria and Cameroon are collectivistic societies, they still practice different parenting styles and the parenting styles being practiced by these two collectivistic Countries must have been effective in achieving their parenting goals. It has been found in a study that young people 
(Nigerians), brought up under authoritative parenting, authoritarian parenting, and the authoritative/authoritarian parenting hybrid were not significantly different in their levels of sense of competence, need for achievement, locus of control, and academic achievement. However participants brought up under authoritative parenting style reported the highest level of self esteem when compared to other parenting styles, [13]. These results indicate that the three parenting strategies are equally effective for Nigerian parents. In the same way it was found that the Nigerian and Cameroonian participants were not statistically different in their restraint, liberal and permissive attitudes towards sexuality issues, and interestingly the Cameroonian participants reported significantly higher judgemental attitude and attitude toward parental responsibility with respect to sexuality issues, [27]. This finding implies that the parental strategies being practiced by Cameroonian parents are effective in achieving their parenting goals. A broader implication of these findings is that parenting styles adopted by a group is a function of the values upheld by the group and the goals of parenting of that group. Besides, a number of studies have demonstrated that different parental strategies work for different groups in different cultural contexts. For example some studies have demonstrated the beneficial effects of authoritative parenting both in individualistic and collectivistic cultures, see [28, 29, 13], while some other studies have also demonstrated the beneficial effects of authoritarian parenting especially in collectivistic cultures, see [7, 30, 31, 13]. Even the permissive parenting style which is associated with negative outcomes, [32], just like authoritarian parenting style, [11], has also been found to be effective in bringing positive child outcomes for Cameroonian parents, [27]. The general conclusion that can be drawn from all these studies is that parenting style as a global construct reflects the quality of parent-child relationships which varies from one cultural context to another and which is driven by the cultural beliefs, values, and practices of the particular culture. As suggested, see [8], when parenting behaviour is consistent with cultural values then the children in that culture will accept it. It therefore follows that in the countries or societies in which authoritative, authoritarian and permissive parenting styles bring about positive child outcomes, parental behaviours must have been consistent with the cultural values of such countries. In addition whether a particular parenting style produces positive or negative child outcomes would depend on the culture within which it is practiced.

Finally it would be interesting if future researchers can explore the possibility of the existence of hybrids of the three single parenting styles in other cultures beside Nigeria and Cameroon which has been documented.

\title{
Author details
}

\author{
Esther F. Akinsola*
}

Address all correspondence to: foluk6@yahoo.com

Department of Psychology, Faculty of Social Sciences, University of Lagos, Nigeria 


\section{References}

[1] Tylor, E.B. Primitive Culture: Researches into the development of mythology, philosophy, Religion, art, and custom 1874.

[2] Taylor, D. "Transculturating TRANSCULTURATION." Performing Arts Journal, 1991;13, 90-104.

[3] Keller, H. Cultures of Infancy. Publisher: New Jersey: Lawrence Erlbuam Associates 2007.

[4] Triandis, H., Individualism-collectivism and personality, Journal of Personality, 69, 907-924 2001.

[5] Darling, N., \& Steinberg, L. Parenting style as context: An integrative model. Psychological Bulletin, 1993; 113, 487-496.

[6] Rogoff, B. The cultural nature of human development. New York: Oxford University Press 2003.

[7] Van Campen, K.S., \& Russell, S.T. Cultural differences in parenting practices: what Asian American families can teach us. (Frances McClelland Institute for Children, Youth, and Families Research Link, 2010 Vol. 2, No 1). Tucson, AZ: The University of Arizona.

[8] Baumrind, D. An exploratory study of socialization effects of black children: Some black-white comparisons. American Psychologist, 1972; 43, 261-267.

[9] Jambunathan, S., \& Counselman, K. Parenting attitudes of Asian Indian mothers living in the United States and in India. Early Child Development and Care, 2002; 172, 657-662.

[10] Baumrind, D. Current patterns of parental authority. Developmental Psychology Monograph, 1971; 4, (1, pt.2).

[11] Baumrind, D. The influence of parenting style on adolescent competence and substance use. Journal of Early Adolescence, 1991; 11, 56-95.

[12] Maccoby, E.E., \& Martin, J.A. Socialization in the context of the family: parent-child interaction. Editor: Mussen, P.H. Handbook of child psychology, 4th edition, vol. 4. New York: Wiley 1983.

[13] Akinsola, E.F. Relationships between Parenting Style, Family Type, Personality Disposition and Academic Achievement of young People in Nigeria. Ife Psychologia: An International Journal of Psychology in Africa, 2011; 19, (2) pp. 246-267.

[14] Akinsola, E.F. Correlation between Parenting Styles and Sexual attitudes of Young People in Nigeria: Comparison of Two Ethnic Groups. Gender \& Behaviour, 2010a; 8 (1), 2771-2788. 
[15] LeVine, V., \& Nye, R.P. Historical Dictionary of Cameroon 1974.

[16] Countries \& Their Cultures - Culture of Cameroon Forum. - Retrieved Friday, 19th October, 2012, from Culture of Cameroon - history, people, clothing, traditions, women, beliefs, food, customs, family.htm.

[17] Ngale, I. F.Family Structure and Juvenile Delinquency: Correctional Centre Betamba, Centre Province of Cameroon. Internet Journal of Criminology, 2009; pp.1-19. Retrieved Friday, 19th October, 2012 from www.internetjournalofcriminology.com

[18] Keller, H., Abels, M., Lamm, B., Yovsi, R., D.,Voelker, S., \& Lakhani, A., Ecocultural effects on early infant care: a study in Cameroon, India, and Germany. Ethos, 2005; 33(4), pp. 512-541

[19] Nsamenang, A. B. A West African Perspective. In Lamb M.E. (ed.): The father's role: Cross-cultural perspective, 1987a; (pp.273-293). Hillsdale, NJ: Erlbuum.

[20] Nsamenang, A.B., Early childhood care and education in Cameroon. In M.E. Lamb, Sternberg, K.J. Hwang,C.P. \& Broberg, A.G. (Eds.), Child care in context: Cross-cultural Perspectives 1992c; (pp.419-439). Hillsdale, NJ: Erlbaum.

[21] Nsamenang, A.B., \& Lamb, M.E. Socialization of Nso children in the Bamenda grassfields of northwest Cameroon. In Greenfield P.M.\& Cocking R.R. (Eds.), Cross-cultural roots of minority child development 1994; (pp. 133-146). Hillsdale, NJ: Lawrence Erlbaum Associates, Inc.

[22] Nsamenang, A.B., \& Lamb, M.E., The force of beliefs: How the parental values of the Nso of northwest Cameroon shape children's progress toward adult models. Journal of Applied Developmental Psychology, 1995; 16, 613-627.

[23] Rohner, R.P. Handbook for the study of parental acceptance and rejection. CT: Rohner research 1990.

[24] Akinsola, E.F. The relationship between parenting styles, personality dispositions and academic achievement of young people in Nigeria. Being a paper presented at 13th European conference on developmental psychology. Jena, Germany 2007.

[25] Akinsola, E.F. \& Arnold Udoka, P., (2013). Parental influence on social anxiety in children and adolescents: Its assessment and management using psychodrama. Psychology: (Special Issue on Applied Psychology), 4, 3A, pp 246-253.

[26] Akinsola, E.F., \& Ojo, A., Parental and personality correlates of self concept in Nigerian children. A paper presented at the ISSBD Biennial Conference held at the University of Alberta, Edmonton, Canada, July 8-12, 2012

[27] Akinsola, E.F. Parenting styles and sexual attitudes of young people in Nigeria and Cameroon: A Comparative Study. Manuscript submitted for publication 2012 
[28] Claes, M., Lacourse, E., Bouchard, C., \& Perucchini, P., Parental practices in late adolescence, a comparison of three countries: Canada, France, and Italy. Journal of Adolescence, 2003; 26, 387-399.

[29] Kaufmann, D., Gesten, E., Santa Lucia, R.C., Salcedo, O., Rendina-Gobioff, G., \& Gadd, R. The relationship between parenting style and children's adjustment. Journal of Child and Family Studies, 2000; 9, 231-245.

[30] Chao, R.K. Beyond parental control and authoritarian parenting style: Understanding Chinese parenting through the cultural notion of training. Child Development, 1994; 65, 1111-1119.

[31] Park, H.S., \& Bauer, S., Parenting practices, ethnicity, socioeconomic status and Academic achievement in adolescents. School Psychology International, 2002; 23 (4), 386-396.

[32] Diaz, M.V., The relations among parenting style, parent-adolescent relationship, family stress, cultural context and depressive symptomatology among adolescent females. Doctoral dissertation, Georgia state University 2005. 
Chapter 6

\title{
Parenting in Amazonian Riverside Context
}

\author{
Simone Souza da Silva Costa, Tatiana Afonso, \\ Thamyris Maués dos Santos and \\ Fernando Augusto Ramos
}

Additional information is available at the end of the chapter

http://dx.doi.org/10.5772/57056

\section{Introduction}

Parenthood is known for its importance in the development of children in different parts of the world. Parental relationships consist of routine actions of care that are necessary for the survival and well-being of the young, including beliefs, values, and expectations in a given culture [1- 6].

Through the journey of daily care, parents and caretakers gradually prepare children with education that is considered important to be inserted into various social contexts, in addition to taking care of the physical and emotional needs of children [4]. Therefore, parenthood involves social practices performed by those who take care of or are responsible for the education of children, serving as examples of values and beliefs. Culture and history also participate in this process $[5,6]$.

What is considered adequate, as well as practices that promote what is considered appropriate in the development of children vary from culture to culture, even within the same country over time history [4]. According to the authors [6] this understanding reflects the contextualist paradigm that challenges the neo-positivist view of the data collected in a given society may be relevant in another, as well as data collected in a particular historical moment are necessarily significant in a period later [6]. In this sense, it is necessary to examine parenting in many social groups.

According to reference [7], the differences observed in beliefs and care practices in different cultures can be described by cultural models that express different methods of parenthood. Parents with high levels of education who live in a city have socialization techniques that are different from those of families with low levels of education who live in the country $[7,6]$. 
In this perspective, the author [3] that made extensive transcultural research, tell us about the differences between the parental practices in terms of cultural prototypes, as being those which can valorize the autonomy within the caring practices, such as situation of the American families, and others that reforce the obedience and the sense of belonging to the group, such as the case of the rural communities. The same way, significant differences are found between the practices of the Minority World (typically represented by the white middle class from North America and Western Europe) and Majority (countries with low human development index) [8]. Such differences take in consideration aspects of the point of view economic and cultural and are evidenced from points such as: the attachment mother-baby, the shared responsibility, the probability of mortality, the size of the family, the roles played by the members of the family and the surrounding community $[8,3]$.

Noteworthy is the fact that studies that compared educational practices between the Minoritary World and poor rural communities in the Majoritary World led to a consensus that parental practices in those countries are a shortcoming [8,3,4].Therefore, parental practices in countries of the Minoritary World are considered more adequate, and such a trend is emphasized by the use of measurement scales and tools for psychological investigation that advocate universal practices [5].

An important topic to evidence is the fact that the studies interested in comparing the educational practices observed between the Minority World and the impoverished rural communities of the Majority World have conducted in a mistaken way to the consensus that the parental practices in those countries are presented as deficient $[8,3,4]$. In this sense, the parental practices present in the countries of the Minority World are taken as more adequate which trend is to reinforce by the use of measure scales and psychological investigation instruments that profess them as universal practices [5].

According to the author [5], more important than the use of such tools is the observation of daily activities and interactions in a given cultural context, which are full of meaning and express the concepts of parental care and how families are connected with the surrounding community $[3,9,10]$. In this sense, the studies by $[1,2,5,3,7]$ are notable. In the case of Brazil, $[11,12,13]$ contribute to the understanding of parenthood in different social groups.

The main interest in studying different cultural communities would, however, focus on the involvement of people in their communities, examining the nature and dynamics of generating individual lives and social practices of the community [3]. In other words, recognize what cultural practices familiar to every social group that permits examining and recognizing the organization, values, visions and social practices that are common and persistent in a given place, at a given social class or social group $[3,4]$

Considering that the roles performed by families are distinct in different cultural communities and in daily care practices, the objective of the present study was to describe the routines of two families who lived in Amazon river regions in the state of Pará, Brazil. These communities are inserted in the Amazonia forest, in which living activities are linked to nature with different degrees of isolation from urban centers. The figure 1 demonstrates this rich and distinctive ecological context. 


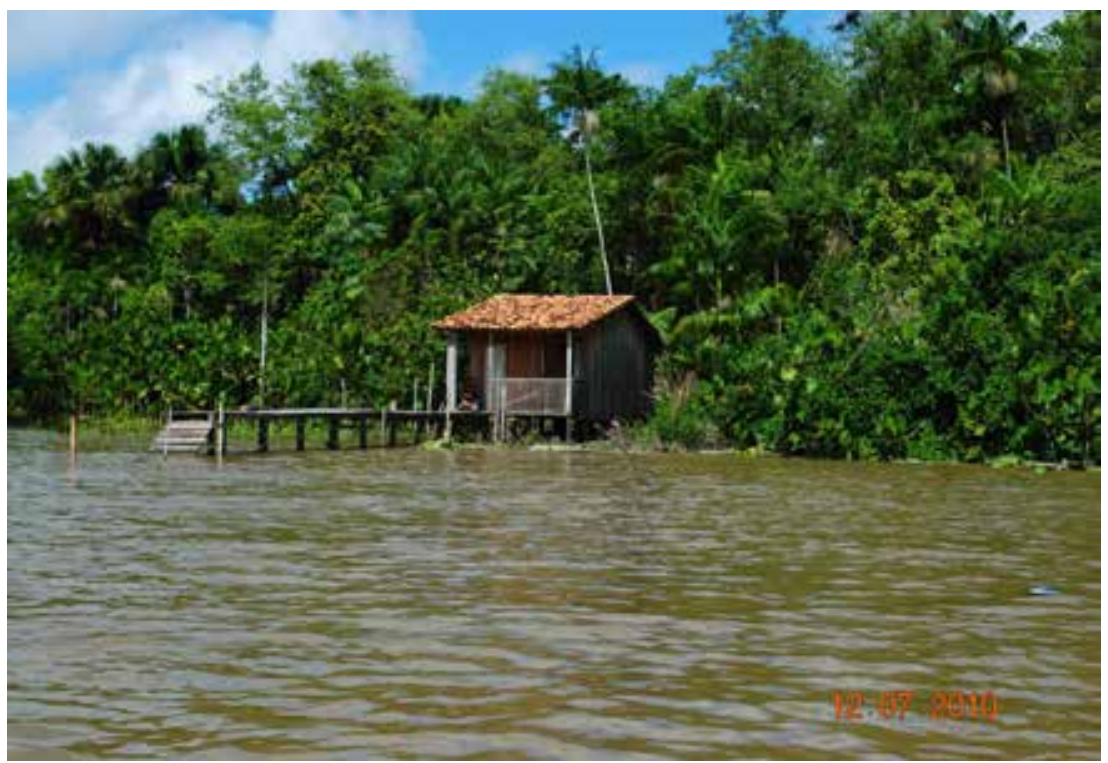

Figure 1. The Amazonian context: the florest and housing typically riverine Amazon (collection of Laboratory Ecology of Human Development)

The Amazon river region consists of a forest rich in biodiversity, possessing $20 \%$ of the freshwater on the planet. Additionally, it represents $50 \%$ of the Brazilian territory and has approximately 11 million people, in which $62.4 \%$ live in the cities and $37.6 \%$ live in the country [14].The riverine area still has energetic resources and wealth and is rich with lush flora and fauna, but it is still considered an economically poor region compared with its natural richness because of its historical lack of infrastructure investment [15].

The riverine communities arranged in the Amazon forest are considered traditional, with occupations associated with waterways, cultures with riverine roots, and small-scale agriculture [16]. Although sharing a way of life and traditional cultures, significant differences are found among these communities in terms of access to public policies and economic development. Thus, riverine communities that live in geographic isolation have more financial stringency and depend more on forest resources and less on commercial interchange. However, in riverine communities near urban centers, people have more accessibility to foreign goods and knowledge, thus incorporating values found in urban areas [17].

With regard to the way of life on the Amazon river, [18] indicated that these populations have an intense relationship with the cycles and dynamics of nature. Residents build their day-today activities and identities based on the river and forest surroundings, with a depth of knowledge about natural dynamics that reflects elaborate strategies for the use and management of natural resources.

Knowledge is orally transferred from generation to generation. From a practical perspective, this is characteristic of such populations, who use symbols and rituals linked to hunting, fishing, and extractive activities. In addition to the practical sense, living with cyclical and 
repetitive periods and guided by the dynamics of nature, distinct senses and meanings are generated in these populations, in which their routine tasks and social relationships develop more slowly [18].

Based on interest in recognizing parenthood within the context such different development, the objective of the present study was to understand parental practices based on the descriptions of the routines of two riverine families and provide evidence of the relationships between cultural activities and the Amazonian context. We highlight the social activities during weekdays and weekends, with parenthood considered based on the daily activities that reflect these families' beliefs.

\section{Method}

This study comprised two periods of data collection, between 2006 and 2010, when visits and interviews were performed in two Amazonia riverine communities that have different geographies and social dynamics. The Araraiana community is located in Ponta de Pedras city in the Marajó archipelago, and the Piriquitaquara community is on Combu Island and belongs to the insular area of Belém. The data form the database of the Laboratory of Ecology of Human Development, which has been conducting scientific studies on the development of Amazonia riverine families.

\section{Sociodemographic contexts}

\subsection{Araraiana community}

The first phase of research was performed in the Araraiana community that belongs to the county of Ponta de Pedras, Marajó Island, PA. The county area is approximately 3,365.30 km², with a population of 20,067 inhabitants. Araraiana is a community geographically isolated from urban centers, with an absence of medical and social assistance see [19].

The Araraiana community, during data collection, consisted of 22 families with 125 inhabitants who lived in stilt houses on the margins of the river. Overall, the houses had three rooms (e.g., living room, bedroom, and kitchen) and were made of wood and straw collected from the forest adjacent to the houses. The houses were distributed along the river with an approximate minimum distance of $300 \mathrm{~m}$ from each other. The houses had no furniture, such as sofas, chairs, wardrobes, or beds. In several houses, it was common to sit and have guests sit on the floor made of wood boards or on benches made of wood close to the walls, typically in the living room and kitchen. The few appliances were wood-burning stoves, radios, and televisions. Because of the absence of local electricity, televisions and radios functioned with batteries for limited periods of time, mainly at night. The houses were essentially occupied by the family, in which the number varied as a function of family type (i.e., nuclear families with one to six residents or extended families with six to 10 residents), whereas multigenerational families were characterized by a higher density (i.e., eight to 12 residents). 
The principal occupation of the men was extraction activities, followed by fishing. Women were housewives or artisans. The river and forest provided food and products for local extraction activities, such as fish, shrimp, game animals, and açaí.

With regard to the availability of health services, no assistance was provided by the state, in addition to the lack of treated water, trash and sewer services, and complex health problems of the population (e.g., stomach and intestinal problems and malnutrition). Similar to the lack of health services, no investments were made in education. The only school in the community was located in the house of a local resident who provided only first-year elementary school education.

\subsection{Piriquitaquara community}

This community belongs to Combu Island, Belém county, Pará state. It has an approximate territorial size of $15 \mathrm{~km}^{2}$ and is approximately $1.5 \mathrm{~km}$ from the capital Belém via waterway. It is characterized by floodplain forest with diversified flower composition in addition to enormous tourist and commercial attractions.

Considered the fourth largest island of Belém county, Combu Island is located at the margins of Guamá River. In this area, approximately 375 families or 1,700 residents live in and are clustered in four communities: Igarapé of the Combu, Igarapé of the Piriquitaquara, "Furo da Paciência," and the margin of Guamá River. The houses are predominantly made of wood and distributed along the margins of the waterways. The social and production structure is organized as a function of local natural resources, such as açaí and cacau harvesting, palm heart extraction, shrimping, fishing, and raising chickens, ducks, and pigs, which constituted the principal local activities.

Access to Combu Island is via waterway on boats that leave daily from different Belém harbors. Such waterways play a strategic role in the transportation of goods and people. Work is performed with activities in the riverine area. Other services, including the marketing of plant and gathering products, health services, schools, shops, and amenities, occur in the urban context.

The houses were made of wood and covered with clay tiles or asbestos. They were built on stilts and located approximately $30 \mathrm{~m}$ from each other. Electricity was not available during data collection, but it became available in July 2011. Treated water was not yet available. Drinking water was obtained from a public tap in Belém and carried in bulk or plastic bottles to the community.

With regard to infrastructure, the community had a health center that was having difficulty with functioning because it was closed for some months due to a lack of physicians, equipment, and medicine. Aside from this health center, a municipal school was located in the igarapé itself, characterized by a typical Amazonia riverine style and made of wood on stilts. The school had two classrooms, a courtyard, a pantry, restrooms, a coordination room, and an external area available for recreation when the river level was low. In this community, almost all of the residents received benefits from the federal program "Bolsa Família” (family grant), a program 
that directly provides income to families depending on health conditions and school attendance.

In the present study, we used two representative families, one from each context (focal families), and the choice was made by considering accessibility and availability.

\section{Inventories}

\subsection{Sociodemographic inventory (SDI)}

We used an inventory prepared by the research group LEDH that presents the following items: identification (name, age, gender, parenthood, and marital status), family income, and house characterization (whether the house was owned, construction type, number of rooms, appliances and furniture, electricity, availability of treated water, and sewage and trash services).

\subsection{Questionnaire of Family Routine (QFR)}

The QFR [20] was used to ascertain the family routine. The QFR consisted of a sheet on which the periods of the day (i.e., dawn, morning, afternoon, and night) were listed in rows and referred to developed activities. The location where the activities took place and the people who were present at the time of the activity were entered in columns, with additional space for other observations. This tool was applied for all participating family members by asking them to describe the activities they performed in a normal day before the interview. Subsequently, we asked the participants to describe their routine on the last Sunday, which was a typical weekend day. The QFR was adapted to the riverine context, which allowed better compatibility with local characteristics [20].

\section{Procedures for data collection and analysis}

The process of insertion of the research team on the islands first involved systematic access to the spaces shared by the family. During the approach of the places frequented by the residents, such as the school, residents' association, and houses themselves, we took care to become part of the population day-by-day by sharing time and activities.

After familiarization with the families, we were able to access their homes with the help of local boaters because of a lack of an address system similar to the ones used in cities given that igarapés are constituted by rivers that intersect, which can cause confusion for those who do not live in the region. After mapping the participants' houses, we began visiting the houses. The observations, talks, and activities were reported in a field diary immediately after the visits.

A statement of consent warranted the rights of the participants, and the ethical committee of the Federal University of Pará approved the study (CAEE - 0016.0.073.000-09). 
The inventories were applied with the parents on previously scheduled days. During the interviews, we asked questions, and the participants were free to respond. The responses were recorded and transcribed. The tabulation of responses into categories of activities was based on discussions and agreement of two of the three researchers who collected the data. In case of discordance, we consulted the project mentors.

\section{Data compilation}

We divided the activities into eight categorical clusters: Economic Subsistence (ES; which refers to all activities that are aimed at obtaining financial resources), Food subsistence (FS; which includes all activities involved in food acquisition and preparation), Domestic tasks (DT; which refers to tasks performed in the house, excluding the kitchen; e.g., sweeping, dish washing, gathering firewood, and fixing the house), Physical care (PC; which refers to tasks related to other people, typically the children; e.g., feeding, bathing, and putting them to sleep), Leisure (L; which refers to activities performed in their free time, including activities for having fun, entertainment, or distraction; e.g., social interaction/talking, watching television, and playing soccer), Play (which represents playful activities with children), and Study (which comprises learning activities in addition to formal teaching).

To facilitate data visualization, we made Diagrams of Family Activities (DFAs) that consisted of forms that allowed descriptions of intrafamilial subsystems in activity performance. The DFAs were composed of a genealogy tree of the groups who shared a house, and the activity subsystems in which the family members were inserted were delineated with lines of different thicknesses, which allowed distinguishing activity categories. Such categories were identified by complementary descriptions around the figure. The DFA allowed knowledge of the tasks and who performed them, the time of the meeting, whether there was close interaction or isolation, and useful reflections on the nature and characteristics of family gatherings [20].

\section{Results and discussion}

\subsection{Contextual characteristics}

The contexts investigated here had similarities and differences that represented peculiar lifestyles in the Amazon river region. Both presented forest vegetation and delimitations from regional rivers, contextual aspects that characterize the disposition of the houses where lands are flooded and promote isolation although they are close to each other.

The authors [21, 22, 23]indicated that this disposition of geographic isolation, marked by the presence of rivers, reveals an important contextual characteristic that is necessary to understand the composition of relationships established in the Amazon river communities. To reach out to neighbors, one must go through natural barriers that restrict exiting from the domestic environment. Therefore, the groups of river families turn to themselves, intensely sharing 
moments of interaction and developing strong affective bonds. Another important aspect is the fact that the families live together in the same community for generations; therefore, relatives mostly comprise the neighborhood. This composition is indicated in figures 2 and 3.

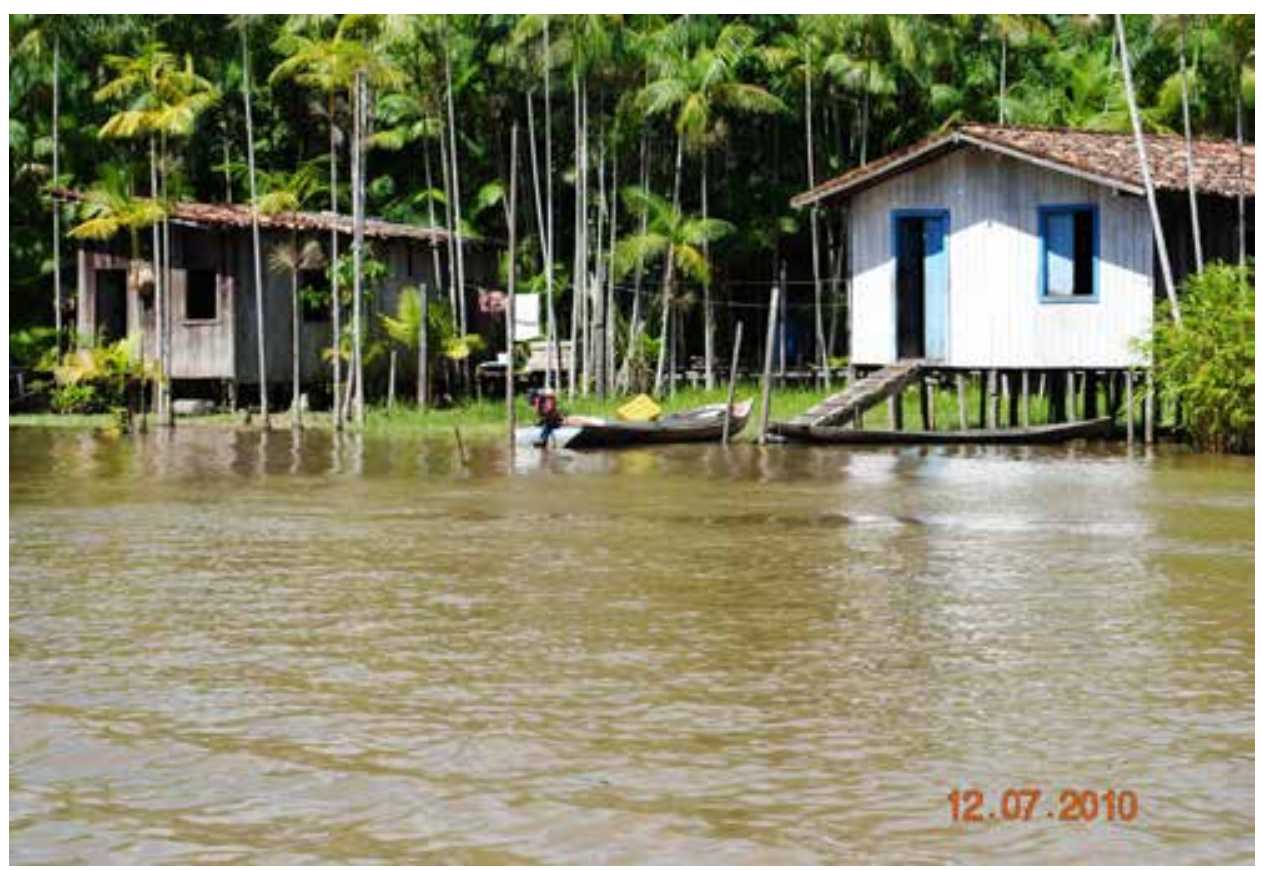

Figure 2. Neighboring houses in the Amazon river context (collection of Laboratory Ecology of Human Development)

With regard to contextual differences, the Araraiana community presented higher isolation and exclusion compared with populations with the same profile. The isolation can be justified based on the following factors: lack of systematic transportation in the region, difficulty contacting river residents, and difficulty accessing media [20]. However, in the Piriquitaquara community, the residents had more access to goods and services, healthcare, and public policies, such as the "Bolsa Família," aspects that softened extreme local poverty.

The contexts also presented similarities in terms of housing characteristics. They were made of wood gathered from the forest, covered with clay tiles or asbestos, and built on stilts. Electricity was nonexistent in the Araraiana community, whereas electricity became available in July 2011 on Combu Island. Therefore, at the time of the study, both communities had no electricity. With regard to basic sanitation, in both contexts, $90 \%$ of the houses had their bathroom in the backyard in a small wooden cubicle with an open bottom where waste was directly dumped on the muddy substrate. During high tide, the river carried the waste away.

In the Araraiana community, only one house had a water well; all of the other residents consumed water directly from the river. Water treatment basically consisted of straining the water with a cloth; thus, the incidence of stomach ailments was epidemic in the locale. On 


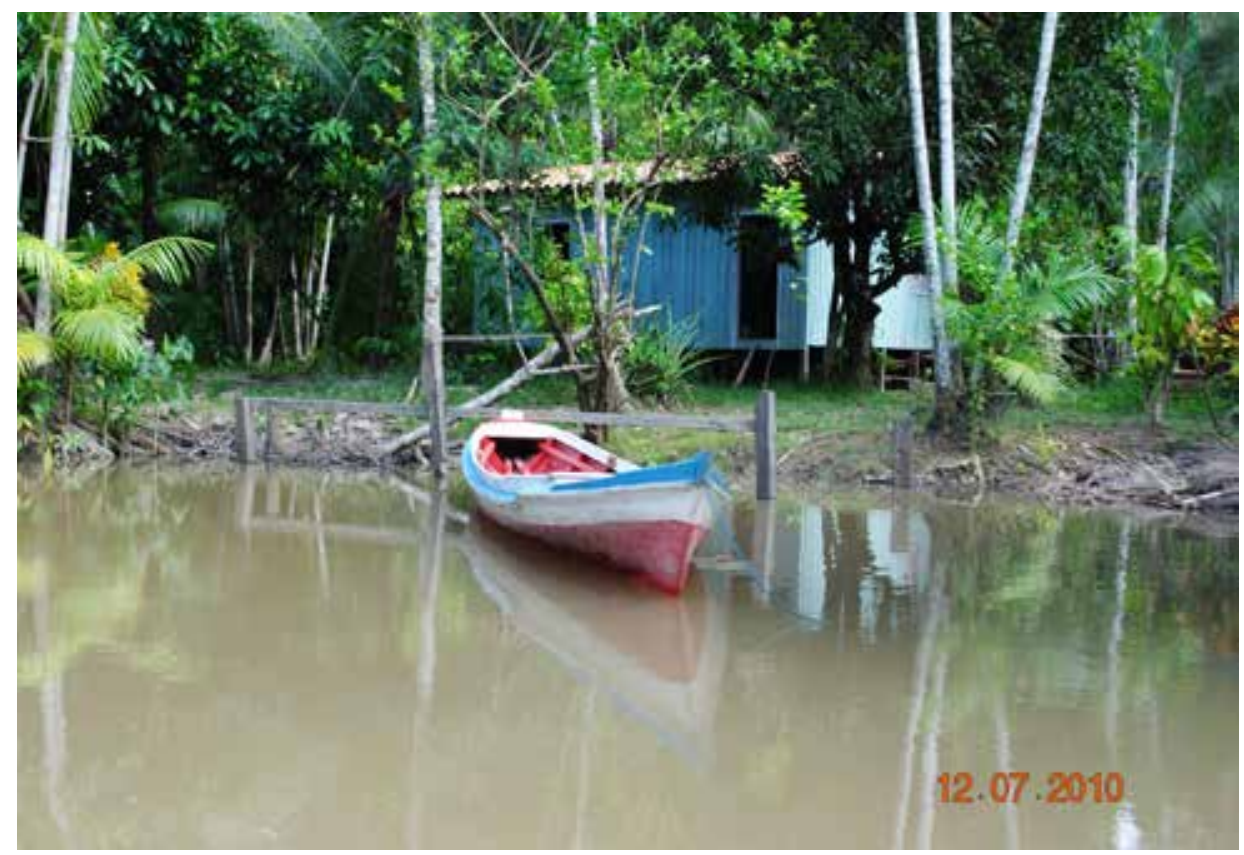

Figure 3. Canoe used to transport families around the house (collection of Laboratory Ecology of Human Development)

Combu Island, drinking water was obtained from a public tap. In Belém, it was carried in buckets and plastic bottles to the community. Therefore, we observed from the daily field records that the community of Combu worried more about water quality compared with the Araraiana community.

With regard to the families' routine, the following examples describe representative families in the riverine contexts studied to help understand parenthood in the context of the Amazon river.

\section{Routine of the Eduardo and Márcia Family, Araraiana Community, Ilha do Marajó, PA}

This is an extended family composed of the couple and their nine children, with the oldest child living in Ponta de Pedras, Ilha do Marajó, PA, with the maternal grandmother. Hence, in the house lived Beto (30), Márcia (age unknown), and the children Paulo (15), Raissa (13), Tamiris (12), Célia (10), Geisa (6), Inaiara (5), Nanci (3), and Ana Paula (1). These are fictitious names, and the ages refer to the time of data collection. The family's living came from gathering açaí, fishing, and extracting other products from the forest.

Eduardo, the father, would wake up early, leave with his boat just after breakfast, and work by hauling and transporting goods. He would return at the end of the morning and afternoon. 
Overall, except in leisure times, which mainly involved playing soccer with his friends, his daily activities were spent alone. Márcia spent her day engaged in domestic tasks and physical care of the eight children with the help of her older daughters. Her routine was restricted to the house and surroundings.

The daughters, Raissa, Célia, Tamiris, Geisa, and Inaiara, went to school early, which was located in the house of one resident of the community (with only one room where all of the children from the community studied). In addition to studying in the same place, the people ate meals and shared several activities together. In the afternoon, they played in the surroundings of their uncle's house, which was next to the school. In addition to helping the mother with DT and FS, the oldest daughters were in charge of taking care of the youngest. At the end of the afternoon, it was common to see them bathe in the river in front of their house.

The oldest son, Paulo, performed activities isolated from his siblings. In the morning, he engaged in ES and SF activities. In the afternoon, he went to school and on his way back he either played soccer with his friends or performed FS activities.

Family gatherings occurred at night when they had dinner together and shared leisure activities. The sleeping place depicted the organization of the family subgroups. The girls slept with the mother in the bedroom. The father slept in the living room, and Paulo, the oldest son, slept in the kitchen. Fig. 4 illustrates the family's routine.

The collected data revealed little sharing of activities between the couple because the division of activities was done by gender. The brothers formed different subsystems (Fig. 1). The oldest brother performed his food subsistence, economic, school, and leisure activities basically alone. Because of similarities in the school schedule with the five sisters (Raissa, Tamiris, Célia, Geisa, and Inaiara), this constituted a subsystem in the school and play time. Because of her important role in activities with her mother, Raissa was isolated from the group of sisters. Geisa, Inaiara, Nanci, and Ana Paula formed an affinity and playing activity subgroup, with Geisa, the oldest sister, playing the role of caretaker. On the weekends, the dynamics of the family changed, with the exception of Márcia who maintained her routine of domestic tasks. The father and son would visit friends in the community, the activities of which often involved eating lunch and having Sunday occupied by leisure activities. The girls played and bathed in the river but did not stop performing the DT, FS, and PC activities to support their mother.

\subsection{The parenting in the family inhabitant of the Araraiana community}

The routine or care practices in this family were strongly linked by gender. The division of tasks and roles between men and women consisted of distinct status occupied by the spouses. The mother's role was to maintain the family through domestic tasks, such as taking care of the children and the family environment, cooking, plant cultivation, and raising animals. The father had the role of provider, taking care of economic activities and food subsistence. Thus, we did not see a time when the father performed activities that were directed at taking care of the children or living with his daughters. The division by gender allowed and encouraged the closeness of the father with the older son and almost totally restricted a closer relationship with the daughters. 


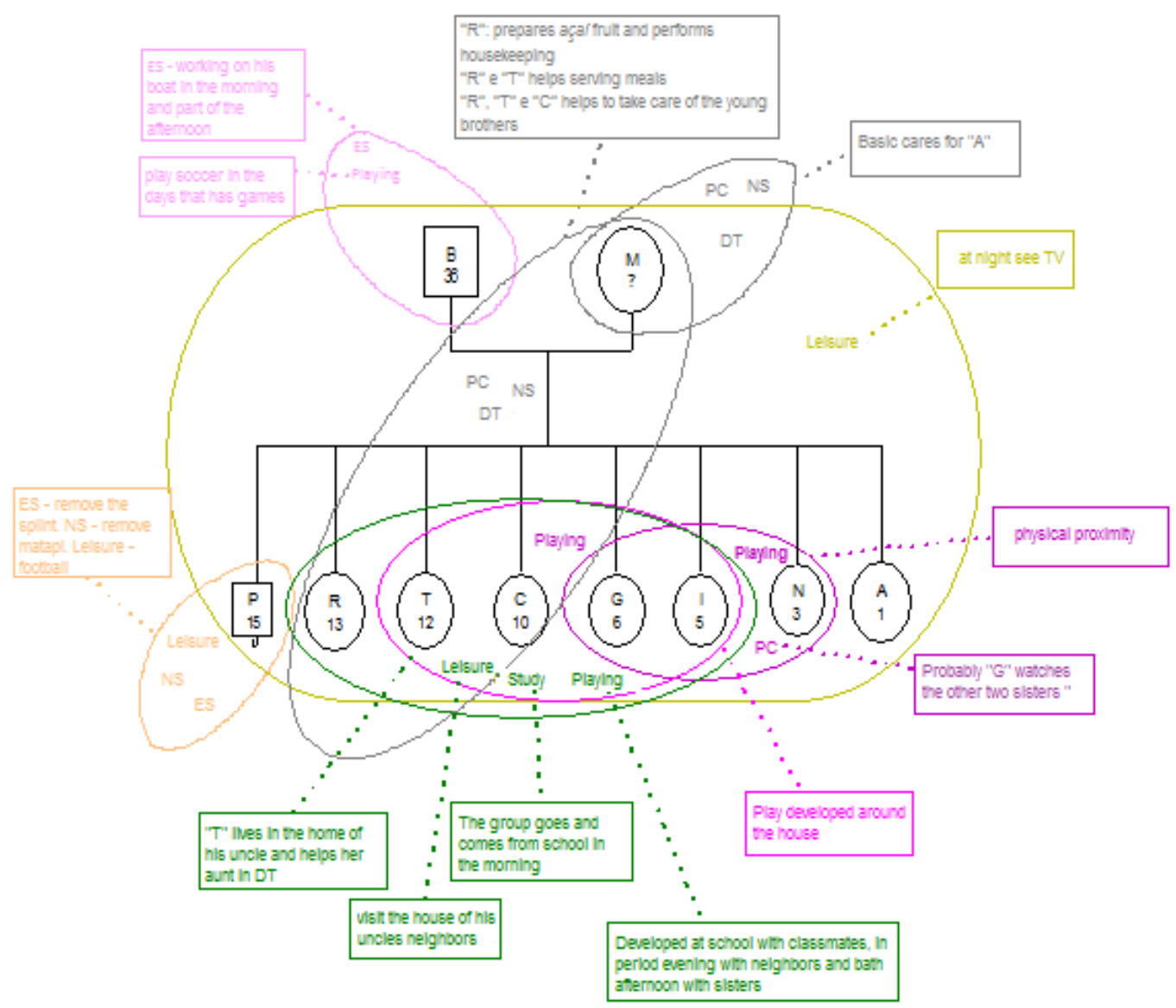

Figure 4. Activities/tasks performed and subsystems involved in the B/M family during weekdays.

Another important aspect related to parenthood concerns the fact that this community presented high incidences of extended families, which is consistent with a survival strategy of families in the rural context that has been present in Amazonia for centuries [16]. This occurs when the source of income is linked to extractive work. It is expected that several children would help with ES activities.

Consistent with this contextual characteristic, in the traditional model adopted, the oldest daughters were encouraged to learn, beginning at early ages, to perform FS and DT activities, stay with their mother all the time, and restrict their relationship networks to the domestic environment. Therefore, they precociously developed roles in which they were allowed to take care of the young and guide them in education and insertion to the surrounding community. This type of brotherly relation, marked by the care common in this community, differs from urban contexts where brotherly relations are more often conflicting, given that the cultural prototypes emphasize individuality and low obedience $[3,5,6]$. 
Being prepared since childhood for domestic tasks, the traditional riverine women get married during adolescence, as opposed to the current urban perspective. Academic education does not appear to be important. Instead, education that ensures marriage and family maintenance is viewed as more important. In fact, in traditional societies, marriage is necessary for survival, and the woman's social role is to be mother and wife, such as in some communities in Oriental Africa $[9,3]$.

In addition to the gender patterns that structure social organization and parental practices, the isolation status of the riverine families is also taken into consideration. The distance and poor access to services impose relationship barriers that make bond formation with other parts of the community difficult; thus, the daily routine has been maintained in a traditional way for centuries.

For comparison purposes, below we present data on the family who resided on Combu Island, an Amazon river region that is close to the capital Belém and not considered a typically traditional community, although it maintains characteristics of the Amazon river region.

\section{Family Routine João and Vânia - Piriquitaquara community - Combu Island}

This remarried family was composed of João, the father (41), Vânia, the mother (32), the adolescents Maura (14) and Alexandre (17), and the children Laís (8) and Amanda (3). These are fictitious names, and the ages refer to the time of data collection. The couple has lived together for 9 years. Laís and Amanda are the biological children of the couple, the latter of whom has Down syndrome. The others are Vânia's children.

The family lived with a fix income composed of João's salary. He worked as a boater hired by Belém city to transport students and teachers of the school located a few meters from his house and from "Benefício Assistencial de Prestação Continuada BPC - LOAS" because of the daughter with a deficiency. Additionally, the children relied on the benefits of "Bolsa Família" (i.e., a program that involves the direct transfer of income to benefit poor families) because they met the health and education requirements that are necessary for this federal program.

All of them would wake up early. João, Vânia, and Alexandre left to gather açaí (ES). Upon returning from the forest, João went to his boating job. Maura prepared breakfast (FS), along with the younger sisters. Alexandre went to "Porto da Palha" to negotiate the selling of açaí. Maura remained at home to help with DTs, and Laís went to the school located next to their house. However, because of the terrain flooded by the river, the shortest route was by boat.

Vânia typically was found at home with the youngest daughter performing DT and PC activities. However, twice per week, the husband took her by boat to the capital to go to the hospital for therapeutic care of her deficiency, which was sometimes done with the help of Maura. Thus, the family organization was adequate for the routine to address the needs of the daughter with Down syndrome. 
Vânia concomitantly performed the SF, DT, and PC activities of Amanda. Around noon, the other family members returned home for lunch. Before eating, Maura took a bath in the river with Amanda during moments of PC and L. After lunch, Alexandre and Maura went by boat to the capital to study in a state school. At the beginning of the afternoon, João transported the students of the afternoon period. Vânia took care of the PC activities of Amanda and Laís, the principal partner of the youngest daughter. At night, everybody performed activities linked to L.

The distribution of the members during sleep followed a similar distribution as the family of the Araraiana community, in which all of the daughters slept in the only bedroom, and the parents and oldest son slept in the living room.

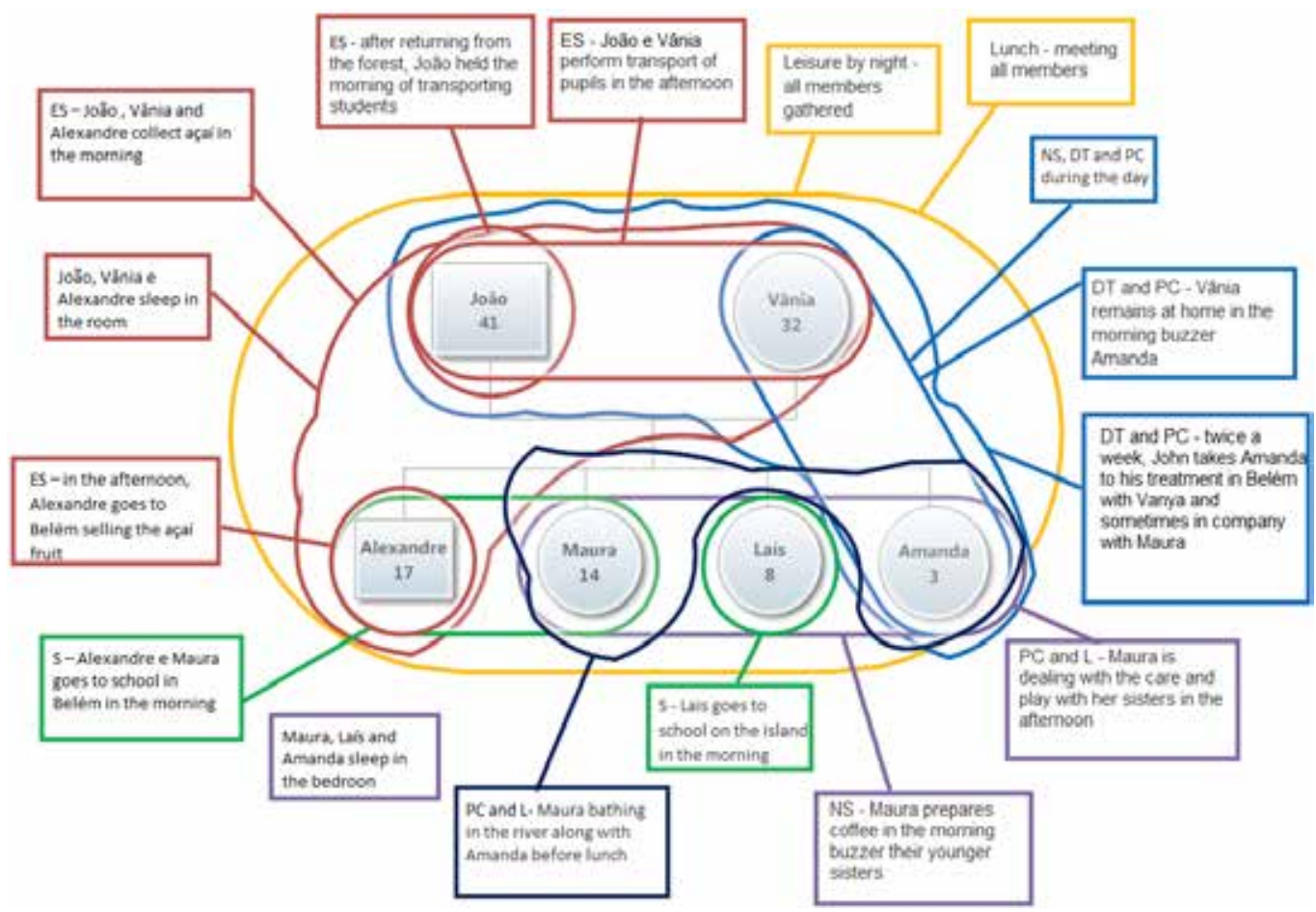

Figure 5. Activities/task performed and subsystems involved in the J/V family during weekdays.

During the weekends, the family went on a boat trip to Vânia's mother's house, a place in the metropolitan region of Belém where most of the relatives lived.

\subsection{Parenthood in the family who lived in the Combu community}

In this community, the participating family presented a way of life with some characteristics common to traditionally isolated families, such as a strong familial bond, which is considered a survival strategy among families who live in the forest [16]. However, because they were 
directly influenced by the urban environment, we found different characteristics compared with traditional families, which is reflected by the speech of the matriarch (Vânia) who, although she is responsible for the house organization and care of the children, presented herself as the family leader who was responsible for day-to-day decisions. Thus, the father, despite being the provider, was not considered the family leader. This posture highlights the flexibility of gender division in traditional communities.

Another important aspect to be emphasized is the fact that the children were able to finish their education in the capital because only up to the fifth year of elementary school (Cycle II) is provided on the island. Thus, we observed from the collected data that significant changes were introduced with regard to the children's beliefs about work, the future, and family. The daughters were allowed to study in the capital. Although they continued to perform routine domestic tasks, they spent more time in school and were encouraged to study and be prepared for paid work in the cities. Thus, marriage was no longer the main goal of the teenagers.

Another important point concerns the detachment of the father from the domestic environment. [3] indicated that the occupational roles marked by gender specify that men be engaged in activities that require physical strength and detachment from the home. In the case of riverine families, separating activities and social relationships between boys and girls is common. A boy's job is to help gather açaí (an Amazonian fruit base of their diet), process it, prepare it, and sell it, in addition to hunting and fishing. The girls should stay around home, and their learning is directed to domestic tasks that do not require high physical effort and do not put them in situations of risk, such as falling and snake bites.

With regard to fraternal subgroups, we observed the same pattern as in traditional Amazonian river families. Siblings of the same sex spent most the time together. The oldest, the majority of which were girls, were responsible for taking care of the young. The oldest, when not at school, helped the adults with domestic tasks, açaí gathering, and fishing. They were also seen at different times playing or bathing in the river.

Thus, the Piriquitaquara community consists of intermediate characteristics between two welldefined contexts: urban and traditional Amazonia riverine. The incorporated family inherited the traditional way of life, combined with influences from the capital. They even relied on a set of services made available by the state and city, such as education, healthcare, and work.

However, although Combu Island is considered a peculiar region from a cultural standpoint, it was composed of a peripheral scenario of strong local economic impoverishment, a common characteristic of all Amazonia riverine communities. Thus, the families studied herein were representative of hundreds of Amazonia riverine communities that survive by gathering forest products within the context of poverty.

\section{Final considerations}

The present study found that the participating families were similar because they shared the same culture, based on knowledge and familiarity with the Amazon forest, and could be 
distinguished based on gender social roles. Both the father and mother had their roles previously defined in the familial environment and surrounding community. Thus, the parental practices were different from those in urban centers and were more similar to rural communities because they were based on cultural prototypes aimed at the division of daily activities between parents and children and obedience in fulfilling domestic tasks, see [3].

The children spent most of their time engaged in activities performed with siblings, and the presence of the parents was not common during these times. The time shared between the father, mother, and children only occurred through daily activities that were directed at the learning necessary to fulfill domestic tasks (e.g., SF, ES, and DT). The parents did not stay busy with the children. The mothers, despite always being present in the domestic environment, kept away from the children, and this trend increased as the children aged. The older children, normally girls, delegated the responsibilities of taking care of the young (i.e., CT).

The fact that the parents did not directly take care of the children does not mean that they were not concerned about the children's well-being or development. However, the concerns were more linked to obtaining food from the river and forest to ensure family survival. The paper of [6] indicated that what the parents do or do not do only makes sense if the specificity of the context where they are inserted is understood.

Living in the middle of the Amazon forest requires that the Amazonia riverine parents' actions are linked to subsistence and the practical direction of daily activities that certainly are unknown in urban contexts. Thus, although parental behavior is considered a task of universal development, the nature of this development is cultural [3,7]. Therefore, any kind of judgment about the best practices for children's' development can only be made by considering the values and beliefs of each specific group [6]. No parental practice should be evaluated in isolation, and there is no cultural standard that is better or worse for human development $[5,6]$.

With the central objective of providing visibility of riverine communities, the present study sought to understand parenthood in such contexts, challenging assumptions that are considered universal with regard to parental care. Moreover, our goal was to compare families in transition communities. According to [3], this helps to better understand how communities are transformed over time based on contextual changes and parental needs to provide essential care for children in an ever-transforming world.

The Piriquitaquara community on Combu Island can be considered a community in transition [3]. For many years, it stopped living exclusively in a traditional way. The closeness with urban centers located on the other side of the river influences the way of life of its residents who participate in social institutions that are present in the cities, sharing commercial exchanges and absorbing typically urban values and beliefs.

The parental practices also adapted to these changes, but this does not mean that they became practices toward autonomy, which is common for parents in urban contexts. However, they no longer reflect the totally prototypical interdependence of rural communities. Something is changing. Some indicators of this transformation have arisen from the flexibility of the maternal role because the mother in the family studied herein was the leader who made the family's decisions. Even the children, including the girls, were encouraged to continue their education in the urban context. 
We conclude that the status of social exclusion in riverine people and the difficulties of their routine are related to the fact that they have stayed in the Amazon forest for such a long period of time. Their routine expresses a way of thinking about parenthood in a specific way, which can cause a series of difficulties linked to health, education, and development, which can and should be remedied by federal and local public policies. Therefore, the present study also sought to make Amazonia riverine communities more visible. The lack of public policies directed toward riverine citizens impedes the quality of life in their particular environment.

Notable is the relevance of the present study and several other previous studies developed by the Laboratory of Ecology of Human Development, which provided information about Amazon riverine communities that are separated by rivers from the urban centers of the cities to which they belong. Therefore, we seek to contribute to the development of public policies that are compatible with the social organization and symbols of their social groups to improve the quality of life of these populations that are isolated and impoverished.

\section{Acknowledgements}

We thank CNPq National Council for Technological and Scientific Development for the provided funding. In addition, we thank to all the members of Laboratory of Ecology Development (LED) that collaborated at different moments, but intensely collecting the data presented here. Our thanks go to Leila Assef Mendes, Daniela Castro Reis, Sara Danielle Baia da Silva, Lorena Santos, Daiane Gasparetto, Eline Monteiro, Katia Carvalho, Viviam Rafaela Barbosa Pinheiro Freire, Júlia de Almeida Roffé Borges, Leandro Cavalcante Lima, Maria Elizabeth Costa Araújo, Suzane Santana Lima dos Santos and external collaborators Julia Bucher-Maluschke and Silvia Helena Koller.

\section{Author details}

Simone Souza da Silva Costa*, Tatiana Afonso, Thamyris Maués dos Santos and Fernando Augusto Ramos

*Address all correspondence to: symon@ufpa.br and symonufpa@gmail.com

Graduate Program in Behavior Theory and Research, Laboratory of Ecology Development, Federal University of Pará, Belém, Pará, Brazil

\section{References}

[1] Valsiner J. Human development and culture: the social nature of personality and its study. Lexington, MA: Lexington Books; 1989. 
[2] Suizzo M. French and American mother's childrearing beliefs: stimulating, responding, and long- term goals. Journal of Cross-Cultural Psychology 2004, (35), 606-626.

[3] Rogoff B. A natureza cultural do desenvolvimento humano. (R. C. Costa, Trad.). Porto Alegre: Artmed; 2005.

[4] Piccinini CA., Alvarenga P. Maternidade e Paternidade: A parentalidade em diferentes contextos.São Paulo: Casa do Psicólogo; 2012.

[5] Tudge JRH. The everyday lives of young children: culture, class and child rearing in diverse societies. New York: Cambridge University Press; 2008.

[6] Tudge JRH., Freitas LB de L. Parentalidade: uma abordagem ecológico-cultural. In: Piccinini CA., Alvarenga P. (ed.) Maternidade e Paternidade: a parentalidade em diferentes contextos. São Paulo: Casa do Psicólogo; 2012.p 171-196.

[7] Keller H. Cultures of infancy. Mahwah, NJ: Lawrence Erlbaum Associates; 2007.

[8] Kagitcibasi C. Family and human development across cultures: A view from the other side. Hillsdale, NJ: Lawrence Erlbaum; 1996.

[9] Harkness S., Super C M. Parents' cultural belief systems: Their origins, expressions, and consequences. New York: Guilford; 1996.

[10] Macarini SM., Vieira ML. Crenças e Práticas Parentais: uma análise transcultural integrando biologia e cultura. In: Moreira LV de C., Rabinovich EP. (ed.) Família e Parentalidade: olhares da psicologia e da história. Curitiba: Juruá; 2011.

[11] Ruela SF., Seidl-de-Moura, ML. Um estudo do nicho de desenvolvimento de um grupo de crianças em uma comunidade rural. Psicologia em Estudo, 2007, 2 (12), 315-324.

[12] Kobarg AP., Vieira ML. Crenças e práticas de mães sobre o desenvolvimento infantil nos contextos rural e urbano. Psicologia Reflexão e Crítica, 2008, 3 (21), 401-408.

[13] Vierira ML., Seidl-de-Moura ML., Lordelo ER. Brazilian mother's beliefs about childrearing practicess. Journal of Cross-Cultural Psychology, 2010, (41), 195-211.

[14] Instituto Brasileiro de Geografia e Estatística (IBGE) HTTP://www.ibge.gov.br. (Access in April 2011)

[15] Castro J C. Cidade e Cidadania In A Amazônia e a Crise da Modernização. Belém, Museu Paraense Emílio Goeldi; 1994.

[16] Trindade Jr SC., Amaral MDB. Cidades ribeirinhas na Amazônia: uma apresentação do tema. In: Trindade Júnior SC., Tavares MG da C. (ed.) Cidades Ribeirinhas na Amazônia - mudanças e permanências. Belém: EDUFPA; 2008. p 9-12.

[17] Reis DC., Araújo MEC., Santos SSL., Silva SSC., Pontes FAR. Araraiana e Combú: um estudo comparativo de dois contextos ribeirinhos amazônicos. Temas em Psicologia (no prelo). 
[18] Cruz V do C. O rio como espaço de referência identitária: reflexões sobre a identidade ribeirinha na Amazônia. In: Trindade Júnior SC., Tavares MG da C. (ed.) Cidades Ribeirinhas na Amazônia - mudanças e permanências. Belém: EDUFPA; 2008, p49-70.

[19] Silva SSC., Lima LC., Pontes FAR., Bucher-Maluschk JSNF., Santos TM. Qualidade Conjugal: Estudo de Caso de Ribeirinhos na Amazônia. Revista Interinstitucional de Psicologia, 2011, 4 (1), 50-59.

[20] Silva SSC., Pontes FAR., Santos TM., Maluschke JB., Mendes LSA., Reis DC., Silva SDB. Rotinas familiares de ribeirinhos amazônicos: Uma possibilidade de investigação. Psicologia: Teoria e Pesquisa, 2010, 26 (2), 341-350.

[21] Silva SSC.Estrutura e Dinâmica das relações familiares de uma comunidade ribeirinha da região amazônica. PhD thesis. Universidade de Brasília, 2006.HTTP:// www3.ufpa.br/led/(Access in March 2010).

[22] Mendes LSA., Pontes FAR., Silva SS da C., Maluske JB., Reis DC., Baia-Silva SD. Inserção ecológica no contexto de uma comunidade ribeirinha amazônica. Interamerican Journal of Psychology, 2008, 42, 1-10.

[23] Afonso T., Silva SSC., Pontes FAR., Koller SH. O uso do diário de campo na inserção ecológica em uma família de uma comunidade ribeirinha amazônica. Revista Psicologia \& Sociedade (no prelo). 
Chapter 7

\title{
Socialization Goals of Mothers and Grandmothers of Children in Institutional Shelter Situation in the North of Brazil
}

\author{
Lília lêda Chaves Cavalcante and \\ Celina Maria Colino Magalhães \\ Additional information is available at the end of the chapter \\ http://dx.doi.org/10.5772/57328
}

\section{Introduction}

The rise of parenthood as an important study field nowadays reveals contributions of research in psychology, sociology, and anthropology areas along with its interfaces (Piccinini \& Alvarenga, 2012).The increase of studies on this theme, and its type of expression in different child developmental contexts, is associated to the understanding that this is a social and culturally organized process.

Parenthood may be defined, broadly, as several activities with the purpose of assuring the child's survival and development, so he/she may grow up in a safe and protected environment (Barroso \& Machado, 2011). In such conditions, the child is expected to benefit from material and emotional comfort, in addition to receive motivation to autonomy (Maccoby, 2000). Consequently, among other tasks imposed to parenthood, maybe the most important one is the challenge for a generation (parents) to prepare a younger generation (children), possibly being helped or replaced by a previous generation (grandparents), with the purpose to make the child able to face risky situations, and socioeconomic and psychosocial difficulties along the developmental pathway, assuring its survival and independence (Barroso \& Machado, 2011).

Parenthood is a socially built category and its conceptual definition tends to emphasize the importance of subjective impressions (Virasiri, Yunibhand \& Chaiyawat, 2011) and/or the importance of eco-cultural conditions characteristic of certain developmental contexts (Keller, Voelker, \& Yovsi, 2005). That is because the conceptions and practices that define it vary across 
cultures, along with individual and family beliefs and moral values which constitute parental ethnotheories and the socialization goals related to it (Keller, Voelker \& Yovsi, 2005).

Several researches have investigated, so far, the role of culture on the formulation of this concept (Harkness \& Super, 1996; Kagitcibasi, 2005), besides such researches have highlighted the role cultural beliefs have on its delimitation. However, even though the cultural differences have been pointed out on the parenthood process, it is not possible to disregard the resemblance of how parents plan socialization strategies and educational practices that, according to their point of view, facilitate the survival of its offspring and their preparation for a more independent life (Keller et al., 2005)..

In the case of human babies, there are enough evidence that primary care have a clearer survival value than in other species. The processes involved in parenthood are vital for their survival. They are performed by parents through functional activities, that direct children towards self-improvement, because they belong to a species that has been beneficiated from social learning and cultural transmission on its evolutionary process. In accordance to Kagitcibasi (2005), generation after generation parents are expected to grant the offspring survival and their intellectual, social, and emotional autonomy, but certainly on the molds recognized and reckoned by the culture in which they are inserted.

Some studies (Keller, Voelker, \& Yovsi, 2005; Mimi McEvoy, Lee, O’Neill, Groisman, RobertsButelman, Dinghra \& Porder, K., 2005) have demonstrated that parenthood is linked to a set of cognitions and parental practices that might be distinguished or similar, depending on the meaning given by the context they live and the activities they do for the child socialization. In these terms, parenthood may and must be investigated by the confluence of sociocultural and psychological processes present on the termed socialization goals (Diniz \& Salomão, 2010).

Socialization goals refer to, according to Moinhos, Lordelo e Seidl-de-Moura (2007), what parents expect their child to be in the future and what they imagine it must be done to achieve this purpose. They are related to how parents guide their children in attaining the tasks imposed by the development, based on styles and parental practices that are particular from the individual or family, but always in agreement to cultural beliefs and moral values that are socially instituted.

The studies performed by Keller, Lamm, Abels, Yovsi, Borke, Jensen et al. (2006), but also Zucker e Howes (2009), discuss the practices used for raising children that represent a certain cultural model and parental conviction about the best way to take care and educate children. In the first study, the researchers used a questionnaire with ten socialization goals, from which five were in reference to preparation for autonomy, the others were of relational aspects. The researchers interviewed mothers from different cultural contexts, hence, who had grown up under different influences of beliefs that emphasize autonomy and/or interdependence in the child socialization. The participants were asked to give their opinions on which of the goals presented could be reached by three-year-old children, as for example, developing selfconfidence (autonomous model), and obeying older people (rational model). The results show that among mothers the autonomous-relational model was prominent, which represents an intermediate position, which means that sometimes they were sure of the children's ability to 
accomplish the goals in the expected period, other times they questioned their ability for that. This and other results suggest that several social changes are leading families (mainly those that live in urban contexts with educated population) to review parental roles and the way of living, reflecting on how parents think the child socialization, which are presumably important for preparing children for future achievements.

In the same way, Leyendecker, Harwood, Lamb e Sholmerich (2002)investigated the socialization goals stated by Latin mothers that migrated to the United States and other American mothers with European American backgrounds, as well as their evaluation of daily situations considered desirable or undesirable for accomplishing such goals. The researchers used a questionnaire composed by questions about the socialization goals they define for their children, the answers were categorized fivefold: Self-maximization (SM), Self-control (SC), Emotionality (E), Social Expectancy (SE), and Proper Demeanor (PD). The results show that Latin mothers emphasize qualities that underline the goal of having children that demonstrate proper demeanor (which works as social approval). On the other hand, American mothers with European American backgrounds emphasize their ambition in terms of their selfmaximization and self-control.

In Brazil similar studies were performed in the last two decades in different states: Bahia (Moinhos et al. 2007), Pará (Silva \& Magalhães, 2011), and Santa Catarina (Westphal et al., 2011). The results demonstrate that the most common socialization goals represent the characteristics of the cultural environment the caretakers live. The results also indicate how complex it can be the challenge of considering a single cultural context of parenthood that represents the Brazilian context, taking into consideration that from the North to the South of the country it is noticed a predominance of autonomous-relational cultural model. Despite the fact that such model is typical of the profound social transformation happening in recent years, this model cannot be considered homogeneous, for the reason that studies have revealed different settings of socialization goals and strategies due to particularities of the socio-cultural context where the investigations were performed.

In a study that involved 350 mothers from five demographic regions of Brazil Moura, Lordelo, Vieira, Piccinnini, Siqueira, Magalhães et al (2008) analyzed differences and similarities in the definitions of socialization goals. The data were collected through and instrument elaborated by Harwood et al. (1999), with the aim of identifying the qualities mothers would like their children to have when adults. According to the results, most Brazilian mothers tend to prioritize the self-maximization goals, which may be due to cultural patterns that value the autonomy and independence in the children socialization process, in addition to those that lead to the development of goals that emphasize the importance for the children to be raised in a way to adapt to the social expectations of families and/or the group in which they live, strengthening the value of interdependence and group belongingness.

According to Para Kagitcibasi (2005),, the responsibility attributed to parents of making the children more autonomous since early childhood, along its developmental pathway, certainly depends on the level of influence of cultural models on the setting assumed for parenthood on each society and time. In this sense, the socialization goals may highlight the value cultural 
models have that appreciate the independence and/or the interdependence in the children socialization, having different weight on its development, in different scopes.

Therefore, it is supposed that if it is true that the societies characterized as western, educated, industrialized, rich, and democratic, or WEIRD, as defined by Henrich, Heine e Norenzayan (2010), treasure the individual's autonomy since the early years of age, and build a path of continuous personal self-maximization, it may also be correct to state that parents may not achieve the socialization goals that they have themselves designed for their children. Autonomy, here understood as a product of opportunities offered together by family, society, and government, may be the most important characteristics of a socialized adult, an ideal standard pursued since childhood, but probably reached by a small parcel of children, more precisely the ones that live in less than $16 \%$ of the countries. In addition, even this small part of countries, considered rich and educated, may face difficulties to accomplish this ideal life, due to the global economic crisis that has been happening for decades and impoverishing families, reducing the chances for parents to watch their children be raised in a safe environment that stimulate an autonomous life (Unicef, 2012). Most countries of Africa, Asia, Latin America, and Caribbean Islands, children have been raised and educated in families that deal with many sorts of difficulties, crises and risks (Sarti, 2010; Vegas \& Santibáñez, 2010). Poverty, in particular, marked by the lack of possessions and sufficient income to support the children, make parents more vulnerable to addictions, violence, diseases, chronic unemployment, that impair the parental roles.

In the present study it is emphasized that poverty, in its multiple aspects, may take away from parents the ability to establish socialization goals and make them to follow strategies that cannot be pursued satisfactorily. In other words, parents design socialization strategies under the influence of eco-cultural conditions that, several times, are responsible for their impossibility. That is because poverty brings for both parents and children a series of limitations and obstacles that make the development path an even harder and more complex process. Some studies consider poverty to have prejudicial effects, mainly on the early development, but also for the future life (Vegas \& Santibáñez, 2010; Bronfenbrenner, 1979).

Historically, poverty, above all the precarious socio-economic condition of the family (low levels of education, income and health), has been pointed as the main reason, among others (Vegas \& Santibáñez, 2010; Bronfenbrenner, 1979), for parents to fail or neglect the parental role. Such fact has made thousands of children in Brazil, and around the world, to go through severe personal and social vulnerable conditions, hence forcing the society and the government to find alternatives for the parental care (provisory, or long-stay shelters, foster-care systems), as exemplified by Roy e Rutter (2006) e Cavalcante, Santos e Magalhães (2012). In very common situations it is noted that parents cannot protect and support the basic needs of their children, for they didn't have their own needs attended since birth, making them believe the shelter may provide at the same time, cover, protection and the necessary care with health and education.

Children around the world have been sent away from their daily living with biological parents, because, according to the child protection legislation from their country, the parents failed constantly to assure their protection and autonomy. Due to reasons related to socio-economical conditions of the family (Bandeira, Seidl de Moura \& Vieira, 2009), but also due to particular 
cognitive and parental characteristics that are in agreement with the culture in which parents and children live (Henrich, Heine \& Norenzayan, 2010), it is admitted that parenthood may not have positive effects for the child development in the sense of promoting security and independence to children. Therefore, parents need to have the support of other family members (maternal grandmothers, usually) and/or institutions for children (shelters, foster home, and the like)

In Brazil, nowadays, there are also thousands of children in shelter institutions (Cavalcante, Costa \& Magalhães, 2012), which may indicate that parenthood has not been executedby many parents in desirable social conditions. In such circumstances, a rising issue for the human development is: in which conditions parenthood is being performed by parents in societies as the Brazilian one, in which about $45 \%$ of children and adolescents live in underprivileged families (IBGE, 2012).Moreover, which are the goals and socialization strategies prepared by them to educate their children with autonomy when parents themselves, commonly, lived in socio-economical conditions that were unfavorable for their full development? Contradictorily, it means to state that few studies have been dedicated to understand socialization goals for children who live in countries where $91 \%$ of the world population of children were born and live (Henrich, Heine \& Norenzayan, 2010).

The previously mentioned data necessarily leads to questioning about how parenthood is been performed in societies that, as the Brazilian one, have great number of children living in shelter institutions, an almost certain fateof those whose poverty conditions meet other social risk conditions (mistreatment, urban violence, abuse of alcohol and other substances in the family, physical and/or mental disorder). In those conditions a question needs to be asked: Which socialization goals have been offered by parents (and other caretakers that replace them in the daily care of children, such as grandparents) who live in contexts where poverty still holds children from been raised in the core of its family and cultural community?

In the specific case of grandparents that help or replace the parents in assuring their grandchildren development and several roles attributable to parent, it might be said that little is known on what they think about the child socialization in the early ages and the goals designed by them to guide this process. In a study performed in a shelter institution in the North region of Brazil Cavalcante, Costa e Magalhães (2012) concluded that mothers have been the usual caretaker of children before, during, and after the institutional sheltering; however, it tends to be closely followed by grandmothers on the daily basis of the child. Serrano (2008), in a similar study performed in the South of Brazil, demonstrated that mothers and grandmothers are reference figures in the family of children that live in institutions for social protection.

From what was exposed, it is noted that researches increasingly show that grandparents have shared or replaced parents in the socialization process of the grandchildren, however, not implying systematic investigations on the socialization goals designed for children in these special conditions. In this sense, this study aimed at investigating mothers' and grandmothers' psychological aspects, when acknowledged as reference figures in the families of children in shelter institutions, in order to enlighten who are those caretakers and which are the socialization goals defined by them for their children and grandchildren. The proposal is to discuss how aspects from the eco-cultural context that mothers and grandmothers live help defining 
the child socialization goals and the strategies for its consecution, possibly inspiring public policies more adequate to the reality of this population in social vulnerability conditions.

\section{Method}

The study was conducted in the largest institution for the care of children zero to six years in poverty and social vulnerability in a city located in northern region of Brazil. Participants were 20 mothers and 20 grandmothers when they visited their children at the host institution. Semistructured interview was conducted with two questions in order to collect data on participants sociodemographic (age, education, occupation and marital status) informations, the age and sex of the child and the socialization goals and strategies designed to reach them. The interview brought the following questions: "What qualities do you want in your child or grandchild as an adult?" and "What do you think is necessary so that he can develop these qualities?".

Mothers and grandmothers answered the questions contained in the questionnaire individually and their responses were audio recorded with their agreement. Then, answers were transcribed and subjected to content analysis according to defined categories from previous studies. As in the study of Bandeira, Seidl-de-Moura and Vieira (2009), the first question involved categories previously used by Harwood et al. (1999): self-improvement (AA) - longs for the child to become self-reliant and independent, and fully develop their talents and skills as an individual; Self-Control (AC) - expect a child to develop the ability to control negative impulses, such as greed, aggression or self-centeredness; Emotionality (iN) - you want the child to develop the capacity for emotional intimacy with others, and to be loved; Social Expectations (ES) - can become a hardworking, honest and law-abiding meeting with so expectations arising from the life of society; and Good Behavior (BC) - brings the concern that the child behaves appropriately, relate well with others, and is likely to play the roles expected with satisfaction (good father, good mother, good wife, good husband, among others), particularly when referring to living with the family.

The answers to the first question were also organized according to another system categories: 1) Maverick (understands the notion of the self as fundamentally distinct and unique, values independence, autonomy, self-esteem, happiness, and exercises self-control to become a better person; crave self-improvement and self-overcoming); 2) sociocentric (recognizes the construction of the self as dependent on its relationship with other beings; involves the notion of social interdependence; emphasizes the importance of respect between people, the social network, the membership in a given group or community). Thus, we considered responses that reinforce an individualistic perspective those that fall into the categories of self-improvement and self-control as the sociocentric when they could be enrolled in categories such as emotions, social expectations and good behavior.

The next moment, the answers to the second question were classified to reveal different possible strategies for action: Self-centered (CS), when mothers or grandparents saw themselves as role models for their children and grandchildren or other positive references, calling themselves the task of disciplining, advising, teaching by demonstration or participation; 
Centric Context ( CC ), which relates to good social opportunities that can put a child in the way they live, access to quality education, among others; and the Child centered (CCr), which highlights the child's active participation in the development of certain qualities or a personal predisposition for having a sense of autonomy that leads to decide what to do and which way to walk.

Further, we calculated the total number of responses given to the first question for each participant, and the percentage for each category considered for analysis. Regarding the second question, the procedure adopted included the analysis of qualitative data, identifying possible strategies for action and the percentage of them in relation to the participants. In addition, the data were statistically treated sociodemographic data of mother and grandparents, in order to build an overall profile of the participants.

The project was submitted to the Ethics Committee for Human Research of the Center for Tropical Medicine, Federal University of Pará, and was approved under the protocol №. 146/11.

\section{Results and discussion}

Socio-demographic characteristics of participants

Most of the twenty informer mothers lived in Belém, aged between 15 and 45 (M=27), had from one to seven children whose ages ranged between nine months to 11 years, and $80 \%$ of them didn't finish Elementary School. From the reasons for sending their children to shelters, the most common were: family negligence, abandonment, domestic violence, and sexual abuse. On the other hand, the twenty grandmothers aged between 37 and 70 years old ( $M=50.95), 57 \%$ didn't complete Elementary School, and $24 \%$ were illiterate. In what concerns to their professional occupation mothers and grandmothers were involved in informal jobs activities.

For the question "What qualities would like your child to have as an adult?" 61 valid answers were given by mothers and 64 by grandmothers, which represents an average of 3.05 and 3.04 for each group. In Table 1 the percentages were presented for each category of socialization goals analyzed.

It may be observed that mothers and grandmothers value four of the five categories in the same order. The social expectation category had a higher percentage, followed by proper demeanor, self-maximization, and emotionality, self-control was mentioned only by the mothers.

The social expectation category was the most mentioned one by mothers and grandmothers of children in institutional shelter. As examples of responses related to this category were the concern that their children have a profession in the future, attend college, are hardworking, study hard, and have a good character, in other words, that they manage to make something out of their lives. How strongly they emphasize the importance of education for their children and grandchildren socialization may be linked to the fact that these mothers and grandmothers 


\begin{tabular}{lcc}
\hline \multirow{2}{*}{ Categories } & Mothers $(\mathbf{n}=\mathbf{6 1})$ & Grandmothers $(\mathrm{n}=64)$ \\
\cline { 2 - 3 } & $\%$ & $\%$ \\
\hline Social Expectancy & 77 & 73 \\
ProperDemeanor & 15 & 19 \\
Sefl-maximization & 4 & 5 \\
Self-control & 2 & 0 \\
Emotionality & 2 & 3 \\
Total & 100 & 100 \\
\hline
\end{tabular}

Table 1. Response percentage of mothers and grandmothers in the socialization goals category.

see in education the possibility for their children to enter the school environment and reach social mobility through college education, as well as the opportunity for them to live with people different from their context, which may mean to broaden their social support network. The mentions about work demonstrate their will to see their children and grandchildren grow up with financial independence, for the mothers and grandmothers work on their own and don't have regular income. Mentioning work regards the possibility of having an increase in their income, hence, having their purchasing power increased, being treated with more dignity by the value provided by it, increasing self-esteem, and having the respect of others. Therefore, the goal of becoming a worker in the future seems to be based more on the feeling of dignity than on the notion of citizenship.

Sarti (2010) considers that underprivileged people attribute moral value to work, making it dignifying, since it enables social mobility through work and personal dedication. Therefore, work is considered an instrument that enables family life and makes it dynamic. Consequently, the interviewed women long for their children and grandchildren to become hardworking in the future, so they can contribute for the success of a collective project that is to improve its own life, as well as enabling the family to have social mobility, because it is expected from them to payback for the time and resources dedicated to their upbringing and care.

Secondly, it appears the category proper demeanor that gathers the goals from mothers and grandmothers that are concerned their child learn to have good manners in the social life, to relate to other people in a collaborative manner, and to perform the expected roles. The emphasis on this category can be explained by the preoccupations mothers and grandmothers have if they will be able to follow rules and norms established by the society and in agreement to the collective environment. For them, once the child is familiar with social norms it will easier to distinguish what is adequate from what is not. This is considered an important socialization goal because it represents the best way of living in society, especially in family.

In the continuance, the category self-improvement mentioned by the participants, gathered answers that demonstrate their concern with the children's and grandchildren's wellbeing once they are adults. This category gathers some characteristics regarding a better future, as for example, to be happy, to have a profession, among others. This kind of concern may be justified 
by the strength of a cultural model that is especially present in the most prosper, educated, industrialized, rich and democratic western societies (Henrich et al., 2010), that disseminated individualism and competitiveness as values that must be essential for the construction of the self. These are societies that, according to these authors, give importance to autonomy and professional accomplishments, in view of new demands of a capitalist society that needs to increase the individual's productive potential. These mothers and grandmothers hope their children self-maximize and are able to accomplish everything they couldn't for several reasons, chiefly, low income, little education, and little access to education and health services for them and their family members. In other words, they design for their children's future socialization goals based on achieving high education levels and a different job than the current one: socially recognized and better paid.

The category emotionality also shows up in the mothers' and grandmothers' speech expressing their hope for their children and grandchildren to be respectful, but also to be respected. To be treated with respect and, likewise, give respect to others is a moral value yet to be harvested in the preparation of children for living socially, mainly among popular sections and/or those who live away from most important urban nuclei (Moinhos et al., 2007; Silva \& Magalhães, 2011; Westphal et al., 2011), essentially because it contributes to cultivate reciprocity in family relations, as pointed out by Sarti (2010). The self-control category was mentioned only by mothers when demonstrated apprehension their children wouldn't be able to control negative impulses, which may lead to aggressive behavior towards parents, for example.

Admitting that individualist dimension gathers the self-maximization and self-control categories, and the sociocentric dimension includes the social expectation, emotionality and proper demeanor categories, Table 2 shows the general distribution of the answers given by mothers and grandmothers in these dimensions.

\begin{tabular}{lcccc}
\hline Categories & \multicolumn{2}{c}{ Mothers $(\mathbf{n}=\mathbf{2 0})$} & \multicolumn{2}{c}{ Grandmothers $(\mathbf{n}=\mathbf{2 0})$} \\
\cline { 2 - 5 } & $\boldsymbol{F}$ & \% & $\boldsymbol{f}$ & \% \\
\hline Individualist & 4 & 6 & 3 & 5 \\
Sociocentric & 57 & 94 & 61 & 95 \\
Total & 61 & 100 & 64 & 100 \\
\hline
\end{tabular}

Table 2. Response percentage of mothers and grandmothers according to the individualist and sociocentric categories.

It is observed that both mothers and grandmothers mentioned predominantly traces of a sociocentric cultural model, appreciating more the posture of interdependence and the esteem for collectivity, as it was identified among agriculturalist mothers from Cameroon, and from villagers from India, studied by Keller et al. (2005), and other studies made in Brazil, including the North region (Silva \& Magalhães,2011).

In the analysis of the second question "What do you think it is necessary for him/her to develop these qualities?", 42 strategies were mentioned by mothers and 38 by grandmothers, grouped 
accordingly to the following categories: centered in the self, centered in the child, or centered in the context.

\begin{tabular}{lcc}
\hline \multirow{2}{*}{ Categories } & Mães $(\mathbf{n}=\mathbf{4 2})$ & Avós $(\mathbf{n = 3 8})$ \\
\cline { 2 - 3 } Centered in the self & \% & \% \\
\cline { 2 - 3 } Centered in the context & 48 & 55 \\
Centered in thechild & 28 & 29 \\
\hline
\end{tabular}

Table 3. Response percentage of mothers and grandmothers in socialization strategies categories.

The data indicate the convergence between the strategies used by mothers and grandmothers, first regarding the ones linked to the centered in the self category, secondly to the ones giving emphasis to factors associated to the context, and finally, to everything that concerns exclusively to the child's characteristics. These data are in agreement to the study of Moinhos et al. (2007), Bandeira et al. (2009), Diniz e Salomão (2010),, in which the most reported strategy was the one regarding the attributions from their role as primary caretakers and main family reference for the child. Those mothers and grandmothers believe the primary caretaker's role that was given to them by society makes them responsible for providing affection and daily attention to the children. It is necessary to note that such way of thinking stood out in the moment they watched their children and grandchildren being taken away from their daily lives and were living in a shelter institution, temporarily, for their ability to protect them, and educate them, was being questioned from the social and judicial standpoint, according to the child social protection legislation.

To what concern the strategies centered in the child, it is noted that mothers and grandmothers delegate to their children and grandchildren the responsibility to develop certain qualities, as illustrated in some statements.

\footnotetext{
"It is necessary that they study..." (M2)

"Study hard, have a good husband, and a good job..." (M5)

"Study a lot to reach their goals..." (M10)

"Their dedication to the studies..." (M13)
}

These statements also show that the participants transfer to their children and grandchildren the responsibility to reach the socialization goals designed by them. If, on one hand, it implies the notion of an active child who is capable of searching its own self-maximization, on the other hand, it suggests that the mothers' and grandmothers' comprehension of how the acquisition of abilities in the child socialization process takes place, chiefly in the early years, 
might be limited. Such apparent contradiction may be happening in a less proportion due to the lack of knowledge on how indispensible the adult supervision is in the early years, and more due to socio-economic conditions and traditional habits of the culture they are inserted, and they need to be responsible for the child's care and education. After all, to offer a stable and responsive care pattern from mothers and grandmothers depend, initially, on how the society and culture they are inserted define these terms, and secondly, on material conditions that enables to rethink practices and/or potentiate protection measures.

In this sense, the strategies centered in the context emphasize the importance of available resources in the family and social environments as fundamental strategies to achieve the designed socialization goals, either attenuating what might be prejudicial for the child, or potentiating the help from support networks formed by people and institutions (as it is the case of those sent to shelters and preschool). It is considered here the child's closest environment, in other words, the closest to the person in development, regarding the most remote dimensions, involving the resources the society may provide to this task in different forms (including the cultural valorization of socialization goals from parents and other family members, as grandparents).

Some studies indicate that it must not be strengthened the idea of a single procedure and/or more efficient one to lead parents and other primary caretakers to reach the socialization goals designed by them, for it is important to know the strategies they can easily make use of, or the ones they need to request support. Likewise, it is necessary to take into consideration the ecocultural conditions that guide the conception of a dominant parenthood in the context these goals were planned, the personal characteristics of the child, and the parental ethnotheories, and, clearly, mainly in the cases involving extreme poverty and other social vulnerability situations, the available means in the social support network that might help mothers and grandmothers in the task of raising and educating today, but looking at the future.

\section{Final considerations}

The present study aimed at approaching in an exploratory fashion the socialization goals of mothers and grandmothers of children in shelter institutions that lived in the North region in Brazil. Such aspects that constitute the parental ethnotheories in this society and culture were approached from evidences regarding what these caretakers long for their children and grandchildren, and the strategies planned by them to achieve these purposes.

In this sense, the results obtained bring contributions to the scarce literature destined to the discussion of this particular subject. Nonetheless, it is necessary to note some limitations of this study, such as the size of the sample. The parental cognition about the socialization goals were studied through their responses to two open questions, which demanded the analysis of the content of the participants' responses. Although the procedure for analyzing the content has been used in several investigations and are bringing relevant and consistent results, new instruments might be developed and/or adapted to be used in future studies, with bigger groups of parents (mother and father) and grandparents (grandmothers and grandfathers), 
including other regions of Brazil. Hence, the cultural models of parenthood of Brazilian parents may be better understood, as well as important aspects of the child development context that are built nowadays, enabling the comparison to the results from other cultures. In addition, other similar studies may stimulate more contextualized investigations, therefore, open new paths for the research of cultural dimensions on the human development.

Another aspect to be mentioned is the disclosure of the thoughts of caretakers of children who were withdrawn from the family living, their belief systems and moral standards, expectations or socialization goals that mothers and grandmothers have about how their children and grandchildren are and/or how they are going to be in the future. These pieces of information are important to the authorities, managers, technicians and educators that work in the shelter institution field, for they help to understand about the quality of care and possible influences on the child development.

\section{Author details}

Lília Iêda Chaves Cavalcante ${ }^{1}$ and Celina Maria Colino Magalhães ${ }^{1,2}$

1 Program in Behavior Theory and Research, Federal University of Pará, Brazil

2 CNPq Research Productivity - Level 2, Brazil

\section{References}

[1] Bandeira, T. A. T., Seidl-de-Moura, M. L.,Vieira, M. L. (2009). Metas de socialização de pais e mães para seus filhos. Journal of Human Growth and Development, , 19 (3), $445-456$

[2] Barroso, R. G. \& Machado, C. (2011). Definições, dimensões e determinantes da parentalidade. Psychologica, 52, 211-230.

[3] Bronfenbrenner, U. (1979). The ecology of human development: experiments by nature and design. Cambridge: Harvard University Press.

[4] Cavalcante, L.I.C., Magalhães, C.M.C., Costa, L. N. (2012). Caretaking behavior among siblings in children's shelters. Psicologia: Reflexão e Crítica (UFRGS. Impresso), 25 (1), 165-173.

[5] Diniz, P.K.C. \& Salomão, N.M.R. (2010). Metas de socialização e estratégias de ação paternas e maternas. Paidéa, 20 (46), 145-154

[6] Fundo das Nações Unidas para a Infância - UNICEF. (2012). Situação mundial da infância. Crianças em um mundo urbano. (B\&C Revisão de Textos, SP, Trad.). Brasília: Autor. 
[7] Harkness, S. \& Super, C. M. (1996). Parent's cultural beliefs systems: their origins, expressions and consequences, The Guilford Press: New York

[8] Harwood, R. L., Schoelmeirch, A., Schulze, P. A., Gonzalez, Z. (1999).Cultural diffrences. In Maternal Beliefs e Behaviors: A study of Middle-Class Anglo Puerto Rican Mother-

[9] Infant Pars in four everyday situations. Child Development ,70 (4) 1005-1016.

[10] Henrich, J., Heine, S., \& Norenzayan, A. (2010). The weirdest people in the world? Behavioral and Brain Sciences, 33, 61-135

[11] Kagitcibasi, C. (2005). Autonomy and relatedness in cultural context: Implications for self and family. Journal of Cross-Cultural Psychology, 36, 403-422.

[12] Keller, H., Lamm, B., Abels, M., Yovsi, R., Borke, J., Jensen, H., Papaligoura, Z., Holub, C., Lo, W., Tomiyama, A. J., Su, Y., Wang, Y., Chaudhary, N. (2006). Cultural models, socialization goals, and parenting ethnotheories: a multicultural analysis. Journal of Cross-Cultural Psychology, 37(2) 155-172.

[13] Keller, H., Voelker, S., \& Yovsi, R. D. (2005). Conceptions of parenting in different cultural communities. The case of west african nso and northern german women. Social Development, 14, 158-180.

[14] IBGE. Instituto Brasileiro de Geografia e Estatística. Síntese de indicadores sociais: uma análise das condições de vida da população brasileira. Rio de Janeiro: IBGE, 2012. http: //ibge.org.br/ (acessed 3 july 2012)

[15] Leyerdecker, B. Lamb, M. E. Harwood, R. L., Sholmerich, A. (2002). Mother's socialization goals and evaluation of deseirable and undesirable everyday situations in two diverse cultural groups. International Journal of Behavioral Development, 26 248-258.

[16] Maccoby, E. (2000). Parenting and its effects on children: on reading and misreading behavior genetics. Annual Review of Psychology, 51, 1-27.

[17] Mimi McEvoy, M., Lee, C., O’Neill, A., Groisman, A., Roberts-Butelman, K., Dinghra, K., \& Porder, K. (2005). Are there universal parenting concepts among culturally diverse families in an inner-city pediatric clinic? Journal of Pediatric Health Care, 19 (3), $142-150$

[18] Moinhos, M.V.C., Lordelo, E. R., \& Seidl-de-Moura, M. L., (2007). Metas de socialização de mães baianas de diferentes contextos socioeconômicos.Journal of Human Growth and Development, , 17 (1), 114-125

[19] Moura, M. L. S., Lordelo, E. R., Vieira, M. L. ; Piccinini, C. A. , Siqueira, J. O., Magalhães, C. M. C., Salomão, N. M., Rimoli, A. (2008). Brazilian mothers' socialization goals: Intracultural differences in seven Brazilian cities. International Journal of Behavioral Development, 32 465-472. 
[20] Moura, M. L., Soares, I., Gomes, A., \& Bornstein, M. (2003). Socioeconomic status in Brazilian psychological research: II. Socioeconomic status and parenting knowledge. Estudos de Psicologia, 8, 385-392.

[21] Piccinini, C. A. \& Alvarenga, P. (2012). Maternidade e paternidade. A parentalidade em diferentes contextos. São Paulo: Casa do Psicólogo.

[22] Roy, P. \& Rutter, M. (2006). Institutional care: associations between inattention and early reading performance. In: Journal of Child Psychology and Psychiatry, 41, 480-487.

[23] Roy, P., Rutter, M. \& Pickles, A. (2000). Institutional care: risk from family background or pattern of rearing? In:: Journal of Child Psychology and Psychiatry, 41, 139-149.

[24] Sarti, C. A. (2010). A Família como Espelho: Um Estudo sobre a Moral dos Pobres. Cortez: São Paulo

[25] Serrano, S. A. Quem são as crianças institucionalizadas e suas famílias? Refletindo sobre os indicadores de abrigamento em Ribeirão Preto. (2011). In: Maria Clotilde Rossetti-Ferreira; Solange Aparecida Serrano; Ivy Gonçalves de Almeida. O acolhimento institucional na perspectiva da criança. São Paulo: Hucitec. pp 86-118.

[26] Silva, R. A. \& Magalhães, C.M.C. (2011). Crenças sobre práticas: estudo sobre mães primíparas de contexto urbano e não-urbano. Journal of Human Growth and Development, 21, (1), 39-50.

[27] Virasiri, S., Yunibhand, J. \& Chaiyawat, W. (2011) Parenting: What Are The Critical Attributes? Journal of The Medical Association of Thailand, 94 (09), 1109-1116

[28] Vegas, E. \& Santibáñez, L. (2010). América Latina. La promesa del desarrollo en la primera infância en América Latina y El Caribe. Washington, DC, Bogotá, Colômbia: Banco Mundial en coedición con Mayol Ediciones S.A.

[29] Westphal, J. P., Vieira, V. \& Vieira, M. L. (2010). O que mães pensam sobre seus filhos em três regiões distintas do estado de Santa Catarina. Psicologia Argumento (PUCPR. Impresso), 28, 235-246.

[30] Zucker E. \& Howes C. (2009). Respectful relationships: Socialization goals and practices among mexican mothers. Infant Mental Health Journal, 30(1), 501-522. 
Chapter 8

\title{
Emotion, Affection and \\ Maternal Speech in Parental Care
}

\author{
Deise Maria Leal Fernandes Mendes and \\ Luciana Fontes Pessôa \\ Additional information is available at the end of the chapter \\ http://dx.doi.org/10.5772/57337
}

\section{Introduction}

This chapter discusses the role of emotions and affective communication in practices of care and the relevance of these components in children development. The importance of considering the different development trajectories as a result of different parental practices that arises from the culture is also discussed. Affection and emotion are considered crucial dimensions of parental care with consequences in child development through daily practices, parental beliefs, and expectations that guide the way to raise and to educate children. In the first year of life, children's participation in mother-infant's interactions, as the free-play situations, involving emotional expressions and vocalizations, is considered a prominent factor for the development of affection, attention, communication and cognitive functioning. Evidence accumulated in recent decades has highlighted the role of affective exchanges between parent and their children for a healthy development. Also, mothers' affective speech and the process by which the language development is constructed or acquired in this interactional context has been subject of various theoretical formulations and gave rise to a diverse literature of empirical investigation. The formulation of models and assumptions about human development requires an understanding of these processes and the factors associated with them. So, we discuss here these mechanisms in the early stages of ontogeny. Arguments are based on results of some international research and current evidence of Brazilian studies.

\section{Development trajectories in different eco-cultural contexts}

Evolutionary and cultural approaches in psychology, taken from a complementary and integrated way, provide us a powerful theoretical synthesis for a broader understanding of 
human development. According to this view, it's reasonable to consider that babies are born biologically prepared to participate and be agents of a social matrix from an early set of skills that allow them to be sensitive and interact with their caregivers. At the same time, from birth they are immersed in culture and become cultural agents. As discussed by Seidl-de-Moura and Mendes (2012), the possibilities and limitations of these competences seem to prepare the infant to interact with parents that have practices of care derived from behavioral predispositions and beliefs.

Parental beliefs and practices of care are understood as been forged by culture, and are associated with goals of development. In all cultures, as evidence from cross-cultural studies (Keller, 2007), parents have the goal that their children develop in a healthy way, and become successful adults. This idea of personal fulfillment is linked with individual, family and cultural values and rules. It is in the developmental niche, a concept of development context formulated by Harkness and Supper (1994), that socialization trajectories are built, grow and change over time.

A component of this proposed system is the psychology of the caretakers, and part of this are the parental ethnotheories (parents' cultural belief systems), that are the nexus through which elements of the larger culture are filtered. They are an important source of parenting practices and the organization of daily life for children and families. As an organized set of ideas that are shared by members of a cultural group, they are often implicit, and have strong motivational properties for parents. Harkness et al. (2010) argues that understanding parents' ethnotheories about their children is essential to understand the strategies parents use to help their children grow up and be successful.

Keller (2007) in her work also emphasizes the role of parental beliefs and goals in parental practices and in the child development. According to her, the baby presents great cerebral plasticity in the first two years of life and their interactions with caregivers in this period are organized according to the predominance of different parental systems. These systems are universal and result of propensities to care. However, they are manifested in different ways according to cultural diversity.

The Component Model of Parenting defined by Keller (2007) is conceptually composed by six universal and independent systems: primary care, that involves a set of activities that aim at meeting babies' survival needs, including health related activities, such as nursing, washing, and so forth, with the function of to reduce stress and promote security and trust in relation to caregivers' protection; body contact system, which promotes corporal contact, and involves carrying the baby close to the body, affecting the bonding between mother and baby and group cohesion, and protecting the baby from dangers; body stimulation system that involves any motor, kinesthetic, tactile and balance stimulation of the baby, promoting communication through the body; object stimulation presents the object world and physical environment to the child, and is related to exploratory activities; face-to-face context is characterized by mutuality through eye-gazing; and narrative envelop, which refers to the symbolic mediation that involves the infant through mothers' conversations. 
Evidence produced by studies developed by Keller and collaborators (Keller, Borke, Yovsi, Lohaus, \& Jensen, 2005; Keller, Borke, Lamm, Lohaus, \& Yovsi, 2011) indicate that culturespecific parenting strategies differ with respect to the type and amount of behaviors expressed, and also to the developmental course of particular behaviors. Different channels are chosen to express socialization strategies, and therefore, caregivers emphasize these systems of parenting differently, depending on the cultural contexts. Variation is manifested in relation to their care practices, and to their beliefs and parental ethnotheories.

These systems prompt different socialization experiences with different psychological consequences to the children. Parent behaviors within these different systems may vary in terms of contingence and warmth. Keller (2007) argues that parenting is the main reason why individuals in different cultures differ from each other. Consequently, it has been considered as a significant feature of culture, constituting the largest mechanism for the transmission of values and practices through the generations.

Cultural differences in terms of parental ethnotheories and interactional mechanisms, especially between family members, are substantial. However, in general, mothers are the main significant figures to take care of babies in the first years of life (Keller, 2007). In this way, parents, specially the mothers, define socialization trajectories and the process of self development. These pathways are designed from individual characteristics based on culture. The socialization of emotion in the first year of life and the acquisition of language will be assessed according to this approach.

\section{Emotional development and social interactions in early stages}

Diverse eco-cultural contexts with its specificity of possibilities and challenges, as discussed, provide differences in terms of parental systems and developmental trajectories for children. As the same time, human development is conceived as a process in which human beings are born as cultural beings that look for interpersonal interaction. In the familiar niche they start social interactions with their parents. This way, family constitutes the centre of their lives in the early stages and can be considered as mediating the relation between child and environment. This notion is contemplated in some important conceptions of developmental context as that of Harkness and Super (1994) and Bronfenbrenner (1996), in which the family is part of development microcontext. This is the context in which children begin to deal with their emotions and those of others.

The importance of interpersonal relations in the lives of children, in particular the emotional and affective exchanges with their mothers, has been highlighted since Bowlby (1969) and the attachment theory. Besides his work, Harlow (1958), studying chimpanzee infants, demonstrated that contact comfort (with a wire mother that was covered with cloth over a wire) was more important for the infant than the hunger drive. Even well before, in an evolutionary perspective, Darwin devoted a book to the emotions and their adaptive role in the life of man and animals. 
In more recent publications, authors as Reddy and Trevarthen (2004) suggest that emotions are the key to psychological engagement, since they are part of us as individuals in our active and assertive relationships and it's part of their nature to be intensely shared. As they said "For all who deal with infants, emotional engagements with them provide the most informative as well as the most helpful route to understanding them." (Reddy \& Trevarthen, 2004, p. 3)

Capacities required for the perception and expression of emotions have been considered fundamental for the quality of early interactions, which in turn are a rich context to promote affective and social development. This early emotional involvement indicates an increase in "awareness" by babies, in relation to their ability of attention and intentions, and to other people's expectations.

Authors from different areas as psychologists, psychoanalysts, and neonatologists raised important questions in relation to the potential for emotional experiences in early life of babies in the womb and their impact in the fetus development (Cunha, 2002; Piontelli, 1992). According to them, positive and negative emotional experiences intra utero make a difference in an infant's development. Our brain develops in direct response to our mother's experience of the world. This way, if a fetus is continually exposed to mother's stress (with the release of cortisol in her bloodstream) it's observed an accelerated fetal heartbeat and hyperactivity. It is still considered certain continuity between intrauterine and earliest infancy, since some children's behaviors seems to maintain associative links with favorite moves and postures showed in the womb.

Recent advances of Neurosciences indicate that since 20 to 24 weeks of prenatal life, when the neuronal migration is complete, the infant can perceive the surrounding environment and construct proto-representations arising from experiences and emotions that will "sculpt" his/ her neural networks. Therefore, it can be thought that it is possible the registration of positive affects sensations that will generate feelings of security and welcomed, and if continuous and strong enough can "sculpt" long-lasting neural circuits. The counterpoint of this can be thought of in relation to negative affects sensations.

After birth, infants and their parents regulate their interactions through the baby's emotional expressions and the parent's behaviors and reactions. The context of affective interchanges in the early stages is considered crucial to the main primary achievements that a baby must make. Since the first moments of life, human being show different emotional expressions, and from a very early age they seem oriented to other person, as a social partner.

Even newborns, when observed, show a variety of emotional behavior. If they are upset, when they feel alone, or in need of food and attention, they cry and express discomfort. They look carefully for people and objects around them, and when they are looked at by someone with joy and treated with care they seem to manifest wellness and positive emotions. At this moment, they show relaxed and often smile. In fact, they smile from birth or before, and with a few weeks of life they begin to smile the "social smiles" (Mendes, Seidl-de-Moura, \& Siqueira, 2009; Messinger et al, 2002). Before long, they begin to react contingently with smiles to affective behaviors of their mothers (Mendes \& Seidl-deMoura, submitted; Mendes et al., 2009). Maternal smiles proved to be powerful elicitors of smiles on baby, but also other affective behaviors. Among them, mother speech/vocaliza- 
tion directed to the baby drew attention for being the only one that elicited responses in contingent smiling babies up to two months of life.

Although displaying a variety of facial expressions and body postures to express emotions, the set of distinct emotions the newborns show can still be considered as limited forward to the diversity of human emotions. The changes observed over the early years, however, are such that after a few months of born, babies exhibit a wide range of emotions. In fact, at around three years of age, one can consider that is present in a child almost any variety of adult emotions (Lewis, 2010). For three years, approximately, the changes observed in this set of human emotions and in their view forms are such that more than a few emotions and their manifestations for many and highly differentiated, with a vast repertoire of demonstrations, of more direct to that denote certain subtleties.

Based on an evolutionary and socio-cultural approach to understand human development, all this behavioral and emotional expressions repertoire which diversifies in a few years, seeks to account for developmental needs and requirements. In addition, to meet the requirements and challenges of a cultural context in which the child develop is adaptive in that it seems to have evolved according to our phylogeny, to promote the survival and future reproductive success of individuals. In this sense, we can consider the sensitivity to social stimuli and social relations with co-regulation of affection, feelings and emotions as the basis of socio-emotional development. Parent's beliefs and goals about emotional experiences and expressions shape the process of socialization of emotion.

\section{The socialization of emotion: parental goals and expectations of children caregivers}

The interactional characteristic that human development has, as already commented, is especially evident in the emotional development. Emotions are powerful resources that humans have to deal with situations experienced and with interpersonal communication. They can also be understand as a mental system of self-regulation, responsible for the regulation of the concern-relevant aspects of an individual's actions, what means that they have a complex function in human action regulation (Holodynsky \& Friedlmeier, 2010).

Emotions are fundamental to children learn to understand themselves and the other in the social world they live. Since before the language acquisition, emotional communications are fundamental in the social interactions. The socio-cultural context constitutes the meaning and the ways to express emotions. In all the cultural groups, parents want to pass on strategies that promote the survival of their children and their cultural competence. As primary socialization agents, parents can guide their children in how to express their emotions and how to "read" the other's emotions, while culture provides guidelines of how to raise children and general patterns of emotion decodification and expression.

Theoretical models that focus on understanding of the emotional socialization process emphasize how ideas about emotions and values of parents influence their choices of practices 
and strategies of emotion socialization (Dix, 1991; Eisenberg, Spinrad, \& Cumberland, 1998). It's also necessary to keep in mind the fact that this socialization process is a two-way process, and, as well as practices of care have effects on the emotional and social competence of children, their behavior and reactions are likely to have repercussions in how their caregivers act and give them orientations. To examine parents' goals and beliefs about emotions an interesting alternative can be to consider the familiar context that plays an important role in the emotional development. Results from Brazilian studies and investigations carried out in other countries underlines how much the actions of parents are important to the processes of comprehension and regulation of emotion of their children.

As argued by Eisenberg et al. (1998) the existing set of available evidence provides support for the view that parental socialization practices have effects on children's emotional and social competence. Particularly, parents play an important role in guiding children's earliest efforts to regulate negative emotions. This way, it's possible to think that socialization of emotion regulation includes mothers' responses to children's distress as well mothers' modeling and use of emotion regulation behaviors.

Mirabile, Scaramella, Sohr-Preston, and Robison (2009) were interested in examining the extent to which children's (2-year-old) propensity towards negative emotional reactivity moderated the relationship between mothers' socialization of emotion regulation and children's use of specific emotion regulation. It was found that mothers with less reactive children who used more soothing had children who were more likely to use interactive, distraction-based regulatory behaviors during a frustration situation. It was also observed that children's propensity towards negative reactivity significantly interacted with mothers' use of physical soothing. It was argued that the effects of mothers' socialization behaviors and children emotion regulation emerged, suggesting that mothers parenting behaviors, specifically their efforts to socialize emotion regulation, influenced children's ability to regulate frustration.

In other study, McElwain, Halberstadt and Volling (2007) show that mothers' and fathers' supportive reactions together contributed to greater coordination between child and a friend (3- to 5-year-olds) when they are playing, during a sharing task. Further, for boys only, when one parent reported low support, greater support by the other parent was related to better understanding of emotions and less intense conflict with friends.

Lunkenheimer, Shields and Cortina (2007) observed the positive emotion socialization practice of parental emotion coaching and the negative socialization practice of emotion dismissing during a family interaction task and examined their effects on children's emotion regulation and behavior problems in middle childhood (children aged 8-11 years). Outcome measures included mother and father reports of emotion regulation and behavior problems, and it was verified that emotion dismissing was a risk factor, contributing to poorer emotion regulation and more behavioral problems.

Previous research indicates that the quality of parenting during early childhood impacts children's ability of self-regulation of emotion within the context of childcare settings (Nicholson \& Artz, 2006). The trend of parents act as advisors and transmit knowledge about emotions increases the ability of the children in relationships with peers, and their capacity to 
understand and talk about emotions (Denham \& Kochanoff, 2002). Besides that, proactive strategies of parents as encouraging presence, clear instructions and placing limits, contribute to the reduction of problems related to externalizing emotions in preschool children (Denham et al., 2000).

Cross-cultural studies are crucial to examine this process in various cultural systems. Even among cultures within the same country in which one might expect that there was much in common evidence show striking cultural differences determining development goals that differ so markedly. It's the case of Tamang and Brahman Nepali children that have culturally specific emotion scripts that may reflect different emotion socialization experiences.

To study emotion socialization and children's ideas about emotional displays the child-adult interactions of children (3-5 years old) were observed and village elders, as well as, first-grade boys and girls (aged 6-9 years) were interviewed in Tamang and Brahman villages (see Cole \& Tamang, 1998; Cole, Tamang \& Shrestha, 2006). Tamang practices are consistent with their view that competent children are socially graceful and never angry. Tamang rebuke the angry child but reason with and yield to the child who appears ashamed. For the other hand, Brahman practices appear to be consistent with the privileges and duties of high caste status, and the principles of Hinduism. Brahmans respond to child anger with reasoning and yielding but ignore shame.

Tamang and Brahman caregivers socialize children's anger and shame differently because of their cultural values. Brahman children, whose mothers reported teaching their children about emotion, were more likely than Tamang children to endorse negative emotions and to report masking negative emotion. Differently, Tamang mothers reported that children learned about emotion by themselves. These differences appeared to be related to socialization processes in the respective cultures.

Studies with mothers of preschoolers in China and India reported on the value they accorded to items tapping two socialization goals, Filial Piety and Socioemotional Development and two parenting styles, Authoritative and Authoritarian. According to Rao, McHaleb and Pearson (2003), there were found positive associations among these three variables for Indian mothers, reflecting Hindu beliefs about young children and childhood. Among Chinese mothers, on the other hand, Filial Piety was negatively related with Socioemotional Development and the use of Authoritative practices. Authors argued that Chinese mothers believe that the use of authoritative practices, which encourage socioemotional development in children, will inhibit achievement of filial behavior and academic achievement.

Brazilian studies with the focus on emotion socialization are rare. One of them (Mendes \& Cavalcante, submitted) reported some beliefs and expectations of 60 dyads composed of a mother and other child care providers (20 dyads mother-grandma, 20 dyads mother-nanny and 20 dyads mother-childcare workers) about emotion expression in infants. They were caregivers of infants up to one year of age, $56.7 \%$ of which was girls.

According to the results, all the participants considered the smile an important facial expression for infants and think that smiling is important to the child express their emotions and feelings. They, in general, reported higher values for the age at which each emotion emerges 
to which the literary indicates. It was also found that mothers were more attentive and concerned than other caregivers, with the necessity of a capacity of emotional regulation by babies. Mothers thought they need to develop this capacity during the first three years of life, especially, those who have their children, part of the day, in a nursery.

The concern of mothers and caregivers in general with the different ways of emotional development is related to the influence of the psychology of the caretakers and health practices they adopted in the early years of life of the children. However, as discussed, ethnotheories and practices of care reflect cultural models prevailing in societies where the child and their different caregivers live, and have implications for emotional competence to the development.

\section{Language: What does it mean for the human development?}

The contact with members of the linguistic community since the first days of a child's life is of basic importance to language development. An important part of information that developing babies process is the linguistic input of members of their community. As Keller (2007) points out, one of the components in the parental system of care is the narrative envelope. Babies are wrapped in this narrative envelope and their development processes are immersed on it, including language acquisition. Focusing on one aspect of the narrative envelope, maternal speech directed to children has been studied for decades in order to understand the process of language acquisition.

From a socio-cultural perspective, one factor of great importance in the development of children's linguistic capacity is the language of members of their socio-cultural context. Vila (1995) emphasizes that the experience of language usage in interpersonal interactions, especially with adults, is the child's main source of information about language itself, about his/her culture, and about the role of language in the culture in which he/she is inserted. From the linguistic input it is possible to identify the speaker's community, to transmit socio-cultural models, and to adapt the use of the language to the community the individual belongs.

The characteristics observed in the structure and the type of maternal speech directed to the child indicate that it constitutes a type of differentiated input (motherese), which intuitively considers the child's age, his/her language development stage, and mother's conceptions and expectations regarding the child's level of development.

In the beginning of last decade, some studies, as Chapman (2000) focus on the individual process of infant language acquisition, considering historical events and variations of the environment evidencing that the research of genetics and input of the environment can both contribute to an interactional perspective. The author has stressed out the importance of the relationship between natural and cultural aspects in the functioning of the linguistic system, and concluded that initial language development must be seen as the integration of multiple aspects, some of them learned at the beginning of the development.

Also, Hoff and Naigles (2002) had investigated vocabulary production in 63 American dyads in linguistic interactions in two different moments (when the child turned two years-old and 
ten weeks later) during twenty five minutes observation sessions. Results indicated that the production of maternal speech in quantitative terms, with a rich lexicon and with complex semantics, can bring significant benefits for the lexical development of children.

\section{Acquisition of language in the first two years: the role of the mother speech}

Discussing the acquisition of language, several studies have focused on the role of maternal input/speech in the process of language acquisition (Weizman \& Snow, 2001; Camaioni \& Longobardi, 2001; Lidz, Gleitman \& Gleitman, 2003; Pessôa \& Seidl-de-Moura, 2008; Pessôa \& Seidl-de-Moura, 2011).

Camaioni and Longobardi (2001) examined speech characteristics of fifteen Italian mothers of high middle-class, in a longitudinal study when the children had four and eight months-old, in three specific contexts: playing with familiar toys, playing with new toys, and being fed. It was observed that mothers produced more verbs than substantive in all the analyzed contexts. According to the authors, this result may have a direct relationship to the morphology of Italian language and the structure of the sentences in this language. Results indicate the importance of the knowledge about the syntactic structures of the studied language. This structure will influence the type of sentences emitted by the mothers to their children and their process of initial language acquisition.

In a cross-sectional study carried out by Bornstein and cols. (2004), which aimed at identifying characteristics of the vocabulary of 20 months-old children in Spain, Germany, France, Italy, Korea and United States, the prevalence of substantives, followed by verbs and adjectives was observed. One can think of how cognitive, linguistic and experimental factors, or the association of all these aspects, can contribute to these results. The cultural aspect cannot be left untouched when analyzing the results found in this study. From the moment we hypothesize the influence of maternal input in both the process of language acquisition and the phenomenon of motherese - in which the mother adjusts her speech to the period of child's development - it can be assumed that, in general, mothers use more substantives in her speech and does not have yet the concern with the correct structures of the phrases, as well as the role played by verbs.

It seems that some of the differences observed in maternal characteristics are perhaps a result of cultural and individual aspects, strategies and maternal expectations. On the other hand, children can develop different forms of appropriating the information presented in Child Directed Speech (CDS), and this process may be related to their own individual characteristics.

The literature indicates that different aspects in maternal speech have been investigated in cross-sectional studies since the 1970s. For instance, pragmatic characteristics of maternal speech had been identified in different social classes and contexts and in different children's age levels. Syntactic and semantic aspects of maternal speech and their relationship to the development of language have also been considered. The effect of the frequency and structure 
of maternal input in the development of child language, the effect produced by different types of maternal type input in distinct classrooms and in different cultures had also been studied. The primary role played by linguistic interaction in the process of language acquisition and the importance of games and social exchanges in this process had been identified, as well as the importance of joint attention in the development of initial language.

Between 10 and 24 months of age, children progress from communicating through conventional signals to communicating through symbols in a variety of situations. Few longitudinal studies focusing on this transition, considering mother-child dyads longitudinally, and using frequent observations over a lengthy period of time have been conducted (i.e. Camaioni, Aureli, Bellagamba \& Fogel, 2003; Pessôa \& Seidl-de-Moura, 2011).

One important longitudinal study had been carried out by Bornstein, Tal and Rahn (1992). In this study the authors analyzed and compared the language used by mothers with babies of 5 and 13 months of age in four different cultures. The two main aspects of language consisted in informative data, which involved direct questions, phrases, etc., and affective aspects, which corresponded to the use of onomatopoeic sounds, not propositional, rhyme, sounds of animals, etc. Data had evidenced, practically for all cultures, a larger use of speech reflecting affective aspects to the five months-old babies, and the use of more informative language to the thirteen months-old babies. This indicates mothers' sensitivity to the developmental characteristics of their special interlocutors.

Considering that languages and cultural characteristics may influence these processes, a preliminary initiative to study Brazilian dyads had also been made by Pessôa and Seidl-deMoura (2008). This preliminary study aimed to identify the pragmatic aspects of maternal input, focusing on the affective and cognitive contents of mothers' speech. Two groups were compared: dyads with one month-old babies and other with five months-old babies. They were observed in natural interactions at home, registered in videotapes. Results indicated that mothers' speech had predominantly affective content in both groups, confirming results found in research carried out in other cultures (Bornstein, Tal, \& Rahn, 1992). This study consisted in a restricted cross-sectional investigation. No Brazilian longitudinal studies of maternal speech transformations in specific communicative frames have been identified in the literature.

Trying to identify the individual development trajectories of socialization, Camaioni et al. (2003) had described these trajectories of four mother-child dyads. They have analyzed the transitions of communicative frames, observing these dyads (mothers of two boys and two girls) longitudinally, from 10 to 24 months of the children's life. Each dyad was filmed in a laboratory with specific toys, bi-weekly, for a period of ten minutes. Similarities and differences between the four dyads have been observed. Among them, it was verified the conventional frame/scenes and the representative gestures served as "bridge" between the attentional frame/scene and the symbolic frame/scene. Observations were organized in three age groups. It was observed that from the $44^{\text {th }}$ to the $66^{\text {th }}$ week all dyads had a predominance of attentional frames; from the $67^{\text {th }}$ to the $85^{\text {th }}$ week, attentional frames/scene also prevailed in dyads 1,2 and 4 , but conventional frames/scene increased substantially in terms of occurrence in time. In contrast, it was identified a predominance of conventional frame/scene for dyad 3. From the $86^{\text {th }}$ week on symbolic frames predominated. 
In Brazil, based on the study above, Pessôa and Seid-de-Moura (2011) also had described these trajectories of development in a longitudinal study to analyzed characteristics of maternal speech directed to children, identifying transitions of mother-child communication frames. Four children and their mothers were observed biweekly from 13 to 24 months of age. The instances of maternal speech were classified in affirmative, negative, imperative and interrogative sentences and the mother-child communication frames were classified in attentional, conventional or symbolic. The transitions from attentional to symbolic mother-child communication frames were also identified. A similar trajectory in the percentage of time of the frames throughout the development of the child was observed in all four dyads. Results indicate some common tendencies, which seem to be regulated by the child's development. In general, a developmental sequence was observed for the different frames in terms of their predominance: first attentional, then conventional and latter symbolic, in accordance to the literature (Camaioni et al., 2003). The percentage of time in attentional and symbolic frames showed a linear relation with the increase of baby's age in all dyads.

Mothers' communicative acts are an important part of this scenario. Mothers seem sensitive to the development of their children. They increase CDS linearly in relation to the child's age, use more declarative affirmative sentences and increase linearly the reference to aspects of the surrounding context of the dyad, decreasing the reference to the child him/herself. It seems that child's language development is the most important variable to explain the variations in the type and content of maternal sentences. The great diversity in the number of mothers' emissions indicates an adjustment to the specific characteristics of their children in this initial linguistic phase (Pessôa, 2008).

All these studies suggest that mothers adjust their behavior to the linguistic development of their children, in order to call their attention to themselves, to what they are speaking and, mainly, to the surrounding context. The significant increase in maternal speech related to the context, throughout the development of the child, seems to indicate that mothers gradually understand what is happening as their children develop across the second year of age.

Mothers make use of language, through different types of sentences (affirmative, imperative and negative) to communicate to their children and to transmit norms, rules, expected behaviors, and information about the world. The use of imperatives, throughout the period studied, can indicate an attempt of mothers to organize children's behaviors, besides being a verbal form to interact to children. The occurrence of interrogative emissions is another indicative of the establishment of linguistic interaction that, along with pauses, create turn taking, which is basic in a process of verbal interaction.

Intuitively, mothers use linguistic resources, through affirmative, negative, imperative and interrogative sentences, to call or to keep the attention of the child directed to them and the situations that involve them. This specific characteristic of maternal sentences has an evolutionary origin (Tomasello, 2003). After all, the necessary condition to establish a verbal communication between the mother-infant dyad is that the child has the attention directed to the mother and that they share attention to the context around them. 
Data from the dyads observed in Brazilian studies (Pessôa \& Seidl-de-Moura, 2008; Pessôa \& Seidl-de-Moura, 2011) indicated that mothers of these studies talk to their children about the situations in which they are involved. They speak about the babies themselves, about the activities carried out jointly by them, and, mainly, about the things and people in the context around them. However, it was possible to observe that almost all maternal emissions are preceded or followed by the children's signals. This means that mothers are not simply communicating information to their children, but are trying to engage them in dialogues. During the initial development, parents are the social agents who better understand children's intentions, attributing meanings to their behaviors, and providing the adequate support they need. Hence, they play an important role as mediators in the construction of children's social and cultural world.

As Keller (2007) points out, one of the components in the parental system of care is the narrative envelope. Babies are wrapped in this narrative envelope and their development processes are immersed on it, including language acquisition. A recent Brazilian research (Pessôa, Seidl-deMoura, Ramos and Mendes, submitted) aimed to verify parenting values among different young children's caretakers, comparing the speech of differents caretakers (mothers, grandmother, nanny and day-care center teacher) taking into account Keller's (2007) parental care systems (primary care, body contact, body stimulation, object stimulation and face to face interaction). The categories affection and physical contact were some of the most mentioned by all participants. These categories were associated with body contact and primary care systems. In all of the system it was found the category of affection. These analyses have served to illustrate that the affective aspects of speech, those which communicate affection and intimacy, were present in caretaker's speeches since early stages of development. Also we must consider the specific cultural characteristics that may be related to these findings. Different cultures may have different forms of communication and affective manifestations, and can vary in relation to the assigned value to each of these aspects in different moments of ontogeny.

As mentioned, according to a socio-cultural perspective to study human behavior, one cannot separate it from people's social and cultural contexts. Each culture has specific characteristics that need to be taken into account. Based on these assumptions, we believe in the importance of studying universal processes, such as initial language development and characteristics of maternal input in different cultures, to understand what may vary in the trajectories of these processes and what does not. The goal in these studies was to work with data from Brazilian dyads, Portuguese speakers and the trajectories observed, with the advantage of being a longitudinal investigation. Although not frequently used, longitudinal studies are particularly important. So, these studies bring a contribution to the literature on maternal speech and initial language development with data from a Brazilian context.

Most of the studies presented in this chapter indicated that a large proportion of maternal speech occurs in response to signals from the child, and this seems to mean that mothers are not simply passing on information to their children, but are trying to engage them in conversations and giving affection. Adopting some specific hypotheses on the philogenetic and ontogenetic origins of the language, Tomasello (2003) suggests that the symbolic dimension of the language has its origin in the singular character of human biological adaptation for 
cultural aspects. As we can think, the ability of caregivers to adjust his speech addressed to the baby seems not only to reflect a trait related to social and cultural beliefs, and related to the knowledge they have about development in early stages, but it also seems to be part of the baggage of predispositions of our species.

\section{Some final considerations}

Our purpose in this chapter was to present and discuss theoretical and empirical evidence about the role of affection and emotion in parental care and its impacts in the early development. It was particularly taken into account, in addition to emotional development, a cognitive process, language acquisition. It should also be highlighted researchers' concern to underline the diversity of ecological and social-cultural contexts in which the studies had been developed, as well as attention to the phylogeny.

According to an evolutionary view, complex behaviors such as language and emotional expressions rarely appear in an abrupt way and seldom present drastic modifications in a short period of time. It is plausible to think that they had their origins in other previous behaviors and simple biological mechanisms during a slow evolutionary history. Humans are social beings immersed in the socio-cultural context in which they live and are constituted by interacting with others. Therefore, some hypotheses for the origins of language, such as discussed by D. Falk (2004), even include the demands of child care in the environment of evolutionary adaptation and the motherese also can be seen as the result of selective pressures of our ancestral past. According to this view, the selection of vocal language occurred after the first mothers in hominids began to engage in emotional vocalizations directed to their babies. Emotional expressions and affective interactions can also be seen as adaptive processes that were selected by evolutionary mechanisms.

Affection and emotional expressions of the mother are important mediators for both emotional development and for language acquisition. As shown by the evidence presented in this chapter, particularly those regarding the Brazilian mothers residing in Rio de Janeiro, the dynamics of the mother-infant interactions from the beginning of life is characterized by adjustments in maternal behaviors, both emotional expression and speech, according to the possibilities and needs of the baby. Mothers intuitively adjust their speech directed to the baby and his emotional expression in order to promote communication between them and the baby's learning of such mechanisms of expression and interpersonal exchanges. In the Brazilian context, the parental ethnotheories are targeted for the presence of affective components on maternal speech and emotional contingency on mother-infant interaction, from the beginning of life.

It is important to bear in mind that the baby since birth has contact with emotional expressions and affective manifestations of his mother during the interactions established between both, through emotional manifestations of the mother in the body and face and through her speech direct to the baby. This is a cultural trait and how babies learn about others and about themselves. This way, it's reasonable to think that emotion, affection and maternal speech in 
parental care came together to constitute developmental trajectories for healthy children. We hope that this chapter may act as a motivating factor for future studies focusing on affection and emotion in parental care and its relevance to child development.

\section{Author details}

Deise Maria Leal Fernandes Mendes and Luciana Fontes Pessôa

Universidade do Estado do Rio de Janeiro, Pontifícia Universidade Católica do Rio de Janeiro, Brazil

\section{References}

[1] Bornstein, M. H., Cote, L. R., Maital, S., Painter, K., Park, S., Pascual, L., Pêcheux, M., Ruel, J., Venuti, P., \& Vyt, A. (2004). Cross-Linguistic Analysis of Vocabulary in Young Children: Spanish, Dutch, French, Hebrew, Italian, Korean, and American English. Child Development, 75 (4), 1115-1139.

[2] Bornstein, M. H., Tal, J., \& Rahn, C. (1992). Functional analysis of the contents of maternal speech to infants of 5 and 13 months in four cultures: Argentina, France, Japan, and United States. Development Psychology, 28 (4), 593-603.

[3] Bowlby, J. (1969), Attachment and loss, Vol. 1: Attachment. New York: Basic Books.

[4] Bronfenbrenner, U. (1996). A ecologia do desenvolvimento humano: experimentos naturais e planejados. Porto Alegre: Artes Médicas.

[5] Camaioni, L., Aureli, T., Bellagamba, F., \& Fogel, A. (2003). A Longitudinal Examination of the Transition of Symbolic Communication in the Second Year of Life. Infant and Child Development, 12 (2), 1-26.

[6] Camaioni, L., \& Longobardi, E. (2001). Noun versus verb emphasis in Italian motherto-child speech. Journal of Child Language, 28, 773-785.

[7] Chapman, R. S. (2000). Children's Language Learning: An Interactionist Perspective. Journal of Child Psychology and Psychiatry, 41, 33-54.

[8] Cole, P. M., \& Tamang, B. L. (1998). Nepali children's ideas about emotional displays in hypothetical challenges. Developmental Psychology, 34, 640-646.

[9] Cole, P. M., Tamang, B. L., \& Shrestha, S. (2006). Cultural Variations in the Socialization of Young Children's Anger and Shame. Child Development, 77(5), 1237-1251. 
[10] Cunha, I. da (2002). A base biomolecular das emoções. Em J. Wilheim (org.), Relação mãe-feto: visão atual das neurociências/Humanização do nascimento (pp. 83-108). São Paulo: Casa do Psicólogo.

[11] Denham, S. A., Workman, E., Cole, P. M., Weissbrod, C., Kendziora, K. T., \& ZahnWaxler, C. (2000). Prediction of externalizing behavior problems from early to middle childhood: The role of parental socialization and emotion expression. Development and Psychopathology., 12, 23-45.

[12] Denham, S., \& Kochanoff, A. T. (2002). Parental Contributions to Preschoolers' Understanding of Emotion. Em R. A. Farbes (Eds.), Emotions and the Family (pp. 311-343). NY: The Haworth Press, Inc.

[13] Dix, T. (1991). The Affective Organization of Parenting: Adaptive and Maladaptative Processes. Psychological Bulletin, 110(1), 3-25.

[14] Eisenberg, N. Spinrad, A., \& Cumberland, T. L. (1998). Parental Socialization of Emotion. Psychologycal Inquiry 9(4), 241-273.

[15] Falk, D. (2004). Prelinguistic evolution in early hominins: Whence motherese? Behavioral and Brain Sciences (27), 491-541.

[16] Harkness, S., \& Super C. M. (1994). The developmental niche: a theoretical framework for analysing the household production of health. Social Science and Medicine, 38 (2), 217-226.

[17] Harkness, S., Super, C. M., Bermudez, M. R., Moscardino, U., Rha, J. H., Mavridis, C. J. et al. (2010). Parental ethnotheories of children's learning. In D. F. Lancy, J. Brock, \& L.S. Gaskins (Eds.), The anthropology of learning in childhood (pp.65-81). Walnutcreek, CA: Alta Mira Press.

[18] Harlow, H. F. (1958). The Nature of Love. American Psychologist, 13, 673-685.

[19] Hoff, E., \& Naigles, L. (2002). How children use input to acquire a lexicon. Child Development, 73 (2), 418-433.

[20] Holodynski, M., \& Friedlmeier, W. (2010). Development of Emotions and Emotion Regulation. NY: Springer.

[21] Keller, H. (2007). Cultures of infancy. Mahwah, NJ: Lawrence Erlbaum.

[22] Keller, H., Borke, J., Yovsi, R., Lohaus, A., \& Jensen, H. (2005). Cultural orientations and historical changes as predictors of parenting behaviour. International Journal of Behavioral Development, 29 (3), 229-237.

[23] Keller, H., Borke, J., Lamm, B., Lohaus, A., \& Yovsi, R. D. (2011). Developing patterns of parenting in two cultural communities. International Journal of Behavioral Development, 35(3), 233-245. 
[24] Lewis, M. (2010). The Emergence of Human Emotions. In M. Lewis, J. M. HavilandJones \& L. F. Barrett (Eds.) Handbook of Emotions, 3nd Edition (pp. 304-319). NY: The Guilford Publications.

[25] Lidz, J., Gleitman, H., \& Gleitman, L. (2003). Understanding how input matters: verb learning and the footprint of universal grammar. Cognition, 73, 135-176.

[26] Lunkenheimer, E. S., Shields, A. M., \& Cortina, K. S. (2007). Parental Emotion Coaching and Dismissing in Family Interaction. Social Development, 16(2), 232-248. doi: 10.1111/j.1467-9507.2007.00382.x

[27] McElwain, N. L., Halberstadt, A. G., \& Volling, B. L. (2007). Mother- and Father-Reported Reac tions to Children's Negative Emotions: Relations to Young Children's Emotional Understanding and Friendship Quality. Child Development, 78(5), 1407-1425.

[28] Mendes, D. M. L. F., Seidl-de-Moura, M. L., \& Siqueira, J. O. (2009). The ontogenesis of smiling and its association with mothers' affective behaviors: a longitudinal data. Infant Behavior and Development, 445-453. Doi:10.1016/j.infbeh.2009.07.004.

[29] Mendes, D. M. L. F., \& Cavalcante, L. I. C. (submitted). Modelos de self e expressão emocional em bebês: concepções de mães e outras cuidadoras. Psico.

[30] Mendes, D. M. L. F., \& Seidl-de-Moura (submitted). Expression of smiling in infants up to six months: different types and contingency to maternal behaviors. The Spanish Journal of Psychology.

[31] Messinger, D., Dondi, M., Nelson-Goens, G. C., Beghi, A., Fogel, A., \& Simion, F. (2002). How sleeping neonates smile. Developmental Science, 5, 48-54. Obtido em http://www.blackwell-synergy.com/ em agosto de 2005.

[32] Mirabile, S. P., Scaramella, L. V., Sohr-Preston, S. L., \& Robison, S. D. (2008). Mothers' Socialization of Emotion Regulation: The Moderating Role of Children's Negative Emotional Reactivity. Child Youth Care Forum, 38, 19-37. DOI: 10.1007/ s10566-008-9063-5

[33] Nicholson, D., \& Artz, S. (2006). Caregiving strategies for reducing aggression and violence in at-risk mothers and their babies. Child $\mathcal{E}$ Youth Care Forum, 35, 411-426. doi:10.1007/s10566-006-9025-8.

[34] Pessôa, L. F. (2008). Maternal speech in communicatives frames and the development of language: a longitudinal study. Unpublished PHD Dissertation. Rio of Janeiro, UERJ.

[35] Pessôa, L. F., \& Seidl-de-Moura, M. L. (2008) A análise da fala materna dirigida a bebês em duas etapas do desenvolvimento. Psicologia em Pesquisa, 2 (2), 74-86. 
[36] Pessôa, L. F., \& Seidl-de-Moura, M. L. (2011). Fala materna dirigida à criança em cenários comunicativos específicos: Um estudo longitudinal. Psicologia: Teoria e Pesquisa, $27(4), 439-447$.

[37] Pessôa, L. F., Seidl-de-Moura, M. L., Ramos, D, \& Mendes, D. M. L. F. (submitted). Valorização dos sistemas de cuidados e características do discurso de diferentes cuidadores do Rio de Janeiro forjando trajetórias de desenvolvimento. Paidéia

[38] Piontelli, A. (1992). From Fetus to Child. NY: Brunner-Routledge.

[39] Rao, N., McHaleb, J. P., \& Pearson, E. (2003). Links Between Socialization Goals and Child-Rearing Practices in Chinese and Indian Mothers. Infant and Child Development, 12, 475-492. DOI: 10.1002/icd.341

[40] Reddy, V., \& Trevarthen C. (2004). What we learn about babies from engaging with their emotions. Zero to Three, 24, no. 3: 9- 15.

[41] Seidl-de-Moura, M. L., \& Mendes, D. M. L. F. (2012). Human Development: The Role of Biology and Culture. In M. L. Seidl-de-Moura (Ed.), Human Development: Different Perspectives (pp. 3-18). Croatia: Intech.

[42] Tomasello, M. (2003). Constructing a language: A usage-based theory of language acquisition. Harvard: University Press.

[43] Vila, I. (1995). Aquisição de linguagem. Em: Coll, C.; Palácios, J. \& Marchesi, A. (Org.), Desenvolvimento psicológico e educação. Porto Alegre: Artes Médicas.

[44] Weizman, Z. O., \& Snow, C. E. (2001). Lexical output as related to children's vocabulary acquisition: Effects of sophisticated exposure and support for meaning. Developmental Psychology, 37 (2), 265-279. 

Chapter 9

\title{
Interventions for Enhancing Parenting Quality in Early Infancy
}

\author{
Jenny A. Ortiz M., Eva Diniz Bensaja dei Schiró, \\ Olga Alicia Carbonell Blanco and Silvia H. Koller \\ Additional information is available at the end of the chapter \\ http://dx.doi.org/10.5772/56974
}

\section{Introduction}

Early infancy is the period of life in which the major biological and psychological bases of human development are built; therefore, it requires a unique social, economic and political commitment on the part of society [1,2]. In early infancy, family is primarily responsible for the daily care and promotion of the rights of children, with a shared responsibility of society and the states, as stipulated in the Convention on the Rights of the Child [3]. Therefore, parents, relatives or unrelated caregivers of children between ages zero and five years old are essential for promoting children's healthy development. These caregivers should be the focus of effective and useful interventions aimed at strengthening the affections and the quality of care that they provide to their children, supporting them through parenting challenges, and helping to create stimulating and safe home environments (World Conference on Education for All in Jomtien, Thailand [4], World Education Forum in Dakar, Senegal, [5])

In this chapter will be presented and discussed how the child socioemotional development is affected by the quality of current parents/caregivers-child relationships, considering the influence of developmental context on these relationships. Next, two distinct interventions created in two Latin American backgrounds will be presented as possible models to enhance the quality of mother/father/caregiver-infant interaction attending to contextual demands.

\section{Parenting and context}

Establishing a durable emotional relationship between parents and children, or between a caregiver and a child, is achieved through daily interactions that are frequent and reciprocal. 
Therefore, interventions for this population should serve to strengthen the emotional and affective bonds between parents and children, improve the motivation of caregivers, and increase the frequency, power, and contingency of their responses [6,7]. Also, interventions should achieve successful mutual behavioral adaptation $[8,9]$.

Successful mutual adaptation between caregivers and children will promote caregiver effectiveness as guides and models for their children; it also will facilitate a stable system in an enduring relationship, enabling and sustaining a child's potential development [9]. The term 'caregiver' applies to all persons responsible for child care during the first years of life; for example, parents, grandparents, aunts and uncles, fosters or any other person who performs that role in the life of the child [10]. The process of providing care for young children has been conceptualized in Attachment Theory, through the study of affective bonds established between a child and those closest to them, the primary caregiver or secondary person in the child's family and social environment. Caregiver availability, how appropriately they respond to the child's needs, environmental demands, and the quality of the situations in which interaction occurs are all factors conceptualized when assessing caregiver sensitivity [6].

Sensitivity involves appropriate caregiver self-control in conflicts that could emerge in the interaction with children, as well as negotiation skills to help resolve those situations [6]. That is, sensitivity implies a co-regulation of emotions that emerge in conflicts, and that must be modulated by the caregiver. Sensitive caregivers help children to modulate their behaviors, not only in positive moments, but also in times of stress [11,12].

Attachment is evident in a child's tendency to maintain proximity and contact with the person who gives them the greatest sense of security, feeling of distress on separation, and joy in reunion [13]. For Bowlby [10], attachment behavior is defined as "any form of behavior that results in a person attaining or maintaining proximity to some other clearly identified individual who is conceived of as better able to cope with the world. It is most obvious whenever the person is frightened, fatigued or sick, and is assuaged by comforting and caregiving" (p26-27). Consequently, attachment relationships give to the child a secure base from which to explore and learn about the physical and social world [14].

Attachment fulfills an important biological function; the care that parents show towards their offspring provides for security and survival in the environment in which they develop. The biological function of attachment, that guarantees the presence of this special affective bond between caregivers and children, is genetically predetermined and found in all individuals. However, this does not mean that attachment is equivalent to an instinct. For an attachment relationship to become established, it is required that the child experience continuous interactions with the caregiver $[13,10]$. One of the basic assumptions of Attachment Theory is that the quality of care provided by the adult caregiver is central for child's secure base behavior organization $[15,16]$.

In this respect, the establishment of an attachment relationship is an interactive process involving both child and mother, or father, or other caregiver. An attachment relationship necessarily refers to the interaction that occurs between two, a dyad, and is possible that the child establish dyadic attachment relationships over many figures without missing their 
emotional bond with their primary caregiver [10,15]. According to Sroufe and Waters [17] the dyad is a unit biologically based, but organized by the effect of culture. Thereby Attachment Theory considers the tendency to establish interpersonal relationships as inherent to human nature, present in newborns and continuing throughout life course. There is debate about whether the importance of the quality of care provided to children and their secure base behavior organization can be generalized to all cultures [18]. The care given to infants, specifically in current relationships, is strongly influenced by characteristics of the culture in which the dyad is involved. Different cultures may have different perspectives about the role of children in family. Thus, cultural values can guide education models that encourage autonomy, while others would value education models that promote interdependence [19]. For example, families of middle and high socioeconomic status, from Western countries, value the individuality and independence of their children, while families of lower socioeconomic status value closeness and dependency. These educational differences reflect different expectations for child development, as well as show a difference in beliefs about development itself, manifested in different interactive practices [20]. Consequently, parents react to the requests of their children according to their knowledge about child development, but also according to the characteristics that they want to promote in their child [21]. In Western societies (European and North American) there is, for example, a greater tendency to interact face-to-face, with the valuation of language addressed to the child, and the use of objects [19]. In African societies, the maternal speech to children is used for the first time around 12 months, and until then the baby is carried in mother's lap or on her back [19]. In Asian societies the interaction with the infants non-verbal, focusing instead on physical contact [19].

Regarding the distinct patterns of interaction found in various cultures, van Ijzendoorn and Kroonenberg [22] conducted a study in 32 countries of differing cultural histories (European, Latin American and Asian). It was found that despite all the different interactive practices observed, all of them were aimed at providing care and comfort to the infant. Researchers observed behaviors identified as contingent and syntonic. These findings confirm Bowlby's principles [15], that is, whatever the cultural origin, infants have a need for protection and their attention-getting methods are easily identified by adults.

However, care and educational strategies provided to children by caregivers, will be affected by the characteristics and demands of the environment in which they are inserted [23-25]. From this perspective, these authors describe development as a continuous process established over time.

In The Bioecological Theory of Human Development (BTHD [24]) Bronfenbrenner conceptualizes the models as $\mathrm{P}$ (person), $\mathrm{P}$ (process), $\mathrm{C}$ (context), and $\mathrm{T}$ (time). A person is defined as an element in constant evolution, wich influences and is influenced by the environment in which they are inserted. Context consists of five distinct aspects: microsystem, mesosystem, exosystem, macrosystem, and chronosystem. The latter refers to the dimension of time spent immersed in an environment, the person and their relationships, so to speak, the sociohistorical conditions of the time in which the person lives [26].

The microsystem is characterized as the environment in which a child has established interactive, face-to-face relationships, and where proximal processes occur (home and school, 
for example). The mesosystem is composed of these microsystems interacting among them. The exosystem context consists of those spaces not frequented by the child directly, but that indirectly influence their development (the parents' place of work and the rules of operation at their school, for example). The macrosystem consists of the society's prevailing cultural, norms, laws, and values.

The element of time is also organized into three distinct aspects and is described as having influence over the entire developmental process, since interactions occur at specific times, the microtime. Mesotime is a set of microtimes, while macrotime is the historic whole of time in which relations are forged. By definition then, macrotime bears a significant influence on microtime [25].

According to Bronfenbrenner [24], the quality of established relationships, constituents of the proximal processes, are the "engines of development". Nevertheless, Bronfenbrenner emphasizes that these relationships are influenced by the context in which they occur, particularly in the microsystem, in which relationships are established face-to-face. However, the microsystem is itself influenced by other systems (meso, exo, and macro) that affect the quality of these relationships.

Olds [27] stated that the form of baby care and how their needs are identified and met influences the development context which surrounds it, as does the childhood context in which the parents developed. It appears that mothers/fathers that developed in hostile environments are more likely to adopt aggressive behavior and take minimal care for their children. Similarly, mothers who had poor relationships with their parents show less ability to bond with their own children and therefore have less maternal attitudes considered appropriate [28,27]. It is necessary to consider that the skills of caring for children result from a developmental process, namely the parents' own childhood [29].

Concerns about the patterns of attachment formed with parents and the relationships that are formed during the rest of life, and among various generations of the same family, and what the underlying processes are, is a topic of research interest. The process by which, intentional or otherwise, an earlier generations psychologically influences the attitudes and parenting behaviors of the next generation, has been called the Model of Intergenerational Transmission of Parenting [30]. This model of transmission has been studied in its three components and their relationships: adult caregivers' mental representation of attachment, parenting practices, and child attachment styles [31].

Studies consistently show a substantial effect of intergenerational transmission of parenting styles within the theory of adult attachment relationships. These findings suggest that the experiences parents had with their own parents'sensitivity, their attentiveness, rejection or ambivalence, generates an internal representation of the grandparents as responsive or unresponsive. The hypothesis behind this idea is that the internal representation of attachment influences the degree to which parents will be responsiveness to their own children [10,32].

According to van IJzendoorn [30], from the hypothesis of internal representation, it would be expected that parents who experienced a high degree of responsiveness/sensitivity in childhood would be more open to the signals and needs of their own children than parents who 
were rejected or treated with ambivalence. However, parents can restructure their internal representation on the basis of experiencing significant and secure attachments after childhood. van IJzendoorn states that the internal representation of past experiences can be considered the results of a complex process of their personal history and memories, in which later experiences influence the perception of past events. In addition, he also notes that parenting includes not only the behavior of children taking-care, but also the attitudes towards childrearing that can influence their early development [30].

In this internal model of relationships, the child constructs an image of himself, and of the established relationship, as well as how these relationships are trusted and secure. Therefore, the sensitivity of the caregiver works as a precursor to formation of affectional bonds [16].

\section{Parenting and vulnerability}

Preventive interventions, especially those directed to early childhood, should be tested under objective, scientific criteria for their impact on the development of social capital of communities and for their relevancy as a strategy to overcome poverty in the most vulnerable populations. Currently, very little is known about the early development of children living in vulnerable conditions, since the proportion of childhood development research conducted within this population is minimal. Bornstein and Putnick [33] argue that, despite the consensus surrounding the importance of earlychildhood years has on development throughout one's life, and the influence of early development environments, the settings and conditions of care surrounding children, there is still a surprisingly scarce amount of data regarding it. According to the authors, at the population level (for example, populations in national territories or locales) there is very little information about the diversity of experiences and conditions that benefit or hinder the wellbeing of children. For Bornstein and Putnick, this lack of information is especially noticeable in developing countries.

Some factors have been described as influencing the quality of the relationships between mother, father, and child. Poverty, for example, can lead to friction in relational quality [34]. The socioeconomic context is a characteristic of the microsystem that tends to be indicated as relevant in the interactions established with the child over the course of their development, modulating the caregiver-child relationships (proximal process) $[29,35,36]$. In studies made to establish an association between maternal sensitivity and infant attachment security in samples taken from high risk, low socioeconomic populations, specifically in a meta-analysis addressed by Wolff and van IJzendoorn [14], were found significantly lower associations between maternal sensitivity and infant attachment security compared to samples taken from middle and higher socioeconomic strata. Subsequent studies conducted by Diener, Nievar and Wright [37] corroborate the findings of the metaanalysis. Also, their results showed that the dyads with more positive resources in their families showed, among the three groups, the highest correlations between maternal sensitivity and attachment security. However, data from a study realized in Colombia by Posada and collaborators [38]comparing two samples, one middle class and one in extreme 
poverty, showed a significant and robust association between these two variables. Nevertheless, in this study the mean scores for maternal sensitivity and attachment security were significantly lower than those from the socioeconomically advantaged. One would assume then that the stressful daily life experienced by families living in poverty might negatively affect the quality of maternal sensitivity and attachment security, as well as the relationship between these two factors; for example, socioeconomic status tends to relate to knowledge about child development, as well as expectations for the infant [36]. Moreover, the interactive pattern tends to be distinct according to socioeconomic level $[29,35,39]$.

Mothers of higher socioeconomic status tend to talk more with their infants when trying to calm them down. Likewise, they tend to hold their children more often and express more affection towards them, compared to mothers of lower socioeconomic status [39]. In this sense, it is considered that the socioeconomic conditions of the family influence the quality of education and care the child will receive, as well as the type of resources and experiences that the child will have access to [40].

Furthermore, Belsky et al. [29] found that stressors of context, namely single parenthood and marital conflict, may lead to parenting practices considered more punitive. In these situations, there were observed more behaviors of rejection and inconsistency in the care of the infant. These behaviors, in turn, would instill in children a sense of defenselessness and unpredictability, which would lead to a model of internalization considered insecure $[16,15,41]$.

Since parents with higher sensitivity are better at identifying their child's needs and responding appropriately, they are less likely to develop behaviors of neglect or maltreatment [27]. In other words, parents tend to resort to practices considered more punitive in environments marked by the presence of stressful events, which in turn can lead to a child's sense of selfdeprecation. In these cases, children tend to view themselves as little worthy of love, while others would regard them as unreliable and non-protective. As a result, their interpersonal relationships would be assessed as unreliable and transient [29].

It is from this perspective that Belsky et al. [29] characterize the practice of infants' caregiving as arising from contextual demands. The authors explained that parents' educational strategies will be influenced by their assessment of reality. For example, if parents rated their life as difficult, violent, unstable, it is natural that they would want to educate their children in light of this reality, making them better suited to deal with these qualities. Likewise, attitudes like warmth and safety can be considered counterproductive and unhelpful to a child's development in an environment considered tough, hostile, and in which a person constantly needs to defend themselves. The way parents raise their children and the type of care they offer are strongly influenced by their assessment of the challenges of their context $[29,40]$.

Nevertheless, it is necessary to emphasize that no context of development is considered better than another, but rather that they provide for distinct experiences. This is a view shared by Keller, Lohaus, Volker, Cappenberg and Chasiottis [42]. These authors postulate that care consist of a set of behaviors that have, as their main objective, to meet contextual demands. Importantly, the different educational strategies adopted in each context aim to provide the best possible development to the child, taking into account the characteristics of the environ- 
ment in which they operate [40]. However, there are contexts that, for their peculiarities, are considered the most challenging for the parenting task.

\section{Enhancing parenting}

The development of parenting interventions improve the quality of the first emotional experiences, present in the infant-mother interactions [28], and stimulate protective factors of child and adolescent development in at-risk social contexts. Interventions aimed family caregivers are important not only to promote the healthy development of boys and girls, but also to prevent violence within the home and to help build equitable and inclusive societies, as well as to reduce abusive and neglectful parental behaviors that continue to affect many children around the world [4,5]. These elements should serve as a guide in the implementation of public and private interventions.

Bronfenbrenner, in his model of bioecological development, considers that the emotional bonding process can be facilitated through intervention programs which involve caregivers as primary intervention agents, and where strong one-on-one relationships are considered essential for the development of young children [8]. The process of emotional bonding can be understood within the Bronfenbrenner model, as a proximal process. That is, as those relationships that occurs in the immediate surroundings of daily care.

According to the initial hypothesis proposed by Bronfenbrenner [23], the proximal processes, such as development contexts characterized by interpersonal structures, may produce two types of effects on the individual involved in this, taking into account the quality of these processes: 1) competence or ability to self-manage skillfully behavior within a domain of development; or 2) dysfunction, difficulty in maintain control over development [26]. Bronfenbrenner always included within the assumptions of the theoretical model, the need of research evidence that would allow public interventions or programs to promote healthy human competency. When designing interventions for early childhood, Bronfenbrenner suggested that these should influence the microsystem, which is in everyday interactions in order to affect the core of parental relationships (i.e., the family microsystem) For Bronfenbrenner [23], the microsystem is "a pattern of activities, social roles and interpersonal face-toface relationships experienced by developing persons in a scenario with physical, social and symbolic individuals that invite, permit or inhibit, and that progressively engage them in more complex and active interaction within the immediate environment " (p1645). That is to say, it is within the microsystem where trigger processes occur, inhibiting or favoring human development, the proximal processes.

To achieve developmental impact through early interventions, Bronfenbrenner [8] emphasizes that during the first three years of life, the main objective of human development is to establish a lasting emotional relationship between parents and children, and that these relationships are built through frequent reciprocal interactions. He also points out that the impact on the development of a primary dyad increases in direct relation to the reciprocity of mutual positive feelings, a gradual shift in the balance of powers, and a progressive autonomy for the child 
[26]. The author said that the effect of interventions at these ages should be to strengthen the bond between parents and children, improve the motivation of parents for upbringing, and to increase the frequency, power and contingency responses of the parents to their children to get them to give mutual behavioral adaptation. Also considers that the emotional bonding process is likely to be facilitated through intervention programs. In these programs, parents must be involved as primary intervention agents, and should seek to strengthen the one-toone time spent with their child, which is essential for the development of young children [8].

Some interventions based on Attachment Theory, attempting to ensure proper child development, aim to raise awareness of caregivers, since their ability to identify signals from young children, interpret them adequately and promptly respond to them, are factors that facilitate the establishment of an attachment relationship that is mutually satisfactory and a powerful variable to determine the safety of the child [43]. In their meta-analytic study of the effects of early interventions on sensitivity and attachment, Bakermans-Kranenburg, van Ijzendoorn and Juffer [44] found that brief interventions, focused exclusively on sensitivity as behavior, are most successful in improving caregivers' sensitivity in daily care of children, as well as infant attachment security.

Infant attachment security largely determines the quality of a child's future social relationships $[10,15,16,45]$. For example, it has been established that children with high levels of attachment security in early childhood, are more flexible and adaptable to changes in the environment at school age, and have more positive expectations in interactions with their peers. These children are described by others as cooperative, popular and resourceful, and are characterized as exhibiting reciprocity in social interaction, as well as verbal and behavioral fluency. Also, in interactions with adults, they are relaxed, friendly and can more easily engage in emotional intimacy [46-49]. In addition, children who show secure attachment can better regulate negative emotions and construct ways to cope with stress [50-52]. They also have a better self concept, in terms of how they see themselves and their capabilities [53,54].

The ideal duration of home intervention programs is a subject of discussion [44,55]. According with Olds [27], interventions should be initiated even during pregnancy and continue for at least the first two years of a child's life. Despite the lack of consensus on the duration of the intervention, it is unanimous that home interventions should occur on a regular time basis. The intervals between visits should be short, to allow the formation of a trustful relationship between coaches and families [27,44,55].

The most effective interventions do not always require a large number of sessions with families, and need not begin before birth or even during the first months a child's life. By contrast, in the aforementioned meta-analysis [44] researchers found that fewer sessions and intervention, beginning six months or more after birth, are the most effective. Taking into account the entire set of interventions studied, regardless of the presence or absence of multiple problems in families, such as poverty, teen pregnancy and prematurity, fewer sessions were more effective. Only cases of interventions with clinical samples (psychopathology or mental illness) showed higher levels of effectiveness, as well as interventions in which both parents participated, as compared with those in which only mothers participated. Other authors suggest that even modest interventions aimed at influencing the responsive performance of mothers in caring 
for their children, such as informative videos about best practices to manage and promote affective interaction with children, can improve a caregiver's sensitive response [56].

In regards to the relationship between sensitivity and infant attachment behavior, it was found that when an intervention is highly successful in increasing sensitivity, there appears a positive parallel change in infant attachment security. It is also noted that interventions are preferable when they have a clear focus, directed exclusively on the sensitive behavior of caregivers with a modest number of sessions [44].

On the evaluation of care behavior in caregivers of younger children, Posada, Carbonell, Alzate and Plata [57] have drawn attention to the importance of knowing not only whether scores on sensitivity or attachment security of children, evaluated with standardized instruments, are or are not similar from one culture to another, but also whether there are any contextual and cultural particularities in sensitive care quality, and above all, what these particularities are. The authors state that only using assessment tools developed with samples of white and middle-class in Western industrialized countries, fails to recognize the specific cultural manifestations of early intervention, and therefore, it is necessary to use mixed methodologies which would reveal such manifestations, especially if the results are to be useful for local intervention. However, there are several standard techniques for assessing the sensitivity of caregivers which are based on naturalistic observation and therefore are ecologically valid [23]. Among the naturalistic techniques implemented most in clinical research and early childhood are: The Home Observation for Measurement of the Environment - HOME [58], The Nursing Child Assessment Teaching Scale - NCATS [59] and the Maternal Behavior Q-Sort [7].

Taking the time to consider the ecological validity of the measurements on the quality of child care is important, since the experiences, environments and opportunities that adults provide children determine their strengths and vulnerabilities. Children that spend early childhood living in violent, emotionally or cognitively deprived situations, or who are subjected to experiences of abuse or neglect, face compromised brain development and restricted developmental potential [60-62]. If, however, a child's world is safe, caring and full of social, emotional and cognitive opportunities, their developmental potential will unfold $[9,63]$. According to De Antoni and Koller [64], through the ecological approach of development, one gains a contextualized view of environmental and situational factors that may have some influence on the development. For these authors, it is necessary that the development of the person be understood from observation in the natural environment and from real situations that affect them, their resources, and their own interpretation of reality.

\section{A home based intervention in the state of Rio Grande do Sul, Brazil}

The development of home visiting programs and parental training are based on the premise that intervention during the early years of a child's life presents a unique opportunity to promote their socio-cognitive development. From this perspective, programs whose main objective is to qualify positive parenting practices, or provide resources for parents towards the care of their children and provide richer experiences for the healthy development have 
been developed [27]. The home intervention programs are traditionally targeted to "at-risk populations" [65]. Risk is defined by the failure and dropping out of school, behavior problems, unemployment, poverty, and teenage pregnancy/motherhood. Data from Canada show that the poverty rate for single parents is $57.1 \%$. However this figure rises to $93.3 \%$ in cases of teenage mothers [66]. Furthermore, the authors show that parents in stressful environments more often display a non-contingent interactive style.

The program Best Early Childhood (Primeira Infância Melhor, PIM) has been integrating government policy from the state of Rio Grande do Sul, Brazil, since 2003. PIM is a socioeducational program involving families and their children, from pregnancy until age six, for those who live in vulnerable background. It is a program that aims to offer essential information and positive experiences to help families to improve the care of their children. This is particularly important, since the families served by PIM are characterized as living in a risky situation, which would hinder their access to adequate information regarding parenting. In this way, PIM aims to educate the caregivers to improve quality interactions, as well as provide them adequate information about socioemotional child development. Therefore, the family is considered a fundamental factor in the development of knowledge and the implementation of new activities with their children in order to minimize risks associated with the conditions of poverty, particularly in the lack of stimulation and neglect that many children face [1].

The PIM program is designed to stimulate an infants' overall development and to promote quality interactions in their family, particularly between children and parent(s) [1]. PIM seeks to attend to the needs of children from pregnancy until the age six, as was described by Brazelton and Greenspan [67]: establishing an stable and continuous relationships; providing physical protection and security; sharing access to experiences appropriate to their developmental level; establishing rules, boundaries, and organized expectations. The program's methodology operates under the assumption that if children are promoted in their potential with their parents/caregivers, they can achieve harmonious and healthy integral development. It is worth noting that the family, namely the mother/caregiver is involved in this process. They are guided through specific recreational activities, aimed to promote the socioemotional skills of children, as well as the quality of the relationship. Moreover, this intervention considers the cultural context of each family, their needs and interests through weekly visits conducted in the homes of families; thus the intervention seeks for the familiar involvement in child development.

The interventions offered by PIM are divided into two main groups: (1) during the pregnancy and up to the age of three. These interventions occur weekly in the family residence; and (2) between three and six, made as a group in the local community. However, both modalities have the same aims, as well as both of them involved the caregiver in the activity with the infant. Both intervention models (home basis and community basis) aimed to promote a healthy socioemotional development of the infant. The families living in at-risk context in Rio Grande do Sul areas, are invited to participate in the program. In 2013, 74\% of those families were enrolled in PIM (http://www.pim.saude.rs.gov.br). Considering the infant's age, they are enrroled in home basis intervention (during pregnancy and until the infant is 3 years old) or group (between 3 and 6 years old). Both home-basis and group interventions have the same 
frequency and structure: they happen in a regular manner, envolving the infant caregiver in order to promote an adequate socioemotional development, as well as to improve the quality of caregiver-infant interaction. Each week has a targeted intervention, stimulating the infant development by recreational activities. The monitor of the program goes each week to the family house and proposes an activity considering the previous diagnosis and needs of that family. Each activity has a specific aim, involving both mother/caregiver and child. It is explained the goals of that activity, as well as how the mother/caregiver can repeat it during the week.

The weekly meetings last approximately 60 minutes and consist of three steps: (1) initial moments, in which previous activities are resumed, and the activities of the day are introduced; (2) development of the activity of the day; and (3) evaluation of the activity of the day and subsequent assignments, with directions of activities that must be performed by the family during the following week. The activities made with family are structured, taking the initial diagnosis as its starting point. The diagnosis characterizes the way to identify the most important problems in each case, constituting a systematic process of decision making, enabling the implementation of strategic actions geared for each family. For the formulation of the diagnosis, it is possible to identify family problems, how they were addressed and later resolved. In the formulation of these diagnoses, interviews are conducted with the families and observations made. The interview consists of open and closed questions which systematize information about: the neighborhood/community in which the family is placed (the neighborhood infrastructure, services, etc.); the family (household composition, income, etc.); as well as the mother and the child. The filling out of notes is done at the time a new element enters into the program and is updated throughout the interventions. Information about the family is also recorded during the intervention, including aspects related to relational quality between parent and infant, and the child's developmental acquisitions. This program is described as an important resource for child development. In the state of Rio Grande do Sul, until 2013, 56.760 children from low socioeconomic status took part in the program (see for detailed information http://www.pim.saude.rs.gov.br/a_PIM/php/pagina-IndicadoresSucessoPim.php).

\section{Parenting group intervention for injury prevention in the city of Bogotá, Colombia}

Safe Environments Module is part of a set of public social policy performed in family environments in the city of Bogotá, Colombia. With this set of interventions, early childhood education is addressed to parents. It teaches parents to promote positive parenting, breastfeeding, healthy child development, play, child participation, and the rights of all children [68]. Family scope intervention is a process of training families with young children which is aimed at strengthening family activities that foster improvements in the home to promote child development. The long-term goal of these interventions is to transform cultural patterns of child abuse, to help improve the health of young children through timely medical and 
nutritional care, and to promote social mobilization and development to open more opportunities for all children in the city [69].

The design of the Safe Environments Module intervention [70] was based on literature about the prevention of domestic accidents, theories for intervention in early childhood, Attachment Theory, and the Bioecological Theory of Human Development. The intervention was developed by the agency responsible for the implementation of the social policy in the city (District Department of Social Integration - SDIS) in cooperation with private entities.

The broad policy framework for the Safe Environments Module intervention arose from the Convention on the Rights of the Child [3] and the Colombian Constitution of 1991 [71]. The local context for the intervention in the city of Bogotá is the Social Policy for the Quality of Life of Children and Adolescents 2004-2008, updated for the period 2008-2011 [69].

This policy excelled within the country by affirming that it is possible to build a society that is tolerant and respectful of diversity and differences, to the extent that the conditions of the places (homes and neighborhoods) where children live and grow in the city become adequate and safe. The policies in Bogotá also stress the importance of intervening in the relationships established between children, families, and other developmental aspects of the child so that interactions would be more affective and respectful. The policy states a set of intolerable situations, for example: "For a city that claims to be modern and humane, it is intolerable that children and adolescents suffer or die from preventable causes such as perinatal diseases, infections, and accidents" and "It is intolerable that children and adolescents are so alone" ([69] p11).

According to the District Diagnosis of Childhood and Adolescence [68], "the third leading cause of violent death in children and adolescents aged 0-17 years are accidents different to those caused by traffic and children in early childhood have been most affected by this type of death during the period 2002-2011 "(p111). In Bogotá, in 2007, when a report was made on the cause of accidental deaths of children in the city, it was observed that the 9099 accident cases recorded, with 3580 of those involving children under 10 years old [72]. These figures are shocking considering not only the age of the victims, but also in recognizing that all accidents were preventable [73]. However such these figures remain in Bogotá, the city still has reduced systematized information of these accidents in childhood, as occurs in the rest of the world $[73,74]$.

According to Peden et al. [73], the preventive actions that have been found effective in the intervention against domestic accidents can be grouped into four categories:

1. Safety devices: there are passive interventions that seek to promote the use of safety devices. It can lead to a rapid decline in accident rates and in fact it is known that a decrease in these rates, in turn increases the confidence of the people in the use of such devices. Examples of this type of preventive actions are the use of helmets for cyclists, installing railings on stairs and windows, safety caps on drugs to secure them from children, and the installation of smoke detectors. 
2. Education, training and behavioral change: interventions in this category have the common goal of encouraging behavioral change through different teaching strategies, for example campaigns for pedestrians to use crosswalks. Such actions may extend beyond the primary caregivers, including health professionals, educators (beginning in kindergarten), among others.

3. Home visits: the approach to the immediate context of children's lives, therefore the ability to impact the real context in which they are growing up. This type of actions is the most effective intervention to a wide range of preventable problems in families, thus such actions usually go beyond the prevention of accidents, even preventing child abuse and increasing childhood immunization rates.

4. Community actions: such actions lead us to believe in interventions with long-term incidence within specific communities. The hallmark of this type of actions is that generally they are based on the initiative of the social group.

With this background, in Bogotá was tested the injury prevention program Safe Environments Module [70], an intervention for domestic accidental injuries prevention addressed to primary family caregivers. The study performed is described below.

The caregivers were trained to modify their home environment with their children in mind, improving their home safety settings and adjusting their own behaviors to prevent unintentional injuries. Intervention was implemented following a detailed protocol. The intervention consists of four- two hours sessions, one per week (see Appendix A).

The impact assessment was divided in two studies. The aim of the first study, as a pilot study, was to determine how protocols and their procedures were applied by data collectors. Opportunities and barriers when applying intervention protocols were analyzed. The findings from this evaluation process were used to improve the protocols and therefore guarantee methodological quality of study 2 regarding intervention effects. A group of 16 volunteer primary family caregivers participated (age range 23-55 years old; $M=33.9, S D=8.7$ ). In study two, an intervention group was formed of 29 caregivers selected conveniently from a public kindergarten in the city of Bogotá, Colombia (27 mothers, 1 grandmother and 1 aunt) (ages ranging from 19-74 years old; $M=31.7, S D=10.8$ ), and a comparison group with 18 caregivers (14 mothers, 1 grandmother, 1 aunt, 1 sister and 1 stepmother) (ages ranging from 20-58 years old; $M=28.6, S D=8.7$ ). Each caregiver was visited twice by three observers, one focusing on injury risk and home safety, and the other two on caregiving quality [75].

Naturalistic measures were used to assess intervention effects on the following variables: early infancy risks and home injury antecedents, the quality of social and physical immediate environment that included housing quality and adult-child social and cognitive interaction at home, and caregiver sensitivity behaviors, correspondingly: Injury Home Risk Scale [76]; Injury Home Antecedents [76]; optional modules of Multiple Indicator Cluster Surveys, MICS3 [77]; and Maternal Behavior Q-sort [7].

Comparing the results between groups with nonparametric statistics showed that groups were similar in social, demographics and research variables. The results displayed a significant 
positive association between age of children and caregivers' report history of home injury $(r(47)$ $=.33, p<.05)$; and an inverse association between level of accident risk and level of housing quality $(r(47)=-.29, p<.05)$ (spearman correlations based on pre-test measurements). It was found that leaving children alone at home declined in frequency after the intervention $(Z=-.20, p<$. $05)$. Also, it was established that intervention increases the number of potential social interactions for children at home $(Z=.22, p<.05)[75]$.

No significant differences in domestic injury risk were found between the comparation group and the intervention group; however, the results suggested that domestic injury risk was a highly determined variable related to socioeconomic conditions, such problems with housing facilities $[78,79]$. These findings support an urgent need to improve housing and environment quality of low income contexts and also the idea that short interventions focusing in caregiver behavior could be effective in domestic accidental injuries prevention in early infancy.

In the case of the city of Bogotá, scientists working in the field of human development are committed with political decisions on early childhood interventions, and their main argue is that interventions themselves most to be based on evidence. It is well known that tested interventions can guarantee that public funds are well spent and produce the desired effect. Scientist in this contexts have begun to include in their academic responsibilities reflections and disclosures on the implications of this type of research, in order to help bridge the gap between academic knowledge, current quality of home care, and children's developmental needs [79-82].

\section{Conclusions}

Preventive interventions in early childhood requires especial attention because in this period of life is when most important neurobiological growth occurs, and it happens faster than any other period of life. Biological structures makes possible psychological and social development, and at the same time, positive social interactions in early infancy promotes the establishment of healty biological basis that would impact all life course. Interventions for children between ages zero and five years old could impact on the development of social capital of communities, therefore it is relevant as a strategy to overcome poverty [83]. In the most vulnerable populations, as well as in prototypical communities, interventions should be build under objective and scientific criteria in order to be able to explain the changes that occurs due to the intervention, and then be replicable [78].

Two main theories were presented as basis of early childhood interventions, the Bioecological Theory of Human Development (BTHD [24]) of Bronfenbrenner and the Attachment Theory of Bowlby and Ainsworth $[6,13,10]$. Both theories emphasize in the importance of specific cultural setting on the performance of parenthood. The role of the parents or caregivers in general, on the promotion of children healthy development was explained focusing on child socioemotional development. According to these theories, the emotional bond between primary caregivers and children was proposed as a core of the early intervention. In this chapter were 
presented two models of interventions that have taken into account the main principles of both theories.

Even though the two presented interventions have distinct patterns, both of them aimed to enhance the infant development, considering the quality of relationship between child and mother/caregiver as a major factor. Besides, both of them conceptualize the importance of contextual variables, like the infant's home environment. That is way the first presented intervention (PIM) occurs in a home-basis or in a community center. The second one is targeted to prevention and aimed to reduce the risks of home environment in child development. It is worth stressing that the caregivers are enrolled in both interventions, because they are considered as main elements to the regulation of infant needs, promoting adjusted outcomes, healthy development and child's adaptation.

Moreover, these interventions addressed to contextual demands looking for the best socioemotional development. These aspects correspond to BTHD principles, in which the change in microsystem needs to be operated by their elements [26]. Each intervention aimed to promote changes in children environment. However, these changes involved the person included in this environment. In agreement with PPCT model [24], these interventions conceptualize the person in constant evolution affecting and affected by the context where they live. Every intervention intends to promote change in contextual background of the infant, besides seeks to promote change in the quality of their relationship, evaluating it as "the secure base" for the further outcomes. Then, it is attempted to ensure an adequate infant development, helping the caregivers to identify and correctly respond the signals and needs of the child. In doing that, a positive relationship is built, mutally satisfactory and, importantly, determining the safety of the child $[43,44]$. Another important factor of the presented interventions is the involvement of caregivers and their sensitivity/responsivity to the challenges of the environment where they operate, minimizing the possible threats of it [40]. Particularly, the interventions are looking to the possible challenges presented in mother/caregiver-infant interaction in order to improve the motivation and knowledge of caregivers about child care quality, and increase the frequency, power, and contingency of their responses $[6,7]$.

Considering that the main core of each intervention is the opportunity of promoting positive parenting, enhancing their skills, and attending to their particular needs and concerns, it is possible to establish that Bronfenbrenner's guidelines for interventions are useful to promote changes in the microsystem as well as in proximal processes in Latin American contexts. In general, the basis of each intervention presented was improving the ability to self-manage caregiving behavior. Therefore these kinds of interventions are relevant, considering the data revealing that children whose caregivers had more sensitive behaviors presented less developmental injuries [14]. As sentenced by Sroufe and Waters [17] the dyad is a unit biologically based, but organized by the effect of culture, so in the Colombian and Brazilian interventions the fact that they focused on mutual adaptation between caregivers and infants, exemplify how those actions help to build an stable system of interactions that enable the children potential of development in their own context. 


\section{Appendix A}

Resource Summary, Contents and Short-Term Results of the Intervention Module Safe Environments

\begin{tabular}{|c|c|c|}
\hline Resources & Sessions and Activities & Short-term results \\
\hline $\begin{array}{l}\text {-A group of participants in lower } \\
\text { socioeconomic status, caregivers of } \\
\text { children from birth to age five years. } \\
\text {-Trainers, technicians trained in } \\
\text { Module Safe Environments (rate not } \\
\text { exceeding } 1 \text { trainer for } 10 \\
\text { participants) } \\
\text {-Logistical coordination of activities. }\end{array}$ & $\begin{array}{l}\text { 1. Warm and affectionate meeting: } \\
\text { Modeling the needs of children, } \\
\text { differences between the ways of } \\
\text { expressing those needs, identifying } \\
\text { conflicts between caregivers and the } \\
\text { needs of children. } \\
\text { 2. I grow-up safe: } \\
\text { In a matrix chart, according to four } \\
\text { basic areas of development: } \\
\text {-Identification of the child's key skills } \\
\text {-Identify the accident risks for } \\
\text { children according to age. } \\
\text {-Associated preventive measures. } \\
\text { 3. My home is a safe place: Making a } \\
\text { plan of the participants' house where } \\
\text { they identify safe areas and } \\
\text { dangerous areas for young children. } \\
\text { 4. My city is a safe place: } \\
\text { Analysis (accidents, causes, } \\
\text { consequences and prevention of five } \\
\text { cases that exemplify different types } \\
\text { of common domestic accidents in the } \\
\text { city.) }\end{array}$ & $\begin{array}{l}\text { Recognitions of the signals and the } \\
\text { needs of the child. } \\
\text { Perception of the child as an active } \\
\text { subject and different from the adult. } \\
\text { Recognition of the child's } \\
\text { developmental processes, both its } \\
\text { scope and its limitations, and } \\
\text { consistent environmental } \\
\text { adjustment. }\end{array}$ \\
\hline
\end{tabular}

\section{Author details}

Jenny A. Ortiz M...$^{*}$, Eva Diniz Bensaja dei Schirón ${ }^{1}$, Olga Alicia Carbonell Blanco ${ }^{2}$ and Silvia H. Koller ${ }^{1}$

*Address all correspondence to: jenny.a.ortiz.m@gmail.com

1 Institute of Psychology, Federal University of Rio Grande do Sul, Porto Alegre, Brazil

2 Psychology Department, Pontificia Universidad Javeriana, Bogotá, Colombia 


\section{References}

[1] Schneider A., Ramires V. Primera Infancia Mejor: una innovación en políticas públicas. Brasilia: UNESCO; 2008.

[2] Shonkoff J., Phillips DA., editors. From neurons to neighborhoods: The science of early childhood development. Washington: National Academy Press; 2000.

[3] United Nations. Convention on the Rights of the Child. General Assembly Resolution $\mathrm{A} / \mathrm{RES} / 44 / 25 ; 1989$.

[4] UNESCO, UNICEF, PNUD, Worl Bank. World Conference on Education for All in Jomtien, Thailand; 1990.

[5] UNESCO. World Education Forum, Dakar, Senegal; 2000.

[6] Ainsworth MDS. Attachment: Retrospect and prospect. In: Parkes CM., StevensonHinde J., editors. The place of attachment in human behavior. New York: Basic Books; 1982. p. 3-30.

[7] Pederson DR., Moran G. A categorical description of infant-mother relationships in the home and its relation to Q-Sort measures of infant-mother interaction. In: Waters E., Vaughn BE., Posada G., Kondo-Ikemura K., editors. Monographs of the Society for Research in Child Development 1995;60: 21-30.

[8] Bronfenbrenner U. A report on longitudinal evaluations of preschool programs: Iis early intervention effective? Washington: Office of Child Development - DHEW; 1974.

[9] Bronfenbrenner U. The ecology of cognitive development: Research models and fugitive findings. In: Wozniak RH., Fischer KW., editors. Development in context: acting and thinking in specific environments. Hillsdale: Erlbaum; 1993. p. 3-44.

[10] Bowlby J. A secure base. New York: Basic Books; 1988.

[11] Emde R. Emotional availability: A reciprocal reward system for infants and parents with implications for prevention of psychosocial disorders. In: Taylor PM. (ed.) Parent infant relations. Orlando: Grune \& Stratton; 1980.

[12] Seifer R., Schiller M. The role of parenting sensitivity, infant temperament, and dyadic interaction in attachment theory and assessment. In: Waters E., Vaughn BE., Posada G., Kondo-Ikemura K., editors. Monographs of the Society for Research in Child Development 1995;60: 146-174.

[13] Ainsworth MDS. Attachments beyond infancy. American Psychologist 1989;14: 709-716.

[14] De Wolff MS., van Ijzendoorn MH. Sensitivity and attachment: A meta-analysis on parental antecedents of infant attachment. Child Development 1997;68: 571-591. 
[15] Bowlby J. Attachment and loss. New York: Basic Books; 1969.

[16] Ainsworth MDS., Blehar MC., Waters E., Wall S. Pattems of attachment: a psychological study of strange situation. New York: Lawrence Erlbaum Associates; 1978.

[17] Sroufe LA., Waters E. Attachment as an organizational construct. Child Development 1977;48: 1184-1199.

[18] van IJzendoorn MH., Sagi A. Cultural blindness or selective inattention? American Psychologist 2001;56: 824-825.

[19] Keller, H. Development as the interface between biology and culture. A conceptualisation of early ontogenetic experiences. In: Keller H., Poorting YH., Scholmerich, A., editors. Between Culture and Biology. Cambridge: Cambridge University Press. 2002. p. 215-240.

[20] Ispa JM., Fine MA., Halgunseth LC, Harper S., Robinson J., Boyce L., Brooks-Gunn J, Brady-Smith C. Maternal intrusiveness, maternal warmth, and mother-toddler relationship outcomes: Variations across low-income ethnic and acculturation groups. Child Development 2004;75: 1613-1631. Doi: 10.1111/j.1467-8624.2004.00806.x.

[21] Trommsdorff, G., Cole PM. Emotion, self-regulation, and social behavior in cultural contexts. In: Chen X., Rubin KH., editors. Socioemotional development in cultural context. New York: The Guilford Press; 2011. p.131-163.

[22] van Ijzendoorn MH., Kroonenberg PM. Cross-Cultural Patterns of Attachment: A Meta-Analysis of the Strange Situation. Child Development 1988;59: 147-56. Doi: $10.2307 / 1130396$.

[23] Bronfenbrenner U. The Ecology of Human Development: Experiments by Nature and Design. London: Harvard University Press; 1979.

[24] Bronfenbrenner U. The bioecological theory of human development. In: Bronfenbrenner U. (ed.) Making human beings human: Bioecological perspectives on human development. Thousand Oaks, CA: SAGE; 2001. p. 3-15.

[25] Bronfenbrenner U., Morris PA. The ecology of developmental processes. In: Damon W., Lerner, RM., editors. Handbook of Child Psychology: Theoretical Models of Human Development. New York: John Wiley \& Sons; 1998.

[26] Bronfenbrenner U., Ceci SJ. Nature-Nurture Reconceptualized in Developmental Perspective: A Bioecological Model. Psychological Review 1994;4: 568-586.

[27] Olds DL. Prenatal and infancy home visiting by nurses: From randomized trials to community replication. Prevention Science 2002; 3: 153-172.

[28] Belsky J., Houts RM., Fearon RMP. Infant attachment security and the timing of puberty: Testing an evolutionary hypothesis. Psychological Science 2010; Doi: 10.1177/0956797610379867. 
[29] Belsky J., Steinberg L., Draper P. Childhood experience, interpersonal development, and reproductive strategy: an evolutionary theory of socialization. Child Development 1991;62: 647-670.

[30] van IJzendoorn, MH. Intergenerational transmission of parenting: A review of studies in nonclinical populations. Developmental Review 1992;12: 76-99.

[31] Berlin LJ., Ziv Y., Amaya-Jackson L., Greenberg MT. Enhancing early attachments: Theory, research, intervention, and policy. New York: Guilford Press; 2005.

[32] Main K., Kaplan N., Cassidy J. Security in infancy, childhood, and adulthood: a move to the level of representation. In: Bretherton I., Water E., editors. Monographs of the Society for Research and Child Development 1985;50(1-2): 66-106.

[33] Bornstein MH., Putnick DL. Cognitive and socioemotional caregiving in developing countries. Child Development 2012;83(1): 16-31.

[34] Evans GW., Boxhill L., Pinkava M. Poverty and maternal responsiveness: The role of maternal stress and social resources. International Journal of Behavioral Development 2008; Doi: 10.1177/0165025408089272

[35] McLoyd, V. The declining fortunes of black children: Psychological distress, parenting, and socioemotional development in the context of economic hardship. Child Development 1990; Doi: 10.1111/j.1467-8624.1990.tb02781.x

[36] Ribas JrRC., Seidl de Moura ML., Gomes AAN., Soares ID., Bornstein MH. Socioeconomic status in Brazilian psychological research. Part 1: Validity, measurement, and application. Estudos de Psicologia 2003;8: 375-383.

[37] Diener ML., Nievar MA., Wright C. Attachment security among mothers and their young children living in poverty: Associations with maternal, child, and contextual characteristics. Merril-Palmer Quarterly 2003;49: 154-182.

[38] Posada G., Jacobs A., Carbonell OA., Alzate G., Bustamante MR., Arenas A. Maternal Care and Attachment Security in Ordinary and Emergency Contexts. Developmental Psychology 1999;35: 1379-1388.

[39] Roopnarine JL., Fouts HN., Lamb ME., Lewis-Elligan TY. Mothers' and fathers' behaviors toward theirs 3-4-monthold infants in lower, middle and upper socioeconomic African American families. Developmental Psychology 2005; Doi: 10.1037/0012-1649.41.5.723.

[40] Fouts HN., Roopnarine J L., Lamb ME., Evans M. Infant social interactions with multiple caregivers: The importance of ethnicity and socioeconomic status. Journal of Cross-Cultural Psychology 2012; Doi: 10.1177/0022022110388564.

[41] Stroufe LA. The coherence of individual development: Early care, attachment, and subsequent developmental issues. American Psychologist 1979; Doi: 10.1037/0003-066X.34.10.834. 
[42] Keller H., Lohaus A., Volker S., Cappenber M., Chasiotis, A. Temporal contingency as an independent component of parenting behavior. Child Development 1999; Doi: $10.1111 / 1467-8624.00034$

[43] Ainsworth MDS., Bell SM., Stayton, DJ. Infant and mother attachment and social development. In: Richards MP. (ed.) The Introduction of the Child Into a Social World. London: Cambridge University Press; 1974. p. 9-135.

[44] Bakermans-Kranenburg MJ., van Ijzendoorn MH., Juffer F. Less is more: Meta-analyses of sensitivity and attachment interventions in early childhood. Psychological Bulletin 2003;129(2): 195-215.

[45] Ainsworth MDS., Marvin RS. On the shaping of attachment theory and research: An interview with Mary S. Ainsworth. In Waters E., Vaughn BE., Posada G., Kondo-Ikemura K., editors. Caregiving, Cultural, and Cognitive Perspectives on Secure-Base Behavior and Working Models: New Growing Points of Attachment Theory and Research. Monographs of the Society for Research in Child Development 1995;60(2-3): 3-24.

[46] Cohn DA. Child-mother attachment of six-year-olds and social competence at school. Child Development 1990;61(1): 152-162.

[47] Main M., Solomon J. Procedure for identifying infants as disorganized/disoriented during the Ainsworth Strange Situation. In: Greenberg M., Cicchetti D., Cummings M., editors. Attachment en the preschool years. Chicago: University of Chicago Press; 1987. p. 121-160.

[48] Sroufe LA. Attachment-classification from the perspective of infant-caregiver relationships and infant temperament. Child Development 1985;56: 1-14.

[49] Waters E., Hamilton CE., Weinfield NS. The stability of attachment security from infancy to adolescence and early adulthood: General introduction. Child Development 2000;71: 678-683.

[50] Gilliom M., Shaw DS., Beck JE., Schonberg MA., Lukon JL. Anger regulation in disadvantaged preschool boys: Strategies, antecedents, and the development of self-control. Developmental Psychology 2002;38(2): 222-235.

[51] Kerns KA., Abraham MM., Schlegemilch A., Morgan TA. Mother-child attachment in later middle school: Assessment approaches and associations with mood and emotion regulation. Attachment and Human Development 2007;9: 33-53.

[52] Kochanska G. Emotional development in children with different attachment histories: The first three years. Child Development 2001;72: 474-490.

[53] Colman RA., Thompson RA. Attachment security and the problem-solving behavior of mothers and children. Merrill-Palmer Quarterly 2002;48: 337-359. 
[54] Doyle AB., Markiewics D., Brendgen M., Lieberman M., Voss K. Child Attachment security and self-concept: Associations with mother and father attachment style and marital quality. Merrill-Palmer Quarterly 2000;46: 514-539.

[55] Tolani N., Brooks-Gunn J., Kagan SL. Parenting Education Programs for Poor Young Children: A Cross-National Exploration. UNICEF/New School International Conference; 2006.

[56] Wendland-Carro J., Piccinini CA, Millar WS. The role of an early intervention on enhancing the quality of mother-infant Interaction. Child Development 1999;70(3): 713-721.

[57] Posada G., Carbonell OA., Alzate G., Plata SJ. Through Colombian lenses: Ethnographic and conventional analyses of maternal care and their associations with secure base behavior. Developmental Psychology 2004;40: 508-518.

[58] Caldwell B., Bradley R. Manual for the Home Observation for Measurement of the Environment. Little Rock: University of Arkansas; 1984.

[59] Barnard KE., Magyary D., Summer G., Booth CL., Mitchell SK., Spieker S. Prevention of parenting alterations for women with low social support. Psychiatry 1988;51: 248-253.

[60] Lecannelier F. Apego e intersubjetividad. Influencia de los vínculos tempranos en el desarrollo humano y la salud mental. Chile: Ediciones LOM; 2006.

[61] Pollack SD., Nelson CA., Shlaak MF., Roeber BJ., Wewerka SS., Wiik KL., Frenn KA., Loman MM., Gunnar MR. Neurodevelopmental effects of early deprivation in postinstitutionalized children. Child Development 2010;81: 224-236.

[62] Putnam FW. The developmental neurobiology of disrupted attachment; Lessons from animal models and child abuse research. In: Berlin LJ, Ziv Y, Amaya-Jackson LM, Greenberg MT., editors. Enhancing early attachments: Theory, research, intervention, and policy. New York: Guilford; 2005. p. 79-99.

[63] Rana AJ. Revisiting the child's brain: insights into latest development in brain research. Journal of Early Child Development 2002;34: 46-55.

[64] De Antoni C., Koller SH. A visão de família entre as adolescentes que sofreram violência intrafamiliar. Estudos de Psicologia 2000;5(2): 347-381.

[65] Belsky J. Early child care and early child development: Major findings of the NICHD Study of early child care. European Journal of Developmental Psychology 2006; DOI: 10.1080/17405620600557755.

[66] Letourneau N., Drummundo J., Flemming D., Kysela G., McDonald L., Stewart M. Supporting Parents: Can Intervention Improve Parent-Child. Journal of Family Nursing 2001; DOI: 10.1177/107484070100700203 
[67] Brazelton TB., Greenspan SI. The Irreducible Needs of Children: What Every Child Must Have To Grow, Learn, And Flourish. Boston: Merloyd Lawrence Book; 2002.

[68] Secretaria Distrital de Integración Social. Diagnóstico distrital de infancia y adolescencia. Comité operativo distrital de infancia y adolescencia. Sistema de monitoreo de las condiciones de vida de la infancia y la adolescencia de Bogotá. Bogotá: Alcaldía Mayor de Bogotá; 2012.

[69] Secretaria Distrital de Integración Social. Oscilaciones y horizontes de la Política de infancia, adolescencia y juventud de Bogotá. Informe de gestión en el marco del proceso de rendición pública de cuentas para la garantía de los derechos de la infancia, la adolescencia y la juventud; 2011. http://www.integracionsocial.gov.co/anexos/documentos/informesdegestion/oscilaciones_y_horizontes_de_la_politica_de_inf_adol_y_juv_en_bogota_final.pdf (accessed 8 October 2012).

[70] Ortiz JA. Módulo Ambientes Seguros. Bogotá: SDIS-CINDE; 2011.

[71] República de Colombia. Constitución política de Colombia. Bogotá: Ministerio de Justicia; 1991.

[72] Secretaría Distrital de Salud. Estadísticas de accidentalidad en la infancia en Bogotá D.C. http://portel.bogota.gov.co/portel/libreria/php/x_frame_detalle.php?id=29204 (accessed 8 October 2012).

[73] Peden M., Kayode M., Ozanne-Smith J., Hyder A., Branche C., Rahman F., Rivara F., Bartolomeos K. World report on child injury prevention. Geneva: World Health Organization - UNICEF; 2008.

[74] World Health Organization. Prevención de los traumatismos en los niños. Informe de la Secretaría. Consejo Ejecutivo EB127/5. 127a Reunión; 2010. http:// apps.who.int/gb/ebwha/pdf_files/EB128/B128_19-sp.pdf (accessed 8 October 2012).

[75] Carbonell OA., Ortiz JA., Koller SH. Evaluación de la Intervención Módulo Ambientes Seguros Informe de Investigación. Pontificia Universidad Javeriana, Universidade Federal do Rio Grande do Sul, Secretaría Distrital de Integración Social. 2012

[76] Gorrita PY., Gorrita RR. Diferentes factores de riesgo de accidentes en hogares de niños menores de cinco años. Revista de Ciencias Médicas La Habana 2008;14(3): 32-37.

[77] UNICEF. Manual para la Encuesta de Indicadores Múltiples por Conglomerados 2005. New York: UNICEF; 2006.

[78] Khandker S., Koolwal G., Samad H. Handbook on impact evaluation: Quantitative methods and practices. Washington: The World Bank; 2010.

[79] Sleet DA., Mercy JA. Promotion of safety, security, and well-being. In: Bornstein MH., Davidson L., Keyes CLM., Moore KA. The Center for Child Well-being., editors. Wellbeing: Positive development across the life course. Mahwah, NJ: Erlbaum; 2003. p. 81-97. 
[80] Fischer CB., Osofsky JD.Training the applied developmental scientist for prevention and practice: Two current examples. Society for Child Development Social Policy Report 1997;11(2): 1-18.

[81] McCall RB., Groark CJ. The future of applied child development research and public policy. Child Development 2000;71: 197-204.

[82] Susman-Stillman AR., Brown JL., Adam EK., Blair C., Gaines R., Gordon RA., White AM., Wynn SR. Building research and policy connections: training and career options for developmental scientists. Society for Child Development Social Policy Report 1996;10(4): 1-19.

[83] Knudsen EI., Heckman JJ., Cameron JL., Shonkoff JP. Economic, neurobiological and behavioral perspectives on building America's future workforce. Proceedings of the National Academy of Sciences 2006;103(27): 10155-10162. 


\section{Edited by Maria Lucia Seidl-de-Moura}

Parenting involves a set of values, beliefs and practices of child care that create a developmental context and vary from culture to culture. Studies about parenting are of fundamental importance to the understanding of human development. This book has nine chapters and it addresses parenting and child care in two South American countries (Brazil and Colombia) and four African ones (Cameroon, Ghana, Liberia and Nigeria). It aims at contributing to the knowledge about human development in contexts of the majority world, not often considered in the psychological literature. Besides bringing data from different countries, it focuses in diverse scenarios in Brazil. The data and discussions include mothers, fathers and grandmothers beliefs and/or practices, parental styles and intervention programs oriented to quality parental care. 